VINÍCIUS OLIVEIRA DA SILVA

ESTUDO E MODELAGEM DA ARQUITETURA MODULAR DE UMA USINA SOLAR FOTOVOLTAICA ARREFECIDA COM PROTÓTIPO DE VERIFICAÇÃO

São Paulo

2015 
VINÍCIUS OLIVEIRA DA SILVA

\section{ESTUDO E MODELAGEM DA ARQUITETURA MODULAR DE UMA USINA SOLAR FOTOVOLTAICA ARREFECIDA COM PROTÓTIPO DE VERIFICAÇÃO}

Dissertação apresentada à Escola Politécnica da Universidade de São Paulo como parte dos requisitos para a obtenção do título de Mestre em Engenharia Elétrica

São Paulo

2015 
VINÍCIUS OLIVEIRA DA SILVA

\section{ESTUDO E MODELAGEM DA ARQUITETURA MODULAR DE UMA USINA SOLAR FOTOVOLTAICA ARREFECIDA COM PROTÓTIPO DE VERIFICAÇÃO}

Dissertação apresentada à Escola
Politécnica da Universidade de São Paulo
como parte dos requisitos para a
obtenção do título de Mestre em
Engenharia Elétrica

Área de Concentração: Sistemas de Potência

Orientador: Prof. Dr. Miguel Edgar Morales Udaeta

\section{São Paulo}


Este exemplar foi revisado e corrigido em relação à versão original, sob responsabilidade única do autor e com a anuência de seu orientador.

São Paulo, de janeiro de 2016

Assinatura do autor:

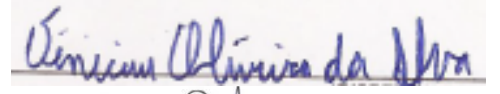

Assinatura do orientador:

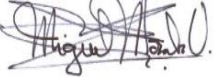

\section{Catalogação-na-publicação}

Silva, Vinícius Oliveira da

Estudo e modelagem da arquitetura modular de uma usina solar fotovoltaica arrefecida com protótipo de verificação / V. O. Silva -- versão corr. -São Paulo, 2015.

$167 \mathrm{p}$.

Dissertação (Mestrado) - Escola Politécnica da Universidade de São Paulo. Departamento de Engenharia de Energia e Automação Elétricas.

1.Geração de energia elétrica 2.Energia solar 3.Usina solar Fotovoltaica arrefecida I.Universidade de São Paulo. Escola Politécnica. Departamento de Engenharia de Energia e Automação Elétricas II.t. 


\section{DEDICATÓRIA}

Para Angela, Bene, Fernanda e Rita. 


\section{AGRADECIMENTOS}

Ao Miguel, grande pessoa, amigo, orientador e pesquisador nato. À sua dedicação, longas conversas e debates que ampliaram meus horizontes sobre a vida e a academia. Seguir suas palavras é, ao mesmo tempo, sair da caixa e produzir conhecimento que almeje nos tirar do status de colônia, paradigma que ainda não quebramos.

Ao prof. Dr. Luiz Claudio Ribeiro Galvão por todo apoio e dedicação à minha formação e por criar condições para que a pesquisa prossiga.

Ao André, por sua disposição, sugestões e conversas que ajudaram a moldar e sedimentar esta pesquisa.

Aos amigos Angélica, Maria, Pascoal e Wagner, pelas grandes lições e por me confiarem parte do projeto que me trouxe ao mundo da pesquisa.

Ao Diego, pelas longas discussões empíricas e principalmente por abrir espaço na Flue8 para que a pesquisa seguisse mesmo em períodos filantrópicos.

Aos grandes amigos da AN-16 por introduzir a narrativa no meu discurso, e mais importante, por criar um espaço que transcende aos cubículos de trabalho.

Aos funcionários do PEA-USP, por toda atenção e ajuda ao longo do trabalho.

À minha família, parte inerente do processo.

Aos meus pais, por todo apoio e amor.

Ao amor, que moldou profundamente a minha mente e paixão pelo saber.

À Fernanda, Linda Lindona, sem a qual tudo isto não teria um início.

Muito grato a todos.

Vinícius 


\section{RESUMO}

O objetivo deste trabalho é modelar a arquitetura de uma usina solar fotovoltaica arrefecida intitulada UFVa, utilizando um protótipo de verificação. A metodologia se baseia na medição, verificação e análise dos dados de temperatura e produção de energia elétrica dos strings de teste (arrefecido) e comparação (não arrefecido), estudo do comportamento da alimentação de água do sistema de arrefecimento e o impacto das condições climáticas na operação do protótipo de UFVa. Por meio das análises dos dados constatou-se que, para o período entre as 09h00min e as 17h30min, os módulos PV do string de teste sempre operam com temperaturas inferiores aos módulos PV do string de comparação. Durante o período de testes, no qual a temperatura dos módulos PV do string de comparação operou acima de $55,0^{\circ} \mathrm{C}$, as temperaturas médias e máximas registradas nos módulos $\mathrm{PV}$ do string de teste foram inferiores a $37,0^{\circ} \mathrm{C}$, operando sempre abaixo da temperatura nominal de operação da célula (NOCT). A produção de energia elétrica no string de teste superou a do string de comparação em 3,0kWh/dia. Portanto, o sistema de arrefecimento reduz a temperatura de operação dos módulos PV, principalmente no período de máxima geração elétrica, que corresponde ao período das 11h00min às $15 \mathrm{~h} 00 \mathrm{~min}$, proporcionando ganhos médios de rendimento de $5,9 \%$ na produção de energia, $10,3 \%$ na potência e $5,4 \%$ no FC.

Palavras-chaves: Usina Solar Fotovoltaica, Sistema de Arrefecimento, Sistema PVT, Análise de Desempenho, Dispositivo de Otimização. 


\begin{abstract}
In this work we use a verification prototype to model the architecture of a solar photovoltaic power plant equipped with a cooling system. The power plant we model is called UFVa. The methodology is based on the measurement, verification, and data analysis of temperature, electricity generation, test strings (cooled) and comparison strings (not cooled), along with a study of the water feeding behavior of the cooling system, and the impact of climatic conditions in the UFVa prototype operation. By analyzing the data we observed that, for the period between 09:00am and 5:30pm, the PV modules of the test string operate at temperatures below those of the PV modules of the comparison string. During the tests, in which the temperature of the PV modules of the comparison string operated above $55.0^{\circ} \mathrm{C}$, the average and the maximum temperatures recorded in the PV modules of the testing string lied below $37.0^{\circ} \mathrm{C}$, operating below the NOCT. Regarding the generation of electricity, the test string generated $3.0 \mathrm{kWh} /$ day more than the comparison string. Hence, the cooling system decreases the operating temperature of the PV modules, particularly during the maximum power generation period which is from 11 am to $3 \mathrm{pm}$. This leads to efficiency average gains of up to $5.9 \%$ in the generation of electricity, $10.3 \%$ in the power, and $5.3 \%$ in the PR and PF.
\end{abstract}

Keywords: PV Power Plant, Cooling System, PVT System, Performance Analysis, Device Optimization. 


\section{ÍNDICE DE FIGURAS}

Figura 1 - Mapa da radiação solar global (média anual) do Brasil...........................22

Figura 2 - Representação da divisão do espectro solar que é convertido em eletricidade e calor em função do comprimento de onda.

Figura 3 - Influência da temperatura da célula na corrente e tensão.

Figura 4 - Exemplificação dos Barramentos, principal e secundário, de uma célula cSl.

Figura 5 - Fotografia infravermelha de um módulo PV. .31

Figura 6 - Influência da variação da radiação solar na corrente e tensão. 32

Figura 7 - Influência da temperatura na eficiência da célula. .33

Figura 8 - Típicas curvas de eficiência térmica para sistema PVT. 38

Figura 9 - Comparação entre os tipos de tecnologias e as energias produzidas. .....38

Figura 10 - Representação de um sistema coletor PVT de placa plana. 40

Figura 11 - Coletor PVT com e sem cobertura de vidro.

Figura 12 - Desenho representativo da estrutura do sistema PVT-água. (a) sistema com isolante térmico e (b) sistema sem isolante térmico.

Figura 13 - Imagem fotográfica infravermelha das superfícies superior e inferior do módulo PV instalado na UFV-ILS.

Figura 14 - Configuração de um sistema PVT com líquido escoando e beneficiando todas as células PV. .45

Figura 15 - Representação de um módulo PV com um sistema de arrefecimento da superfície. .54

Figura 16 - Incidência solar global $\left(\mathrm{kWh} / \mathrm{m}^{2}\right)$ na região da cidade de llha Solteira...55 Figura 17 - Comportamento dos índices pluviométricos e insolação mensal para o período 2004-2013.

Figura 18 - Comportamento da radiação global média e insolação mensal para o período 2004-2013. 
Figura 19 - Comportamento da radiação média global e temperatura média para o período maio/2008 a junho/2009

Figura 20 - Comportamento da radiação global média, mínima e máxima para o período 2004-2013.

Figura 21 - Unidade de Provas.

Figura 22 - Arranjo esquemático do sistema de arrefecimento dos módulos PV da U.P. 65

Figura 23 - Alocação dos sensores PT-100 nos módulos PV.

Figura 24 - Período de testes da U.P. (a) geração de energia e horas de geração e

(b) temperaturas dos módulos PV. .70

Figura 25 - Temperaturas dos módulos PV-2, 3 e 5 da U.P. no dia 04/03/2015 em $24 \mathrm{~h}$ do dia.

Figura 26 - Operação da U.P. no dia 16/03/2015 (a) produção de energia e (b) temperatura dos módulos PV-2, 3 e 5.

Figura 27 - Temperatura de operação dos módulos PV em 16/03/2015. (a) temperatura registradas pelos sensores PT100, (b) Máximas temperaturas e (c) diferença entre temperaturas em um mesmo módulo PV. .73

Figura 28 - Operação da U.P. no dia 02/04/2015 (a) produção de energia e (b) temperatura dos módulos PV-2, 3 e 5.

Figura 29 - Temperatura de operação dos módulos PV em 02/04/2015. (a) temperatura registradas pelos sensores PT100, (b) Máximas temperaturas e (c) diferença entre temperaturas em um mesmo módulo PV.

Figura 30 - Temperaturas de operação dos módulos $\mathrm{PV}>60,00{ }^{\circ} \mathrm{C}$. (a) Diferença entre maior e menor temperatura medida (b) diferença de temperatura medida em um mesmo módulo PV.

Figura 31 - Fotos da superfície superior dos módulos PV nos períodos (a) 10h00min,

(b) $12 \mathrm{~h} 00 \mathrm{~min}$ e (c) $15 \mathrm{~h} 00 \mathrm{~min}$. .79

Figura 32 - Subsistema em solo da UFV-ILS. 
Figura 33 - Inversores instalados na sala de inversores da UFVa-ILS.

Figura 34 - Representação do arranjo multifilar da UFV. (a) subsistema em solo (b) subsistema do telhado.

Figura 35 - Strings de teste e comparação do subsistema em solo do protótipo de UFVa. 84

Figura 36 - Arranjo esquemático do sistema de arrefecimento do protótipo de UFVa.

Figura 37 - Identificação dos módulos PV com sensores PT-100. .88

Figura 38 - Período de teste de operação (a) Temperatura dos módulos PV 1.02.M e 7.02.M, (b) Vazão do sistema de arrefecimento e (c) Temperatura e vazão de um dia de cada período

Figura 39 - Impacto do fornecimento contínuo de água no sistema de arrefecimento. (a) Fornecimento contínuo 08/06/2015 e (b) Fornecimento interrompido 17/06/2015.

Figura 40 - Temperatura de entrada, saída e vazão de água do período P1. (a) 07h00min às $18 \mathrm{~h} 00 \mathrm{~min}$, (b) 09h00min às $17 \mathrm{~h} 30 \mathrm{~min}$ e (c) $11 \mathrm{~h} 00 \mathrm{~min}$ às $15 \mathrm{~h} 00 \mathrm{~min} .94$ Figura 41 - Temperatura de operação dos módulos PV, 1.02.M e 7.02.M, no primeiro dia de cada período. (a) P1, (b) P2, (c) P3 e (d) P4. .96

Figura 42 - Temperatura de operação dos módulos PV no Período P1. (a) Período com máxima diferença de temperatura e (b) Período com mínima diferença de temperatura. .99

Figura 43 - Distribuição das máximas e mínimas temperaturas nos dias do período P1. (a) 08/06/2015, (b) 09/06/2015, (c) 10/06/2015 e (d) 11/06/2015. 100

Figura 44 - Temperaturas registradas pelos sensores PT100 para o mesmo instante. (a) 08/06/2015, (b) 09/06/2015, (c) 10/06/2015 e (d) 11/06/2015. 101

Figura 45 - Energia total (Wh) dos strings para o período $\mathrm{P} 1$. (a) 07h00min às $18 \mathrm{~h} 00 \mathrm{~min}$ e (b) 09h00min e 17h30min e (c) 07h00min às 9h00min. 103 
Figura 46 - Potência (W) nos strings para o período P1. (a) 07h00min às $18 \mathrm{~h} 00 \mathrm{~min}$ e (b) 09h00min e 17h30min e (c) 07h00min às 9h00min. 105

Figura 47 - Curva do RP para o período das 11h00min às $15 \mathrm{~h} 00 \mathrm{~min}$ do dia $11 / 06 / 2015$. 106

Figura 48 - Vento local entre às $09 \mathrm{~h} 00 \mathrm{~min}$ e às $17 \mathrm{~h} 30 \mathrm{~min}$ do período $\mathrm{P} 1$. (a) frequência da direção dos ventos e (b) velocidade média e máxima dos ventos....109 Figura 49 - Curvas diárias das grandezas climáticas analisadas. (a) Velocidade do vento e (b) Temperatura ambiente e radiação solar 112

Figura 50 - Imagens da temperatura dos módulos PV com câmera termovisora. (a) superfície superior e (b) superfície inferior.

Figura 51 - Módulo solar fotovoltaico MEMC SILVANTIS ${ }^{\text {TM }}$ P290 MODULE. 126

Figura 52 - Desenho representativo das dimensões do módulo PV utilizado no projeto.

Figura 53 - Curvas características de operação do módulo PV (a) por faixa de radiação incidente operando a $25^{\circ} \mathrm{C}$ e (b) em relação à temperatura de operação considerando radiação incidente de $1.000 \mathrm{~W} / \mathrm{m}^{2}$. 129

Figura 54 - Representação do sensor de temperatura do tipo termoresistência PT100 130

Figura 55 - Câmera termovisora FLIR i5. 130

Figura 56 - Fluxograma de construção do modelo final de arrefecimento. 133

Figura 57 - Eficiência térmica em relação ao tipo de material utilizado no coletor de calor. 135

Figura 58 - Materiais selecionados e comprados para a produção dos modelos de UMAr

Figura 59 - Dobradeira manual a frio para teste. 138

Figura 60 - Tubo de aço carbono DIN 2394 após teste de dobragem 138

Figura 61 - Dobradeira automática a frio utilizada na produção das serpentinas dos dois modelos do tipo chapa-tubo 139 
Figura 62 - Serpentinas dos modelos 1 e 2 . 140

Figura 63 - Junção dos tubos por processo de soldagem do tipo (a) MIG e (b) MAG.

Figura 64 - Junção Chapa-Tubo por soldagem tipo TIG de teste 142

Figura 65 - Junção Chapa-Tubo por soldagem tipo MIG de teste 143

Figura 66 - Junção chapa-tubo final do tipo MIG 143

Figura 67 - Maçarico, filamento de estanho e acabamento da deposição de material. 144

Figura 68- tipos de acabamento da junção chapa-tubo utilizando três diferentes pastas epóxi condutora. 145

Figura 69 - Modelos de UMAr após receberem aplicação de pasta epóxi condutoras.

Figura 70 - Figuras representativas do polimento e aplicação de tinta anticorrosão.

Figura 71 - Chapas finas cortadas, dobras e fixadas por ponteamento de solda de solda. 147

Figura 72 - Dutos fixados na chapa. 148

Figura 73 - Representação dos locais de instalação do arrefecedor. (a) superfície inferior do módulo PV e (b) quadro metálico do módulo PV 149

Figura 74 - UMAr do tipo chapa-tubo com raio de curvatura de 140,00 mm. 151

Figura 75 - UMAr do tipo chapa-tubo com raio de curvatura de $85,00 \mathrm{~mm}$. 152

Figura 76 - UMAr de múltiplos canais. 153

Figura 77 - Representação do diagrama multifilar elétrico da U.P. 156

Figura 78 - Layout da linha de alimentação de água do sistema de arrefecimento da U.P. 157

Figura 79 - Representação do diagrama multifilar elétrico da UFVa-ILS 158 
Figura 80- Figura representativa da tubulação de água bruta do enrocamento MEUHE ILS.

Figura 81 - Figura representativa da tubulação de água bruta do enrocamento MEUHE ILS e da sua expansão até a usina fotovoltaica 160

Figura 82 - Fotos registradas com a câmera térmica em 04/03/2015 para o período das 10h00min00ss (a) Meio_A, (b) Ponta_A, (c) Meio_B, (d) Ponta_B, (e) Meio_Sem e (f) Ponta_Sem. 161

Figura 83 - Fotos registradas com a câmera térmica em 04/03/2015 para o período das 12h00min00ss (a) Meio_A, (b) Ponta_A, (c) Meio_B, (d) Ponta_B, (e) Meio_Sem e (f) Ponta_Sem. 162

Figura 84 - Fotos registradas com a câmera térmica em 04/03/2015 para o período das 15h00min00ss (a) Meio_A, (b) Ponta_A, (c) Meio_B, (d) Ponta_B, (e) Meio_Sem e (f) Ponta_Sem 163

Figura 85 - Módulo PV com UMAr instalada na UFVa. 165

Figura 86 - Filtro da linha A do sistema de alimentação de água do protótipo de UFVa. 166

Figura 87 - Filtro da linha A. (a) Filtro conectado a linha A, (b) filtro sujo e (c) filtro limpo. 167 


\section{ÍNDICE DE TABELAS}

Tabela I - Recomendação para tipo de coletor baseado no tipo de demanda. .42

Tabela II - Índices de temperatura e pluviométricos para a cidade de llha Solteira/SP. .56

Tabela III - Lista dos componentes da U.P. .64

Tabela IV - Identificação e localização dos modelos de arrefecedores e sensores de temperatura.

Tabela V - Te e Ts saída da água do sistema de arrefecimento da U.P. .68

Tabela VI - Temperaturas médias, mínimas e máximas dos 21 dias com temperaturas dos módulos $\mathrm{PV}>60,00^{\circ} \mathrm{C}$. .77

Tabela VII - Temperaturas nos pontos medidos pela câmera termovisora. 79

Tabela VIII - Lista de códigos de identificação dos sensores de temperatura PT100 e local de instalação.

Tabela IX - Lista de equipamentos do sistema de medição de temperatura do protótipo de UFVa.

Tabela X - Períodos de dias analisados. .89

Tabela XI - Períodos e horários de ocorrência de temperaturas máximas e maiores que $45,0^{\circ} \mathrm{C}$

Tabela XII - Dados consolidados de potência, Geração e RP para o período P1. .107

Tabela XIII - Dados consolidados de Yield, PR e FC para o período P1 108

Tabela XIV - Custos de implantação do protótipo de UFVa 114

Tabela XV - Estimativa do custo de implantação de UMAr com produção em escala. 115

Tabela XVI - Dados técnicos do Módulo PV. 128 
LISTA DE ABREVIATURAS E SIGLAS

AC

BIPV

$\mathrm{CC}$

CEC

CESP

DC

ECN

EUT

FC

GLP

MAG

MIG

MIT

MM

m-Si

NOCT

PR

p-Si

PV

PVT

Q

REP

SIN

$\operatorname{Re}$
Alternating Current

buildingintegrated photovoltaic

Corrente Contínua

Clean Energy Council

Companhia Energética de São Paulo

Direct Current

Energy research Centre of the Netherlands

Eindhoven University of Technology

Fator de Capacidade

Gás Liquefeito de Petróleo

Metal Active Gas

Metal Inert Gas

Massachusettes Institute of Technology

Milhões

Silício Monocristalino

Normal Operating Cell Temperature

Performance Ratio ou Taxa de Desempenho

Silício Policristalino

Fotovoltaico

PhotoVoltaic/Thermal

Vazão de água ou Vazão de fluido refrigerante

Relação Energia gerada por Período de geração

Sistema Interligado Nacional

Reynolds 
$\mathrm{RP}$

STC

$\mathrm{Ta}$

Te

TIG

Tmáx

$\Delta \mathrm{T}$

$\Delta \mathrm{T}$ (máx-mín)

$\Delta \mathrm{TPV}$

$T_{\text {mín }}$

$T_{P V}$

Ts

UFV-ILS

UFVa-ILS

UMAr

U.P.

Y
Relação potência instantânea e capacidade instalada Standard Test Condition

Temperatura ambiente

Temperaturas de entrada da água ou fluido refrigerante

Tungsten Inert Gas

Temperatura máxima

Diferença de temperatura entre um módulo PV com e sem UMAr

Diferença entre a maior e menor temperatura de operação

Diferença de temperatura em um mesmo módulo PV

Temperatura mínima

Temperaturas do módulo PV

Temperaturas de saída da água ou fluido refrigerante

Usina Solar Fotovoltaica de llha Solteira

Usina Solar Fotovoltaica arrefecida de Ilha Solteira

Unidade Modular Arrefecedora

Unidade de Provas

Yield ou Produtividade do módulo PV ou string 
RESUMO

7

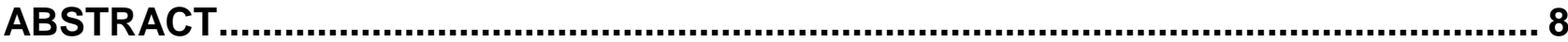

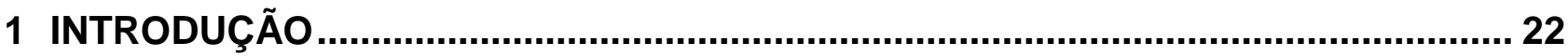

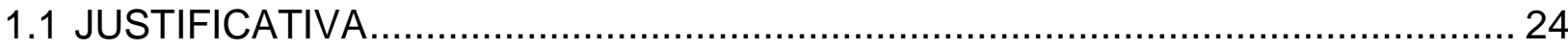

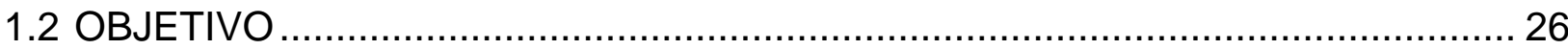

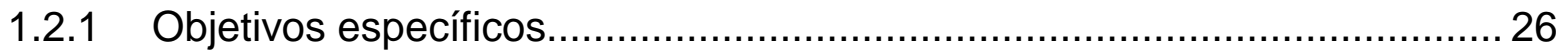

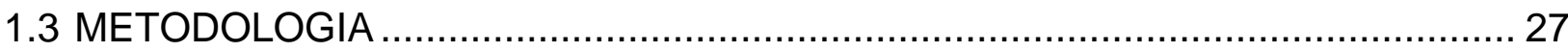

2 CARACTERISTICAS DE UM MÓDULO PV .............................................................. 29

2.1 EFEITO DA TEMPERATURA EM MÓDULOS PV ........................................ 29

2.2 EFEITO DA SUJEIRA/POEIRA NA SUPERFÍCIE DOS MÓDULOS ..................... 34

3 SISTEMA DE ARREFECIMENTO DE MÓDULOS PV .............................................. 36

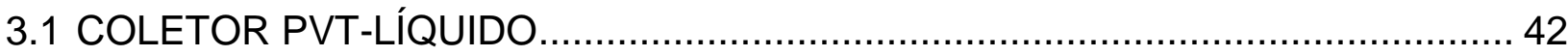

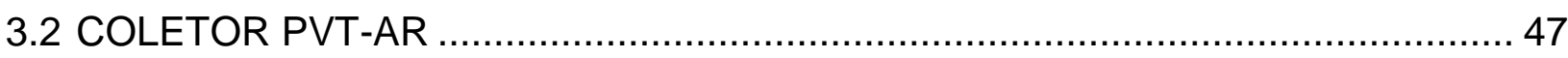

3.3 PV VENTILADO COM RECUPERAÇÃO DE CALOR .................................... 49

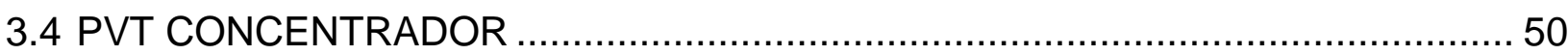

3.5 SISTEMA DE ARREFECIMENTO DE MÓDULOS PV NÃO PVT ........................ 52

4 ANÁLISE E SELEÇÃO DO MODELO FINAL DE UMAR .................................... 55

4.1 CARACTERÍSTICAS CLIMÁtICAS DA REGIÃO DA CIDADE DE ILHA

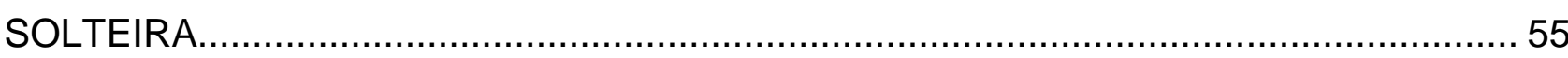

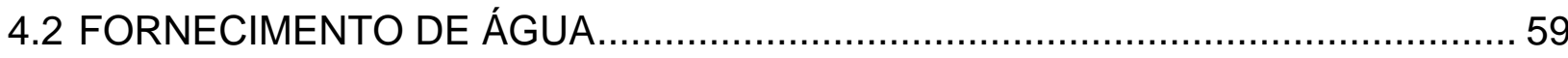


4.2.1 Água de saída do sistema de refrigeração dos Mancais das Turbinas 60

4.2.2 Água da linha de enrocamento da UHE 61

4.3 SELEÇÃO DO TIPO DE TECNOLOGIA INDICADA PARA CONSTRUÇÃO DOS MODELOS DE TESTE 62

4.4 TESTES EMPÍRICOS EM UNIDADE DE PROVAS PARA SELEÇÃO DE MODELO FINAL DE UMAR

4.4.1 Unidade de provas 63

4.4.2 Procedimento de operação e montagem da U.P 64

4.4.3 Testes empíricos e análise dos dados 67

4.4.4 Resultados dos testes e análise da U.P. 79

\section{TESTES EMPÍRICOS E DETERMINAÇÃO DO DESEMPENHO DE UM} PROTÓTIPO DE USINA SOLAR FOTOVOLTAICA ARREFECIDA

5.1 USINA SOLAR FOTOVOLTAICA ARREFECIDA 81

5.2 PROCEDIMENTO DE OPERAÇÃO E MONTAGEM DA UFVA 83

5.2.1 Sistema de arrefecimento da UFVa 84

5.2.2 Sistema de supervisão e monitoramento de temperatura do protótipo de UFVa 86

5.3 TESTES EMPRÍCOS E ANÁLISE DOS DADOS 89

5.3.1 Sistema de arrefecimento. 89

5.3.2 Análise da geração de energia elétrica para o Período P1 102

5.3.3 Estudo do impacto do clima local no comportamento de operação do protótipo de UFVa para o Período P1 108 
6 RESULTADOS

7 CONCLUSÕES

8 CONSIDERAÇÕES E RECOMENDAÇÕES. 120

9 REFERÊNCIA BIBLIOGRÁFICA 122

ANEXO A 126

ANEXO B 130

ANEXO C 131

C.1 DESENVOLVIMENTO DOS MODELOS DE UMAR DO TIPO CHAPA-TUBO 133

C.1.1 Chapa-tubo 134

C.1.2 Junção chapa-tubo 141

C.1.3 Acabamento, limpeza e inspeção 146

C.2 DESENVOLVIMENTO DO MODELO DE UMAR DO TIPO MÚLTIPLOS CANAIS

C.3 DESENVOLVIMENTO DA ESTRUTURA DE FIXAÇÃO MODELO DE UMAR/MÓDULO PV 149

ANEXO D 154

ANEXO E 155

ANEXO $F$ 156

ANEXO G 157 


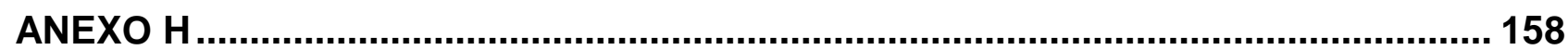

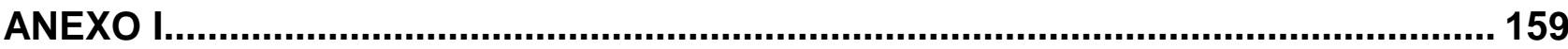

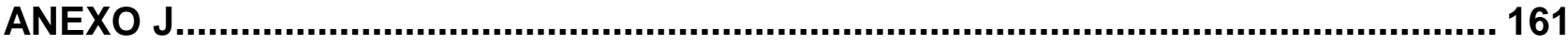

ANEXO K

K.1 SUPERVISÃO E MONITORAMENTO DA INSTALAÇÃO DE UMAR EM

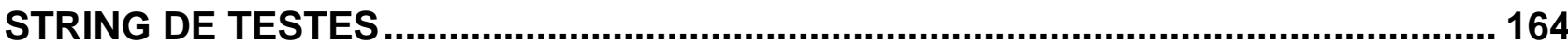

K.2 DESCRIÇÃO DOS PROBLEMAS DO SISTEMA DE FORNECIMENTO DE ÁGUA 


\section{INTRODUÇÃO}

O território brasileiro, quinto maior em extensão do mundo com 8,5 $\mathrm{MMkm}^{2}$ (IBGE, 2013), apresenta características climáticas muito diferentes entre seus eixos, Norte-Sul e Leste-Oeste, e ao longo do ano. Apesar disso, a média anual de radiação global apresenta boa uniformidade, com médias relativamente altas em todo o país variando entre 4,200 e 6,700 kWh/m²/dia, superior à maioria dos países da União Europeia (EU), que tem média entre 0,900 e 1,850 kWh/m²/dia, onde há grandes investimentos em projetos para aproveitamento de recursos solares.

No Brasil, a menor taxa de radiação solar global, $4,250 \mathrm{kWh} / \mathrm{m}^{2}$ ocorre no litoral norte de Santa Catarina devido à ocorrência de precipitação pluvial consistente ao longo do ano, e a maior, $6,500 \mathrm{kWh} / \mathrm{m}^{2}$, incide no norte do estado da Bahia, próximo à fronteira do estado do Piauí. Essa região apresenta a menor média anual de cobertura de nuvens do Brasil, ver Figura 1, (INPE, 2006).
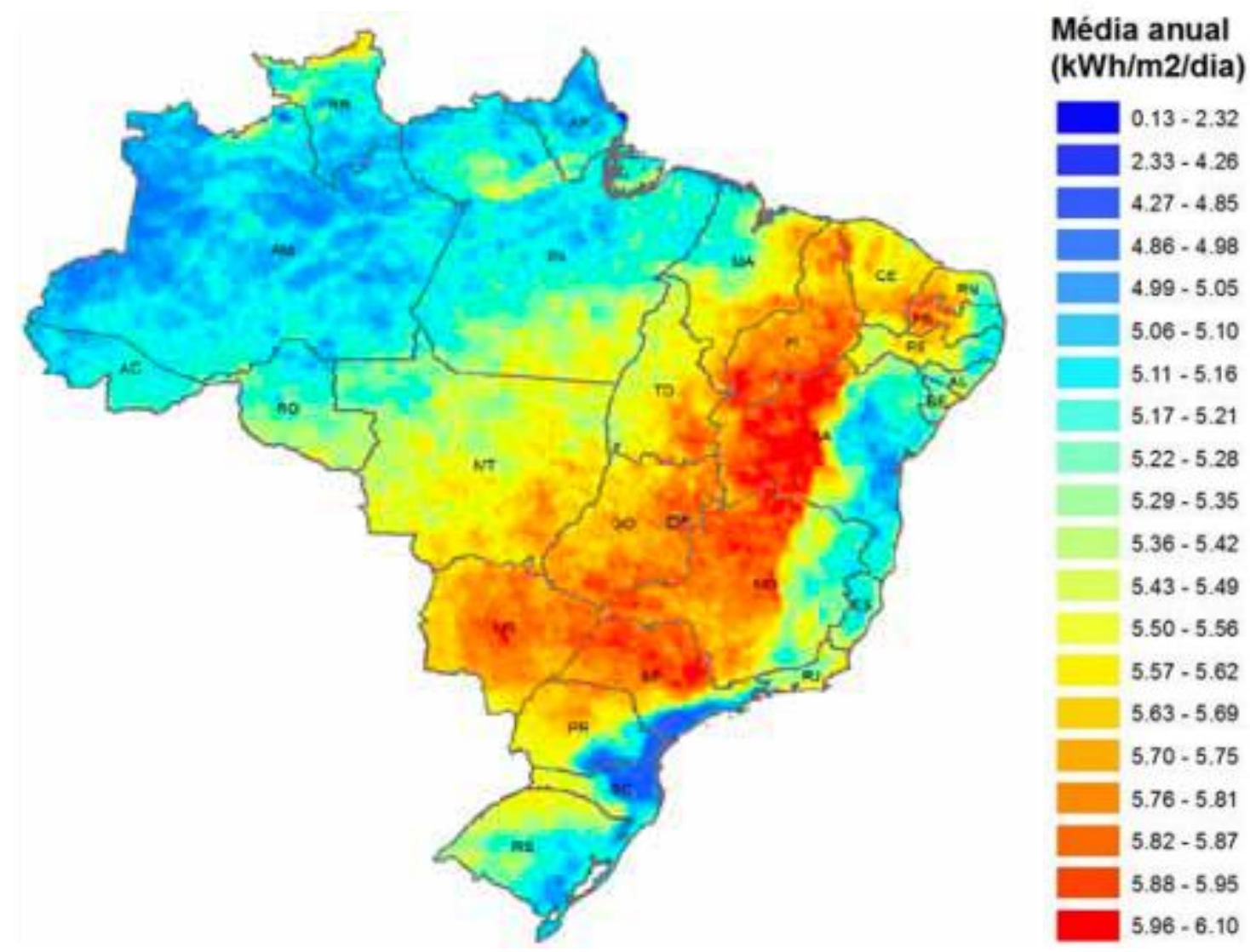

Figura 1 - Mapa da radiação solar global (média anual) do Brasil.

Fonte: INPE, 2006. 
O estado de São Paulo apresenta sete tipos climáticos distintos, com características dominantemente marcadas pelo clima tropical de altitude, com chuvas no verão e seca no inverno e média de temperatura do mês mais quente superior a $22^{\circ} \mathrm{C}$. A região noroeste do estado apresenta clima tropical chuvoso, o mais quente do estado, com características de inverno seco, mês mais frio com temperatura média superior a $18^{\circ} \mathrm{C}$ e mês mais seco com precipitação inferior a 60 $\mathrm{mm}$, com período chuvoso compreendendo os meses de outubro a março (CEPAGRI, 2015a). Além disso, possui a maior média anual de irradiação solar do estado, $5,520 \mathrm{kWh} / \mathrm{m}^{2}$, com médias mensais máximas no verão e primavera, 5,970 e $6,672 \mathrm{kWh} / \mathrm{m}^{2}$.dia respectivamente, próximas às máximas do país, (SEE, 2006).

Os sistemas PV são utilizados num vasto conjunto de aplicações, dentre as quais se destacam aplicações em baixa e média potência (EPIA, 2008) em sistemas isolados, utilizados para o abastecimento de cargas domésticas sem acesso à rede de distribuição elétrica da concessionária local, e na produção descentralizada utilizada como fonte de produção dispersa e integrada às edificações conectadas à rede de distribuição da concessionária local, ou seja, junto ao ponto de consumo. Neste caso, o produtor/consumidor pode optar por utilizar a energia elétrica convencional, advinda da rede, para complementar sua demanda ou vender a energia gerada para concessionária local, em períodos de baixo consumo ou com excedente de produção, mas as condições de venda ou troca estão atreladas à regulamentação específica e muitas vezes tornam 0 empreendimento economicamente inviável devido ao alto custo de instalação, falta de área disponível e baixo custo da energia.

No caso dos sistemas PV centralizados conectados à rede, a usina geradora é instalada em áreas geralmente afastadas dos centros consumidores, semelhante às usinas hidrelétricas e eólicas, e a energia produzida não está associada a um consumidor ou cliente exclusivo, ou seja, toda a eletricidade é disponibilizada instantaneamente na rede da concessionária.

A desvantagem desse sistema deve-se ao fato de estarem, geralmente, afastadas dos centros de consumo, necessitando de um sistema de transmissão para levar a energia até os centros consumidores, além disso, ocupam grandes 
áreas. Esses dois fatores impactam diretamente no custo de instalação da usina, tornando o empreendimento ainda mais caro $\mathrm{e}$, dependendo da região, inviabilizando a sua construção devido à concorrência com outras fontes de energia, sejam elas renováveis ou convencionais.

\subsection{JUSTIFICATIVA}

A produção de energia, seja ela elétrica e/ou térmica, ocasiona o aumento da temperatura dos equipamentos envolvidos na operação. Para reduzir este aumento que impacta diretamente na eficiência, vida útil e emissão de poluentes são empregados sistemas de arrefecimento, presentes em máquinas rotativas de produção de energia como os radiadores e bomba d'água utilizados para evitar o superaquecimento e a emissão de $\mathrm{NOx}, \mathrm{CO}, \mathrm{CO}_{2}, \mathrm{SO}_{x}$ em motores de combustão interna do tipo Diesel e Otto, trocador de calor dos mais diversos no caso das turbinas hidráulicas e a gás natural garantindo a integridade física dos mancais e das pás.

Os módulos PV, equipamentos de produção de energia elétrica em estado sólido estacionário, também sofrem com os efeitos do aumento da temperatura durante a sua operação, pois da parte da energia do espectro solar incidido (radiação extraterrestre) sobre a superfície do PV, apenas 5 a $20 \%$ é convertido em energia elétrica, dependendo do tipo de tecnologia utilizada, os $80 \%$ restante são refletidos e/ou convertidos em calor. A partir da Figura 2, a qual apresenta os componentes da intensidade espectral absorvido pelo PV em relação ao seu comprimento de onda, tem-se que parte da energia é perdida para o meio, uma segunda convertida em eletricidade e uma terceira parte, referente aos maiores comprimentos de onda, não é aproveitada como fonte de energia, seja ela térmica ou elétrica. Todo esse processo ocorre simultaneamente fazendo com que a temperatura dos módulos PV alcance até $35^{\circ} \mathrm{C}$ acima da temperatura ambiente (van HELDEN et al., 2004), em algumas regiões esses módulos $\mathrm{PV}$ atingem temperaturas superiores a $90^{\circ} \mathrm{C}$, podendo comprometer o seu funcionamento e até danificá-lo permanentemente $(\mathrm{OH}$ et. al., 2010). Esse fenômeno compromete ainda mais o rendimento dos módulos PV. 


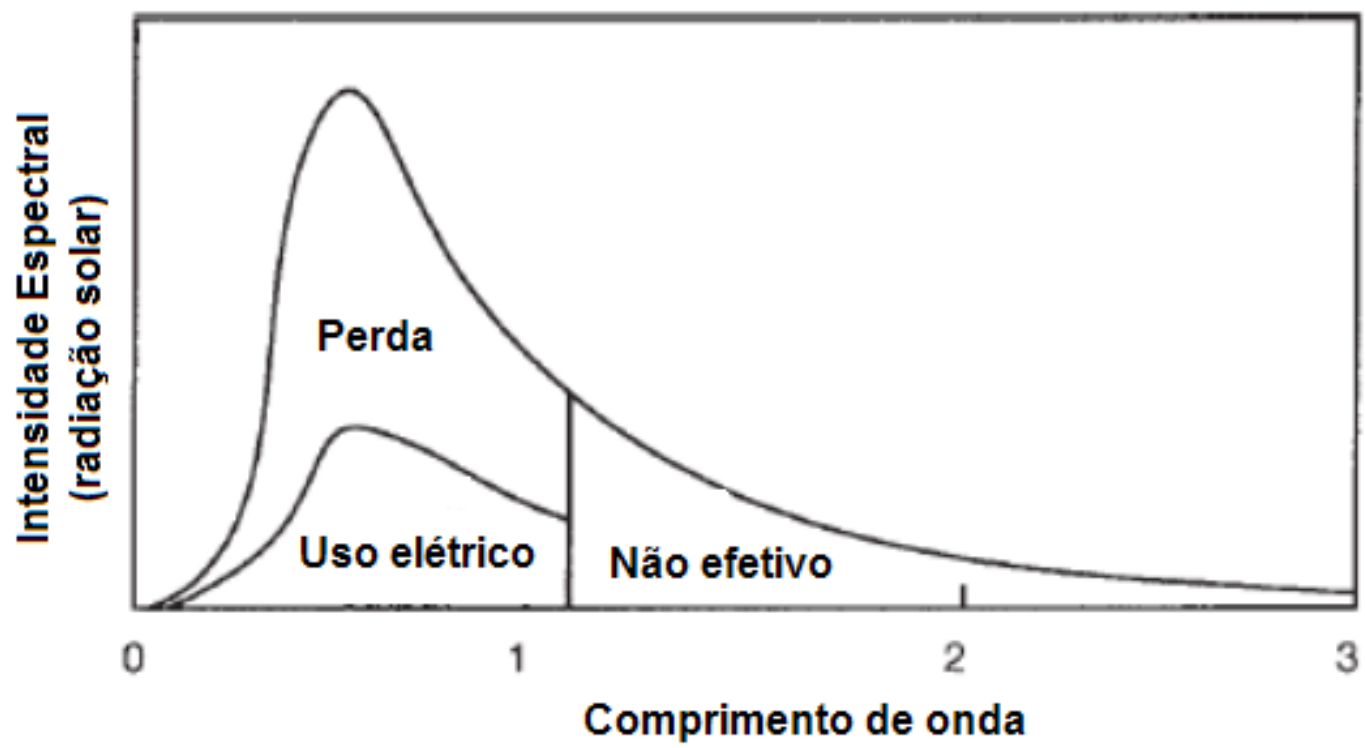

Figura 2 - Representação da divisão do espectro solar que é convertido em eletricidade e calor em função do comprimento de onda.

Fonte: van Helden et al., 2004.

Segundo PRIEB (2002), à medida que aumenta a temperatura do módulo de silício observa-se uma diminuição da tensão a uma taxa de $-2,2 \mathrm{mV} /{ }^{\circ} \mathrm{C}$, já a corrente de curto-circuito (CC) apresenta um ligeiro incremento da ordem de $0,06 \% / 0 \% \mathrm{C}$, ver Figura 3. Esse aumento impacta na potência, porém é insuficiente para compensar a perda de potência decorrente da diminuição da tensão, ou seja, a grande exposição à radiação solar associada com alta temperatura ambiente eleva a temperatura de operação do módulo impactando diretamente na sua eficiência e energia de saída, uma vez que temperaturas mais altas de operação reduzem a tensão produzida. Esse efeito ocorre principalmente em regiões tropicais, baixas latitudes e com grande incidência de radiação solar. 


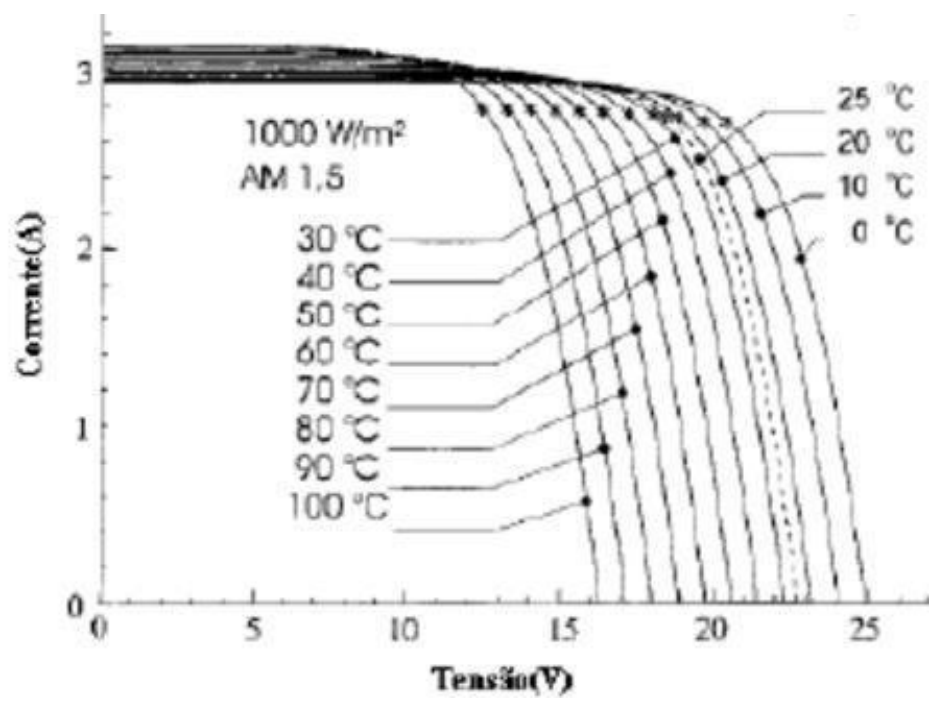

Figura 3 - Influência da temperatura da célula na corrente e tensão.

Fonte: TEe.

Assim, o desenvolvimento de tecnologia de arrefecimento para módulos PV pode aumentar o desempenho na geração de energia elétrica de uma UFV com a diminuição da temperatura de operação dos módulos PV, principalmente em locais com altas temperaturas ambiente e grande radiação solar incidente, como é o caso de muitas regiões brasileiras, viabilizando a implantação desses empreendimentos devido ao aumento do fator de capacidade (FC) e redução do tempo de retorno do investimento.

\subsection{OBJETIVO}

O objetivo deste trabalho é modelar a arquitetura de uma usina solar fotovoltaica arrefecida utilizando um protótipo de verificação.

\subsubsection{Objetivos específicos}

- Estudo da característica climática do local de instalação do protótipo de Usina Solar Fotovoltaica arrefecida (UFVa);

- Estudo do estado da arte de sistemas de arrefecimento para módulos fotovoltaicos (PV) rígidos de silício, analisando seus aspectos construtivos, de funcionamento e desempenho;

- Redução da temperatura de operação de módulos PV e estudo da sua influência na geração de energia elétrica; 
- Desenvolvimento, construção e teste de três modelos diferentes de unidade modular arrefecedora (UMAr) para análise e seleção de modelo final para implantação nos módulos PV do protótipo de UFVa;

- Avaliação e quantificação da redução de temperatura e o desempenho na produção de energia elétrica dos módulos PV do protótipo de UFVa em relação ao sistema PV convencional;

- Avaliação do comportamento do fluido refrigerante e seu impacto na temperatura de operação dos módulos PV; e

- Determinação de parâmetros operativos para melhoria do funcionamento do protótipo de UFVa.

\subsection{METODOLOGIA}

A metodologia adotada para elaboração da dissertação baseia-se em:

1. Estudar os fatores que impactam no aumento da temperatura dos módulos PV e, por sua vez, na produção de energia elétrica;

2. Estudar exaustivamente e fundamentar técnica e cientificamente o estado da arte das tecnologias de arrefecimento de módulos PV visando o entendimento dos fatores que influenciam seu funcionamento e desempenho, levantando, quanto possível, os materiais empregados na construção dessas tecnologias, métodos e processos de construção, operação, manutenção e medição das grandezas envolvidas;

3. Estudar os fatores locais e geográficos da região de instalação do protótipo de UFVa, como clima, irradiação solar, temperatura ambiente e índice pluviométrico. Velocidade e direção do vento a fim de determinar e entender as condições locais de operação e produção de energia elétrica da UFV;

4. Levantar e analisar a disponibilidade de água, pois a UFV encontra-se instalada em uma UHE em operação;

5. Avaliar as tecnologias de arrefecimento e selecionar o tipo mais indicado para a região de instalação da UFV. 
6. Verificar e monitorar os testes empíricos com modelos reais construídos para selecionar a UMAr final para ser instalada no protótipo de UVFa; e

7. Verificar e monitorar os testes empíricos para determinação dos ganhos operativos do protótipo de UFVa. 


\section{CARACTERÍSTICAS DE UM MÓDULO PV}

Os módulos ou módulos PV são constituídos por agrupamentos de células PV conectados em série e/ou em paralelo de forma a se obter os valores desejáveis de tensão $(V)$, corrente $(A)$ e, por sua vez, potência $\left(W_{p}\right)$.

A função de uma célula PV é converter diretamente a energia solar em eletricidade e a forma mais comum é por meio do efeito fotovoltaico. Uma célula individual, unidade de base de um sistema fotovoltaico, produz apenas uma pequena potência elétrica variando, tipicamente, entre 01 e $03 \mathrm{~W}$. Para disponibilizar potências mais elevadas, as células são integradas, formando um módulo. A maioria dos módulos comercializados é composta por 36 células de silício cristalino, conectadas em série, para aplicações de $12 \mathrm{~V}$. Quanto maior for o módulo, maior será a potência e/ou a corrente disponível (CEEETA). Existe uma grande variedade de opções e tipos de tecnologias de células PV no mercado que podem ser de silício monocristalino ( $m-\mathrm{Si}$ ), silício policristalino ( $\mathrm{p}-\mathrm{Si}$ ), amorfa ou de película fina, mas nem todas respeitam as normas, e, por consequência, não são certificadas.

Quando se faz a escolha por um modelo de módulo PV é necessário o conhecimento de alguns fatores, como qualidade da inspeção visual e verificar se as características construtivas são confiáveis. O carimbo de certificação, por si só, já deve garantir que o módulo foi construído segundo normas, mas, por outro lado, o próprio fabricante já é um fator que influencia a escolha.

Ao se analisar a eficiência das células $\mathrm{PV}$, verifica-se que quanto maior é a eficiência menor será a área ocupada por kW produzido. Este fator é muito importante, principalmente nos casos onde a potência total instalada é grande, pois impacta diretamente no custo de aquisição de terreno que estão associados à região de instalação, área disponível/capacidade de geração e disponibilidade de investimento.

\subsection{EFEITO DA TEMPERATURA EM MÓDULOS PV}

A temperatura do módulo PV é um parâmetro de grande importância devido à sua influência no comportamento de um sistema PV. As células PV, por estarem expostas aos raios solares, aquecem modificando a eficiência do sistema e da 
energia de saída, uma vez que temperaturas mais altas reduzem a tensão produzida e, inversamente, tensões mais altas são produzidas em temperaturas menores (MERAL et al., 2011). Qualquer sistema PV deve incluir o cálculo de ajuste devido ao efeito da temperatura (KRAUTER, 2004).

O aumento da temperatura é resultado de uma característica natural do silício presente nas células PV c-Si (MERAL et al., 2011), pois parte da incidência solar absorvida não é convertida em energia elétrica, mas dissipada sob a forma de calor. Este é o motivo pelo qual a temperatura das células e módulos PV, quando estão gerando, sempre apresentam temperaturas superiores à ambiente (TEe).

A queda da tensão ocasionada pelo aumento da temperatura se dá pelo encolhimento do semicondutor devido à abertura da banda que influencia diretamente a tensão de circuito aberto ( $\mathrm{Vca}$ ), que decresce seguindo a queda de tensão da junção $p$-n. Este efeito pode ser explicado pelo fator de potencial térmico do diodo, $\mathrm{g} / \mathrm{kT}$. Portanto, as células PV possuem um coeficiente de temperatura negativo para a $\vee c a$ e, além disso, uma potência de saída menor para uma mesma fotocorrente, resultado dos portadores de carga que são liberados com um menor potencial (SHENCK, 2010).

Com o aumento da temperatura na abertura da banda, intrínseco ao encolhimento dos semicondutores, mais energia incidente é absorvida devido ao aumento da porcentagem de luz incidente, que tendo energia suficiente eleva os portadores de carga da banda de valência para a banda de condução (MERAL et al., 2011). Uma maior corrente fotoelétrica resulta, portanto, no aumento da corrente de curto-circuito para um determinado isolamento e as células fotovoltaicas tem um coeficiente positivo de temperatura Icc (SHENCK, 2010).

Segundo MAKRIDES et al. (2009) a região de maior aumento de temperatura ocorre no barramento principal, uma linha condutora que permite a interligação, captação e condução dos elétrons dos barramentos secundários, que assim como o primário, é uma linha condutora em paralelo responsável pela captação dos elétrons produzidos na banda de valência da célula PV, ver Figura 4. Nessa região encontram-se as maiores temperaturas da célula PV, como é possível verificar na Figura 5 , a região branca é a mais quente, $41^{\circ} \mathrm{C}$, local do barramento principal. 


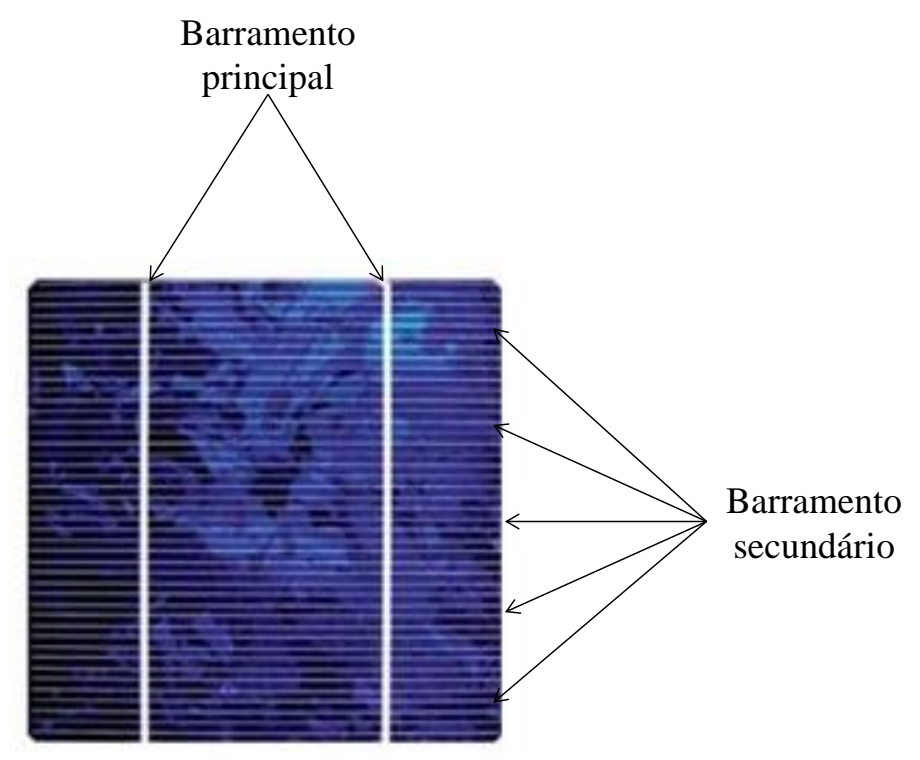

Figura 4 - Exemplificação dos Barramentos, principal e secundário, de uma célula c-SI.

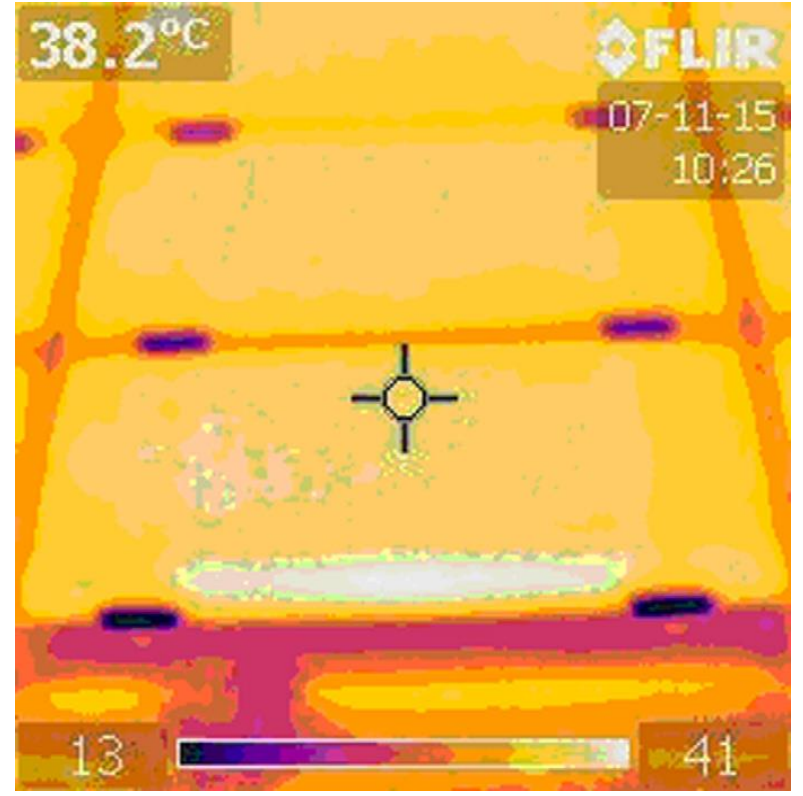

Figura 5 - Fotografia infravermelha de um módulo PV.

Fonte: Makrides et al., 2009.

A partir da Figura 6, é possível verificar que a potência de saída aumenta com o aumento da radiação incidente. A corrente de curto-circuito aumenta de forma quase que linear com o aumento da radiação incidente ao passo que o valor de tensão de circuito aberto pouco varia com radiação. 


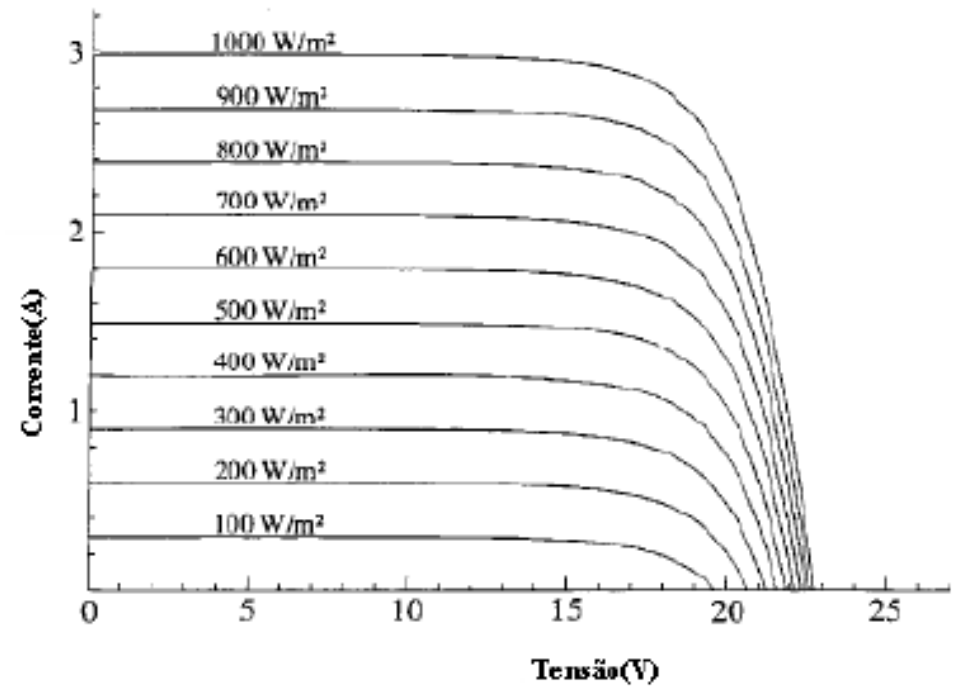

Figura 6 - Influência da variação da radiação solar na corrente e tensão.

Fonte: TEe.

A influência da temperatura sobre as características das células, ver Figura 3, tem seu principal efeito relacionado à tensão de circuito aberto, que diminui acentuadamente com o aumento da temperatura reduzindo a eficiência da célula, já a corrente de curto circuito aumenta sutilmente com o aumento da temperatura das células (Kalogirou, 2009). Esta variação, vinculada ao aumento progressivo de temperatura, faz com que os pontos de operação correspondentes à extração de potência máxima variem.

A temperatura de operação de uma célula PV (TPV), incluída na norma IEC (IEC, 2005 e IEC, 2008), pode ser determinada a partir da NOCT deste, que pode ser considerado independente da temperatura ambiente $\left(T_{a m b}\right)$ e linearmente proporcional a radiação solar (E) a níveis acima de $400 \mathrm{~W} / \mathrm{m}^{2}$, a partir da Equação 1, que se baseia na soma do NOCT menos um fator, determinado empiricamente, vezes a radiação solar local dividida por outro fator, também determinado empiricamente, mais a $T_{\text {amb }}$ (GARCIA et al., 2004).

$$
T_{P V}=T_{a m b}+(N O C T-20) x\left(\frac{E}{800}\right)
$$

Onde:

- $\mathrm{T}_{\mathrm{PV}}$, temperatura da célula em ${ }^{\circ} \mathrm{C}$;

- $\mathrm{T}_{\mathrm{amb}}$, temperatura ambiente medida em ${ }^{\circ} \mathrm{C}$; 
- Índice de radiação solar incidente no modulo em W/m²; e

- NOCT, sigla em inglês para temperatura nominal de funcionamento da célula.

A eficiência de conversão de energia $(\eta)$ de uma célula PV é o porcentual de potência convertida em relação à coletada quando conectado a um circuito elétrico, ou seja, é a relação entre a potência elétrica produzida e a energia absorvida da radiação solar, que pode ser calculada utilizando a razão entre o ponto de máxima potência $\left(P_{\text {máx }}\right)$ dividida pela radiação solar de entrada $\left(E\right.$ em $\left.W / \mathrm{m}^{2}\right)$, sob as condições normais de ensaio, incidente na área superficial da célula $\left(A_{c}\right)$.

Assim, é possível compreender o porquê da $\eta$ decrescer com o aumento da temperatura, que decresce linearmente com a diminuição da potência de saída que é diretamente proporcional à tensão de saída que decresce com o aumento da temperatura, ver Figura 7.

Portanto, assim como a tensão, a eficiência de um módulo PV diminui com o aumento da sua temperatura.

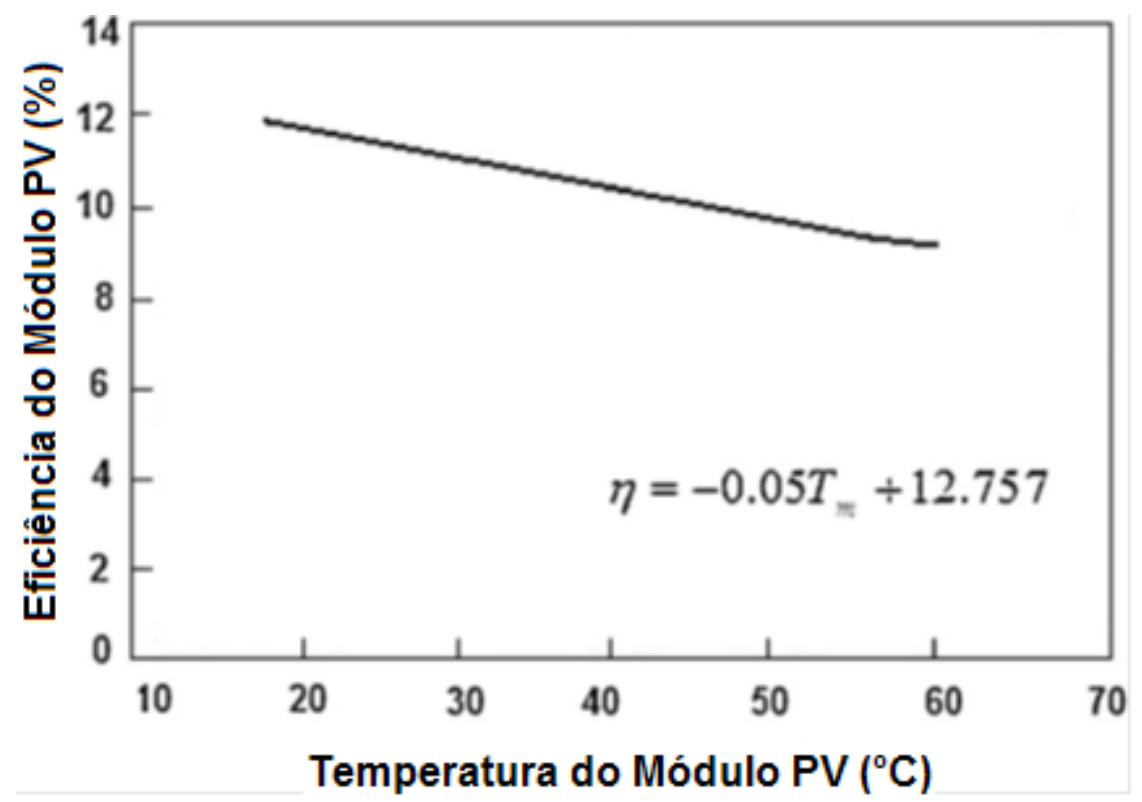

Figura 7 - Influência da temperatura na eficiência da célula.

Fonte: Yamaguchi et al., 2003.

O $\eta$ define-se como a relação entre o ponto de máxima potência, para uma célula, e a potência da radiação solar incidente sobre ela, como mostra a Equação 2.

$$
\eta=\frac{P_{\operatorname{máx}}}{A x G} \quad \text { (Eq. 2) }
$$


Na qual:

A é a área da célula;

- G é a radiação solar incidente por unidade de superfície.

A potência elétrica de saída $(P)$ de um módulo $P V$ é o produto entre a tensão e a corrente de saída dada pela Equação 3.

$$
\mathrm{P}=\mathrm{VI}=\mathrm{V}\left\{\mathrm{I}_{\mathrm{CC}}-\left[\mathrm{I}_{0}\left(\mathrm{e}^{\frac{\mathrm{V} \mathrm{VVt}}{\mathrm{V}}}-1\right)\right]\right\}
$$

O ponto de máxima potência é calculado por meio da Equação 4.

$$
\mathrm{P}_{\text {máx }}=\mathrm{V}_{\text {máx }} \mathrm{XI}_{\text {máx }}
$$

\subsection{EFEITO DA SUJEIRA/POEIRA NA SUPERFÍCIE DOS MÓDULOS}

Outro importante fator que afeta o funcionamento dos módulos fotovoltaicos é a sujeira/poeira. O seu acúmulo na superfície dos módulos fotovoltaicos bloqueia parte da luz incidente reduzindo sua capacidade de produção de energia, ou seja, reduz a eficiência dos módulos (Meral et al., 2011).

Durante as épocas chuvosas os módulos PV são limpos naturalmente, desta maneira é importante estimar o sistema PV para épocas de seca quando o acúmulo de sujeira/poeira se intensifica.

Um sistema PV com capacidade instalada de $100 \mathrm{Wp}$, operando com acúmulo de sujeira/poeira, gera em torno de 79Wp (Endecon Engineering, 2001). Esse cálculo é determinado por:

Um fabricante pode classificar a saída do seu módulo PV em $100 \mathrm{~W}$ de potência sob condições padrão de funcionamento, mas este frequentemente terá uma tolerância de $\pm 5 \%$, o que significa que o módulo pode produzir $95 \mathrm{Wp}$;

A potência de saída do módulo, como explicado no item anterior, reduz à medida que sua temperatura aumenta. Por exemplo, um módulo operando em um telhado vai aquecer substancialmente, atingindo temperaturas internas de $50^{\circ} \mathrm{C}$ a $75^{\circ} \mathrm{C}$. Para os módulos cristalinos, um fator de redução de temperatura típica recomendada pela certificação CEC (Clean Energy 
Council) é de $89 \%$ ou 0,89 . Assim, o módulo de $100 \mathrm{Wp}$ que normalmente opera em cerca de $95 \mathrm{Wp}$, operará devido ao aumento da temperatura a uma potência de $85 \mathrm{Wp}$; e

O fator atípico anual de redução da potência devido à sujeira/poeira é de $93 \%$ ou 0,93 . Portanto, o módulo poderá operar em média com $79 \mathrm{Wp}$. 


\section{SISTEMA DE ARREFECIMENTO DE MÓDULOS PV}

A técnica mais estudada e aplicada de sistema de arrefecimento para módulos PV é o sistema híbrido de módulos fotovoltaicos térmicos (PVT, sigla em inglês para Photovoltaic/Thermal), no qual o calor gerado é extraído a partir do módulo PV para o sistema absorvedor térmico por condução e principalmente convecção.

A primeira pesquisa sistemática sobre as possibilidades de combinação de técnicas PV e solares térmicas foi realizada no início de 1980 por um grupo do Massachusettes Institute of Technology (MIT) (HENDRIE, 1982). Neste estudo abrangente, vários modelos PVT foram feitos e testados, tanto do tipo ar e do tipo água. $\mathrm{O}$ trabalho foi interrompido por mudança no financiamento do governo.

A pesquisa PVT recuperou a atenção em meados de 1990, com, entre outros, o trabalho de doutorado de De Vries, que projetou vários conceitos de módulos PVT, dos quais um foi construído e testado (de VRIES, 1998). Um modelo numérico foi desenvolvido para cálculo de ambos os desempenhos, elétrico e térmico. As previsões do modelo foram condizentes com os resultados experimentais encontrados (ZONDAG et al., 2002). O trabalho prosseguiu com um programa de desenvolvimento no ECN (sigla em inglês para Centro de Pesquisas de Energias da Holanda) (ZONDAG et al.., 2003) em colaboração com a indústria e o Eindhoven University of Technology (EUT), o desempenho térmico foi melhor aperfeiçoado e uma tecnologia de produção foi desenvolvida (van HELDEN et al., 2002). Também no ECN, Bakker investigou outro conceito PVT, no qual utilizava dois módulos absorvedores de calor (BAKKER et al., 2002).

Nos últimos anos, vários outros grupos de pesquisa trabalharam com os sistemas PVT. Na Universidade de Patras, na Grécia, diferentes modelos de sistemas PVT foram projetados, construídos e testados (Tripanagnostopoulos et al., 2002). $\mathrm{Na}$ Suécia, a partir de uma tese de doutorado, foi projetado um sistema PVT com refletor parabólico de baixa concentração (Brogren et al., 2002). Na Noruega, foi desenvolvido um conceito no qual um amortecedor térmico plástico é utilizado para retirar calor do módulo PV (Sandnes et al., 2002). Além disso, trabalhos com a aplicação da película fina em conceitos PVT foram realizados na Suiça (Platz et al. 1997 e Affolter et al., 2000). 
A partir de uma visão mais completa da literatura sobre sistemas PVT (Leenders et al., 2001) pode-se concluir que as atividades de P\&D são difundidas pelo mundo inteiro e realizadas em programas relativamente pequenos. Devido a esta dispersão, houve pouca atenção na comunidade internacional que trabalha e desenvolve projeto vinculado à tecnologia PV. Como resultado, o desenvolvimento desta tecnologia limitou-se à aplicação e à adaptação de tecnologias PV disponíveis ao mercado (van Helden et al., 2004).

Atualmente existem diversos tipos de sistemas PVT, sendo o mais simples o que utiliza corrente de ar direcionada para a parte de trás do módulo PV para refrigerá-lo, no qual o ar aquecido pode ser empregado para calefação do ambiente. Um outro sistema, um pouco mais complexo, consiste na utilização de um absorvedor de calor acoplado à superfície inferior do módulo PV, o absorvedor utiliza um fluido circulante, geralmente água, no qual o calor flui do módulo PV para o fluido, que posteriormente pode ser empregado, no caso doméstico, para banhos e torneiras.

Os coletores térmicos ainda podem ser divididos em dois grupos. No caso dos sistemas onde o absorvedor está em contato direto com o meio, ele é chamado de PVT descoberto, neste caso as perdas de calor para o meio são consideráveis e as temperaturas e eficiência térmicas alcançadas por esse modelo são relativamente baixas, este tipo de sistema é indicado para os casos nos quais se deseja temperaturas de aquecimento mais baixas para a água ou para melhorar o rendimento na conversão elétrica do módulo PV. O outro grupo é caracterizado pelo sistema PVT coberto, que utiliza uma cobertura, geralmente transparente, colocada sob o absorvedor. Essa cobertura, dependendo do tipo de material utilizado, transmite cerca de $90 \%$ da radiação solar incidente, essa redução, para a maioria das aplicações, é menos importante do que o efeito do isolamento térmico da cobertura, que tem um efeito direto no aumento da eficiência térmica do sistema.

A partir da análise da Figura 8, na qual a temperatura de entrada do fluido, temperatura ambiente e incidência da radiação solar são as mesmas para os dois sistemas, é evidente que as curvas de eficiência térmica do sistema estão diretamente ligadas ao coeficiente de perda térmica. Além disso, é possível verificar 
que as perdas térmicas no sistema descoberto são mais acentuadas que no coberto, comprovando que as perdas por radiação e convecção são muito influentes.

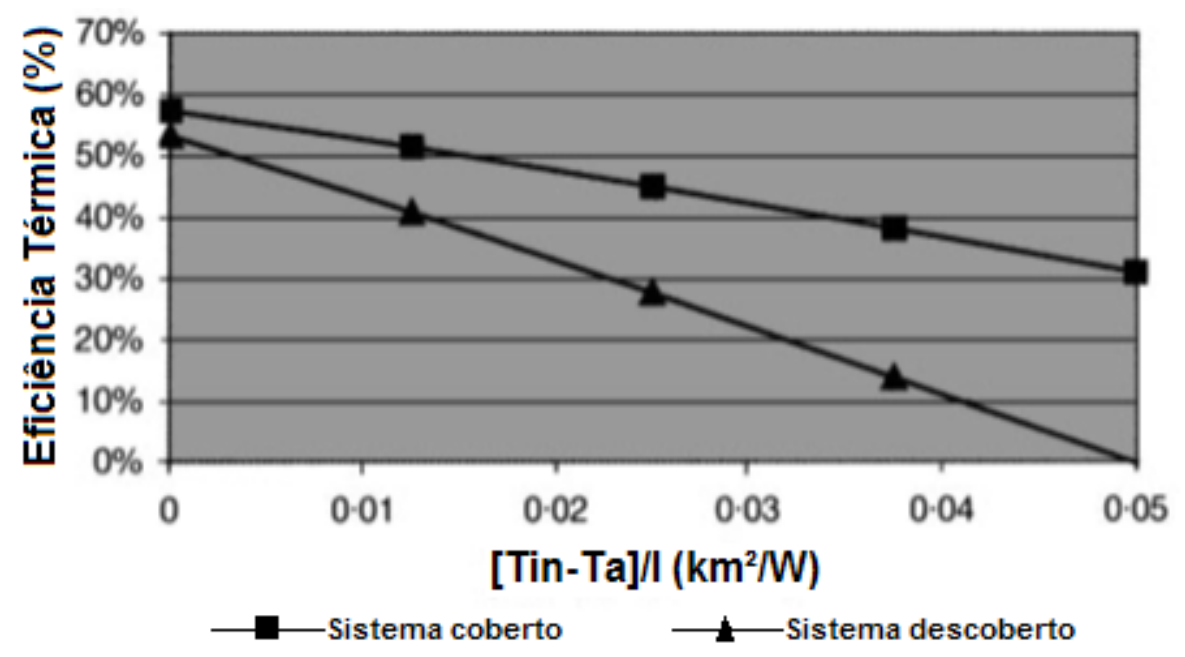

Figura 8 - Típicas curvas de eficiência térmica para sistema PVT.

Fonte: van Helden et al., 2004

Resumindo, o sistema PVT consolida a produção de eletricidade dos módulos PV e calor dos concentradores solares, ver Figura 9.

\section{Entrada}

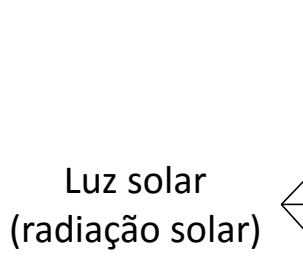

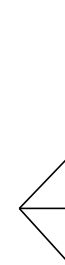

Sistema

PV

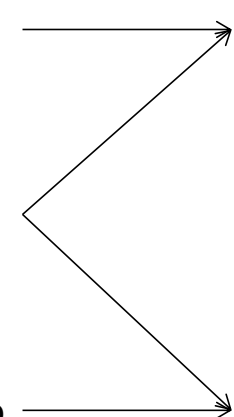

\section{Saída}

Eletricidade

\section{Calor}

Figura 9 - Comparação entre os tipos de tecnologias e as energias produzidas.

Fonte: adaptado de Hasan et al., 2010.

Segundo van HELDEN et al. (2004), existem diversas razões para se combinar sistemas PV e térmico em um único dispositivo, que se deve, principalmente pela maior eficiência da conversão global, reduzindo o tempo de retorno da energia obtida, redução do tempo de retorno econômico e melhoria estética da edificação. 
No que diz respeito à estética, os arquitetos e os consumidores preferem uma área de telhado PVT mais uniforme do que uma área do telhado parcialmente coberto com coletores térmicos e outra com módulos PV. Em segundo lugar, sistema PVT tem a mesma aparência externa dos módulos PV, que muitos consumidores consideram ser mais atraente do que os coletores solares térmicos.

O projeto de um sistema PVT varia com o tipo de aplicação e como a viabilidade técnica desse sistema está comprovada (HASAN et al., 2010), o mercado de PVT pode se tornar até maior que os mercados PV convencionais e solares térmicos. Pois tanto demanda térmica quanto elétrica podem ser supridas simultaneamente a partir da escolha e dimensionamento do sistema PVT apropriado.

Existem vários tipos e formas de sistemas PVT, que variam com o tipo de módulo $\mathrm{PV}$, de fluido, quantidade de radiação e posicionamento geográfico da instalação.

Os sistemas PVT podem ser de placa plana ou concentrador e sua classificação varia de autor para autor, sendo mais comum a classificação de acordo com o tipo de fluido de trabalho utilizado, os mais comuns são a água e o ar.

Sistemas PVT-água são mais eficientes na remoção de calor dos PV do que os sistemas PVT-ar (PRAKASH, 1994) devido à alta condutividade térmica da água em relação ao ar, resultando em uma grande transferência de calor dos módulos PV para o fluido. O grande problema desse sistema deve-se a disponibilidade da água e a necessidade de grandes modificações para permitir a passagem do fluido e evitar a corrosão do coletor.

Segundo CHARALAMBOUS (2007), os sistemas PVT podem ser divididos e classificados em três categorias:

- Coletores PVT de placa plana, que são muito semelhantes aos coletores térmicos, a única diferença significativa é a presença do módulo PV que está ligado no topo da placa do absorvedor metálico, ver Figura 10;

Coletores do PVT do tipo água e ar, no caso dos PVT-água, estes são diferenciados pelo padrão do fluxo da água que pode ocorrer em tubos, canais, fluxo livre e por dois absorvedores. Assim como no sistema PVTágua o sistema PVT-ar é diferenciado pelo tipo de padrão do fluxo que 
ocorre sobre e/ou sob o absorvedor com simples ou dupla passagem, ver Figura 10, e

Coletor PVT concentrador, esse sistema é utilizado para aumentar o nível de irradiância solar nos módulos PV, nos quais são incorporadas estruturas físicas refletoras aumentando a taxa de concentração solar em 4,3 vezes. Além disso, é fixado à parte de trás dos módulos PV um tubo com água para retirar o calor produzido durante a conversão PV. Alguns tipos de tecnologias (Coventry, 2005) são capazes de aumentar a concentração solar em 37 vezes.
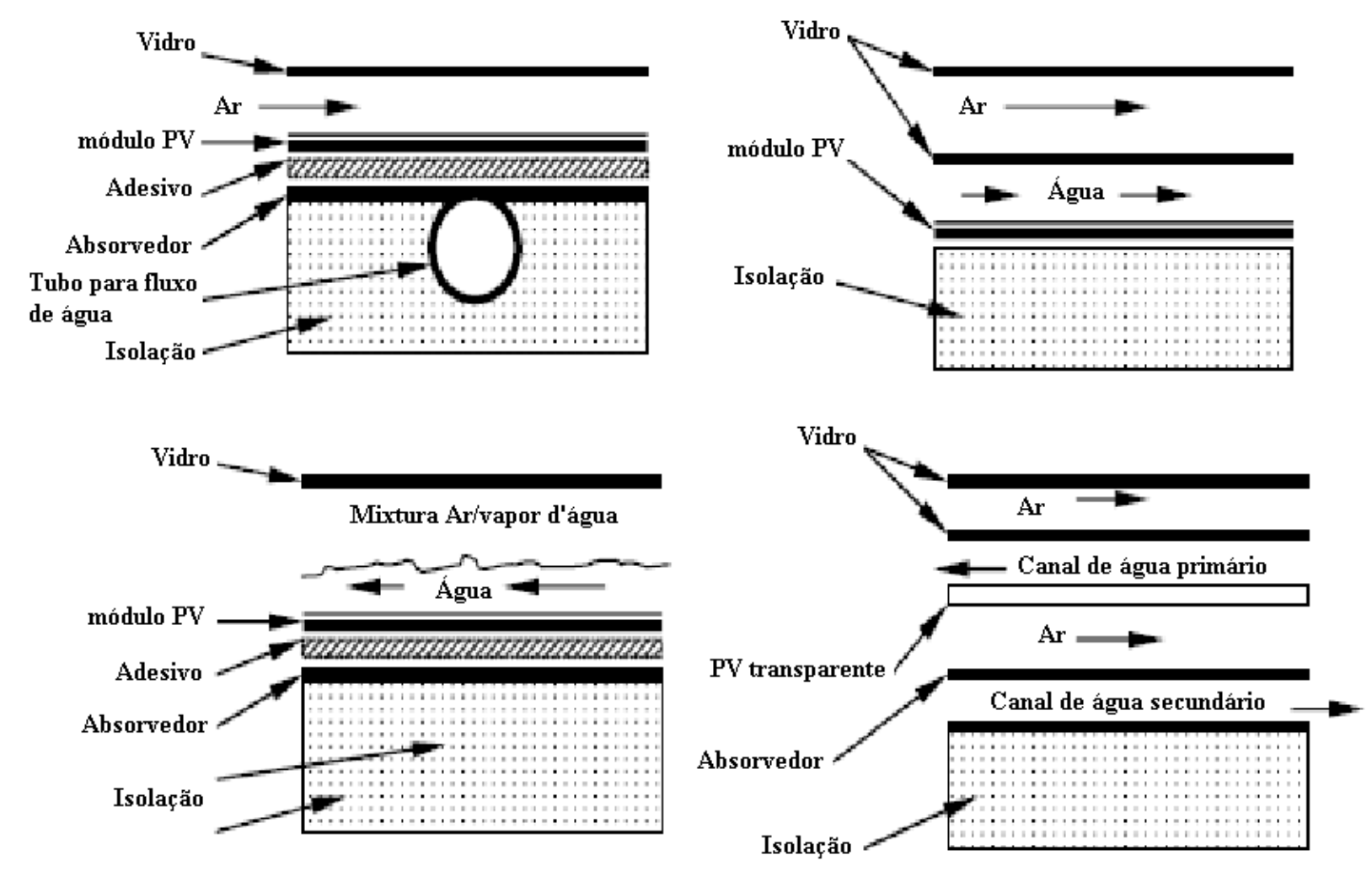

Figura 10 - Representação de um sistema coletor PVT de placa plana.

Fonte: adaptado de Charalambous, 2007.

Outro autor, HASAN et al. (2010), classifica os sistemas PVT em quatro categorias, apresentadas detalhadamente nos subitens a seguir.

- Coletor PVT-líquido;

- Coletor PVT-ar; 
- PV ventilado com recuperação de calor; e

- PVT concentrador.

Esta classificação assemelha-se a anterior, diferindo, principalmente, pela classificação dos sistemas PVT-ar e PVT-água em grupos diferentes.

Independentemente do tipo de tecnologia escolhida, o absorvedor de cada coletor PVT pode conter uma cobertura de vidro para reduzir as perdas térmicas, no caso de regiões frias. Quando esta cobertura está presente, o coletor é chamado de glazed ou com vidro e quando não, unglazed ou sem vidro, ver Figura 11. Coletores glazed têm perdas térmicas menores, especialmente com fluido em altas temperaturas, resultando num altíssimo rendimento térmico anual, já os coletores térmicos unglazed resultam em elevadas temperaturas de estagnação para as células PV sendo críticas para alguns tipos de encapsulamento, risco de amarelamento e deslaminação das células PV tornando o módulo PV mais suscetível a pontos quentes, além disso, pode ocasionar perda do antirreflexo e aumento da temperatura do módulo reduzindo o rendimento elétrico ( $\mathrm{CHOW}$ et. al., 2009).

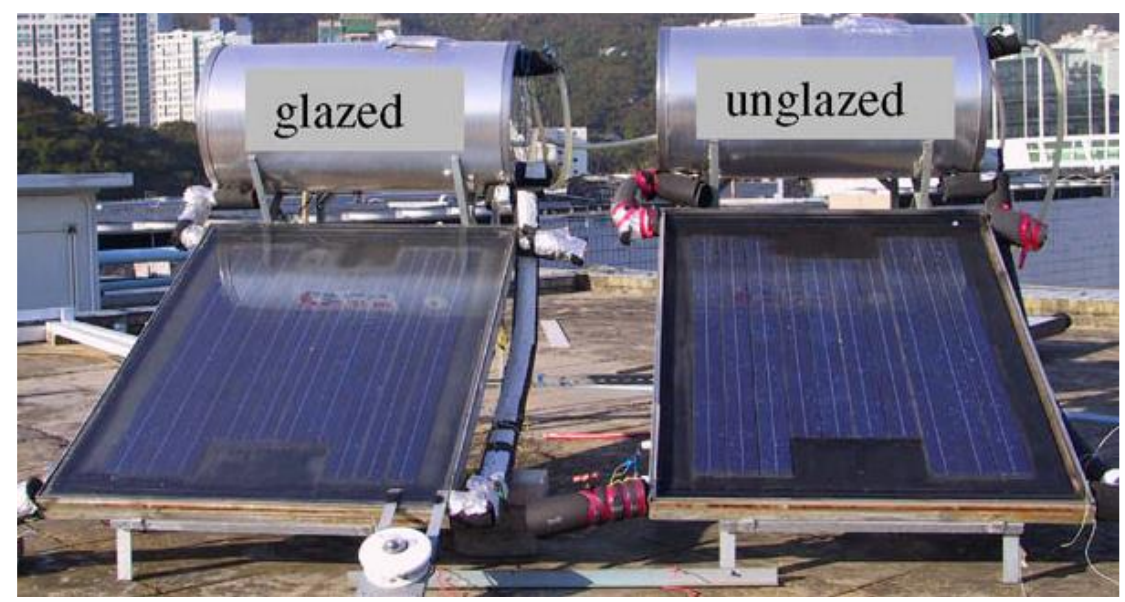

Figura 11 - Coletor PVT com e sem cobertura de vidro.

Fonte: CHOW et. al., 2009.

Assim, na escolha de um sistema PVT, deve se levar em conta se o mesmo terá ou não cobertura de vidro, procurando equilíbrio entre o aumento do rendimento térmico e elétrico, ver Tabela I. 
Tabela I - Recomendação para tipo de coletor baseado no tipo de demanda.

\begin{tabular}{|c|l|l|}
\hline Tipo & \multicolumn{1}{|c|}{ Demanda } & \multicolumn{1}{c|}{ Recomendação } \\
\hline \multirow{4}{*}{ Água } & $\begin{array}{l}\text { Alta } \\
\text { temperatura }\end{array}$ & $\begin{array}{l}\text { Utilizar um coletor com vidro. Além disso, um coletor sem } \\
\text { vidro pode ser usado quando se pretende integrar o } \\
\text { sistema PVT a uma bomba de calor. }\end{array}$ \\
\cline { 2 - 3 } & $\begin{array}{l}\text { Baixa } \\
\text { temperatura }\end{array}$ & $\begin{array}{l}\text { Para atender apenas a demanda no verão, utilize coletor } \\
\text { sem vidro, por outro lado, para atender tanto a demanda } \\
\text { do verão quanto do inverno utilizar coletor com vidro. }\end{array}$ \\
\hline \multirow{2}{*}{ Ar } & $\begin{array}{l}\text { Alta } \\
\text { temperatura }\end{array}$ & $\begin{array}{l}\text { Pode ser utilizado tanto um coletor a ar com vidro quanto } \\
\text { sem vidro. PV ventilado pode ser usado como fonte de } \\
\text { calor se o sistema PVT estiver integrado a uma bomba } \\
\text { de calor. }\end{array}$ \\
\cline { 2 - 3 } & $\begin{array}{l}\text { Para atender apenas a demanda de verão ou para locais } \\
\text { que recebem alta irradiação no inverno, utilizar coletor a } \\
\text { temperatura sem vidro ou PV ventilado. Por outro lado, para } \\
\text { atender tanto as demandas de inverno quanto as de } \\
\text { verão, utilizar coletor de ar com vidro. Coletor sem vidro } \\
\text { pode ser uma opção se o sistema PVT puder ser } \\
\text { integrado a uma bomba de calor. }\end{array}$ \\
\hline
\end{tabular}

Fonte: adaptado de HASAN et al., 2010.

\subsection{COLETOR PVT-LÍQUIDO}

Os coletores PVT-líquidos consistem em um absorvedor de calor que pode ser uma serpentina ou uma série de tubos paralelos acoplados à superfície inferior do laminado de PV ou colado com um material adesivo epóxi por onde circula um fluido que promove o resfriamento do módulo, além disso, o absorvedor pode conter um isolante térmico para reduzir as perdas térmicas da água para o meio, ver Figura 12(a), ou no caso que se almeje a maior retirada de calor do módulo PV, o absorvedor não recebe o isolante térmico, garantindo maior troca de calor com o meio, ver Figura 12(b). Esse tipo de resfriamento é realizado por convecção forçada, na qual o fluido retira calor do módulo aumentando a eficiência elétrica na ordem de $4-5 \%$. 


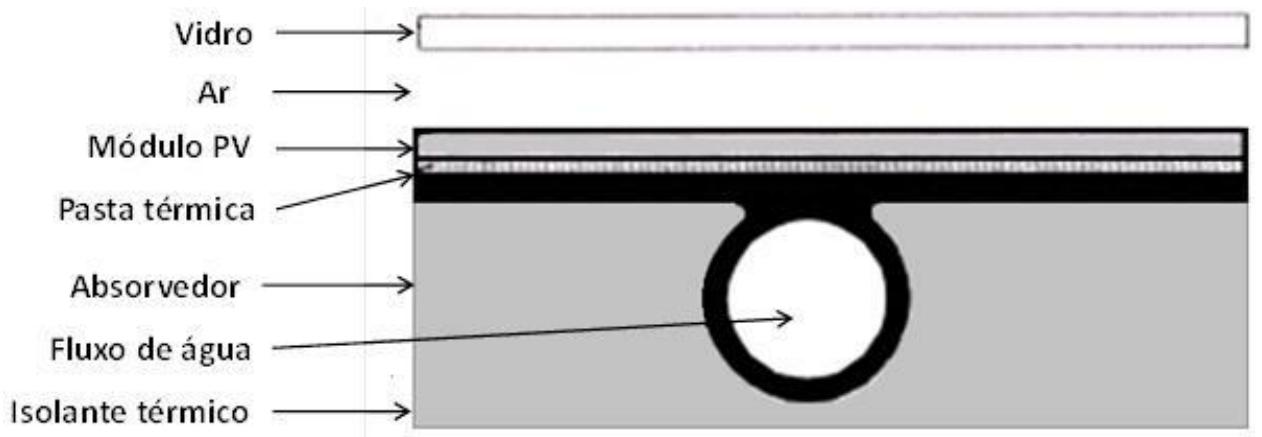

(a)

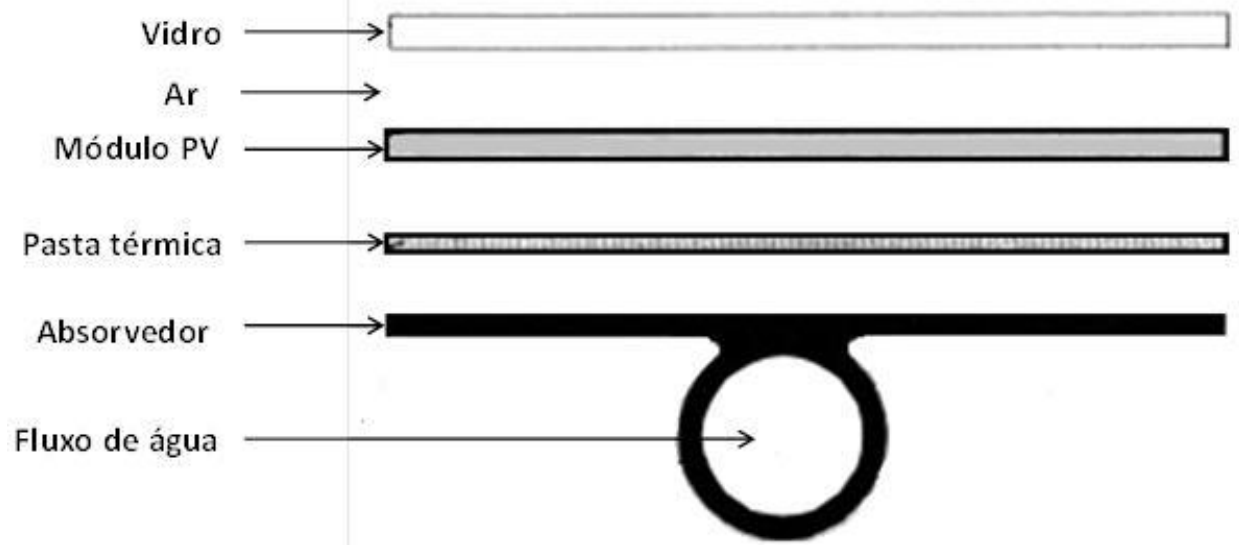

(b)

Figura 12 - Desenho representativo da estrutura do sistema PVT-água. (a) sistema com isolante térmico e (b) sistema sem isolante térmico.

As maiores temperaturas em um módulo PV são encontradas em sua superfície inferior devido a maior condutividade térmica do silício, material da célula PV, em relação ao material polímero da superfície inferior, geralmente é o tedlar (Teo et al., 2012).

Portanto, é preferível arrefecer o módulo PV a partir da superfície inferior, em vez de utilizar água, por exemplo, para arrefecer a superfície superior, esse fenômeno pode ser visto na Figura 13, que apresenta a temperatura de operação das superfícies, superior e inferior, de um mesmo módulo PV, com diferença de $8,1^{\circ} \mathrm{C}$. 


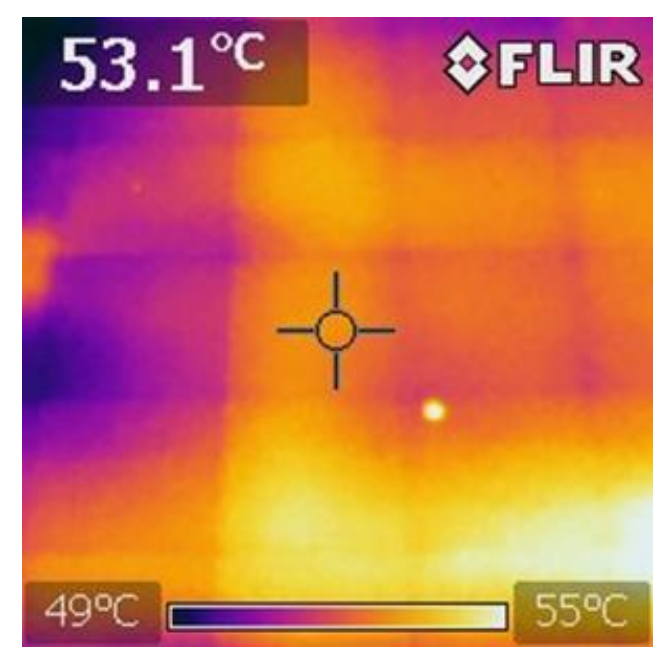

Superfície superior

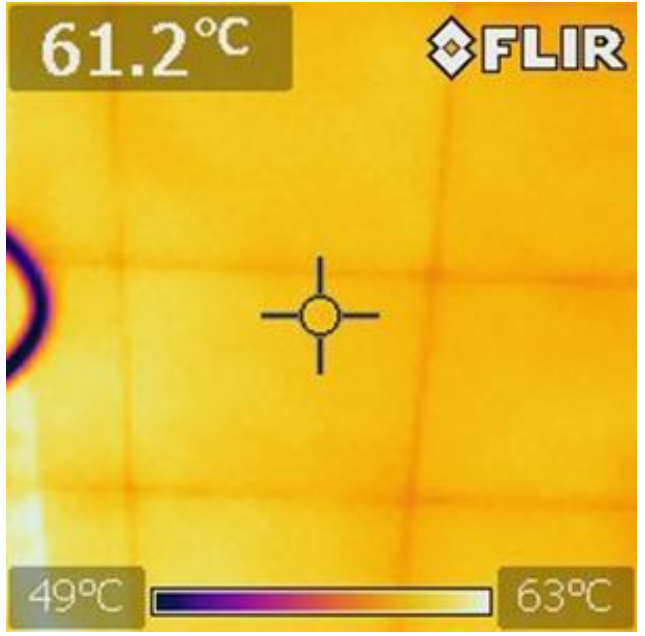

Superfície inferior

Figura 13 - Imagem fotográfica infravermelha das superfícies superior e inferior do módulo PV instalado na UFV-ILS.

A forma como é efetuada a circulação do fluido térmico no absorvedor de um sistema PVT-líquido pode ser classificada como:

Passivo: onde o fluido escoa através do sistema de arrefecimento sem a necessidade de se utilizar uma bomba, neste caso, é muito comum a utilização do desnível geométrico do sistema PVT em relação ao reservatório ou a utilização de termosifão que utiliza a convecção do fluido para circulação de fluido no reservatório; e

- Ativo: onde a circulação é feita por meio de bombeamento, ou seja, há a necessidade de se utilizar uma bomba para alimentar o sistema de arrefecimento. Neste caso, a utilização de energia é intrínseca, sendo necessário projetar corretamente o sistema para que o bombeamento não utilize energia a ponto de comprometer o ganho de eficiência elétrica com a sua utilização.

Existem diversos tipos de configurações para este tipo de coletor, sendo necessário utilizar, para todos os casos, uma bomba de circulação de água para o sistema. Os quatro principais modelos encontrados na literatura são: coletor chapa e tubo, coletor de canal, coletor de corrente livre e coletor com dois absorvedores.

Segundo Zodag et al. (2003), é preferível que o fornecimento de água se dê por baixo do módulo PV, de modo a melhorar a eficiência do ponto de vista do coletor. No entanto, do ponto de visto da simplicidade estrutural e do bom desempenho do 
sistema como um todo, é preferível um coletor do tipo chapa-tubo, pois apresenta facilidades referentes à fabricação e instalação junto ao módulo PV.

Para que haja maior transferência de calor é preciso que a distância média entre a geração de calor e de coleta seja mínima. Outra sugestão, que se refere à área na qual o líquido flui sob a célula PV, é de que esta seja a maior possível e de preferência abranja toda a sua superfície. Para esta aplicação, existe a sugestão apresentada por van Helden et al. (2004), cujos múltiplos canais, cada um sob um conjunto de células PV em série, retira o calor gerado por meio do fluxo de água circulante dentro deles, ver Figura 14. Esta técnica permite que todas as células sejam atendidas igualmente.

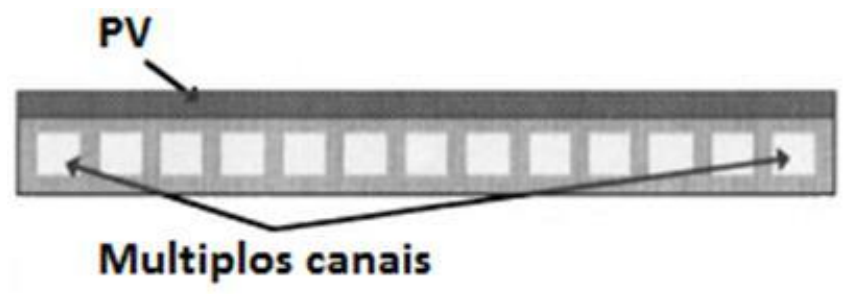

Figura 14 - Configuração de um sistema PVT com líquido escoando e beneficiando todas as células PV.

A forma mais simples de se fabricar um coletor PVT é por meio da fixação do laminado PV comercial ao absorvedor de um coletor térmico, também comercial. Esta configuração tem uma grande desvantagem que se deve ao módulo PV não ficar suficientemente protegido do ambiente, principalmente da umidade, trazendo problemas para aplicação comercial.

Além disso, outros problemas relacionados ao isolamento elétrico podem ocorrer, como por exemplo, o aumento da resistência térmica entre o laminado PV e o absorvedor, que pode ser demasiado devido ao aparecimento de camadas de ar, resultado de irregularidades na laminação ou devido ao material de polimérico, usualmente empregado na parte inferior de módulos $\mathrm{p}$-Si, apresentar baixa condutividade térmica quando comparado aos outros materiais vinculados ao sistema (Zondag et al., 2005).

Uma técnica mais avançada para produção desta tecnologia baseia-se na produção do módulo PVT compreendendo um laminado de células fotovoltaicas, seguido por um isolamento elétrico e por último um absorvedor. Este método é 
utilizado para obter uma resistência elétrica alta entre as células solares e o absorvedor, evitando o aumento da temperatura e de perdas elétricas. Essa técnica possui alguns problemas, como a deformação do laminado PVT devido à diferença de dilatação térmica entre o vidro da superfície e do laminado de metal do coletor. Para evitar este problema, um laminado de polímero aplicado à superfície inferior em vez do vidro reduz essa deformação, mas ao mesmo tempo a ausência do vidro requer um absorvedor suficientemente rígido para proporcionar apoio às células (Zondag et al., 2005).

Módulos PVT produzidos em tiras com película superior de plástico com suporte fornecido por um tubo de cobre, o absorvedor, ao longo do centro da tira. Outro modelo utilizado, também de tiras de PVT, construído sobre chapas galvanizadas, no qual o suporte é fixado nas bordas, que são dobradas, resultando em um perfil que posteriormente recebe os tubos de cobre que são fixados por meio do processo de soldagem.

Absorvedores do tipo chapa-tubo possuem algumas restrições construtivas, devido aos tubos estarem fixados no nível inferior do absorvedor que acabam por dificultar o processo de laminação do PV, aumentando o tempo de produção. Resolver esse problema construtivo é demasiadamente complexo, pois soldar os tubos após a laminação das células PV prejudica o encapsulamento devido à alta temperatura da solda, ao mesmo tempo colá-lo pode comprometer a confiabilidade da transferência de calor. Uma possível opção para esta fixação é a utilização de uma placa de alumínio fixada por meio de cladeamento (Chow et al., 2006), processo que consiste na união de dois metais de ligas distintas em estado sólido por meio da deformação plástica de ambas superfícies.

Independentemente da técnica e configuração escolhida para a produção do sistema PVT, é importante salientar que o encapsulante das células precisa suportar altas temperaturas na ordem de $130^{\circ} \mathrm{C}$. Além disso, as propriedades óticas das células PV devem ser suficientemente boas e nem todas as células PV disponíveis comercialmente são adequadas para esta aplicação devido às perdas por reflexão do infravermelho. Há a opção de encapsulamento à baixa temperatura em detrimento a laminação, que consiste na utilização de silicone com alta resistência à 
temperatura. Para o isolamento elétrico deve-se aplicar primeiramente uma camada de silicone sobre o absorvedor, pressionando com uma camada de tecido, seguido por uma segunda camada de silicone para a fixação das células. Mas como toda solução possui algum tipo de desvantagem, a aplicação de silicone em termos de manuseio possui o risco de aprisionamento de ar entre as camadas fixadas.

\subsection{COLETOR PVT-AR}

Os coletores PVT-ar são semelhantes a um coletor de ar quente convencional com um laminado de PV funcionando na cobertura superior do canal de ar. Coletores PVT-ar são mais baratos que os PVT-líquidos devido à flexibilidade e facilidade de conversão, com poucas modificações, dos módulos PV convencionais e podem ser construídos com ou sem vidro. Em geral são aplicados quando o usuário final possui uma demanda por ar quente, principalmente para usar o ar diretamente para aquecimento. Por outro lado esta aplicação depende diretamente do mercado de sistemas de aquecimento de ar, que é baixa na maioria dos países, por exemplo, o Brasil, sendo indicado para pré-aquecimento do ar de ventilação de edifícios onde as temperaturas requeridas variam de $15-25^{\circ} \mathrm{C}$.

Como a transferência de calor no sistema PVT-ar é mais critica do que no sistema PVT-líquido, é importante que o modelo de transferência de calor adotado seja adequado, pois os efeitos na entrada, relacionados à transferência de calor em coletores a ar, mostram que em média o número de ${ }^{1}$ Nusselt $(\mathrm{Nu})$ varia $10 \%$ ao longo do comprimento de entrada para um canal suficientemente largo e o diâmetro hidráulico deve ser duas vezes a altura do canal. O impacto do fluxo de ar induzido pela flutuação e transferência de calor por meio do canal vertical, aquecido a partir de uma das superfícies do módulo PV, aumenta a velocidade do fluxo de calor não uniforme dentro do duto. Esse efeito está ligado diretamente ao formato de saída do duto.

Em síntese, para melhorar a transferência de calor do sistema a ar é necessário controlar o seu fluxo forçado e flutuação da vazão. Outra opção, muito usada em

\footnotetext{
${ }^{1}$ Grandeza adimensional utilizada para a determinação do coeficiente de transferência de calor por convecção.
} 
pesquisas experimentais, é o aumento da turbulência no canal de escoamento e da área da superfície de transferência de calor (HASAN et al., 2010).

Em relação aos aspectos construtivos de fixação, do sistema de arrefecimento no módulo PV, e seus materiais empregados, o sistema PVT-ar se assemelha ao sistema PVT-água. A aplicação do ar como meio de transporte de calor em relação a outros fluidos de trabalho, como a água, possui algumas vantagens como o não congelamento do fluido no coletor, fator importante para regiões de clima frio, não há riscos em caso de vazamento, o custo do insumo refrigerante é zero e a sua disponibilidade é imediata e perene, é indicado para regiões no qual o acesso à água é restrito ou economicamente inviável. Por outro lado possui baixa capacidade e condutividade térmica, resultando numa baixa transferência de calor, ou seja, não recomendado quando se deseja o arrefecimento do módulo PV. Grandes perdas de calor ocorrem devido ao vazamento de ar e, no caso de sistema passivo, sem auxílio de um sistema de injeção de ar, o sistema PVT-ar pode operar com baixo rendimento devido à baixa densidade e condutividade térmica do ar circulante.

A aplicação do ar como meio de transporte de calor em relação a outros fluidos de trabalho, como a água, possui algumas vantagens e desvantagens.

Vantagens:

- Não há problema relacionado ao congelamento do fluido no coletor, fator importante para regiões de clima frio;

· Não há riscos em caso de vazamento;

- O custo do insumo refrigerante é zero e a sua disponibilidade é imediata e perene; e

- Indicado para regiões onde o acesso à água é restrito ou economicamente inviável.

Desvantagens:

- Baixa capacidade e condutividade térmica, resultando numa baixa transferência de calor, ou seja, não recomendado quando se deseja o arrefecimento do módulo PV; 
- Grandes perdas de calor devido ao vazamento de ar;

Baixa densidade do ar, necessitando de grande quantidade de fluxo de ar para compensar a baixa transferência térmica do fluido; e

No caso de sistema passivo, sem auxílio de um sistema de injeção de ar, o sistema PVT-ar pode operar com baixo rendimento.

\subsection{PV VENTILADO COM RECUPERAÇÃO DE CALOR}

A diferença entre PV ventilado com recuperação de calor e coletores PVT devese ao fato de o sistema PVT, geralmente, ser projetado para um prédio específico não possuindo um sistema padronizado de fabricação. A forte ligação existente entre os dois tipos muitas vezes faz com que projetistas, sem experiência em relação a este tipo de tecnologia, forneçam a opção menos adequada ao projeto. Esta situação pode mudar uma vez que vários institutos e fabricantes, principalmente dos países europeus, onde essas pesquisas e tecnologias são mais desenvolvidas, estão fazendo um esforço para padronizar esses sistemas.

Módulos PV convencionais para fachadas e telhados, onde a incidência de ar é muito frequente na superfície inferior dos módulos PV, devido à inclinação de instalação, permite que o ar os arrefeça por convecção natural (PV ventilado). Esse calor pode ser recuperado e, neste caso, é considerado que o PV funciona como um coletor PVT.

Devido às facilidades de construção e operação, os sistemas PVT com extração de calor por meio do ar são muito estudados como alternativa e solução para sistemas Build Integrated PV (BIPV, sigla em inglês para construção integrada a fotovoltaicos). Este sistema pode operar durante o inverno produzindo calor para aquecimento interno e durante o verão como sistema de refrigeração ativo (Eicker et al., 2000).

Um estudo abrangente de Bazilian et al. (2001), demonstrou que esse tipo de sistema é mais adequado a aplicações de baixa temperatura, além disso, foi observado que a integração de sistemas $\mathrm{PV}$ às construções poderia atingir um projeto coeso tornando-se uma solução para fornecimento de energia em edifícios, concluindo que há grande necessidade de pesquisas na área para que os sistemas 
PVT se tornem uma realidade comercial. Outro estudo (Charalambous et al., 2007), demonstrou que coletores BIPV são mais adequados para condições com climas frio, ou seja, com baixa temperatura ambiente.

Esse sistema, se utilizado em fachadas, pode proporcionar além de eletricidade ganhos como proteção do edifício à radiação solar, reduzindo a carga térmica de arrefecimento, por meio do fornecimento e complemento de calor para aquecimento interno dos edifícios. Caso não haja demanda direta para o calor gerado pelo sistema, este pode ser utilizado para induzir diferença de pressão e ajudar no sistema de ventilação. Devido à qualidade estética dos módulos PV, estes podem contribuir para a redução do custo de acabamento do edifício (HASAN et al., 2010). Além disso, o tempo de retorno da energia para um sistema $\mathrm{p}$-Si convencional adaptado ao telhado com insolação anual global de $1,530 \mathrm{kWh} / \mathrm{m}^{2}$, no caso para cidade de Roma, é reduzido de 3,3 para 2,8 anos. Apesar dos diversos melhoramentos, a aplicação comercial dos $\mathrm{PV}$ ventilados a ar com recuperação de calor ainda é marginal, espera-se que no futuro, sua utilização seja mais ampla devido ao aumento de escala, quando muitos telhados e fachadas estiverem cobertos com células PV.

\subsection{PVT CONCENTRADOR}

O sistema PVT concentrador é a combinação de módulos PV convencionais com sistema de arrefecimento e dispositivos de concentração solar, que são dispositivos ópticos de reflexão e refração caracterizados pela sua capacidade de concentração CR (Hasan et al., 2010):

- $\mathrm{CR}>2,5$ deve utilizar um seguidor solar; e

- $\mathrm{CR}<2,5$ pode ser estacionário.

Essa combinação é conhecida como CR PVT, e até o presente momento é o método mais viável para reduzir o custo do sistema $\mathrm{PV}$, pois ele substitui parte das células PV caras por um sistema de concentração da radiação solar, mais barato (Hasan et al., 2010) ao fazer isso automaticamente se reduz grande parte da área com dispositivos PV substituídos por lentes tipo Fresnel, reduzindo o tempo de 
retorno do investimento. Este argumento se traduz devido à força motriz ligada aos concentradores PV possuírem maiores eficiências do que os sistemas típicos PV.

Embora a combinação dos dois sistemas permita áreas menores contendo material PV, mais caros, a utilização de lentes e refletores aumenta a temperatura de estagnação aumentando a velocidade de degradação do material PV, pois este só consegue manter a sua eficiência e o tempo de vida útil caso a sua temperatura de funcionamento seja mantida igual ou menor que a temperatura NOCT. Este problema pode ser resolvido, até certo ponto, com a utilização de refletores difusos.

Além disso, a distribuição da radiação solar sobre a superfície do módulo PV e sua temperatura são dois fatores que afetam a produção de energia elétrica. A distribuição uniforme e concentrada da radiação solar juntamente com um arrefecimento adequado pode contribuir para uma operação mais eficiente do sistema e aumentar a sua potência elétrica de saída. Assim, sistemas PVT absorvedores podem ser combinados com dispositivos concentradores. Atualmente os pequenos CR PVT são os mais estudados e por sua vez são mais desenvolvidos.

Diversos sistemas refletores de baixa concentração foram estudados mostrando que refletores difusos aumentam tanto a produção térmica quanto elétrica quando integrados a sistema PVT. Sistema com refletor apresenta eficiência total ligeiramente maior em comparação ao sistema sem concentrador, mas que devido ao aumento da radiação solar, o módulo PV sofre um aumento acentuado da temperatura prejudicando o desempenho do sistema em relação à produção de energia elétrica das células PV. Desta forma é importante que esse sistema seja acompanhado por sistema de arrefecimento bem dimensionado, pois este pode não ser suficiente como é o caso do sistema estudado por Othman et al. (2005), que observou durante o seu experimento, que consistia em um sistema PVT com dupla passagem de ar e aletas para arrefecimento, que a produção de eletricidade diminuía, pois o fluxo de ar para arrefecimento sofria aumento da temperatura expressivo. Até mesmo sistemas que utilizam água para arrefecimento sofrem com os efeitos da temperatura provocados pela concentração solar (Hasan et al., 2010).

Mesmo que a eficiência dos sistemas PVT concentrador seja alta, essa tecnologia, até o momento, tem se mostrado insignificante no mercado, pois 
sistemas de médio e grande porte ocupam grande área, os desqualificando para muitas aplicações PV, a tecnologia requer acompanhamento do sol, tornando a sua integração com o edifício muito complicada, além disso, nem todos os climas são

adequados para recebê-la, pois seu funcionamento está diretamente ligado à quantidade de radiação direta recebida e, sob o ponto de vista estético, este sistema produz diferentes tipos de reflexões e efeitos ópticos, prejudicando o ambiente ao redor e dificultando a sua instalação nas fachadas, ficando restrita apenas a instalação em telhados horizontais e usinas isoladas.

\subsection{SISTEMA DE ARREFECIMENTO DE MÓDULOS PV NÃO PVT}

Uma forma eficaz de melhorar a eficiência e reduzir a taxa de degradação térmica de um módulo fotovoltaico é pela redução da temperatura de operação da sua superfície. Isto pode ser conseguido por meio do arrefecimento do módulo PV e reduzindo o calor armazenado no interior das células durante a operação (Meral et al., 2011).

Os sistemas de arrefecimento de módulos PV não classificados como PVT consistem da injeção de água sobre a sua superfície superior do módulo PV. Esta água, ao escorrer pela superfície retira o calor armazenado no módulo por meio da transferência de calor por condução, convecção e radiação. Esse tipo de sistema é simples e conta com um módulo PV, uma bomba e um tanque de armazenamento de água. A injeção da água é feita sobre a superfície superior do módulo PV por diversos orifícios presentes num tubo, de modo a garantir que as trocas de calor sejam homogêneas em toda a superfície, ver Figura 15.

Resultados obtidos pela Endecon Engineering (2001) indicaram que devido à perda de calor por convecção entre a água de refrigeração e a superfície superior do módulo PV, ocasionou um aumento de $15 \%$ na produção elétrica do sistema em condições de pico de radiação solar. Além disso, os resultados indicaram que um aumento em $5 \%$ da energia entregue pode ser obtido durante as estações secas e quentes.

Outro experimento realizado por Odeh et al., (2009), com o intuito de melhorar o rendimento de um sistema de bombeamento de água alimentado pela energia 
elétrica, produzida por módulos PV, foi montar um arranjo que consistia em tubos para permitir o fluxo de água agindo por gravidade sobre a superfície do módulo PV. Os testes foram realizados em diferentes cidades da Austrália, Sydney, Perth e Darwin, as quais possuem latitudes diferentes, e assim verificar o sistema em condições climáticas distintas. Os resultados mostraram que o aumento da potência de saída dos sistemas variava entre 4-10\%, quando o sistema de arrefecimento operava, no qual parte desse aumento, $50 \%$, deve-se diretamente pela refrigeração do módulo resultante do contato da água com a sua superfície, e a outra parte devese ao aumento da radiação solar incidente no módulo PV devido à refração do feixe de luz solar na camada de água.

Além dos ganhos já citados, este sistema possui outras vantagens como:

- Devido ao fluxo contínuo, a água mantém a superfície superior do módulo PV livre de poeira e sujeira que bloqueiam parte da luz incidente reduzindo sua capacidade de produção de energia em até 7\%;

- Eliminação da bomba de circulação caso haja desvio geométrico entre reservatório e módulos $\mathrm{PV}$;

- Baixa perda de carga devido ao escoamento ser realizado por gravidade; e

- Como esta técnica de arrefecimento é simples, pode ser adicionada a qualquer módulo padrão sem aumento significativo do custo.

- Por outro lado, pode haver grandes perdas de água por evaporação e após a injeção de água sobre a superfície do módulo PV, pois o sistema opera em aberto. 


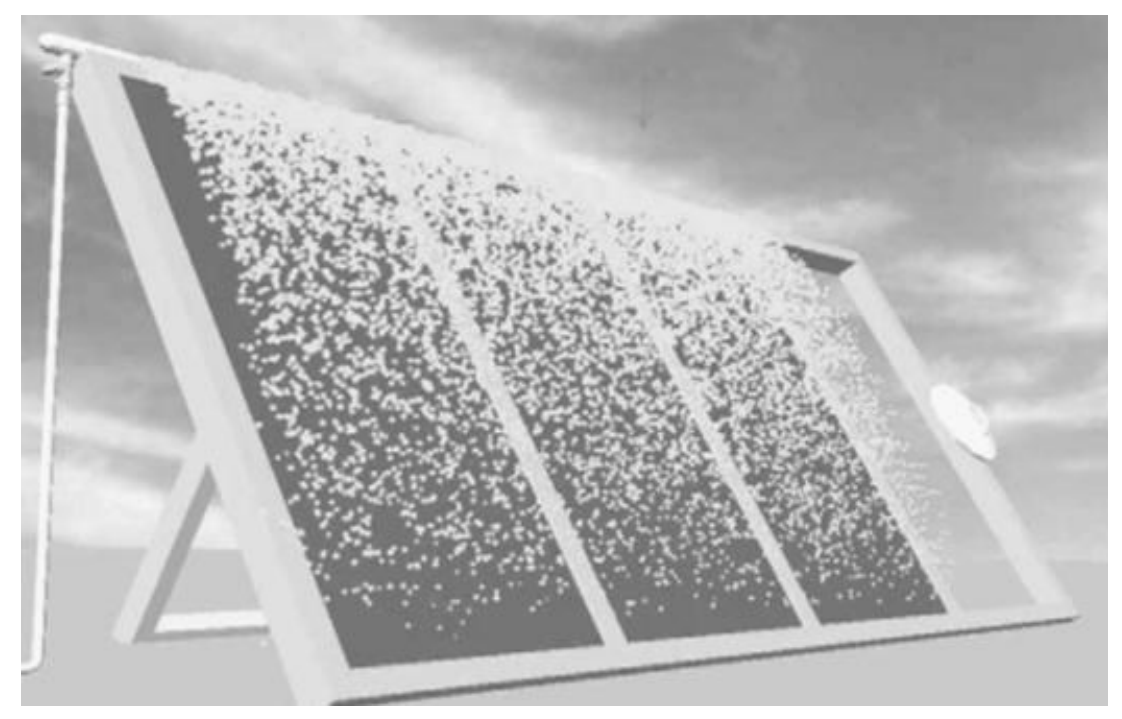

Figura 15 - Representação de um módulo PV com um sistema de arrefecimento da superfície. Fonte: Abdolzadeh et al., 2009. 


\section{ANÁLISE E SELEÇÃO DO MODELO FINAL DE UMAR}

\subsection{CARACTERÍSTICAS CLIMÁTICAS DA REGIÃO DA CIDADE DE ILHA SOLTEIRA}

A cidade de llha Solteira, local de instalação da Usina Hidrelétrica de llha Solteira (UHE-ILS), $20^{\circ} 22^{\prime} 48.34^{\prime \prime} S 51^{\circ} 22^{\prime} 10.71$ 'O, com 3.444 MW de potência instalada e reservatório de $1.195 \mathrm{~km}^{2}$ de extensão (CESP, 2014), sendo de extrema importância para o controle de tensão e oscilação do Sistema Interligado Nacional (SIN), é o local escolhido para a instalação da Usina Solar Fotovoltaica (UFV), e apresenta média anual de irradiação solar $5,5 \mathrm{kWh} / \mathrm{m}^{2}$.dia, ver Figura 16 , média mensal máxima de $6,6 \mathrm{kWh} / \mathrm{m}^{2}$.dia no verão e média mensal mínima de $4,6 \mathrm{kWh} / \mathrm{m}^{2}$.dia no outono (SEE, 2013).

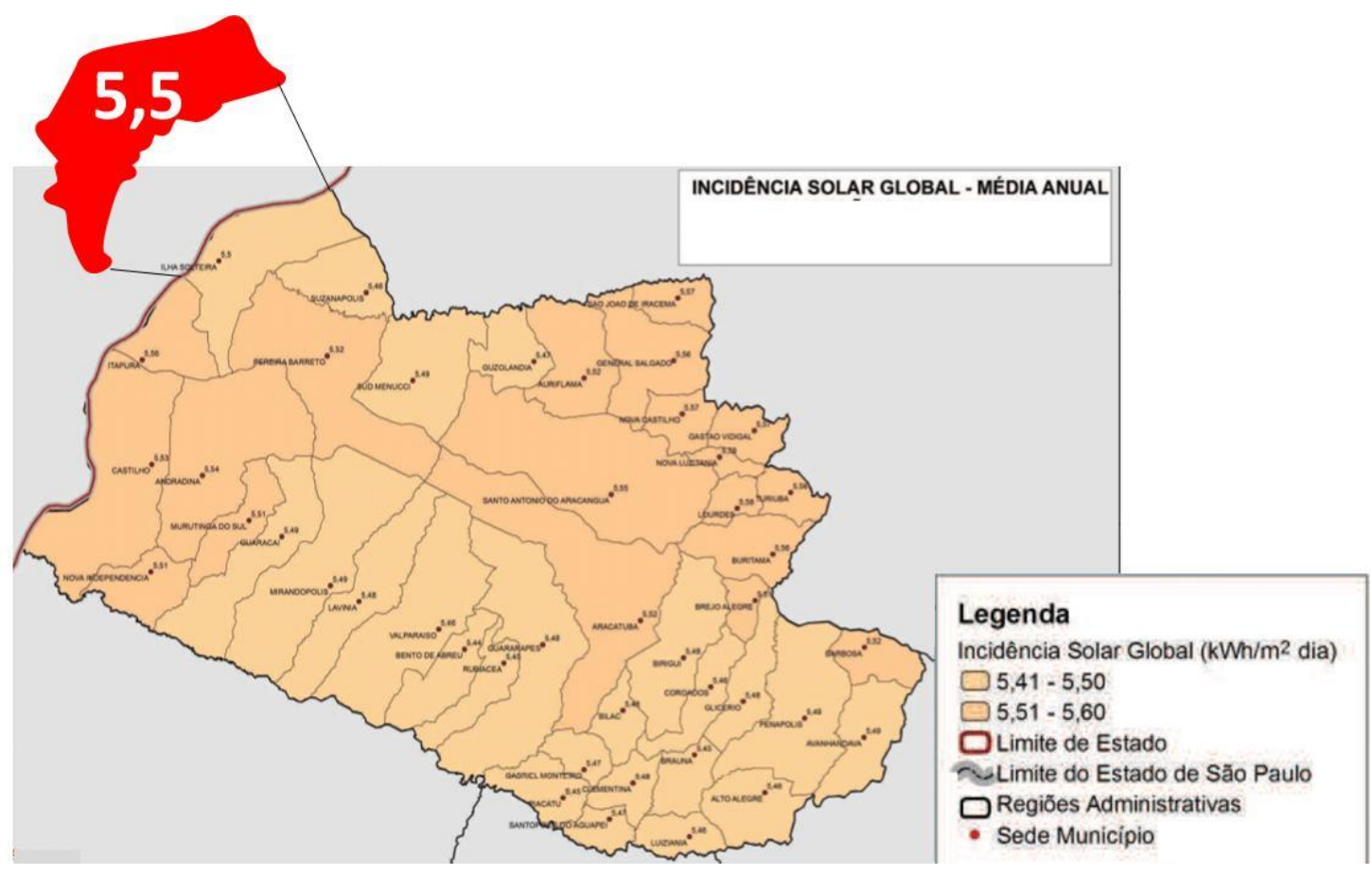

Figura 16 - Incidência solar global $\left(\mathrm{kWh} / \mathrm{m}^{2}\right)$ na região da cidade de Ilha Solteira.

Fonte: adaptado de SEE, 2013.

Segundo a classificação Koppen, a cidade de Ilha Solteira apresenta clima quente e seco (CEPAGRI, 2015b), com temperatura média anual de $24,8^{\circ} \mathrm{C}$ com máxima e mínima média no ano de $33,0^{\circ} \mathrm{C}$ e $13,1^{\circ} \mathrm{C}$, respectivamente. Índice pluviométrico anual de $1.309,4 \mathrm{~mm}$. No período seco que compreende os meses de abril a setembro, o índice pluviométrico é de $288,3 \mathrm{~mm}$ com média de $48,1 \mathrm{~mm}$ ao 
mês e menor índice, $22,80 \mathrm{~mm}$, no mês de agosto. As temperaturas neste período apresentam média de $22,8^{\circ} \mathrm{C}$ e média máxima de $30,0^{\circ} \mathrm{C}$.

Durante o período chuvoso que compreende os meses de outubro a março, o índice pluviométrico é de $1.021 \mathrm{~mm}$, abrangendo $77 \%$ das chuvas do ano, com média de $170,2 \mathrm{~mm}$ ao mês e maior índice, $225,9 \mathrm{~mm}$, no mês de janeiro. Temperaturas neste período apresentam média de $26,9^{\circ} \mathrm{C}$ e média máxima de $32,5^{\circ} \mathrm{C}$, ver Tabela II.

Tabela II - Índices de temperatura e pluviométricos para a cidade de llha Solteira/SP.

\begin{tabular}{|c|c|c|c|c|}
\hline \multirow[b]{2}{*}{ Mês } & \multicolumn{3}{|c|}{ Temperatura do $\operatorname{Ar}\left({ }^{\circ} \mathrm{C}\right)$} & \multirow{2}{*}{$\begin{array}{c}\text { Índice } \\
\text { Pluviométrico } \\
\text { (mm) }\end{array}$} \\
\hline & $\begin{array}{l}\text { Mínima } \\
\text { média }\end{array}$ & $\begin{array}{l}\text { Máxima } \\
\text { média }\end{array}$ & Média & \\
\hline Jan & 20,4 & 32,0 & 27,0 & 225,9 \\
\hline Fev & 20,5 & 32,1 & 26,3 & 178,1 \\
\hline Mar & 22,0 & 32,0 & 27,0 & 135,0 \\
\hline$A b r$ & 17,4 & 31,1 & 24,3 & 81,2 \\
\hline Mai & 14,9 & 29,3 & 22,1 & 59,3 \\
\hline Jun & 13,7 & 28,4 & 21,0 & 29,5 \\
\hline Jul & 13,1 & 28,8 & 21,0 & 23,0 \\
\hline Ago & 14,8 & 31,6 & 23,2 & 22,8 \\
\hline Set & 19,0 & 31,0 & 25,0 & 72,5 \\
\hline Out & 21,0 & 33,0 & 27,0 & 125,0 \\
\hline Nov & 22,0 & 33,0 & 27,0 & 146,0 \\
\hline Dez & 22,0 & 33,0 & 27,0 & 211,1 \\
\hline Ano & 18,4 & 31,3 & 24,8 & 1309,4 \\
\hline Mín & 13,1 & 28,4 & 21,0 & 22,8 \\
\hline Máx & 22,0 & 33,0 & 27,0 & 225,9 \\
\hline Seco & 15,5 & 30,0 & 22,8 & 48,1 \\
\hline Chuvoso & 21,3 & 32.5 & 26,9 & 170,2 \\
\hline
\end{tabular}

Fonte: CEPAGRI, 2015b.

Segundo dados da UNESP (2013), a maior temperatura ambiente registrada na cidade foi de $42,0^{\circ} \mathrm{C}$, ocorrida em quatro dias distintos, e a maior média diária de temperatura foi $34,9^{\circ} \mathrm{C}$, com mínima de $29,3^{\circ} \mathrm{C}$ e máxima de $38,9^{\circ} \mathrm{C}$ neste dia.

Quando analisado o período de dez anos, 2004-2013, dos índices pluviométricos (mm) e insolação (h/dia) mensal da cidade, ver Figura 17, é possível verificar que os picos de mínimos períodos de insolação coincidem com os picos de máximos índices pluviométricos, ou seja, são inversamente proporcionais, e oscilam ao longo de um ano para o período selecionado. 
Os maiores índices pluviométricos ocorrem no início de cada ano e os maiores período contínuos de insolação no meio do ano. O maior índice registrado no período, 596,1mm ocorrido em janeiro/2008, apresentou insolação média mensal de $5,4 \mathrm{~h} /$ dia, já à máxima insolação, 11,6 h/dia, ocorrida em novembro de 2010, apresentou índice de 138,9mm.

A média mensal de insolação e do índice pluviométrico para o período selecionado é de 7,7 h/dia e 127,6mm, respectivamente.

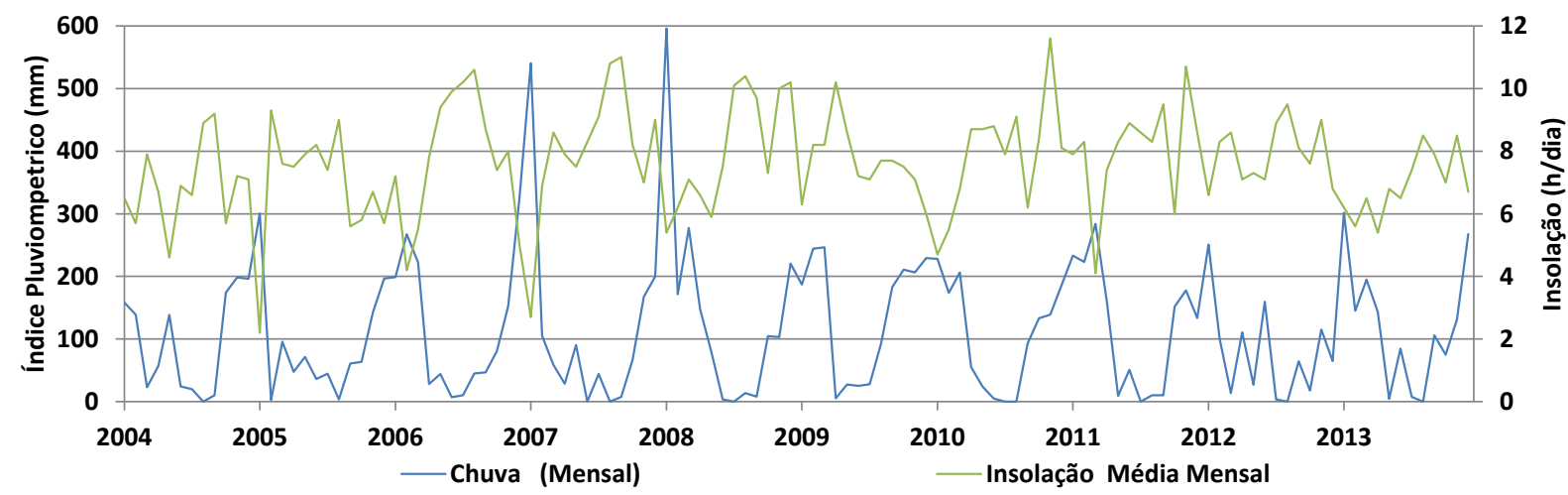

Figura 17 - Comportamento dos índices pluviométricos e insolação mensal para o período 20042013.

Fonte: Dados retirados de Unesp, 2013.

Diferentemente dos índices pluviométrico e de insolação mensais da cidade de Ilha Solteira, o comportamento da radiação global $\left(\mathrm{MJ} / \mathrm{m}^{2}\right.$.dia) é diretamente proporcional ao período de insolação, ver Figura 18. Os picos de máxima radiação global média coincidem com os picos de insolação oscilando ao longo do ano e do período selecionado.

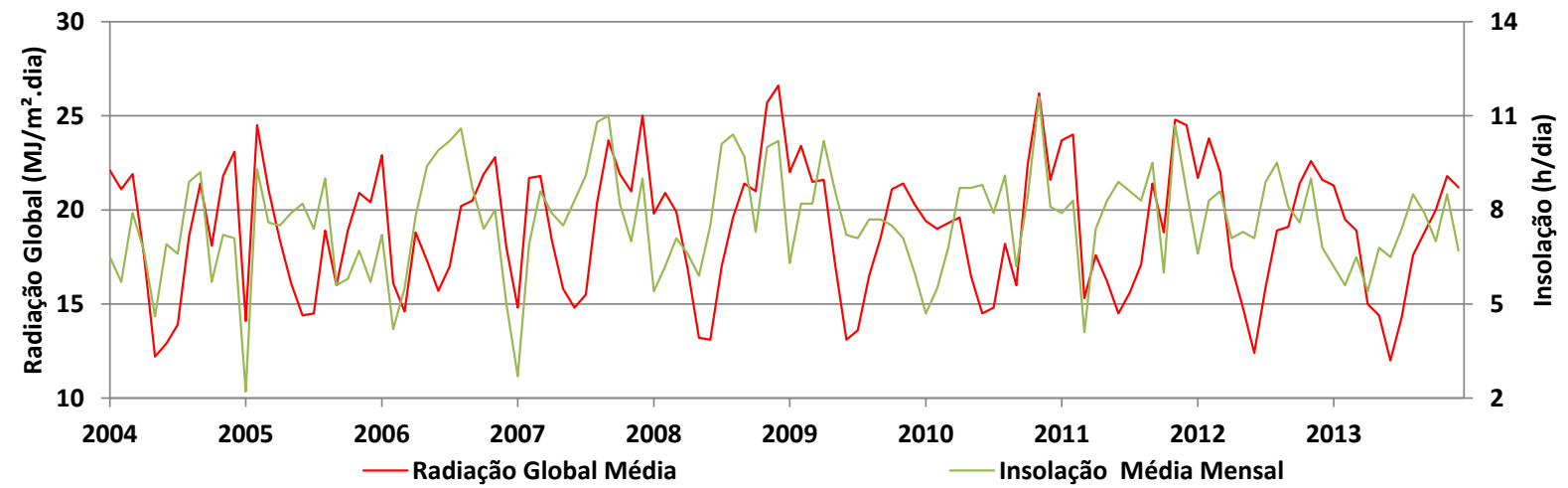

Figura 18 - Comportamento da radiação global média e insolação mensal para o período 20042013.

Fonte: Dados retirados de Unesp, 2013. 
A maior radiação global média, 26,6 $\mathrm{MJ} / \mathrm{m}^{2}$.dia ocorrido em dezembro/2008 coincide com a maior temperatura média desse ano de $26,7^{\circ} \mathrm{C}$, ver Figura 19 , e apresentou insolação média mensal de 10,2 h/dia. No período de máxima insolação, 11,6 h/dia ocorrida em novembro de 2010, a radiação global média foi de 26,2 $\mathrm{MJ} / \mathrm{m}^{2}$.dia, segunda maior média registrada para o período selecionado.

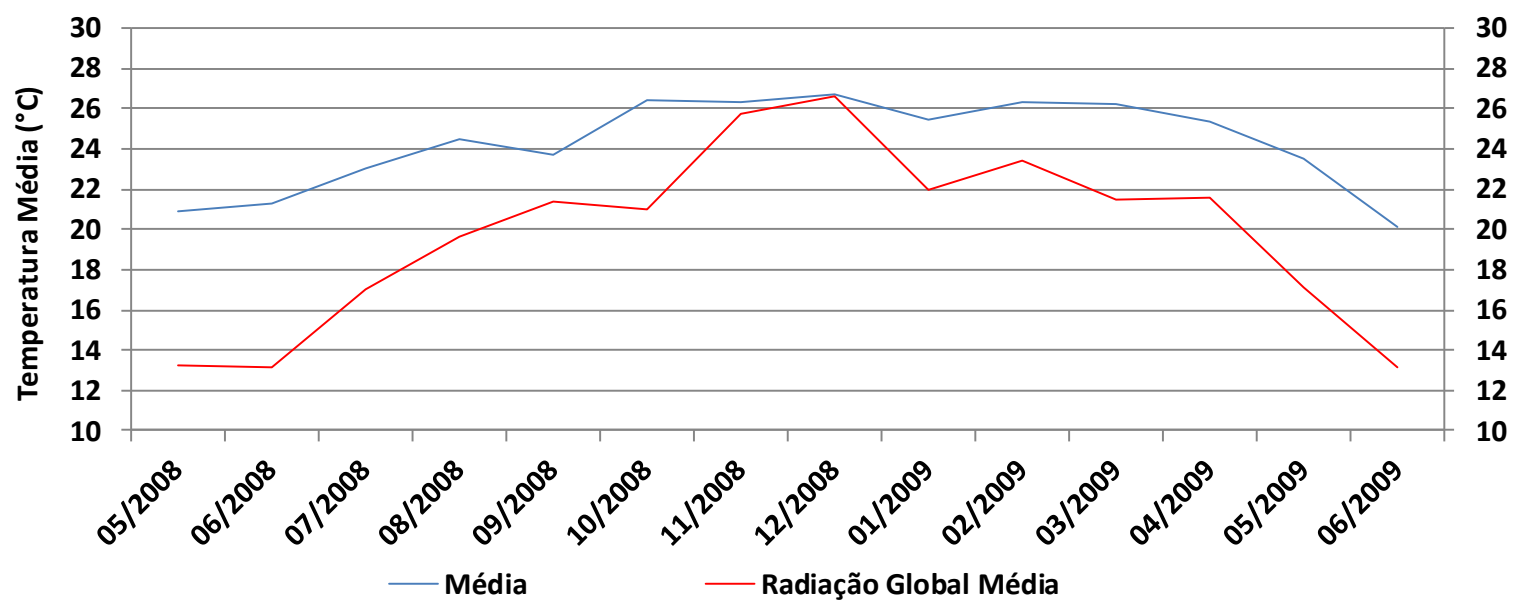

Figura 19 - Comportamento da radiação média global e temperatura média para o período maio/2008 a junho/2009.

Fonte: Dados retirados de Unesp, 2013.

A média da radiação global média para o período selecionado é de 19,1 $\mathrm{MJ} / \mathrm{m}^{2}$.dia, pela análise da Figura 20 é possível verificar que a curva de radiação global máxima apresenta oscilação menos intensa do que a apresentada pela radiação global mínima. Essa característica demonstra que os valores de mínimo oscilam mais que de máximo ao longo do ano, além disso, demonstram que a condição de alta radiação global é comum na região, já que a curva de radiação global média encontra-se mais próxima da máxima do que da mínima.

A média da radiação global mínima e máxima para o período selecionado 9,4 e $24,9 \mathrm{MJ} / \mathrm{m}^{2}$.dia, respectivamente, com pico de máximo de $35,4 \mathrm{MJ} / \mathrm{m}^{2}$.dia registrado no dia 04/12/2008 e insolação de 15,8 h/dia. 


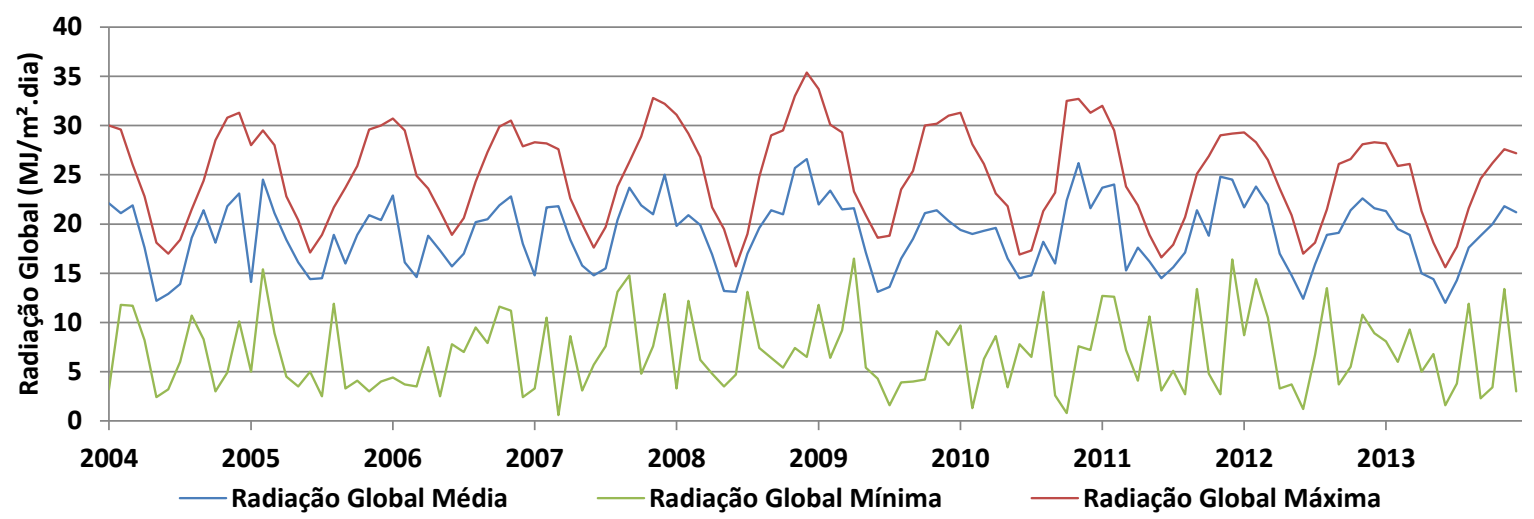

Figura 20 - Comportamento da radiação global média, mínima e máxima para o período 20042013.

Fonte: Dados retirados de Unesp, 2013.

\subsection{FORNECIMENTO DE ÁGUA}

A instalação da UFVa-ILS está localizada dentro da área da UHE de llha Solteira, isto facilita a captação de água para o sistema de arrefecimentos dos módulos PV viabilizando o protótipo de UFV arrefecida.

A utilização dessa água é possível caso seja aproveitada no final dos processos, quando a água após o uso é descartada à jusante da UHE retornando ao Rio Paraná, ou pela utilização direta da água do reservatório, à montante, no sistema de arrefecimento com a condição de que ela retorne para algum processo na UHE, ou seja, a água só será disponibilizada caso seu uso cubra algum dos processos na UHE, além de arrefecer os módulos PV da UFV.

Diversas opções para o fornecimento de água foram encontradas, pois além da sua utilização para alimentação das máquinas geradoras de energia elétrica, esta é utilizada no processo de arrefecimento do sistema de lubrificação dos mancais, fornecimento para o enrocamento, limpeza dos espaços físicos e frota de veículos, usos nos banheiros para descarga e torneira. Mas várias opções foram descartadas devido à distância entre captação e fornecimento, pela necessidade de sistema de bombeamento, qualidade e periodicidade de fornecimento. Assim, duas opções disponíveis foram analisadas e discutidas, água de saída do sistema de refrigeração dos Mancais e Água da linha de enrocamento da UHE, discutidas a seguir. 


\subsection{1 Água de saída do sistema de refrigeração dos Mancais das Turbinas}

A água de refrigeração dos mancais está disponível intermitentemente ao longo do ano apenas no período de operação em que as máquinas geradoras, na qual o sistema refrigera, estão operando. Esta, antes de entrar nos trocadores térmicos dos mancais, passa por um processo químico de cloração para eliminar o mexilhão amarelo e evitar a sua fixação nas superfícies das tubulações e mancais que podem inviabilizar a operação ao longo do tempo.

Vantagens:

Água clorada, o que dificultaria a proliferação de mexilhão amarelo nos módulos arrefecedores, não havendo necessidade de implantar um sistema de tratamento de água para arrefecimento da UFV; e

Água de final de processo excluindo a necessidade de retorná-la para montante ou outro processo da UHE após a sua passagem pelos módulos arrefecedores; e

. Não há necessidade de implantar um sistema de bombeamento.

Desvantagem:

- Diversas intervenções na estrutura civil da barragem da UHE;

- Desligamento de duas máquinas geradoras, caso estas estejam operando durante o período de montagem do sistema de arrefecimento;

- Desligamento e perfuração da linha principal de descarga dos trocadores de calor de quatro turbinas;

- Remanejamento de dutos elétricos e lubrificantes utilizados na operação de máquinas geradoras;

- Construção de uma tubulação de $700 \mathrm{~m}$ até a linha de enrocamento da barragem mais um prolongamento de $77 \mathrm{~m}$ desta até a área da UFV;

- Altas temperaturas de fornecimento de água. Durante o verão apresenta temperaturas altas, máxima de $39^{\circ} \mathrm{C}$ e média anual de $32^{\circ} \mathrm{C}$ e nos períodos mais frios, máxima de $29^{\circ} \mathrm{C}$ e média de $26^{\circ} \mathrm{C}$; e 
- Fornecimento de água vinculado à operação das máquinas geradoras.

\subsection{2 Água da linha de enrocamento da UHE}

A água da linha de enrocamento da UHE é bruta, captada no fundo do reservatório da UHE, proporcionando temperaturas amenas ao longo do ano devido à grande coluna de água existente, com máxima $29^{\circ} \mathrm{C}$ no verão, e média anual de $24^{\circ} \mathrm{C}$, com mínima de $19^{\circ} \mathrm{C}$ no inverno.

A linha de enrocamento, após sair das instalações internas da barragem é fixada numa canaleta com cobertura, para abrigá-la do Sol e evitar avarias, percorrendo uma distância inferior a $500 \mathrm{~m}$ e terminando no estacionamento do prédio administrativo da UHE. A distância entre o final desta linha à área de instalação da UFV é de $77 \mathrm{~m}$, detalhes no Anexo I.

Essa água apresenta diversos usos como: limpeza geral do prédio administrativo e frota de veículos (ônibus, caminhão, tratores e carros), irrigação dos jardins, alimentação de hidrantes, fornecimento para caminhões pipas utilizados em diversos serviços dentro e fora da UHE. Essas condições tornam seu fornecimento contínuo, não havendo interrupções ao longo do ano.

Vantagens:

- Não há necessidade de intervenções na estrutura física da represa;

- Implantação isenta de intervenções físicas que prejudiquem ou inviabilizem momentaneamente algumas operações na UHE;

- Água de final de processo excluindo a necessidade de retorná-la para montante ou outro processo da UHE após a sua passagem pelos módulos arrefecedores;

· Não há necessidade de implantar um sistema de bombeamento;

- Pequeno prolongamento da tubulação até a área da UFV;

- Fornecimento ininterrupto ao longo do ano; e

- Temperatura da água amena ao longo do ano, média anual $24^{\circ} \mathrm{C}$.

Desvantagem: 
- Implantação de um sistema de cloração na linha de alimentação do sistema para evitar a proliferação de mexilhão amarelo no sistema de arrefecimento.

\subsection{SELEÇÃO DO TIPO DE TECNOLOGIA INDICADA PARA CONSTRUÇÃO DOS MODELOS DE TESTE}

Após verificação em campo das possibilidades de fornecimento de água, constataram-se duas possibilidades viáveis para utilização de água sem a necessidade de se utilizar bombeamento. Por meio de análise qualitativa determinou-se que a alimentação do sistema de arrefecimento, caso opte-se pela tecnologia PVT-água, seja fornecida pela linha do enrocamento da UHE, pois apresenta vantagens como proximidade entre a linha existente e a área da UFV, fornecimento contínuo e intermitente ao longo do ano e principalmente por não necessitar de intervenções físicas na barragem da usina.

A partir da bibliografia e pelo entendimento do processo de termalização dos módulos PV, no qual a temperatura da superfície inferior é maior que a superior, com diferença medida em campo de $8^{\circ} \mathrm{C}$, pela condição de não desperdiçar água (sistema fechado), e necessidade de arrefecer o módulo PV ao máximo para o aumento da produção de energia elétrica, fica evidente que a solução PVT-líquido sem isolamento térmico é a mais indicada. Outra característica observada deste tipo de sistema deve-se ao fato de permitir a utilização de módulos PV convencionais, apresentar alta capacidade de trocas térmicas e ser indicado para região com clima quente.

As soluções que utilizam ar, PVT-ar e PV ventilado utilizados para recuperação de calor, são descartadas por apresentarem baixa capacidade de trocas térmicas, não serem indicados para climas quentes e no caso do segundo ser uma aplicação vinculada a edifícios ou BIPV, já o PVT concentrador, não se aplica a tecnologia aplicada a UFV. No caso do sistema de arrefecimento pela superfície, mesmo apresentando bom rendimento para regiões de baixa latitude, é descartado por haver probabilidade de problemas relacionados a vazamentos e por sua vez desperdício e inundação da área de instalação da UFV. 
Dentro das opções do sistema selecionado são construídos três modelos diferentes de UMAr, dois do tipo chapa tubo (serpentina) e um do tipo múltiploscanais para teste real e seleção final antes da construção em série e instalação na UFV.

Os métodos construtivos, seleção de materiais e projetos de tais unidades são apresentados no Anexo C.

\subsection{TESTES EMPÍRICOS EM UNIDADE DE PROVAS PARA SELEÇÃO DE MODELO FINAL DE UMAR}

\subsubsection{Unidade de provas}

A Unidade de Provas (U.P.), ver Figura 21, é uma micro usina solar PV dotada de cinco módulos PV p-Si com potência de $290 W_{p}$ cada, cujos detalhes são apresentados no Anexo $A$, totalizando $1.450 \mathrm{~W}_{\mathrm{p}}$ de potência instalada.

O arranjo dos módulos PV da U.P. está ligado em série e conectado a um inversor solar ou inversor grid tie, responsável por inverter a energia elétrica gerada pelos módulos $\mathrm{PV}$ de corrente contínua $(\mathrm{CC})$ para corrente alternada $(\mathrm{AC})$ à tensão de $220 \mathrm{~V}$, garantir a segurança da U.P. e armazenar dados da geração de energia para a supervisão e monitoramento. Além disso, a U.P. possui dois quadros elétricos, um ao lado do inversor e outro próximo aos módulos, apresentados em detalhes no Anexo F, uma bomba elétrica de circulação de água, um datalogger, seis sensores de temperaturas ligados aos módulos $\mathrm{PV}$ e dois reservatórios de água (10 $\mathrm{m}^{3}$ cada), ver Tabela III. 


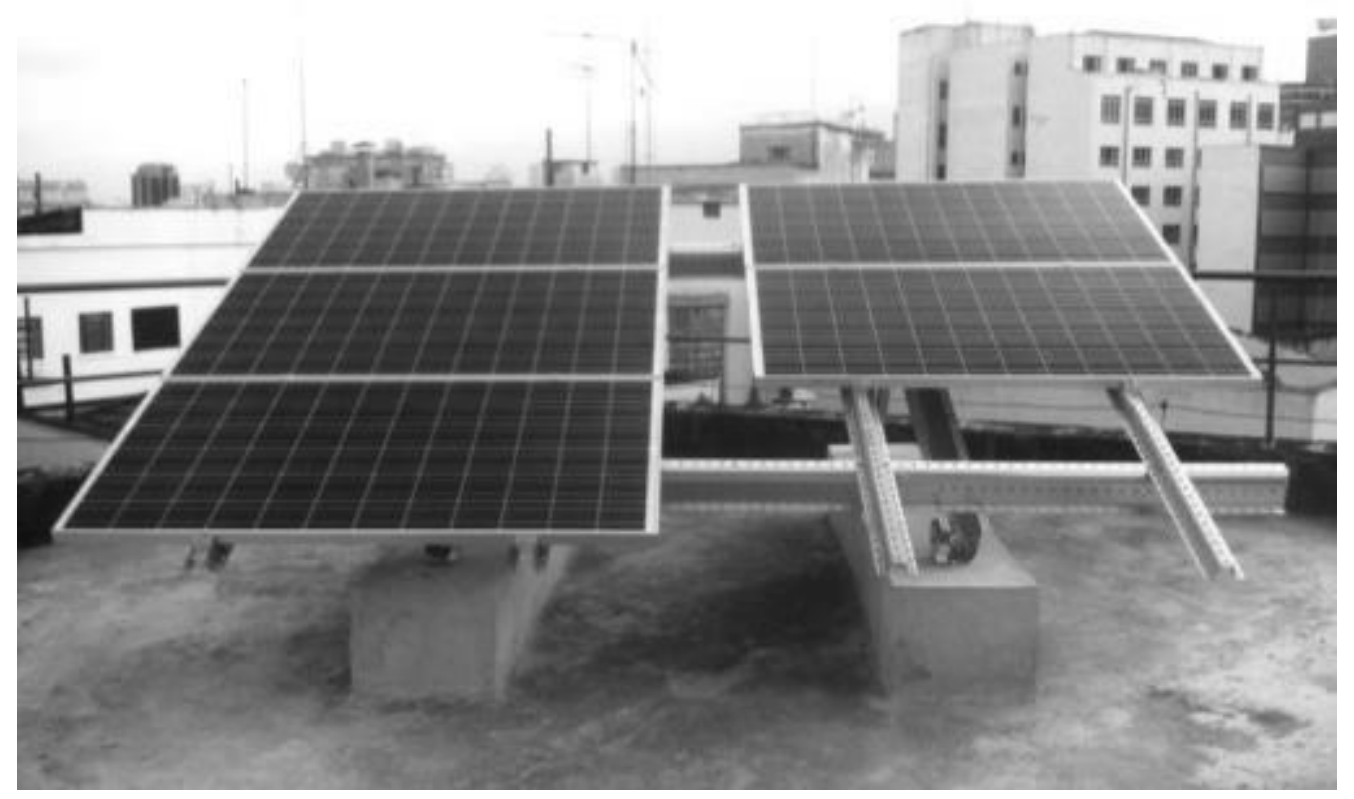

Figura 21 - Unidade de Provas.

Em relação à montagem física, a U.P. possui estrutura metálica para sustentação dos módulos PV com furações ao longo do corpo, na qual está instalado um quadro de força para alimentação elétrica da bomba d' água $(0,5 \mathrm{CV}-2$ polos $-220 \mathrm{~V})$, responsável pela alimentação de água dos arrefecedores, armazenagem e alimentação elétrica do datalogger, equipamento responsável pelo armazenamento dos dados de temperatura de operação dos módulos PV.

Tabela III - Lista dos componentes da U.P.

\begin{tabular}{lc}
\hline \multicolumn{1}{c}{ Componentes da U.P. } & Unid. \\
\hline Módulo PV & 5 \\
Inversor solar & 1 \\
Quadro de energia & 2 \\
Bomba d' água & 1 \\
Reservatório de água & 2 \\
Datalogger & 1 \\
\hline
\end{tabular}

\subsubsection{Procedimento de operação e montagem da U.P.}

A metodologia baseia-se no detalhamento e descrição dos procedimentos e métodos empíricos empregados na realização dos testes de operação da U.P. que compreende a supervisão e monitoramento da produção de energia elétrica, diferença e variação da temperatura dos módulos PV arrefecidos e não arrefecidos. 
4.4.2.1 Sistema de arrefecimento da U.P.

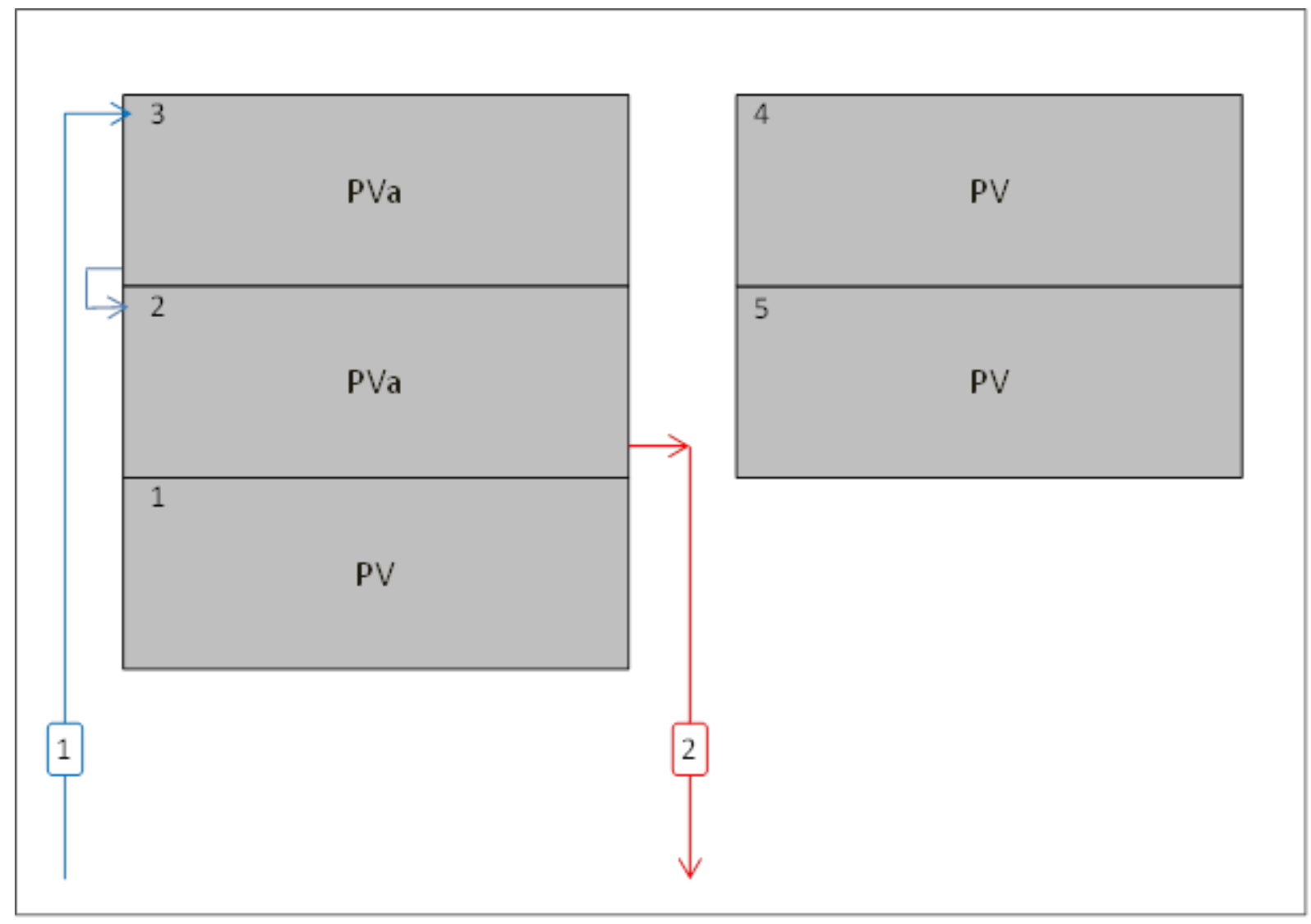

Figura 22 - Arranjo esquemático do sistema de arrefecimento dos módulos PV da U.P.

O arranjo esquemático da U.P e o funcionamento do sistema de arrefecimento, ver Figura 22, e sua operação seguem o seguinte escopo:

- O Ponto 1, linha de alimentação de água dos módulos PV arrefecidos. A água circula ininterruptamente para reduzir a temperatura de operação dos módulos PV ao longo do dia. Esta linha é alimentada pelo reservatório de água existente no local. O fluido chega por meio de uma linha principal que alimenta os arrefecedores ligados em série;

- O Ponto 2, linha de descarga da água. Esta linha conduz o fluido refrigerante da saída do arrefecedor até o reservatório. Desta forma, toda a água disponibilizada para o arrefecimento retorna para o mesmo local sem que haja perdas, evitando o aumento do custo de captação;

- O módulo PV-2, PVa (PV arrefecido), recebe o modelo B arrefecedor do tipo chapa-tubo; 
- O módulo PV-3 recebe o modelo A arrefecedor, também do tipo chapatubo;

- Os módulos PV-1, PV-4 e PV-5 não recebem modelos de arrefecimento, e são utilizados para analisar e comparar a temperatura de operação ao longo do dia, além de servirem como backup, caso algum dos módulos sofra avarias.

\subsubsection{Sistema de supervisão e monitoramento de temperatura da U.P.}

O sistema de medição de temperatura consiste em seis termoresistências do tipo PT-100, ver Figura 54, com sinal de saída compatível com o datalogger e uma câmera termovisora ver Figura 55.

A alocação dos sensores PT-100, ver Figura 23 e Tabela IV, é idêntica tanto nos módulos arrefecidos quando nos não arrefecidos. Para cada módulo PV são fixados diretamente na superfície inferior, região com maiores temperaturas de operação do módulo PV verificado no estudo, dois sensores de temperatura. A escolha de dois sensores por módulo PV serve para verificar a diferença e entender como se dá a distribuição de temperatura no módulo PV com e sem arrefecedor. Assim os locais definidos são:

- Um sensor na região central (Sensor Meio ou SM) para verificar a temperatura no centro do módulo $\mathrm{PV}$, além de ser local referente à metade do comprimento da serpentina e do centro do arrefecedor; e

- Um segundo (Sensor Ponta ou SP), próximo a junction box do módulo PV local que consolida a ligação entre as células PV e por sua vez apresenta as maiores corrente e tensões do módulo PV.

No caso dos módulos PV com arrefecedores é realizada uma intervenção física consistindo na abertura de dois furos na chapa metálica do absorvedor, de modo a permitir o contato direto entre o sensor e a superfície inferior do módulo PV.

A câmera termovisora é utilizada para medir e verificar a distribuição das temperaturas dos módulos $\mathrm{PV}$ e arrefecedores operando em horários específicos, às $10 \mathrm{~h} 00 \mathrm{~min}, 12 \mathrm{~h} 00 \mathrm{~min}$ e $15 \mathrm{~h} 00 \mathrm{~min}$. 


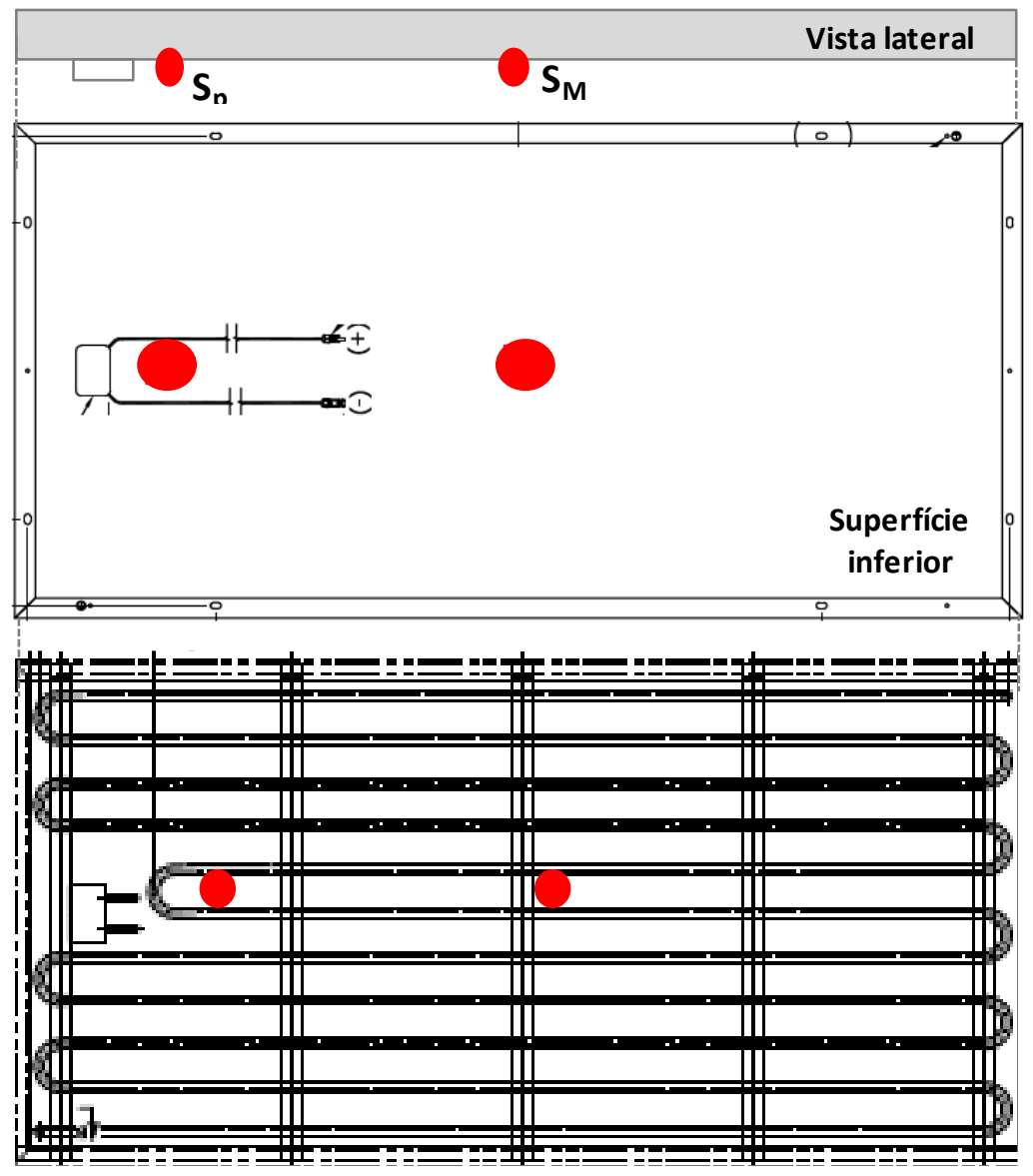

Figura 23 - Alocação dos sensores PT-100 nos módulos PV

Tabela IV - Identificação e localização dos modelos de arrefecedores e sensores de temperatura.

\begin{tabular}{ccccc}
\hline $\begin{array}{c}\mathbf{N}^{\circ} \text { do } \\
\text { Módulo PV }\end{array}$ & $\begin{array}{c}\text { Cód. do } \\
\text { Módulo PV }\end{array}$ & $\begin{array}{c}\text { Modelo } \\
\text { Arrefecedor }\end{array}$ & $\begin{array}{c}\text { Sensor } \\
\text { PT100 }\end{array}$ & $\begin{array}{c}\text { Código } \\
\text { PT100 }\end{array}$ \\
\hline 1 & PV & - & - & - \\
2 & PVa & $\begin{array}{c}\text { Modelo B } \\
(140,0 \mathrm{~mm})\end{array}$ & $\mathrm{SM}_{\mathrm{M}}$ & Meio_B \\
& & Modelo A & $\mathrm{SM}_{\mathrm{M}}$ & Ponta_B \\
3 & $\mathrm{PVa}$ & $(85,0 \mathrm{~mm})$ & $\mathrm{SP}_{\mathrm{P}}$ & Ponta_A \\
4 & $\mathrm{PV}$ & - & - & - \\
5 & $\mathrm{PV}$ & - & $\mathrm{SM}_{\mathrm{M}}$ & Meio_Sem \\
& & & $\mathrm{SP}_{\mathrm{P}}$ & Ponta_Sem \\
\hline
\end{tabular}

\subsubsection{Testes empíricos e análise dos dados}

Os testes empíricos e as supervisões e monitoramento da operação dos módulos PV da U.P. ocorreram no período de dois meses, totalizando 61 dias de medições, no qual foram analisados os dados das leituras de temperatura dos módulos PV, arrefecidos e não arrefecidos, a produção de energia elétrica da U.P e o fornecimento de água. 


\subsubsection{Análise do fornecimento de água}

Durante o período de teste de operação da U.P., a alimentação de água operou fornecendo vazão, inicialmente, a $0,483 \mathrm{l} / \mathrm{s}$ ou $1,732 \mathrm{~m}^{3} / \mathrm{h}$, velocidade de 1,69 $\mathrm{m} / \mathrm{s}$ e Reynolds $^{2}(\mathrm{Re})$ de 32.257, escoamento turbulento $(10.000<\mathrm{Re})$, esse escoamento garante melhores trocas térmicas por convecção forçado do fluido.

As temperaturas de entrada (Te) e saída (Ts) da água não apresentaram diferenças durante as medições pontuais. As variações de temperaturas ao longo do período de testes ficaram condicionadas a temperatura da água no reservatório e em relação à temperatura ambiente (Ta), ver Tabela $\mathrm{V}$.

Tabela V - Te e Ts saída da água do sistema de arrefecimento da U.P.

\begin{tabular}{ccccc}
\hline $\begin{array}{c}\text { Data } \\
\text { (dd/mm/aaaa) }\end{array}$ & $\begin{array}{c}\text { Hora } \\
\text { (h:min) }\end{array}$ & $\begin{array}{c}\mathbf{T}_{\mathbf{e}} \\
\left({ }^{\circ} \mathbf{C}\right)\end{array}$ & $\begin{array}{c}\mathbf{T}_{\mathbf{s}} \\
\left({ }^{\circ} \mathbf{C}\right)\end{array}$ & $\begin{array}{c}\mathbf{T}_{\text {amb }} \\
\left({ }^{\circ} \mathbf{C}\right)\end{array}$ \\
\hline 05/03/2015 & $10: 09$ & 21,0 & 21,0 & 28,9 \\
16/03/2015 & $10: 00$ & 20,5 & 20,5 & 26,2 \\
$31 / 03 / 2015$ & $10: 00$ & 21,0 & 21,0 & $(1)$ \\
14/04/2015 & $11: 04$ & 21,5 & 21,5 & 28,6 \\
$31 / 04 / 2015$ & $10: 29$ & 20,5 & 20,5 & $(1)$
\end{tabular}

(1) Não houve medição de temperatura ambiente, pois a Estação Meteorológica (EM) estava fora de operação.

Na última semana dos testes de operação constatou-se redução da vazão de água em $86 \%$, mas apresentando fornecimento constante com vazão a 0,066 l/s ou $0,237 \mathrm{~m}^{3} / \mathrm{h}$, velocidade de $0,23 \mathrm{~m} / \mathrm{s}$ e Re de 4.415 , escoamento turbulento liso $(2.000<R e<10.000)$. A diminuição da vazão não reduziu a capacidade de retirar calor dos módulos PV, e sua causa foi constatada após a retirada e análise dos arrefecedores da U.P. que apresentaram oxidação interna na serpentina devido ao aumento da concentração de cloro na água, o que impactou no aumento da perda de carga do sistema reduzindo a vazão de água.

\footnotetext{
${ }^{2}$ Número adimensional utilizado em mecânica dos fluidos para o cálculo do regime de escoamento de determinado fluido sobre uma superfície. Obtido por meio da relação entre a velocidade do fluido e diâmetro da tubulação pela viscosidade cinemática do fluido.
} 


\subsubsection{Análise do sistema de arrefecimento}

O período diário de geração de energia elétrica registrado pelo inversor grid tie, durante os 61 dias de medições, tem início mínimo às 06h10min00ss e término máximo às $19 \mathrm{~h} 00$ min00ss. A média diária foi de $11 \mathrm{~h} 13 \mathrm{mim} 27 \mathrm{ss}$, com máxima de 12h10min00ss, no dia 05/03/2015, e mínima de 10h10min00ss, no dia 06/03/2015, mostrando que num período de dois dias consecutivos ocorreu o maior e menor período de geração diário de energia elétrica, revelando que os eventos climáticos influenciam diretamente na produção de energia elétrica, esse fato fica evidente quando analisada a Figura 24(a), da energia gerada e período de geração diário da U.P., é possível verificar que dias com mesmo período de geração, $11 \mathrm{~h} 05$ min00ss, a energia gerada é diferente, como no caso de três dias consecutivos, 16/04/2015, 17/04/2015 e 18/04/2015, que geraram 3,91kWh/dia, 6,69kWh/dia e 6,11kWh/dia, respectivamente, apresentando relação energia gerada por período de geração (REP) de 8,46, 14,48 e 13,23, respectivamente.

A REP máxima, 16,34, ocorrida em 27/03/2015, apresentou geração de $7,70 \mathrm{kWh} /$ dia, valor inferior a máxima geração de $7,82 \mathrm{kWh} /$ dia, ocorrida em 02/04/2015 com REP de 16,31 e período 11h25min00ss. No caso das REP mínimas, a menor foi de 2,75 condizendo com a menor geração, $1,31 \mathrm{kWh} / \mathrm{dia}$, ocorrida em $30 / 03 / 2015$, por outro lado o período de geração $11 \mathrm{~h} 24 \mathrm{~min} 47 \mathrm{ss}$ foi superior a segunda menor REP, 3,00, ocorrida em 22/04/2015, com geração de 1,32kWh/dia e período de 10h35min00ss. Para o menor período de geração registrado, 10h10min00ss, a REP foi 10,41 com geração de $4,41 \mathrm{kWh} /$ dia.

Assim como a geração de energia elétrica, o comportamento das temperaturas dos módulos PV-2 (TPV-2), PV-3 (TPV-3) e PV-5 (TPV-5) oscilam ao longo do período de testes, Figura 24(b). Estas oscilações ocorrem devido à radiação solar e temperatura ambiente, mutáveis ao longo dos 61 dias, que impactam diretamente na energia de saída produzida pela U.P.

A geração de energia registrada no período de testes totalizou $302,79 \mathrm{kWh}$, com REP e geração média de 10,61 e 4,96kWh/dia. 


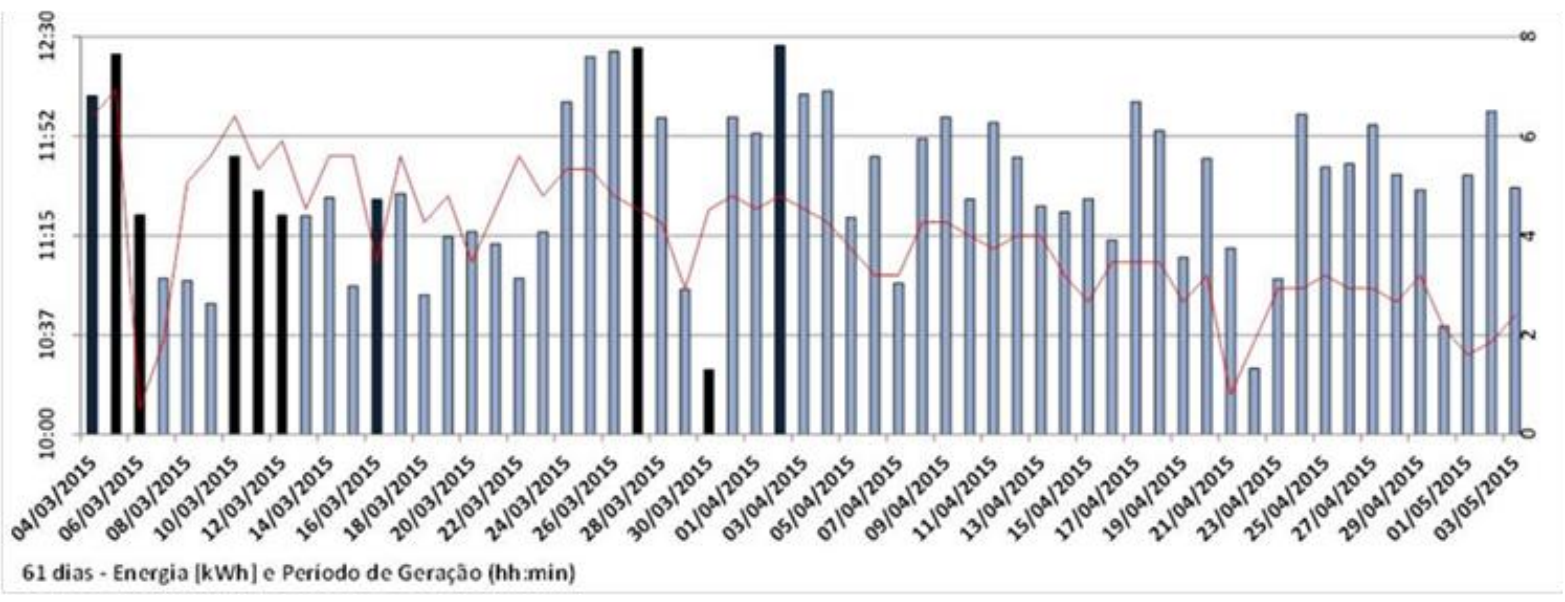

(a)

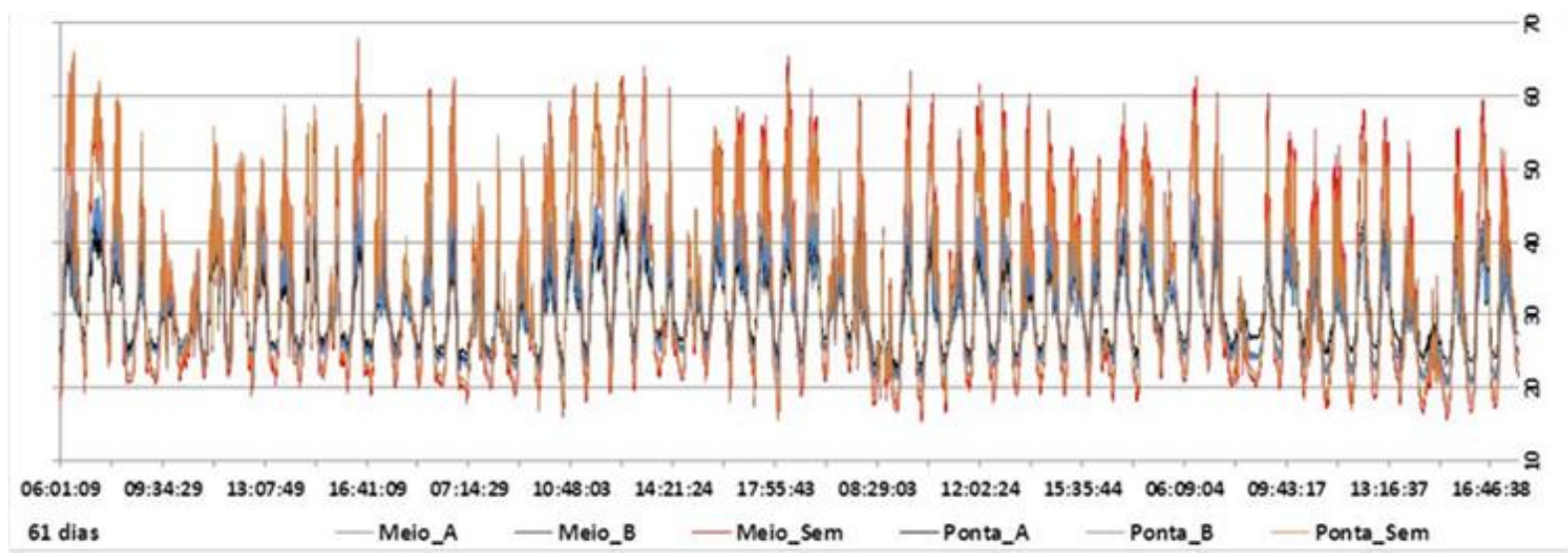

(b)

Figura 24 - Período de testes da U.P. (a) geração de energia e horas de geração e (b) temperaturas dos módulos PV.

Analisando a Figura 25(a) é possível verificar que a temperatura do módulo PV sem UMAr apresenta temperaturas noturnas inferiores às dos módulos PV com UMAr. Isto ocorre por não existir radiação solar, temperaturas ambientes amenas em relação ao dia e, principalmente pela capacidade térmica da água circulante ser maior que a do ar, ou seja, durante a noite a água perde menos calor do que o ar mantendo a sua temperatura e a do módulo PV maiores que a temperatura do ar ambiente. Após o início da geração, as temperaturas dos módulos PV, arrefecidos e não arrefecidos, aumentam, no caso dos módulos PV não arrefecidos, isso ocorre mais acentualmente ultrapassando a temperatura dos módulos PV com arrefecimento no início da manhã mantendo-se maior até o final da tarde, próximo ao término da geração, desde que não haja nenhum evento climático como chuvas, aparecimento de nuvens densas por longo período, como verificado no estudo. 
Os dados medidos para o dia 04/03/2015 apresentaram bom rendimento em comparação com as medições para o período, apresentando REP de 13,62 e geração de $6,81 \mathrm{kWh} / \mathrm{dia}$, sendo ambas as grandezas superiores à média para o período de testes.

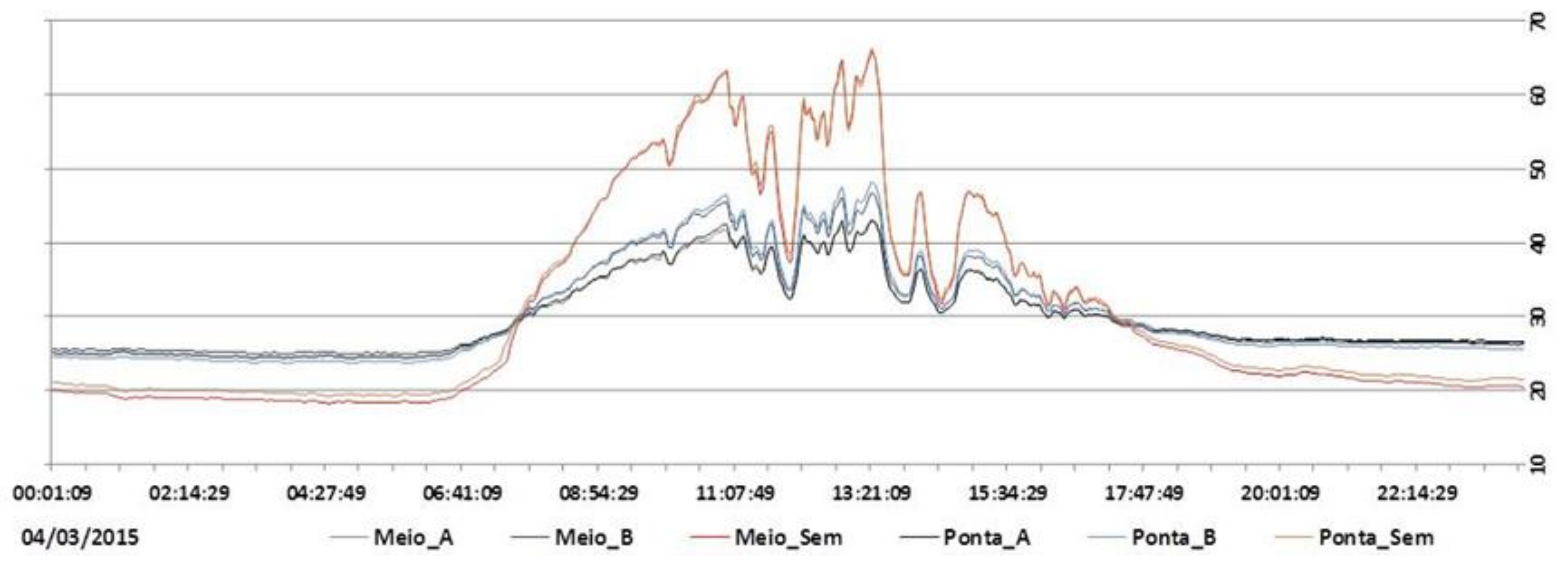

Figura 25 - Temperaturas dos módulos PV-2, 3 e 5 da U.P. no dia 04/03/2015 em 24h do dia.

Os dados de geração, no dia 16/03/2015, apresentaram rendimento diário abaixo da média para o período de teste, uma vez que a geração de energia foi de $4,72 \mathrm{kWh} /$ dia apresentando REP de 10,22, sendo ambas as grandezas abaixo da média para o período de testes.

Analisando a Figura 26(a) e Figura 26(b) referentes à energia gerada e temperatura de operação dos PV-2, PV-3 e PV-5, observa-se uma correlação, pois há coerência na oscilação das curvas com picos de máximo e mínimo próximos. $\mathrm{A}$ geração de energia apresenta boa produção até o início da tarde, com pico de 410 Ws, as $11 \mathrm{~h} 15 \mathrm{~min} 39 \mathrm{ss}$, mas após as $14 \mathrm{~h} 00 \mathrm{~min} 39 \mathrm{ss}$ a geração decresce atingindo patamares abaixo dos $30 \mathrm{Ws}$, mantendo essa produção até o fim do dia. $\mathrm{O}$ mesmo ocorre com as $\mathrm{TPV}_{\mathrm{P}-2}, \mathrm{~T}_{\mathrm{PV}-3}$ e $\mathrm{T}_{\mathrm{PV}-5}$, que decrescem devido ao aparecimento de nuvens e precipitação de chuva que reduzem a radiação solar incidente e a temperatura ambiente da região da U.P. 


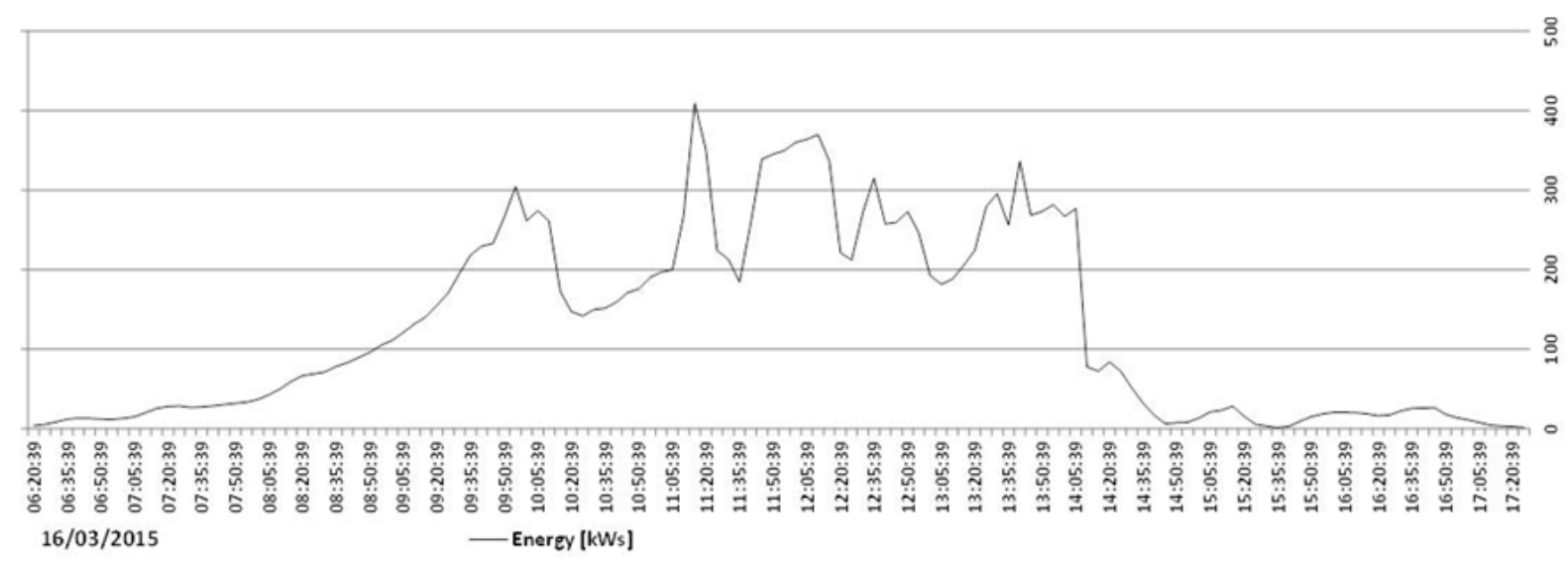

(a)

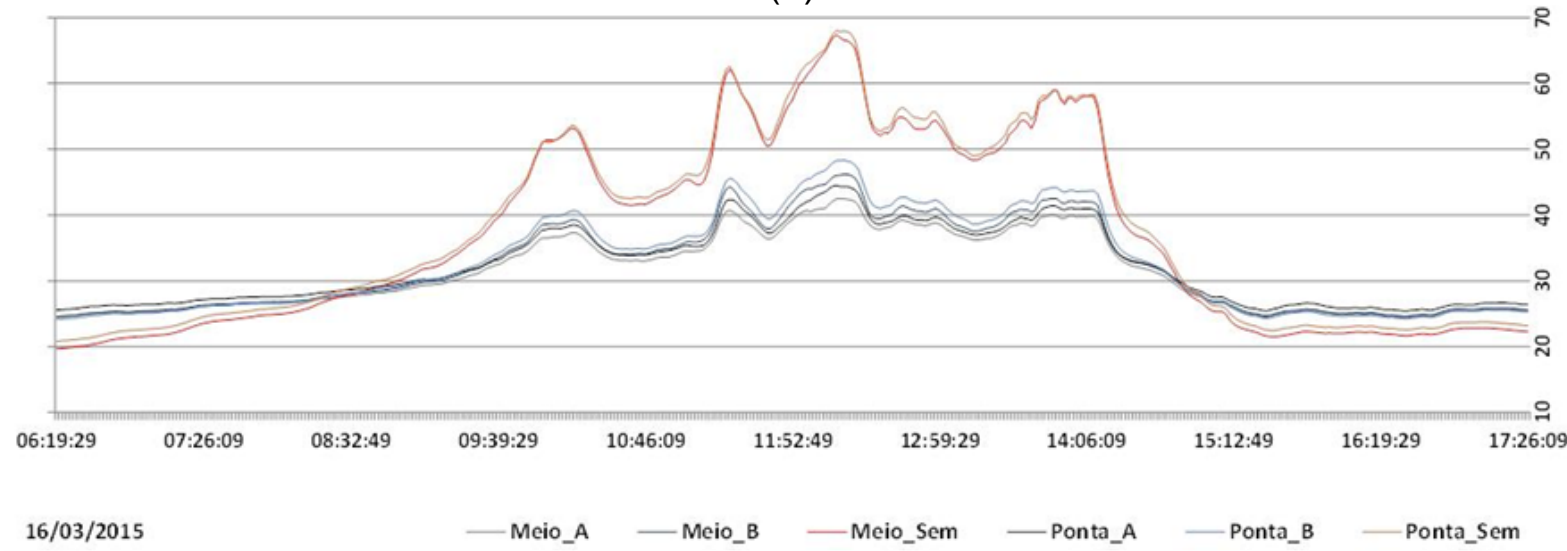

(b)

Figura 26 - Operação da U.P. no dia 16/03/2015 (a) produção de energia e (b) temperatura dos módulos PV-2, 3 e 5.

Por meio da análise da Figura 27(a), referente às TPV-2, TPV-3 e TPV-5 no instante, 12h12min49ss, de registro da temperatura máxima ( $\left.T_{\text {máx }}\right)$ em 16/03/2015, com Tmáx $=68,06^{\circ} \mathrm{C}$, registrado pelo sensor Ponta_Sem, referente ao módulo PV-5, e temperatura mínima ( $T_{\text {mín }}$ ) de $42,45^{\circ} \mathrm{C}$ registrada pelo sensor Meio_A, referente ao módulo PV-3, diferença de $25,61^{\circ} \mathrm{C}$ entre a maior e menor temperatura medida

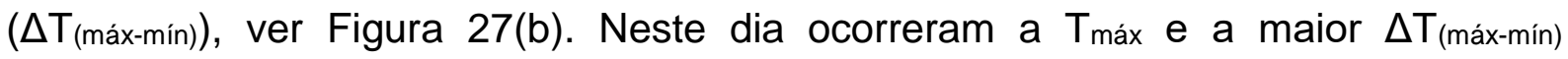
registradas durante os 61 dias de testes.

Quando analisada a diferença de temperatura em um mesmo módulo PV $(\Delta T P V)$, tem-se que o PV-3 apresenta $\Delta \mathrm{T}_{\mathrm{PV}-3}=2,06^{\circ} \mathrm{C}$, o PV-2 a diferença é maior, $\Delta \mathrm{T}_{\mathrm{PV}-2}=$ $2,26^{\circ} \mathrm{C}$, e o PV-5 apresentam $\Delta \mathrm{TPV}_{\mathrm{P}-5}=0,67^{\circ} \mathrm{C}$, nesse instante o PV-5 apresenta temperaturas de operação mais homogênea dentre os três, ver Figura 27(c). Além disso, as temperaturas registradas pelos dois sensores do PV-3 mostram que este opera abaixo do NOCT. 


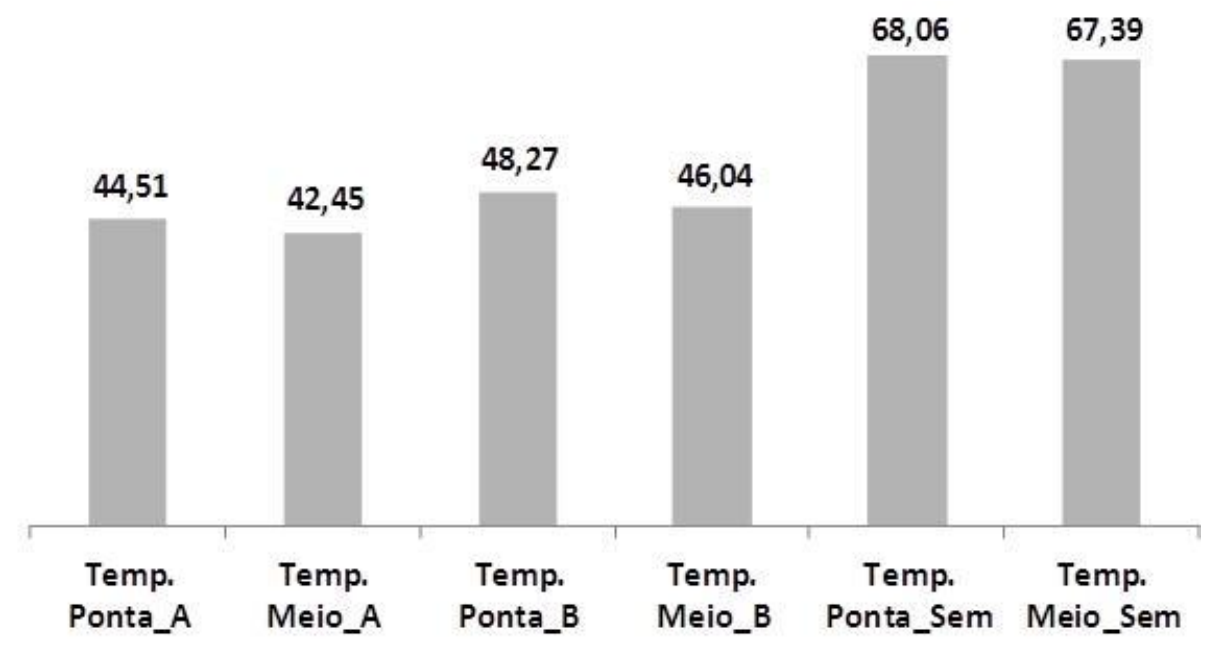

(a)

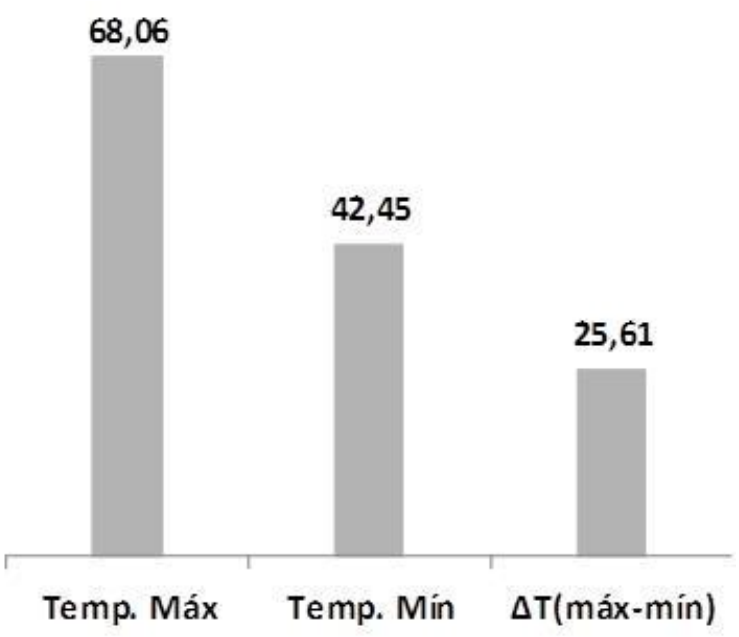

(b)

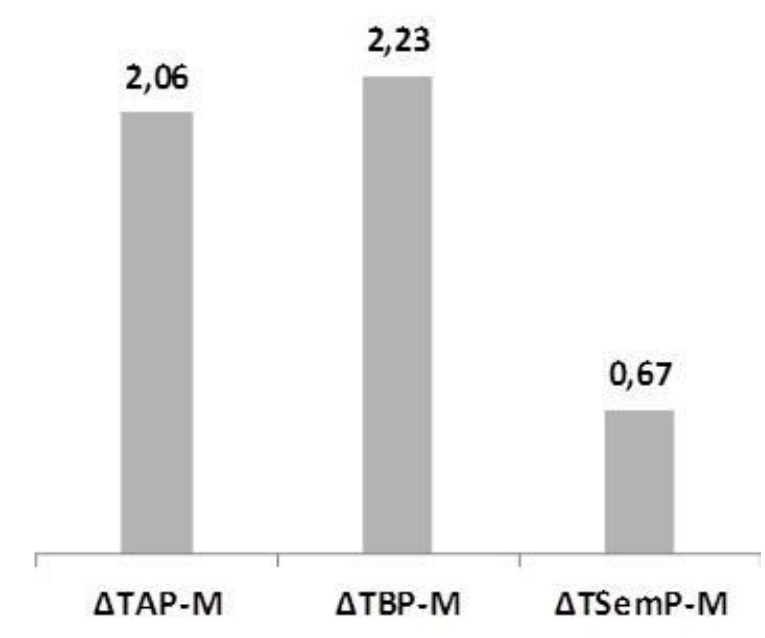

(c)

Figura 27 - Temperatura de operação dos módulos PV em 16/03/2015. (a) temperatura registradas pelos sensores PT100, (b) Máximas temperaturas e (c) diferença entre temperaturas em um mesmo módulo PV.

O dia 02/04/2015 apresentou a maior geração de energia elétrica do período, $7,82 \mathrm{kWh} / \mathrm{dia}$, com a segunda maior REP, 16,31. As grandezas ficaram 57,6\% e $53,7 \%$ acima da média para o período de testes.

Analisando a Figura 28(a) e Figura 28(b) referentes à energia gerada e a TPV-2, TPV-3 e TPV-5, assim como no dia 16/06/2015, observa-se correlação da oscilação das curvas, picos de máximo e mínimo, pois estão temporalmente próximos, ou seja, o aumento e queda das temperaturas e geração de energia estão na mesma faixa de horário. A geração de energia apresenta boa produção durante todo o dia.

A curva de geração diária de energia inicia-se às 07h25min00ss, com crescimento acentuado até $10 \mathrm{~h} 35 \mathrm{~min} 00 \mathrm{ss}$, atingindo patamar de $300 \mathrm{Ws}$ e 
mantendo-se neste nível até as $15 \mathrm{~h} 10 \mathrm{~min} 00 \mathrm{ss}$, salvo alguns períodos com quedas devido ao aparecimento de nuvens que reduzem a radiação solar direta incidente, após esse período há o decrescimento acentuado até o final da tarde finalizando a produção às $18 \mathrm{~h} 55$ min00ss. O pico de geração, $407 \mathrm{Ws}$, ocorreu às $12 \mathrm{~h} 50$ min00ss, ver Figura 28(a), o comportamento desta curva se assemelha à curva característica de geração padrão de uma UFV, a qual possui aumento acentuado da geração ao longo da manhã com normalização entre o início e fim da tarde, seguido por forte queda até zerar a geração ao final da tarde. O mesmo comportamento ocorre com as curvas de temperatura de operação dos módulos PV, ver Figura 28(b).

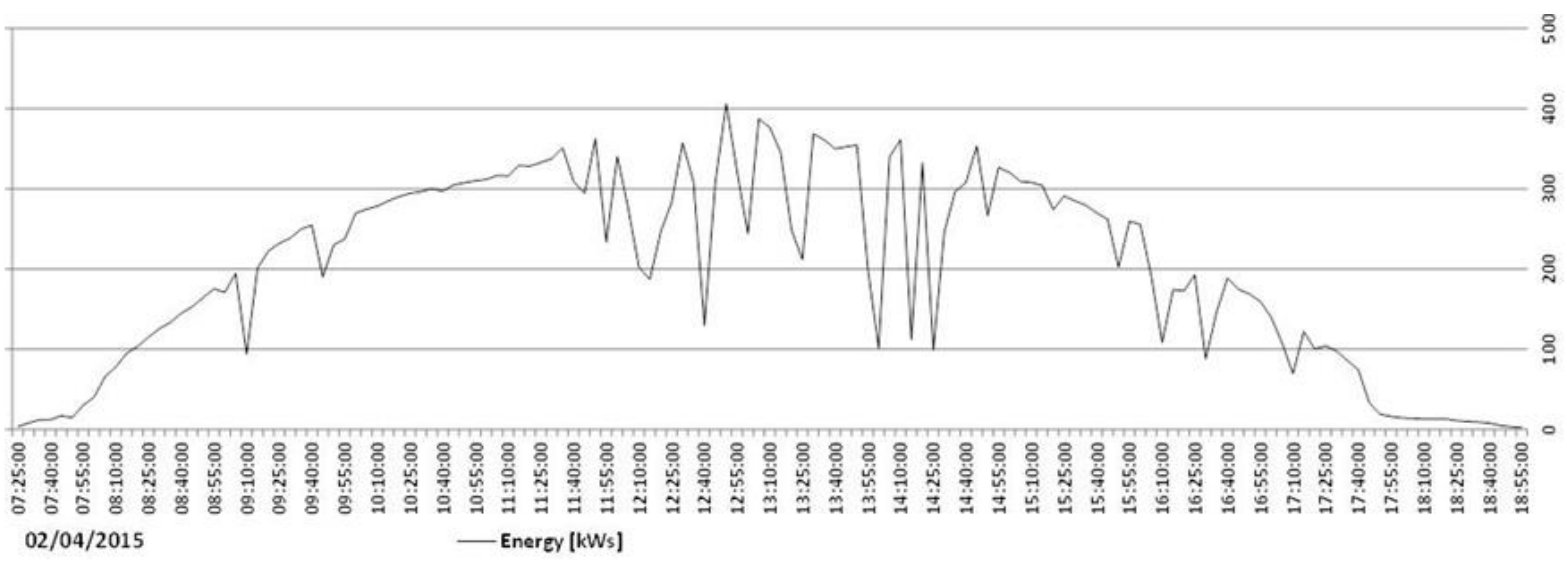

(a)

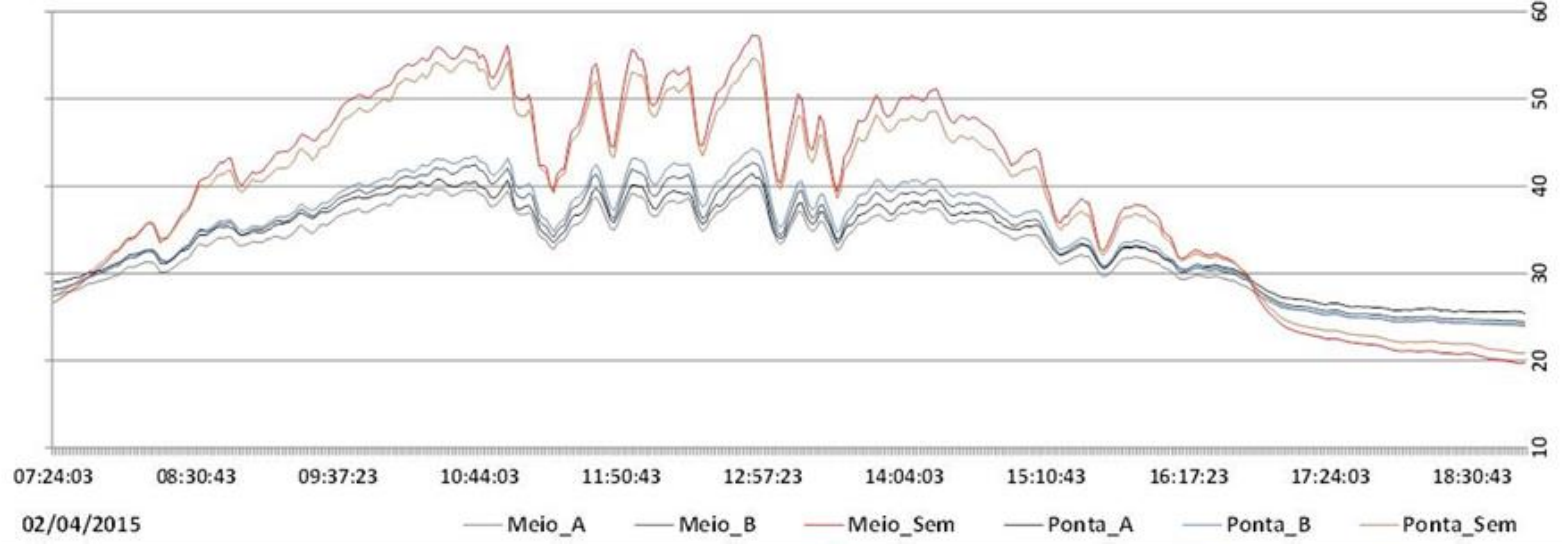

(b)

Figura 28 - Operação da U.P. no dia 02/04/2015 (a) produção de energia e (b) temperatura dos módulos PV-2, 3 e 5.

Por meio da análise da Figura 29(a), referente às TPV-2, $T_{P V-3}$ e TPV-5 no instante, 12h52min23ss, de registro da $T_{\text {máx em }} 02 / 04 / 2015$, com $T_{\text {máx }}=57,31^{\circ} \mathrm{C}$, registrada pelo sensor Meio_Sem, referente ao módulo PV-5, e T mín $=40,18^{\circ} \mathrm{C}$, registrada pelo sensor Meio_A, referente ao módulo PV-3, uma $\Delta \mathrm{T}_{\text {(máx-mín) }}$ de $17,13^{\circ} \mathrm{C}$, ver Figura 29 (b). 
Quando analisada a $\Delta \mathrm{TPV}_{\mathrm{PV}}$, tem-se que o PV-3 apresenta $\Delta \mathrm{TPV}-3=1,30^{\circ} \mathrm{C}$, o PV-2 a $\triangle \mathrm{TPV}_{\mathrm{PV}}$ é maior, $1,67^{\circ} \mathrm{C}$, já o $\mathrm{PV}-5$ apresenta $2,65^{\circ} \mathrm{C}$, maior diferença registrada nesse instante, ver Figura 29(c). Além disso, a temperatura registrada pelos dois sensores do PV-3 mostra, assim como observado em 16/03/2015, que este opera abaixo do NOCT.

Mesmo a geração de energia tendo sido a maior de todo o período de testes, a Tmáx registrada, quando comparada com $16 / 03 / 2015$, foi inferior em $10,75^{\circ} \mathrm{C}$. Além disso, a Tmáx registrada em 02/04/2015 ocorreu no sensor Meio_Sem diferindo do dia 16/03/2015 que ocorreu no sensor Ponta_Sem.

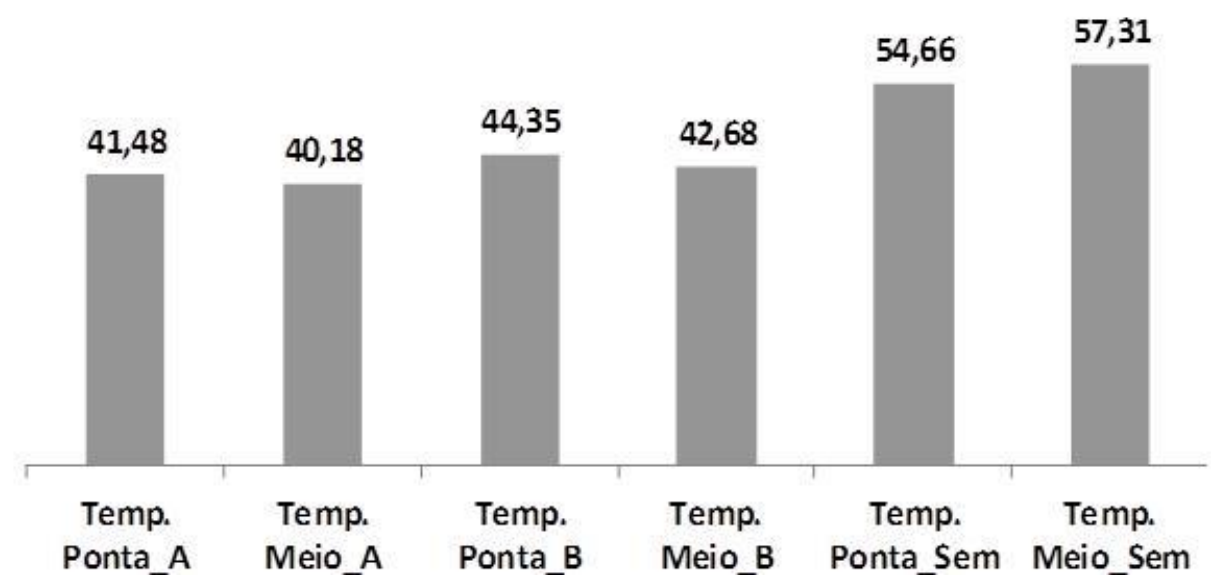

(a)

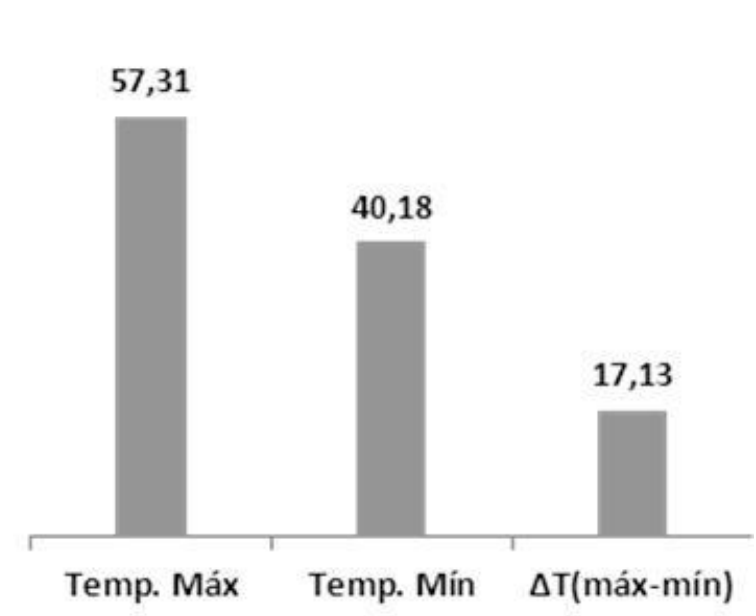

(b)

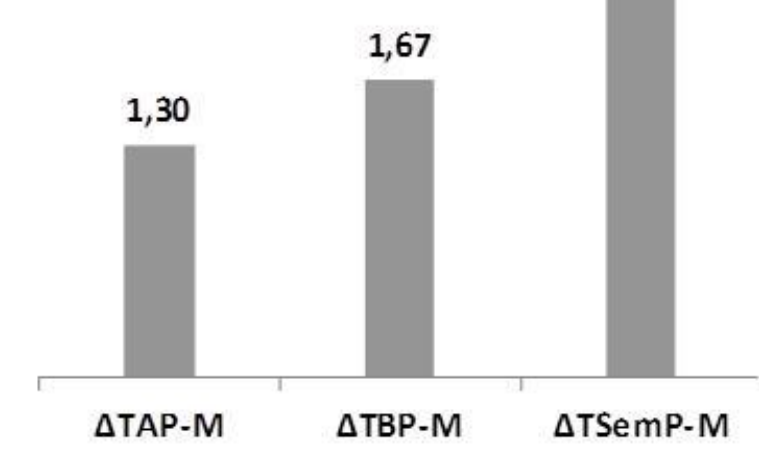

(c)

Figura 29 - Temperatura de operação dos módulos PV em 02/04/2015. (a) temperatura registradas pelos sensores PT100, (b) Máximas temperaturas e (c) diferença entre temperaturas em um mesmo módulo PV. 
Durante 0 período de testes foram registradas 235 temperaturas superiores a $60^{\circ} \mathrm{C}$ presentes em 21 dias, $34,4 \%$ dos 61 dias. Essas apresentaram Temperatura média ( $T_{\text {méd }}$ ) de $62,01^{\circ} \mathrm{C}$, mínima de $60,01^{\circ} \mathrm{C}$ e máxima de $68,06^{\circ} \mathrm{C}$. Os registros ocorreram exclusivamente nos sensores do PV-5, dos quais $77,0 \%$ registrado no sensor Meio_Sem. No mesmo instante, as menores temperaturas registradas ocorreram exclusivamente no PV-3, com modelo A de arrefecedor, das quais $97,4 \%$ ocorram no sensor Meio_A, ver Figura 30(a), com média de temperatura de $41,48^{\circ} \mathrm{C}$, mínima de $39,4^{\circ} \mathrm{C}$ e máxima de $43,55^{\circ} \mathrm{C}$, com média de temperatura de $41,48^{\circ} \mathrm{C}$, mínima de $39,4^{\circ} \mathrm{C}$ e máxima de $43,55^{\circ} \mathrm{C}$. A média da diferença entre a máxima e mínima temperatura registrada num mesmo instante pelos sensores foi de $20,53^{\circ} \mathrm{C}$, com mínima de $17,79^{\circ} \mathrm{C}$ e máxima de $25,61^{\circ} \mathrm{C}$.

Em relação à $\Delta T_{P V}$, têm que o PV-3 apresenta diferença de temperatura média de $1,13^{\circ} \mathrm{C}$, menor média registrada, mínima de $0,01^{\circ} \mathrm{C}$ e máxima de $3,68^{\circ} \mathrm{C}$, no $\mathrm{PV}-2$ a diferença média é de $1,69^{\circ} \mathrm{C}$, mínima de $0,63^{\circ} \mathrm{C}$ e máxima de $2,34^{\circ} \mathrm{C}$, já o $\mathrm{PV}-5$ apresenta média de $1,43^{\circ} \mathrm{C}$, mínima $0,01^{\circ} \mathrm{C}$ e máxima de $5,12^{\circ} \mathrm{C}$, maior diferença máxima registrada, ver Figura 30(b). 


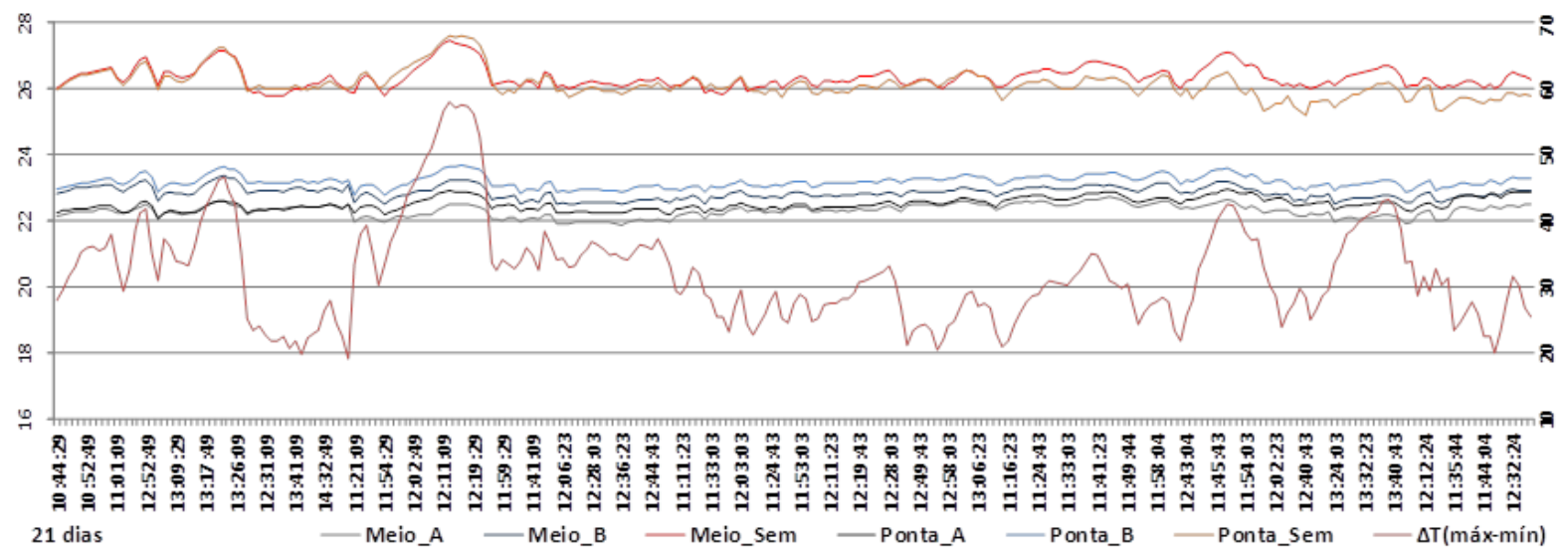

(a)

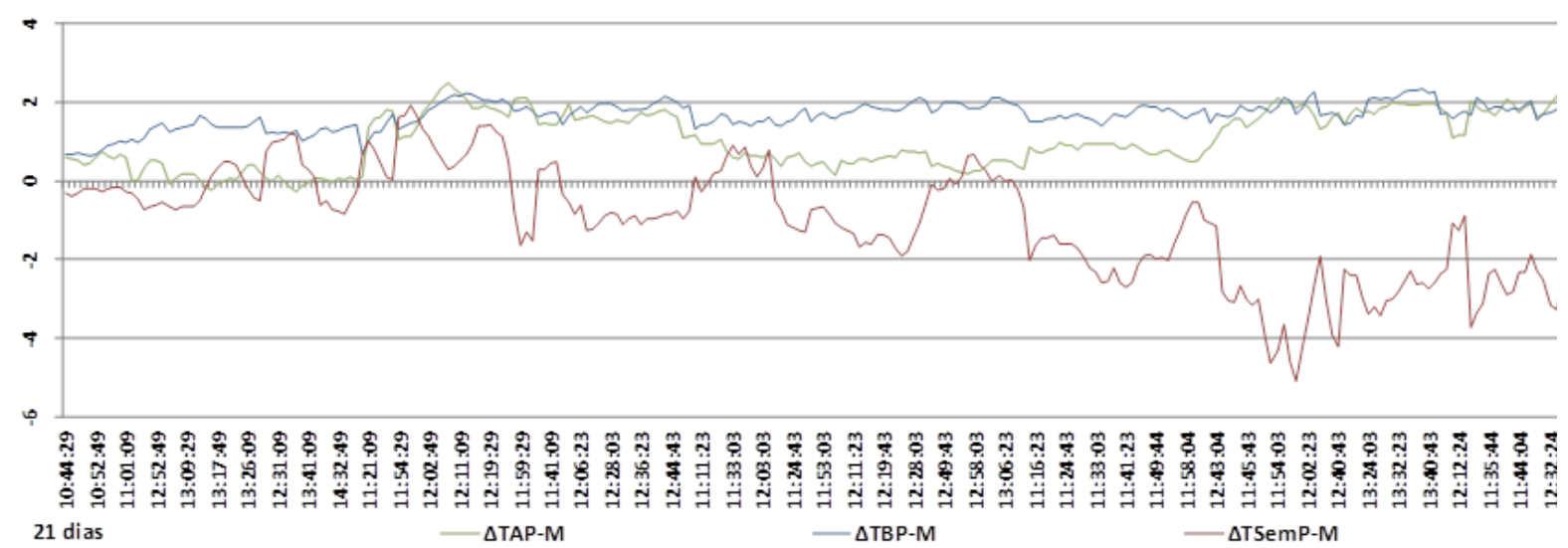

(b)

Figura 30 - Temperaturas de operação dos módulos PV $>60,00^{\circ} \mathrm{C}$. (a) Diferença entre maior e menor temperatura medida (b) diferença de temperatura medida em um mesmo módulo PV.

Além disso, a temperatura registrada pelos sensores do módulo PV-3 mostram, assim como observado nos dias 16/03/2015, 02/04/2015, que este operou sempre abaixo do NOCT, com TMáx registradas nos sensores Meio_A e Ponta_A de $43,55^{\circ} \mathrm{C}$ e $44,75^{\circ} \mathrm{C}$, respectivamente, ver Tabela VI.

Tabela VI - Temperaturas médias, mínimas e máximas dos 21 dias com temperaturas dos módulos $\mathrm{PV}>60,00^{\circ} \mathrm{C}$.

\begin{tabular}{cccccc}
\hline Módulo PV & $\begin{array}{c}\text { Modelo de } \\
\text { Arrefecedor }\end{array}$ & $\begin{array}{c}\text { Sensor } \\
\text { PT100 }\end{array}$ & $\begin{array}{c}\text { Temp. } \\
\text { Média }\left({ }^{\circ} \mathbf{C}\right)\end{array}$ & $\begin{array}{c}\text { Temp. } \\
\text { Mín. }\left({ }^{\circ} \mathbf{C}\right)\end{array}$ & $\begin{array}{c}\text { Temp. } \\
\text { Máx. }\left({ }^{\circ} \mathbf{C}\right)\end{array}$ \\
\hline \multirow{2}{*}{ PV-2 } & Modelo B & Meio_B & 44,21 & 42,49 & 46,76 \\
& & Ponta_B & 45,90 & 43,84 & 48,33 \\
PV-3 & Modelo A & Meio_A & 41,48 & 39,40 & 43,55 \\
& & Ponta_A & 42,61 & 40,24 & 44,75 \\
PV-5 & & Meio_Sem & 61,86 & 58,86 & 67,39 \\
& & Ponta_Sem & 60,73 & 56,06 & 68,06 \\
\hline
\end{tabular}




\subsection{Supervisão e monitoramento com auxilio da câmera termovisora}

Durante o dia 04/03/2015 foram feitos diversos registros fotográficos em três períodos de horários, 10h00min, 12h00min e 15h00min, das superfícies, inferior, no local de fixação dos sensores PT100, e superior dos módulos PV-1, PV-2, PV-3, PV4 e PV-5, ver Anexo J.

Com a análise das imagens constata-se que as temperaturas são $\mathrm{T}_{\mathrm{PV}-3}<\mathrm{TPV}-2<$ TPV-5, assim como registrado pelos sensores PT100, característica presente nos três períodos de supervisão e monitoramento com auxilio da câmera termovisora, ver Tabela VII.

A maior temperatura, $56,6^{\circ} \mathrm{C}$, ocorreu no período das $10 \mathrm{hh}: 00 \mathrm{~min}$ registrado no sensor Meio_Sem do PV-5, ver Figura 82(e), excetuando-se o módulo PV-3, as maiores temperatura foram registradas no local de fixação dos sensores $S_{M}$.

Outra observação, tanto o PV-3, $37,1^{\circ} \mathrm{C}$ registrado no sensor Ponta_A, quanto o PV-5 registraram as maiores temperaturas no período das 10h00min, já o PV-2 registrou a maior temperatura, $41,9^{\circ} \mathrm{C}$, no período das $12 \mathrm{~h} 00 \mathrm{~min}$, na região do sensor Meio_B, ver Figura 83 (c) e Tabela VII.

As menores temperaturas registradas ocorrem para os três módulos PV no período das $15 \mathrm{~h} 00 \mathrm{~min}$, ver Figura $84(\mathrm{a})$, (d) e (f), sendo a menor, $32,3^{\circ} \mathrm{C}$, região do sensor Meio_A, referente ao PV-3, seguido pelo $\mathrm{PV}-2,35,5^{\circ} \mathrm{C}$, região do sensor Ponta_B, e pelo PV $-5,43,7^{\circ} \mathrm{C}$, região do sensor Ponta_Sem.

Com relação à temperatura na superfície superior dos módulos PV, ver Figura 31, qualitativamente, o módulo PV-1, não arrefecido, apresenta temperaturas mais elevadas, em todos os três períodos, em relação aos módulos PV-2 e PV-3, arrefecidos.

Quanto à distribuição das temperaturas, no PV-1 encontram-se mais uniformes do que as dos módulos PV arrefecidos, ver a região de contato com a serpentina do arrefecedor zona azul da Figura 31(a). A região com maior temperatura no módulo PV-1, ver Figura 31(c), encontra-se, como esperado, na região da junction box, canto inferior direito, nessa região concentra-se a transmissão de toda a energia gerada pelas células do módulo PV. 


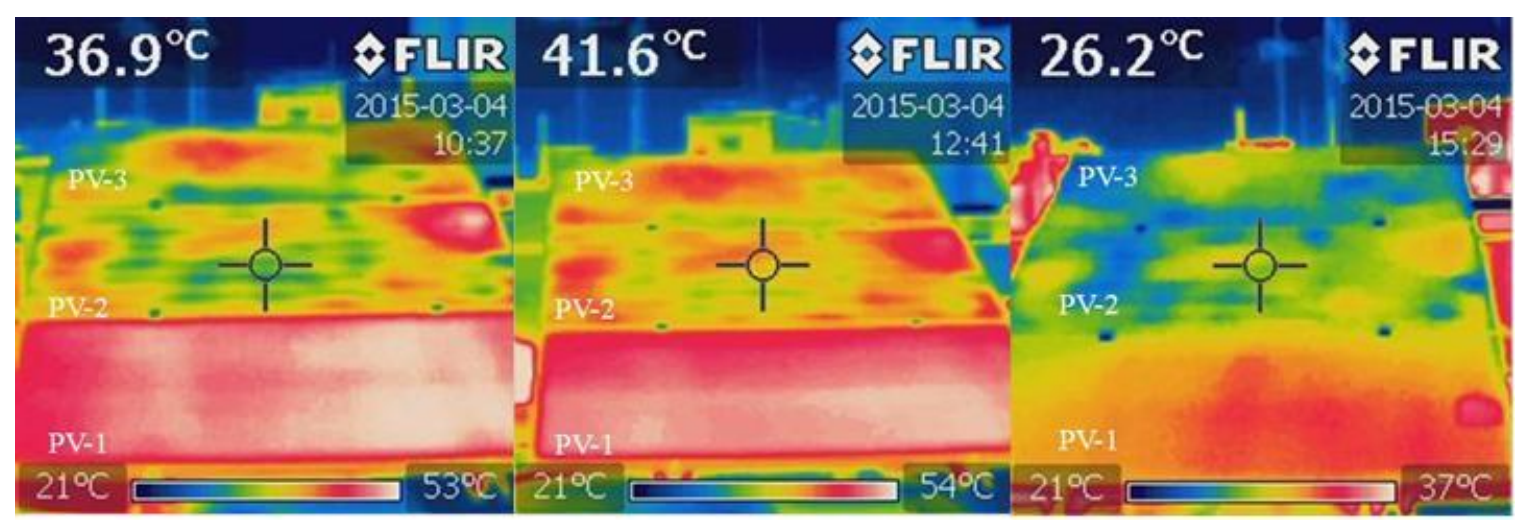

(a)

(b)

(c)

Figura 31 - Fotos da superfície superior dos módulos PV nos períodos (a) 10h00min, (b) $12 \mathrm{~h} 00 \mathrm{~min}$ e (c) $15 \mathrm{~h} 00 \mathrm{~min}$.

Tabela VII - Temperaturas nos pontos medidos pela câmera termovisora.

\begin{tabular}{|c|c|c|c|c|}
\hline $\begin{array}{l}\text { Período } \\
\text { (h:min) }\end{array}$ & Módulo PV & $\begin{array}{c}\text { Modelo de } \\
\text { Arrefecedor }\end{array}$ & Sensor PT100 & $\begin{array}{l}\text { Temp. } \\
\left({ }^{\circ} \mathrm{C}\right)\end{array}$ \\
\hline \multirow{6}{*}{$10: 00$} & \multirow{2}{*}{ PV-2 } & \multirow{2}{*}{ Modelo B } & Meio_B & 40,9 \\
\hline & & & Ponta_B & 39,2 \\
\hline & \multirow{2}{*}{ PV-3 } & \multirow{2}{*}{ Modelo A } & Meio_A & 36,6 \\
\hline & & & Ponta_A & 37,1 \\
\hline & \multirow{2}{*}{ PV-5 } & \multirow[b]{2}{*}{ - } & Meio_Sem & 56,6 \\
\hline & & & Ponta_Sem & 55,4 \\
\hline \multirow{6}{*}{$12: 00$} & \multirow{2}{*}{ PV-2 } & \multirow{2}{*}{ Modelo B } & Meio_B & 41,9 \\
\hline & & & Ponta B & 40,0 \\
\hline & \multirow{2}{*}{ PV-3 } & \multirow{2}{*}{ Modelo A } & Meio_A & 36,1 \\
\hline & & & Ponta_A & 35,5 \\
\hline & \multirow{2}{*}{ PV-5 } & \multirow{2}{*}{-} & Meio_Sem & 55,2 \\
\hline & & & Ponta_Sem & 54,0 \\
\hline \multirow{6}{*}{$15: 00$} & \multirow{2}{*}{ PV-2 } & \multirow{2}{*}{ Modelo B } & Meio_B & 35,7 \\
\hline & & & Ponta_B & 35,3 \\
\hline & \multirow{2}{*}{ PV-3 } & \multirow{2}{*}{ Modelo A } & Meio_A & 32,3 \\
\hline & & & Ponta_A & 33,5 \\
\hline & \multirow{2}{*}{ PV-5 } & \multirow[b]{2}{*}{-} & Meio_Sem & 44,1 \\
\hline & & & Ponta Sem & 43,7 \\
\hline
\end{tabular}

\subsubsection{Resultados dos testes e análise da U.P.}

Mesmo com toda a metodologia empírica determinada, a supervisão e monitoramento dos módulos $\mathrm{PV}$ e dos modelos $\mathrm{A}$ e $\mathrm{B}$ de arrefecedores não foram triviais, uma vez que a tecnologia é nova, sem conhecimento do comportamento real da sua operação. Por outro lado, a elaboração prévia da metodologia reduziu os imprevistos.

O sistema de alimentação operou sem vazamentos nas tubulações e junções, não houve interrupção no fornecimento de água, exceto em pausas programadas. A 
operação do sistema não alterou o volume de água dos reservatórios, não houve diferença de temperatura entre a água de entrada e saída do sistema. O único problema encontrado foi à redução da vazão de água entre o início e fim do período de teste que variou em $86 \%$.

Pela análise dos dados, gráficos e tabelas apresentados no estudo, foi comprovado que os PV-2 e PV-3, com arrefecedor, apresentam temperaturas de operação, durante o período de geração de energia, menores que o PV-5, sem arrefecedor. As máximas temperaturas diárias registradas no período ocorreram exclusivamente no módulo PV-5, com $T_{\text {méd, }} T_{\text {mín e }} T_{\text {máx }}$ de $62,011^{\circ} \mathrm{C}, 60,01^{\circ} \mathrm{C}$ e $68,06^{\circ} \mathrm{C}$, respectivamente. A diferença dessas temperaturas com as mínimas registradas no mesmo instante são $20,53^{\circ} \mathrm{C}$ superior na média, com mínima diferença de $17,7^{\circ} \mathrm{C}$ e máxima de $25,61^{\circ} \mathrm{C}$. Todas as $T_{\text {mín }}$ foram registradas nos sensores PT-100 do PV-3, com modelo A de arrefecedor.

Quando comparadas as temperaturas do PV-2, com modelo B de arrefecedor, as temperaturas do PV-3, com modelo A de arrefecedor, constatou-se que o PV-3 opera sempre abaixo dos $45^{\circ} \mathrm{C}$, ou seja, o modelo A permite que o módulo PV opere com temperatura inferior ao seu NOCT, pois como verificado e demonstrado, as máximas temperaturas registradas no PV-3 foram de $43,55^{\circ} \mathrm{C}$ no sensor Meio_A e $44,75^{\circ} \mathrm{C}$ no sensor Ponta_A.

Além disso, a relação da diferença de temperatura entre os sensores $S_{M}$ e SP em um mesmo módulo $\mathrm{PV}$, para essas máximas temperaturas, são menores no módulo PV com modelo $A$, média $1,13^{\circ} \mathrm{C}$, do que no módulo $P V$ com modelo $B$, média de $1,69^{\circ} \mathrm{C}$.

Portanto, o modelo de arrefecedor escolhido para a produção em série para ser instalado no protótipo de UFVa após os testes na U.P. foi o modelo A de arrefecedor por garantir que o módulo PV opere a temperaturas inferiores as do módulo PV com o modelo B de arrefecedor. 


\section{TESTES EMPÍRICOS E DETERMINAÇÃO DO DESEMPENHO DE UM PROTÓTIPO DE USINA SOLAR FOTOVOLTAICA ARREFECIDA}

\subsection{USINA SOLAR FOTOVOLTAICA ARREFECIDA}

A Usina Solar Fotovoltaica (UFV) do estudo, ver Figura 32, é um sistema PV centralizado dotado de 344 módulos PV p-Si com potência de $290 W_{p}$ cada e área superficial $1,81 \mathrm{~m}^{2}$, detalhes são apresentados no Anexo A, totalizando $99.760 \mathrm{~W}_{\mathrm{p}}$ de potência instalada e $622,79 \mathrm{~m}^{2}$ de área, distribuídos em dois subsistemas. Um em solo constituído por 264 módulos PV com 76,56 kWp de potência instalada e $477,95 \mathrm{~m}^{2}$ de área, e um no telhado do prédio administrativo da UHE-ILS, com 80 módulos PV, potência instalada 23,20 kW e $144,83 \mathrm{~m}^{2}$ de área.

O subsistema em solo, ver Figura 34(a), apresenta 12 strings contendo cada um 11 módulos PV conectados em série associados em paralelo à outra fileira de 11 módulos, também conectados em série, e interligados a um inversor solar ou inversor grid tie de $12,0 \mathrm{~kW}$, o qual cada um recebe dois arranjos de string, totalizando 44 módulos PV por inversor.

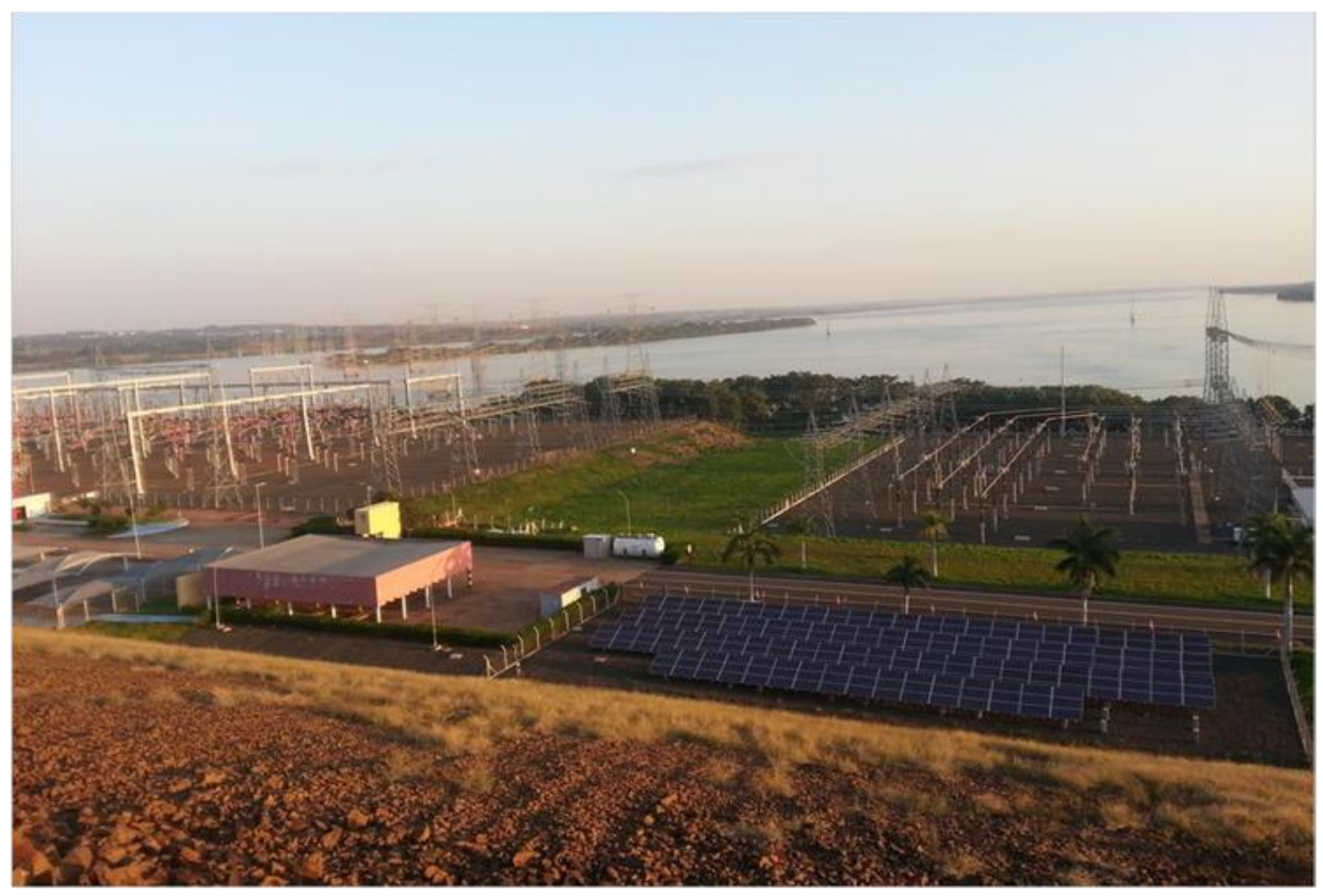

Figura 32 - Subsistema em solo da UFV-ILS. 
O subsistema do telhado, ver Figura 34(b), apresenta oito strings contendo dez módulos conectados em série associados em paralelo a outra fileira de 10 módulos, também conectados em série, e interligados a um inversor solar ou inversor grid tie de 5,0 kW, o qual cada um recebe um arranjo de string, totalizando 20 módulos PV por inversor.

A UFVa-ILS possui dez inversores solares, ver Figura 33, sendo seis de 12,0 kW e quatro de $5,0 \mathrm{~kW}$ conectados aos subsistemas do solo e telhado, respectivamente, que converte a energia elétrica $\mathrm{CC}$, produzida pelos módulos $\mathrm{PV}$, em AC enviando a para um transformador de acoplamento trifásico de $100 \mathrm{kVA}$, que reduz a tensão de 380/220 para 220/127 $V_{A C}$, fornecendo energia elétrica ao sistema de serviço interno da UHE-ILS. Além disso, todos os inversores estão conectados a um datalogger que infere a potência útil, tensões e correntes $\mathrm{AC} / \mathrm{CC}$, horas de operação e produção, totalização da produção diária/mensal/anual de energia elétrica.

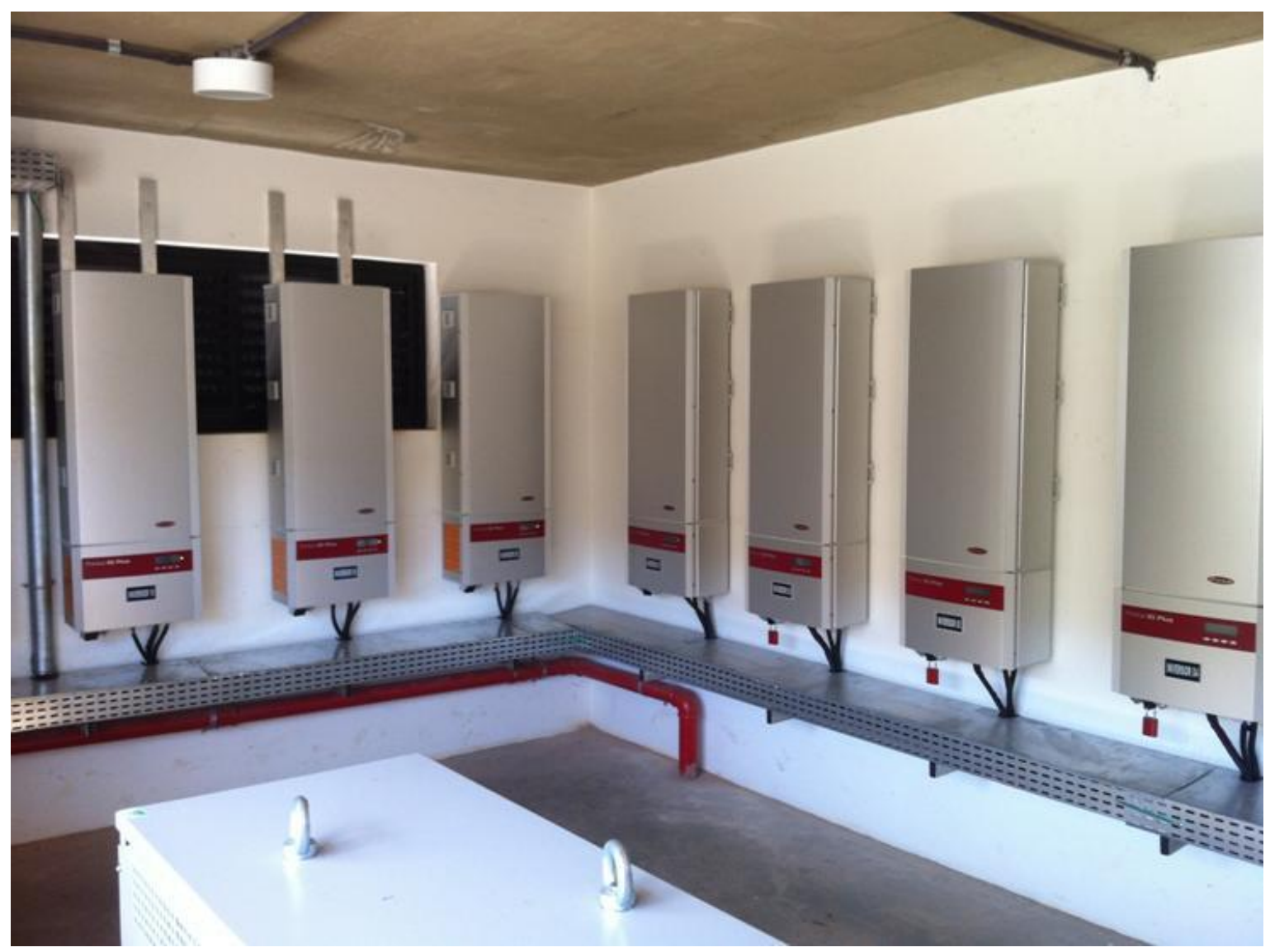

Figura 33 - Inversores instalados na sala de inversores da UFVa-ILS. 
4 Fileiras de 11 painéis $P V$

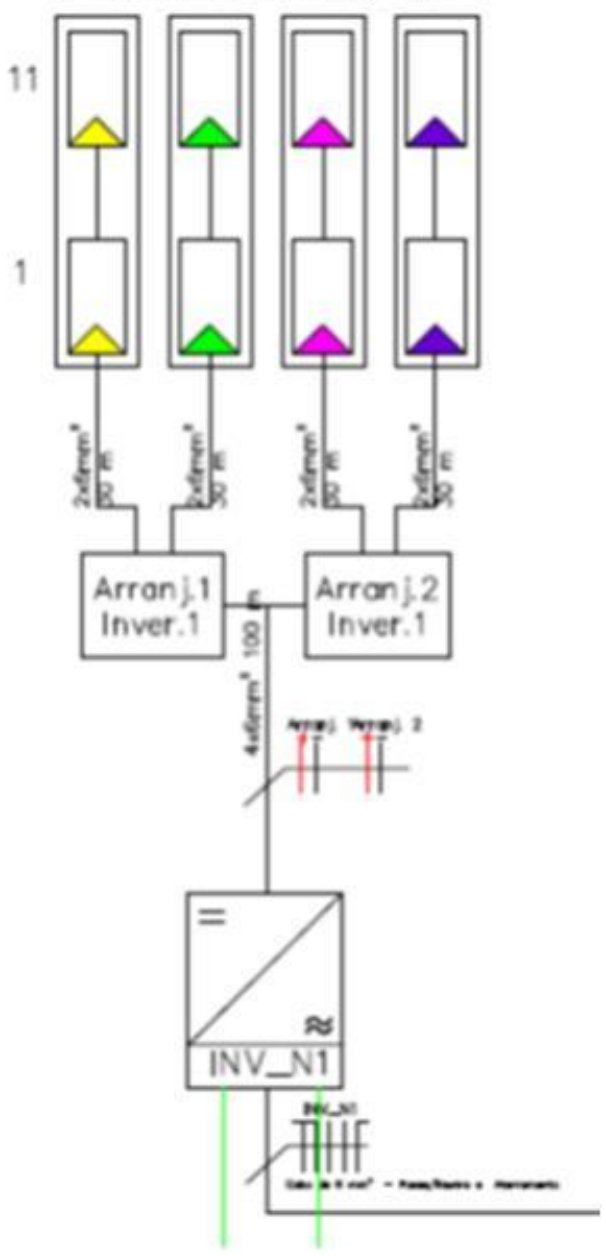

(a)

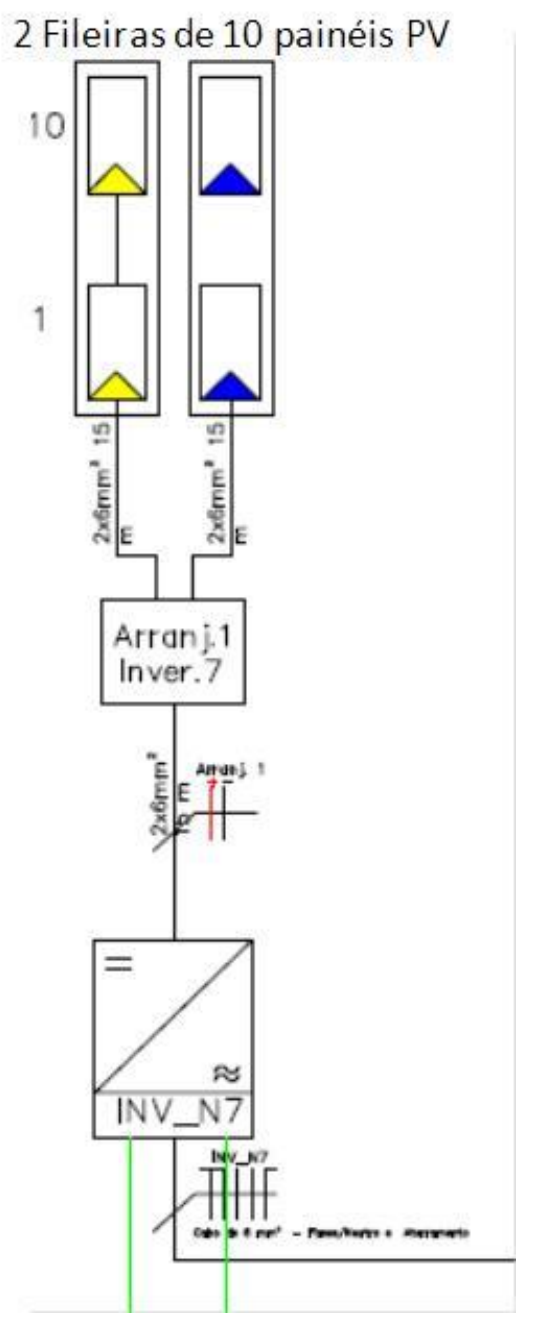

(b)

Figura 34 - Representação do arranjo multifilar da UFV. (a) subsistema em solo (b) subsistema do telhado.

A energia gerada nesta usina em llha Solteira é utilizada para suprir a demanda de um prédio de escritórios situado dentro da área da UHE e, se houver excedente de energia, é destinada a rede elétrica de baixa tensão.

\subsection{PROCEDIMENTO DE OPERAÇÃO E MONTAGEM DA UFVA}

A metodologia se baseia no detalhamento e descrição dos procedimentos e métodos empíricos empregados na realização dos testes de operação do protótipo de UFVa que compreende a supervisão e monitoramento do sistema de alimentação de água, produção de energia elétrica, diferença e variação da temperatura dos módulos PV do string de teste e comparação. 


\subsubsection{Sistema de arrefecimento da UFVa}

O desenvolvimento e implantação do sistema de arrefecimento do protótipo de UFVa compreende a instalação de UMAr em um string experimental correspondendo a $12,8 \%$ do total de módulos PV da UFV-ILS, denominado string de teste abrangendo uma área superficial de módulos PV de 79,66 m². Para o estudo, análise e determinação do desempenho de tal sistema, utiliza-se um segundo string convencional, denominado string de comparação. Ambos encontram-se instalados no subsistema do solo, apresentando juntos $25,6 \%$ da capacidade total instalada, ver Figura 35.

A configuração de cada um dos strings é idêntica em termos de conexão elétrica, arranjo, posicionamento, e tipo e número de módulo PV e capacidade instalada, sendo formada por quatro fileiras de onze módulos PV, ver Figura 34(a), ou seja, 44 módulos PV de um string recebem as UMAr e os outros 44 do segundo string são utilizados de comparação.

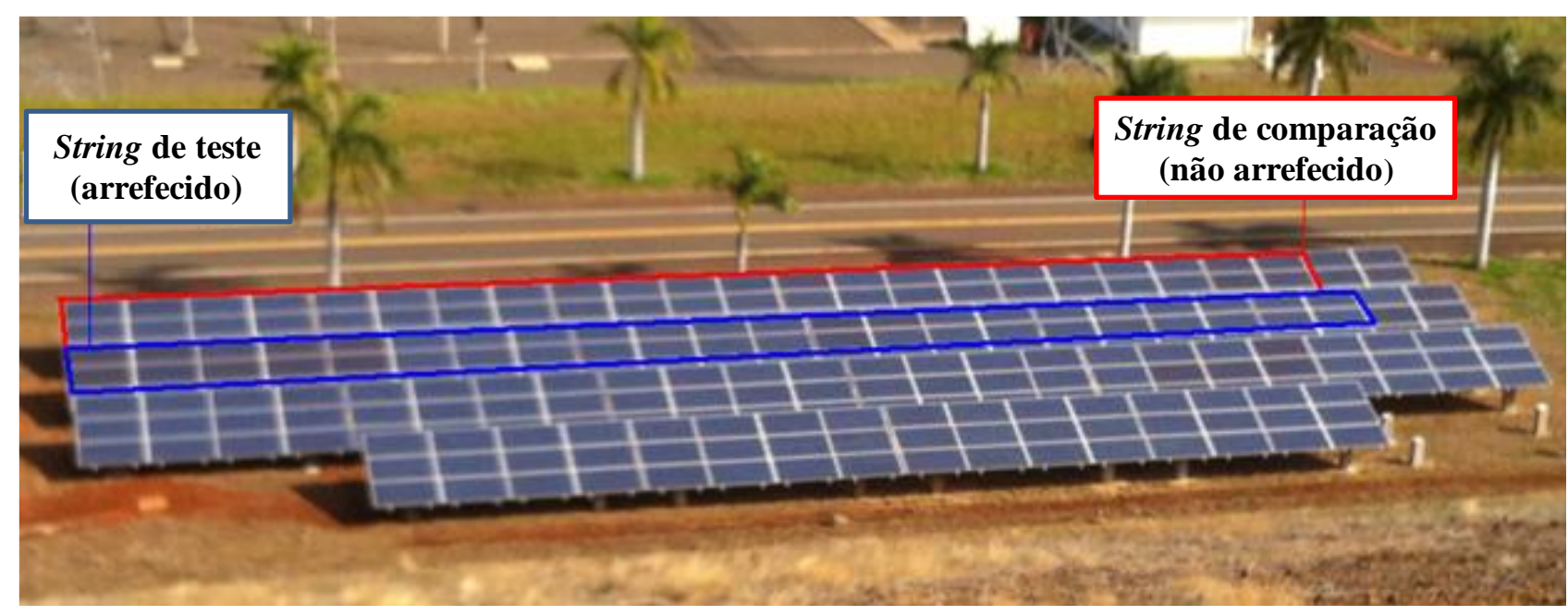

Figura 35 - Strings de teste e comparação do subsistema em solo do protótipo de UFVa.

Os testes operacionais no protótipo de UFVa compreendem a medição e monitoramento sistêmico da vazão do fluido refrigerante (água), comparação e análise do desempenho de grandezas energéticas básicas dos strings e grandezas climáticas, que compreendem:

- Geração de energia elétrica;

- Fluxo de potência; 
- Temperatura de operação dos pares de módulos PV, de teste e comparação;

- Temperatura de entrada e saída do fluido refrigerante do sistema de arrefecimento;

- Temperatura ambiente;

- Radiação solar direta; e

- Velocidade e direção do vento.

Essas medições sistêmicas permitem a análise comparativa para obter o rendimento dos dois sistemas e correlacionar às grandezas energéticas e climáticas medidas. É válido frisar que a análise dos dados é feita apenas para os dias nos quais ambos os strings estejam operando com fornecimento constante de água.

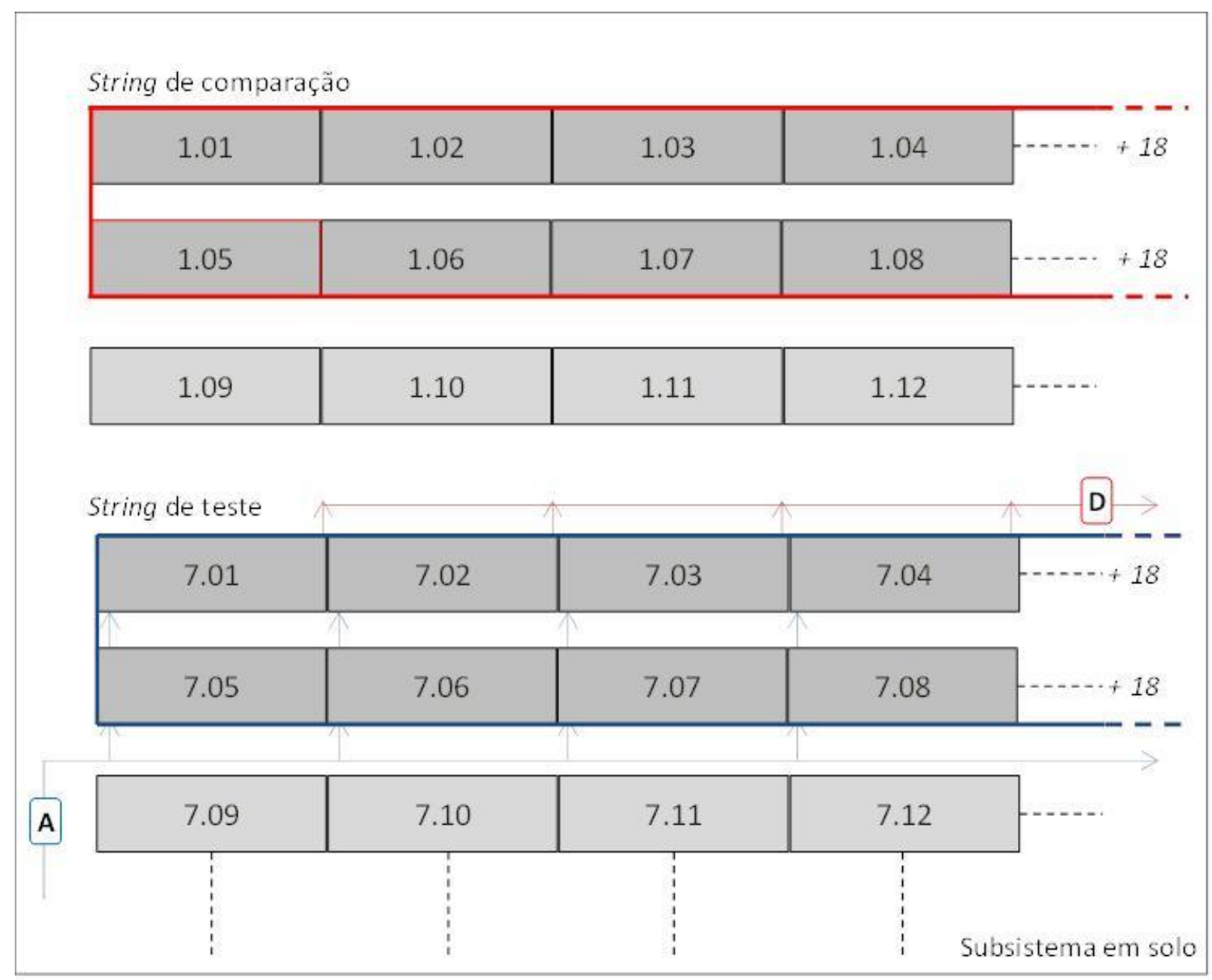

Figura 36 - Arranjo esquemático do sistema de arrefecimento do protótipo de UFVa. 
O arranjo esquemático dos strings, teste e comparação, do protótipo de UFVa, o funcionamento do sistema de arrefecimento e sua operação seguem o seguinte escopo:

O Ponto A, linha azul com setas da Figura 36, representa a linha de alimentação (linha A) do fluido refrigerante, no caso a água, das UMAr. A água circula ininterruptamente para reduzir a temperatura de operação dos módulos PV ao longo do dia, sendo fornecida pela linha do enrocamento da UHE. O calor armazenado nos módulos PV devido ao aquecimento solar e de operação é removido pelo fluido por meio de troca de calor pelo processo de convecção forçada;

- A interligação física entre duas UMAr é feita por uma mangueira flexível, já que o sistema é interligado em série de dois, ou seja, o fluido fornecido pela linha A circula pela serpentina da primeira unidade, em seguida, entra na segunda unidade, circulando por meio da serpentina até ser descartada;

- O Ponto D, linha vermelha com setas da Figura 36, representa a linha de descarga (linha D), que conduz o fluido refrigerante da saída da segunda unidade arrefecedora até o canal de escoamento da UHE;

- As UMAr, modelo A do tipo chapa tubo, são instaladas nas superfícies inferiores e fixadas na estrutura do quadro metálico dos módulos PV do string de teste. Cada módulo PV recebe uma unidade modular; e

- Os módulos PV do string de comparação não recebem UMAr, uma vez que são utilizados para analisar e comparar a temperatura de operação e produção de energia elétrica ao longo do dia, de modo a evidenciar o impacto da utilização de equipamento de arrefecimento em UFV.

\subsubsection{Sistema de supervisão e monitoramento de temperatura do protótipo de UFVa}

O sistema de arrefecimento do string de teste possui um medidor de vazão de água e um sensor PT-100, instalado na entrada da linha A, e um segundo sensor, também PT100, instalado no fim da linha D, após a última série de UMAr, para 
supervisão e monitoramento das temperaturas do fluido refrigerante fornecida a uma vazão média de $11,0 \mathrm{~m} 3 / \mathrm{h}$ e velocidade de $1,08 \mathrm{~m} / \mathrm{s}$. Tanto a vazão quanto a velocidade de fornecimento do fluido, variam ao longo do ano com a cota do reservatório de água a montante da UHE-ILS. Além disso, a temperatura de entrada do fluido dependerá da temperatura da água do enrocamento e do comprimento e exposição ao sol da linha principal de alimentação e de saída da temperatura de operação dos módulos PV. Esses sensores e o medidor de vazão, com seus códigos e descrições podem ser vistos na Tabela VIII e Anexo B.

O sistema de medição de temperatura dos módulos PV dos strings de teste e comparação consiste em 16 sensores do tipo termoresistências PT-100, ver Figura 54, com sinal de saída compatível com o datalogger, instalados nos módulos PV (arrefecido e não arrefecido) e câmera termovisora, ver Figura 55. Estes têm como intuito aferir e registrar as temperaturas ao longo do dia dos módulos PV, arrefecidos e não arrefecidos, auxiliando os testes e a determinação do desempenho do protótipo de UFVa. Os dados medidos nos sensores PT-100 são coletados e armazenados em um equipamento do tipo Datalogger.

A disposição dos sensores, do tipo PT-100, são idênticas nos módulos PV e local de posicionamento dos strings, ver Figura 37 , no qual cada um dos strings recebe oito sensores instalados em quatro módulos PV selecionados de forma a entender o comportamento da temperatura ao longo do sistema de arrefecimento. Assim dois módulos encontram-se no início e dois no meio do string, usando como referência o inicio e o fim da linha A. Além disso, um sensor PT100 de cada string serve redundância, sendo utilizado caso algum dos sensores apresente problema durante os testes. 


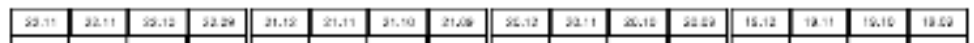

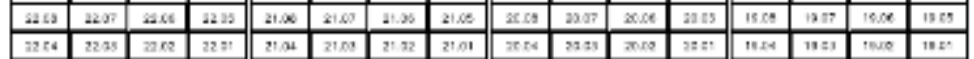

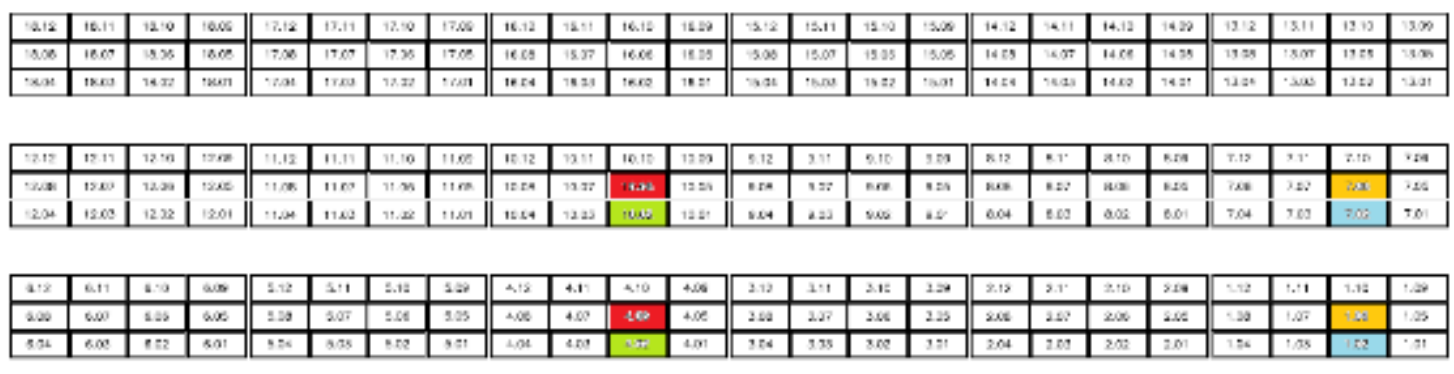

Figura 37 - Identificação dos módulos PV com sensores PT-100.

Para cada módulo, arrefecido e não arrefecido, é fixado um sensor na região central, Sensor Meio ( $\mathrm{S}_{\mathrm{M}}$ ), e um segundo, Sensor Ponta (SP), com disposição e método de fixação idêntica aos descritos na U.P.

Na Tabela VIII estão descritos os códigos e local de instalação de todos os PT-100.

Tabela VIII - Lista de códigos de identificação dos sensores de temperatura PT100 e local de instalação.

\begin{tabular}{|c|c|c|c|c|c|}
\hline $\begin{array}{c}\text { Posição do } \\
\text { String }\end{array}$ & $\begin{array}{l}\text { Local de } \\
\text { Instalação }\end{array}$ & $\begin{array}{c}\text { Posição } \\
\text { PT100 }\end{array}$ & $\begin{array}{l}\text { Código } \\
\text { PT100 } \\
\end{array}$ & $\begin{array}{c}\text { Identificação } \\
\text { do Cabo }\end{array}$ & Obs. \\
\hline \multirow{2}{*}{ Comparação } & Módulo PV & $\mathrm{S}_{\mathrm{m}}$ & $1.02 . \mathrm{M}$ & N12N & \\
\hline & 1.02 & $S_{p}$ & 1.02.P & N12S & Redundância \\
\hline \multirow{2}{*}{ Comparação } & Módulo PV & $S_{m}$ & 1.06.M & $\mathrm{N} 16 \mathrm{~N}$ & \\
\hline & 1.06 & $S_{p}$ & 1.06.P & N16S & - \\
\hline \multirow{2}{*}{ Comparação } & Módulo PV & $\mathrm{S}_{\mathrm{m}}$ & 4.02.M & N42N & . \\
\hline & 4.02 & $S_{p}$ & $4.062 \mathrm{P}$ & N42S & - \\
\hline \multirow{2}{*}{ Comparação } & Módulo PV & $\mathrm{S}_{\mathrm{m}}$ & 4.06.M & $\mathrm{N} 46 \mathrm{~N}$ & . \\
\hline & 4.06 & $S_{p}$ & 4.06.P & N46S & - \\
\hline \multirow{2}{*}{ Teste } & Módulo PV & $\mathrm{S}_{\mathrm{m}}$ & 7.02.M & S72N & - \\
\hline & 7.02 & $S_{p}$ & 7.02.P & S72S & Redundância \\
\hline \multirow{2}{*}{ Teste } & Módulo PV & $\mathrm{S}_{\mathrm{m}}$ & 7.06.M & S76N & - \\
\hline & 7.06 & $S_{p}$ & 7.06.P & S76S & - \\
\hline \multirow{2}{*}{ Teste } & Módulo PV & $\mathrm{S}_{\mathrm{m}}$ & 10.02.M & S102N & - \\
\hline & 10.02 & $S_{p}$ & 10.02.P & S102S & - \\
\hline \multirow{2}{*}{ Teste } & Módulo PV & $\mathrm{S}_{\mathrm{m}}$ & $10.06 \mathrm{M}$ & S106N & - \\
\hline & 10.06 & & 10.06.P & S106S & - \\
\hline Teste & Linha A & $\begin{array}{l}\text { Inicio } \\
\text { linha A }\end{array}$ & $\begin{array}{c}\text { Entrada } \\
\text { Água }\end{array}$ & $4 N$ & - \\
\hline Teste & Linha B & $\begin{array}{l}\text { Fim } \\
\text { linha D D }\end{array}$ & $\begin{array}{l}\text { Saída } \\
\text { Áqua }\end{array}$ & $4 S$ & - \\
\hline
\end{tabular}

Uma câmera termovisora é utilizada para medir e verificar a distribuição das temperaturas dos módulos PV e UMAr. em dia selecionado aleatoriamente. A lista 
de equipamentos do sistema de medição de temperaturas do protótipo de UFVa pode ser visto na Tabela IX.

Tabela IX - Lista de equipamentos do sistema de medição de temperatura do protótipo de UFVa.

\begin{tabular}{lc}
\hline \multicolumn{1}{c}{ Equipamento } & Qde \\
\hline Datalogger & 1 \\
Porta expansora do datalogger & 5 \\
Sensor de temperatura: & 16 \\
Câmera Termovisora & 1 \\
\hline
\end{tabular}

\subsection{TESTES EMPÍRICOS E ANÁLISE DOS DADOS}

\subsubsection{Sistema de arrefecimento}

Os testes empíricos, as supervisões e monitoramento de operação das temperaturas do protótipo de UFVa compreendem quatro períodos distintos determinados pela vazão média $\left(Q_{\text {méd}}\right)$ de fluido do sistema de alimentação do protótipo de UFVa ao longo do dia, ver Tabela X, totalizando quatorze dias de medições, nos quais foram analisados os dados das leituras de temperatura dos módulos PV selecionados dos strings de teste e comparação, vazão de água do sistema de arrefecimento e a produção de energia elétrica de cada string para entendimento da operação e determinação do desempenho de uma UFV arrefecida.

Tabela X - Períodos de dias analisados.

\begin{tabular}{|c|c|c|c|}
\hline Período & $\begin{array}{l}\text { Código do } \\
\text { Período }\end{array}$ & $\mathrm{N}^{\circ}$ dias & $Q_{\text {méd }}(\mathrm{I} / \mathbf{s})$ \\
\hline $\begin{array}{c}08 / 06 / 2015 a \\
11 / 06 / 2015\end{array}$ & P1 & 4 & $Q>3,0$ \\
\hline $\begin{array}{c}13 / 06 / 2015 \mathrm{a} \\
14 / 06 / 2015\end{array}$ & P2 & 2 & $Q=0$ \\
\hline $\begin{array}{c}16 / 06 / 2015 a \\
19 / 06 / 2015\end{array}$ & P3 & 4 & $2,0<Q<2,7$ \\
\hline $\begin{array}{c}27 / 06 / 2015 a \\
30 / 06 / 2015\end{array}$ & P4 & 4 & $1,5<Q<1,7$ \\
\hline
\end{tabular}

Na Figura 38(a) e (b) são apresentadas para cada período (P1, P2, P3 e P4), as temperaturas $\left({ }^{\circ} \mathrm{C}\right)$ de operação para dois módulos $\mathrm{PV}$, um arrefecido e outro não arrefecido, e a vazão de água (1/s) do sistema arrefecimento, no qual é possível observar que, em maiores vazões, $P 1 \operatorname{com} Q>3,0 \mathrm{l} / \mathrm{s}$, a diferença de temperatura entre os módulos PV são as maiores e mais constantes ao longo do dia, com 
diferença acima de $22,0^{\circ} \mathrm{C}$, já no período $\mathrm{P} 2$, no qual o fornecimento de água é interrompido $(Q=0)$ essa diferença é inferior a $8,0^{\circ} \mathrm{C}$. As temperaturas dos módulos PV com e sem UMAr não são as mesmas devido à presença de água na serpentina e pela superfície inferior da UMAr ser metálica, aumentando as trocas de calor com o meio, ou seja, neste caso a UMAr atua como trocador de calor do tipo aletado.

Além disso, é possível verificar na Figura 38 (c) que as temperaturas do módulo PV com UMAr oscilam menos e com menores amplitudes, ao longo do dia, essa condição se deve a capacidade térmica da água ser maior que a do ar. 


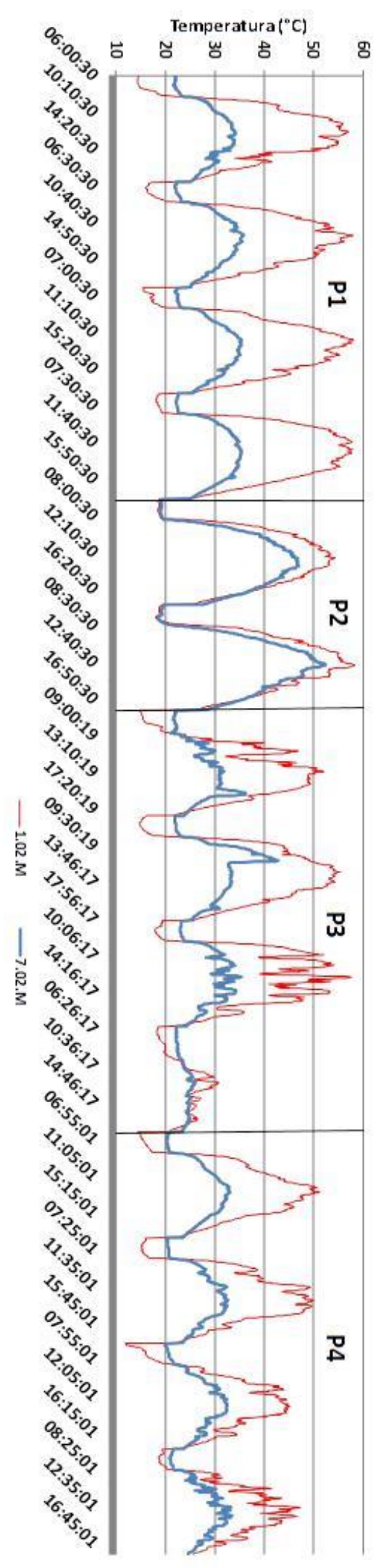

(a)

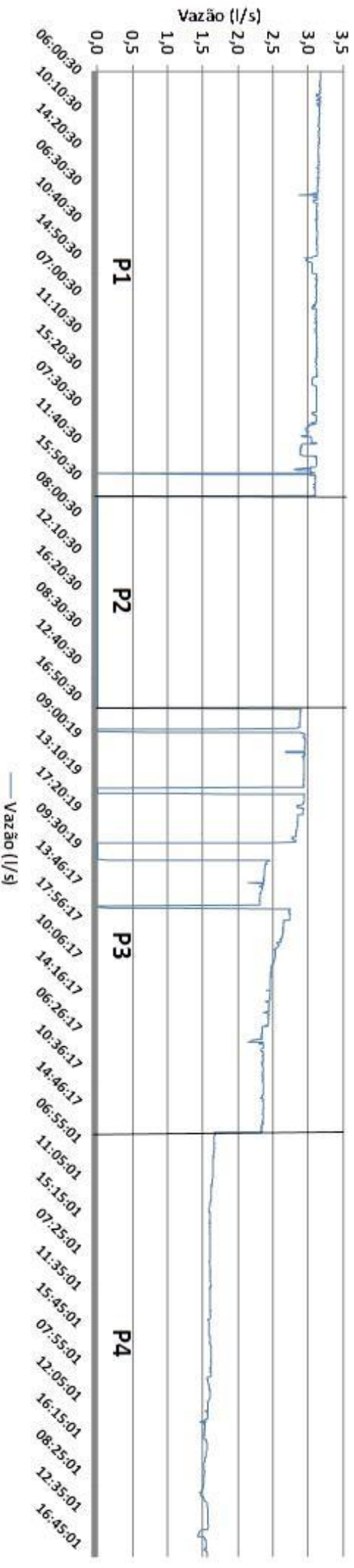

(b)

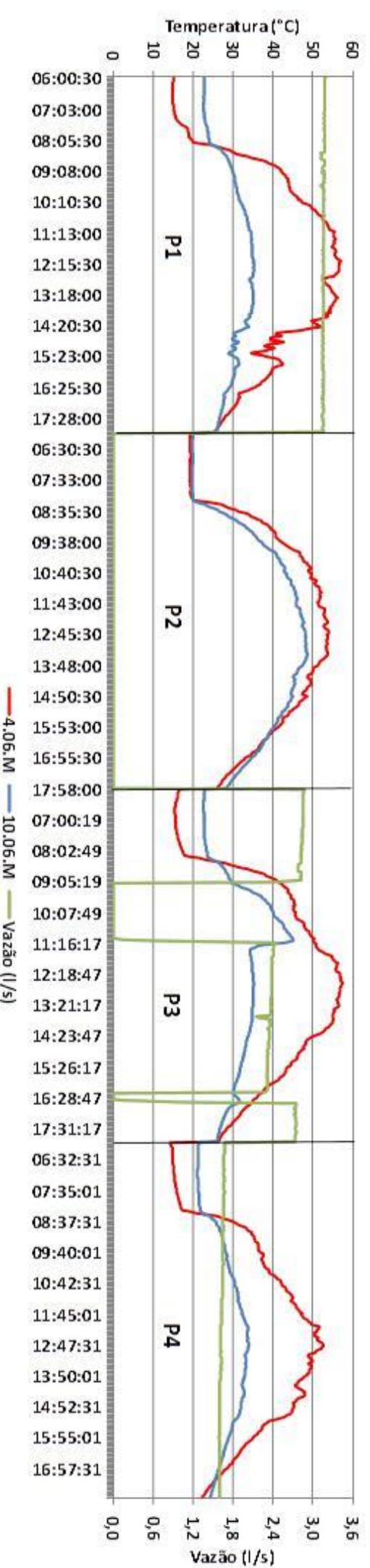

(c)

Figura 38 - Período de teste de operação (a) Temperatura dos módulos PV 1.02.M e 7.02.M, (b) Vazão do sistema de arrefecimento e (c) Temperatura e vazão de um dia de cada período . 
Pela observação e análise das temperaturas do período P3 fica evidente o impacto do fornecimento de água ao sistema de arrefecimento na diferença de temperatura $(\Delta T)$ entre um módulo PV com e sem UMAr, ver Figura 39. Pois quando interrompido o fornecimento de água, $Q=0$, no instante $09 \mathrm{~h} 10 \mathrm{~min} 19 \mathrm{ss}$, o $\Delta \mathrm{T}$ é de $12,99^{\circ} \mathrm{C}$ e ao longo do tempo que permanece interrompido, a diferença de temperatura diminui rapidamente alcançando patamares inferiores a $6,00^{\circ} \mathrm{C}$, com $\Delta T$ mínimo de $5,92^{\circ} \mathrm{C}$ e médio de $7,93^{\circ} \mathrm{C}$. Com o restabelecimento da vazão, no instante $11 \mathrm{~h} 16 \mathrm{~min} 17 \mathrm{ss}$, o $\Delta \mathrm{T}$ volta a aumentar com o declínio da temperatura do módulo PV com UMAr enquanto o não arrefecido permanece em constante aumento de temperatura, ver Figura 39(b). Em termos comparativos, para o mesmo período de tempo, entre os dias 08/06/2015, ver Figura 39(a), e 17/06/2015, ver Figura 39(b), o $\Delta \mathrm{T}$ médio para o primeiro foi de $16,80^{\circ} \mathrm{C}$ com máxima de $22,11^{\circ} \mathrm{C}$ e mínima de $12,99^{\circ} \mathrm{C}$, essa mínima diferença ocorre no instante $09 \mathrm{~h} 13 \mathrm{~min} 00 \mathrm{ss}$, semelhante à máxima diferença do segundo dia, na qual ambas os $\Delta \mathrm{T}$ máximos foram de $12,99^{\circ} \mathrm{C}$.

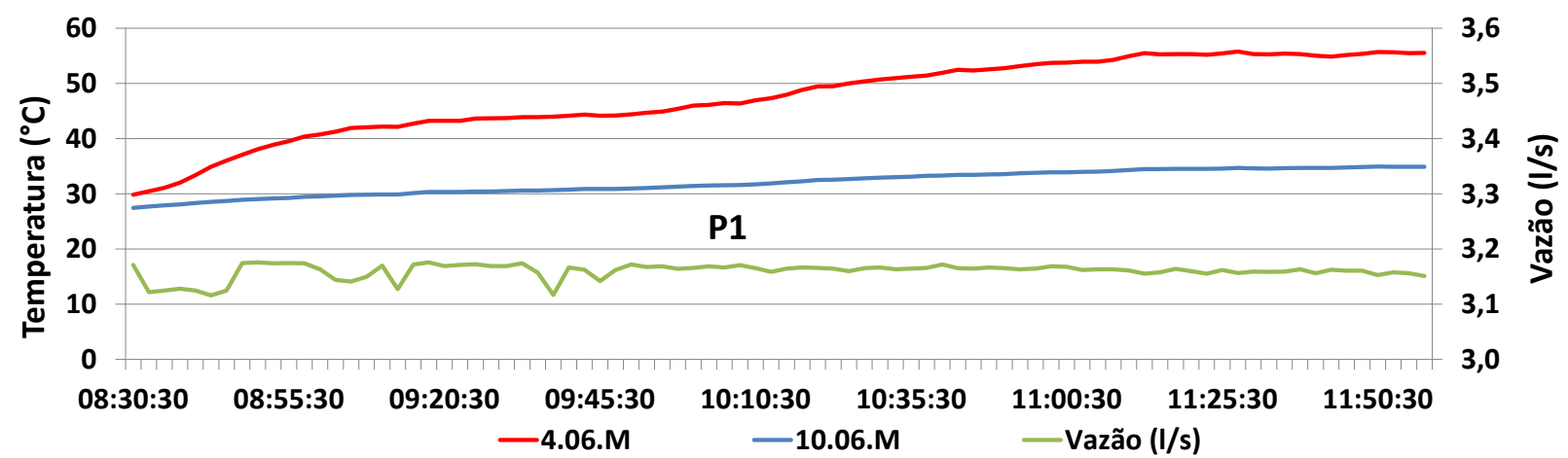

(a)

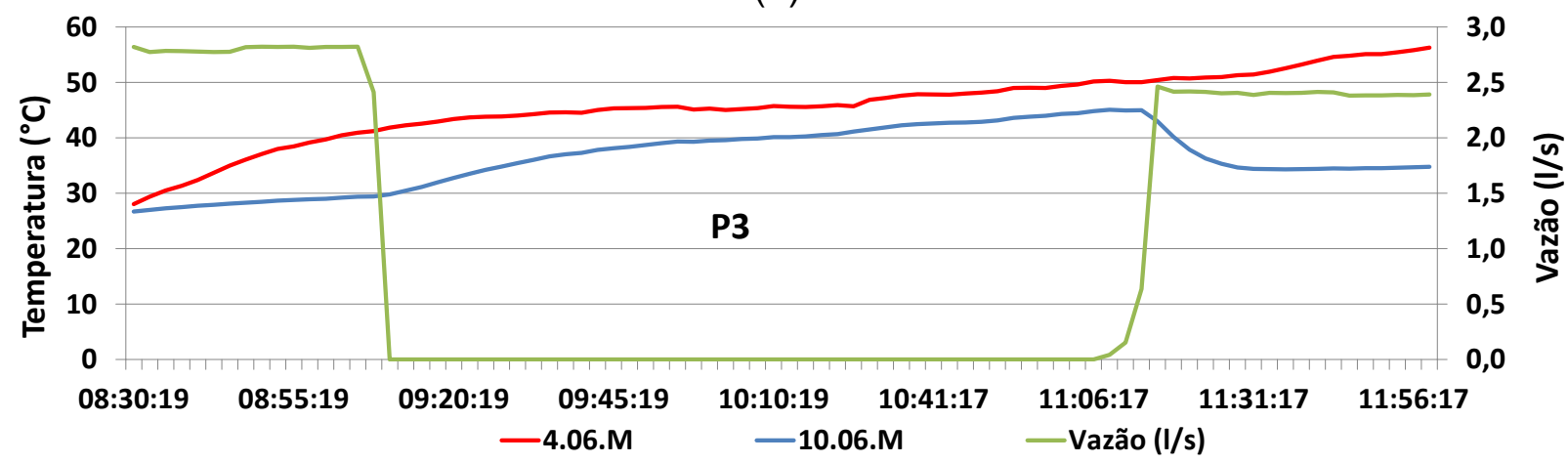

(b)

Figura 39 - Impacto do fornecimento contínuo de água no sistema de arrefecimento. (a) Fornecimento contínuo 08/06/2015 e (b) Fornecimento interrompido 17/06/2015.

Os testes empíricos e as supervisões e monitoramento da operação do sistema de alimentação e descarga de água compreendem o período entre os dias 
08/06/2015 e 11/06/2015, no qual a alimentação operou com Q médio superior a 3,0 $\mathrm{l} / \mathrm{s}$, exceto num breve período do dia $11 / 06 / 2015$, quando houve o bloqueio do fornecimento de água, ver Figura 40 (b), neste instante a Ts aumentou $0,85^{\circ} \mathrm{C}$, valor aparentemente baixo, mas, se comparado a intervalos sucessivos com fornecimento constante, este é $4150 \%$ maior.

A Q média dos dias do período $P 1$ variou entre 3,04 a $3,16 \mathrm{l} / \mathrm{s}$. No instante de $Q$ máxima, $3,18 \mathrm{l} / \mathrm{s}$, a velocidade na linha $A$ foi de $1,62 \mathrm{~m} / \mathrm{s}$ e Re de 80.978 , escoamento turbulento $(10.000<R e)$.

Analisando apenas as temperaturas que compreendem o período entre as 11 h00min às $15 \mathrm{~h} 00$ min do período $\mathrm{P} 1$, que corresponde às maiores $\mathrm{TPv}, \mathrm{Te} \mathrm{e} T \mathrm{~s}$, ver Figura 40(c), observamos que sucessivas temperaturas apresentam variação máxima de $0,19^{\circ} \mathrm{C}$ e $0,37^{\circ} \mathrm{C}$ com média de $0,02^{\circ} \mathrm{C}$ e $0,04^{\circ} \mathrm{C}$ para a Te e Ts, respectivamente.

Assim, verifica-se que a amplitude da variação das Te e Ts ao longo de um dia de operação são pequenas, caso não haja bloqueio do fornecimento de água. Mas por outro lado, se o fornecimento é interrompido a TPV com UMAr aumenta aproximando-se da TPV sem UMAr apresentando $\Delta T$ média $8,87^{\circ} \mathrm{C}$ inferior em relação ao período com fornecimento contínuo. 


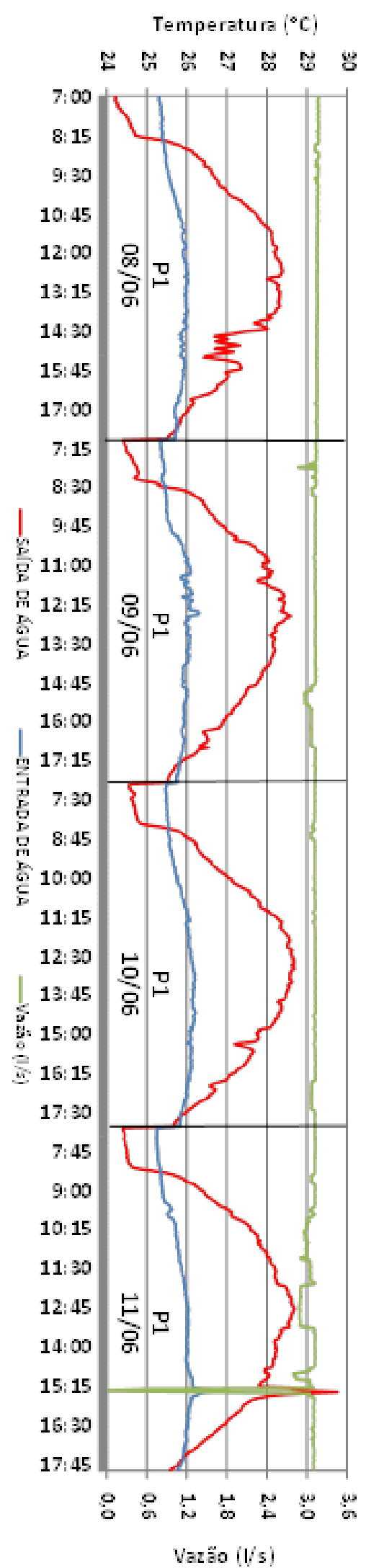

(a)

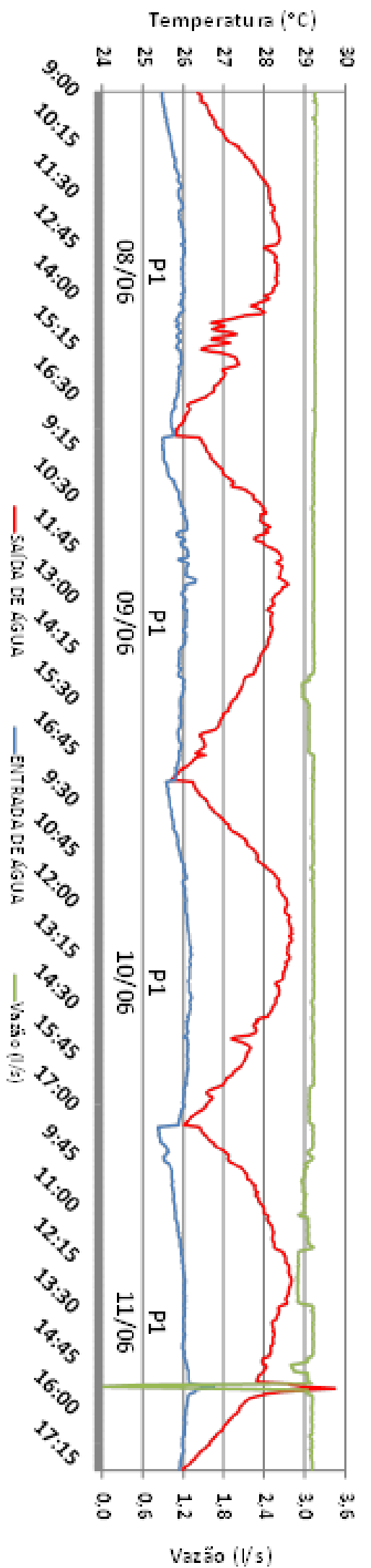

(a)

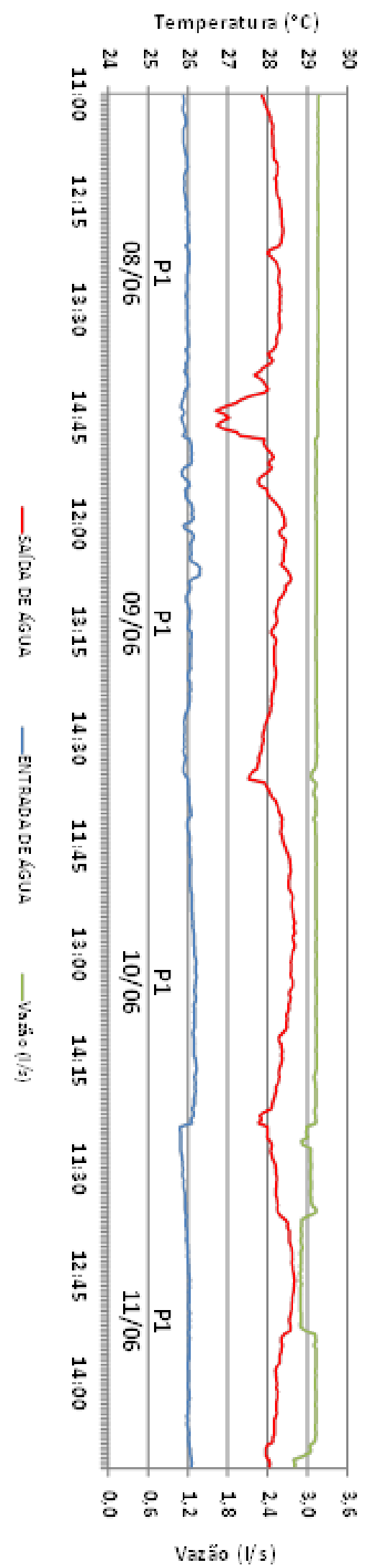

(a)

Figura 40 - Temperatura de entrada, saída e vazão de água do período $P 1$. (a) 07h00min às $18 \mathrm{~h} 00 \mathrm{~min}$, (b) $09 \mathrm{~h} 00 \mathrm{~min}$ às $17 \mathrm{~h} 30 \mathrm{~min}$ e (c) $11 \mathrm{~h} 00 \mathrm{~min}$ às $15 \mathrm{~h} 00 \mathrm{~min}$. 
Durante os períodos de trabalhos de supervisão e monitoramento in loco, observou-se que a incidência de radiação solar direta iniciava a partir das 07h45min incidindo na primeira fileira de módulos PV do string de comparação, sendo a completa incidência em ambos os strings do estudo, após as 09h00min. Isto ocorre devido ao local de instalação do SS da UFV estar à jusante da barragem da UHEILS que sombreia os strings nas primeiras horas da manhã, este efeito impacta diretamente na produção de energia elétrica uma vez que partes dos módulos recebem radiação direta e outra apenas a indireta.

Verificou-se que ao longo de um dia de operação a temperatura dos módulos PV do string de comparação apresenta temperaturas noturnas inferiores às temperaturas dos módulos PV do string de teste, que ocorre por não haver radiação solar, temperaturas ambientes amenas em relação ao dia e pela capacidade térmica da água circulante ser maior que a do ar, ou seja, durante a noite a água perde menos calor do que o ar mantendo a sua temperatura e dos módulos PV maiores que a temperatura do ar ambiente.

Após o nascer do sol, a partir das 06h00min00ss, e posteriormente ao início da produção de energia elétrica registrado nos inversores, a partir das 07h15min00ss, as TPV aumentam, no caso dos módulos PV do string de comparação, isso ocorre mais acentuadamente ultrapassando a TPv do string de teste no início da manhã, às 08h15min, mantendo-se superior até o final da tarde, às 17h30min próximo a termino da produção de energia elétrica, ver Figura 41, quando o ângulo de incidência da radiação solar direta nos módulos PV é muito grande, ou seja, com o sol se pondo no horizonte.

Vale destacar que o horário da inversão das temperaturas dos módulos PV não arrefecidos em relação aos arrefecidos varia em relação à vazão de água do sistema de arrefecimento e em relação a eventos climáticos como chuvas, aparecimento de nuvens densas por longo período durante o dia e queda da temperatura ambiente. Essas características operativas evidenciam a sensibilidade das TPV com e sem UMAr, evidenciando a importância e o impacto do fornecimento contínuo de água e das condições de incidência da radiação solar ao longo do dia. 


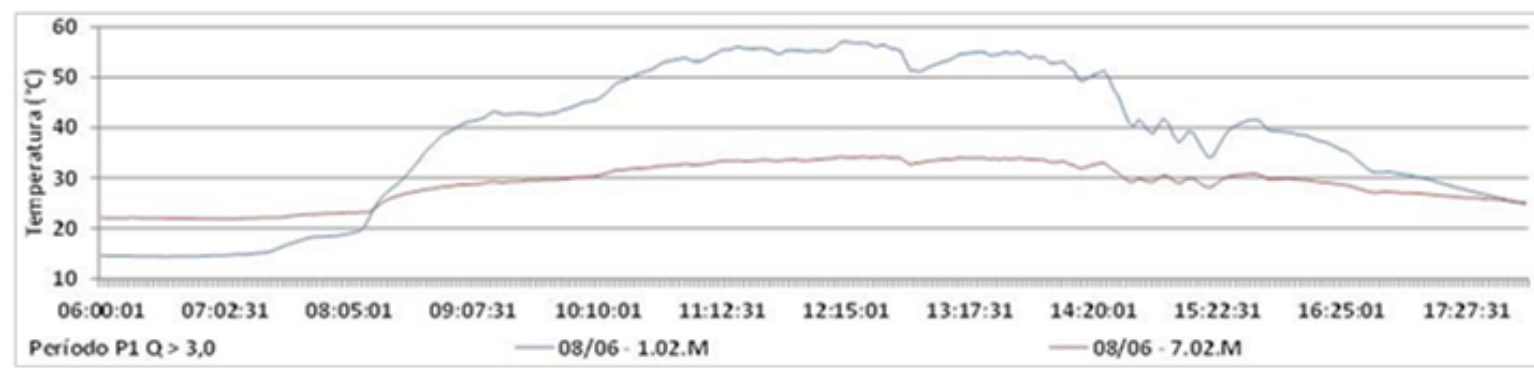

(a)

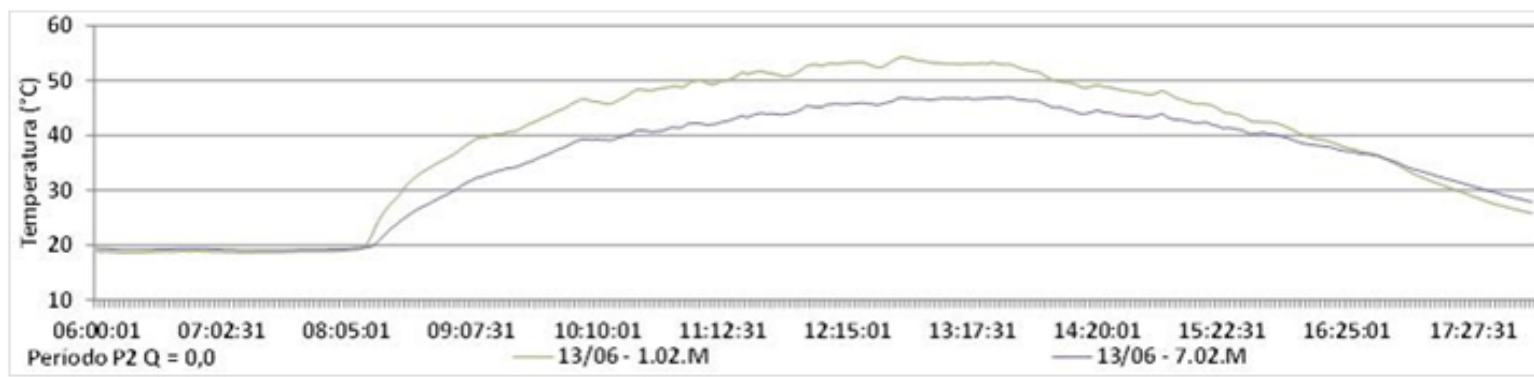

(b)

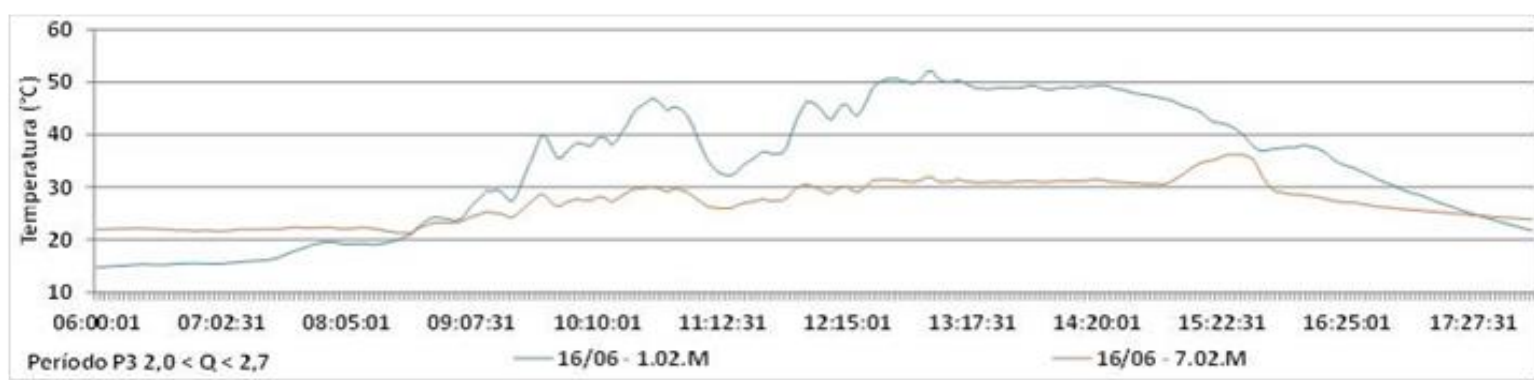

(c)

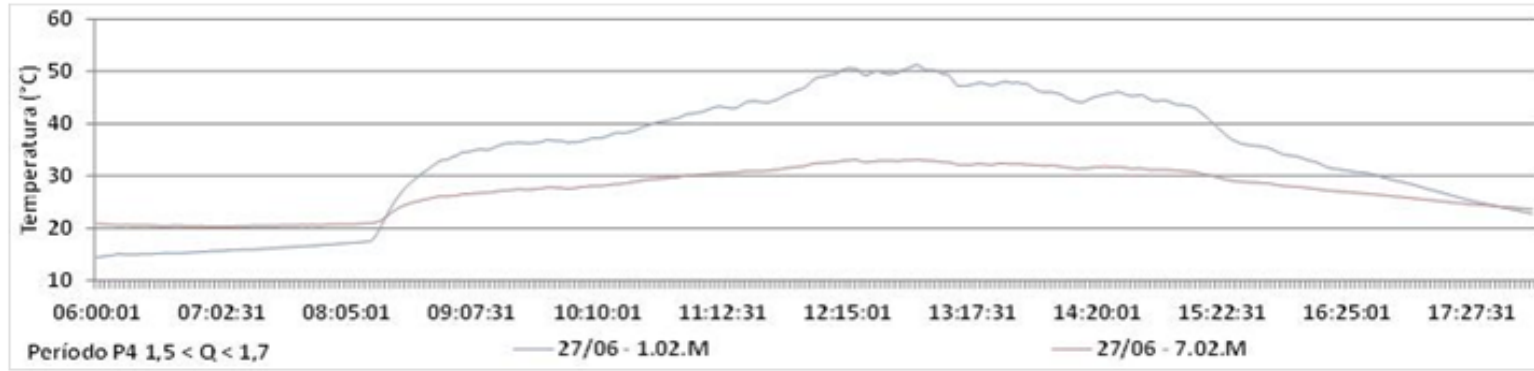

(d)

Figura 41 - Temperatura de operação dos módulos PV, 1.02.M e 7.02.M, no primeiro dia de cada período. (a) P1, (b) P2, (c) P3 e (d) P4.

Assim, o estudo minucioso e sistemático do protótipo de UFVa se dá pela análise das temperaturas de operação, produção de energia elétrica e das características climáticas locais para os dias de operação do período $\mathrm{P} 1$, único período que apresentou fornecimento de fluido primordialmente continuo e com vazão superior a 3,0 l/s, valor mínimo de projeto. Além disso, os horários diários para análise 
compreendem o período entre as 09h00min e 17h30min, de modo a garantir que a radiação solar esteja incidindo diretamente nos dois strings do estudo.

\subsubsection{Análise da temperatura dos módulos PV no Período P1}

Os módulos PV do string de comparação apresentam aumento acentuado de temperatura após as 09h00min atingindo patamares de temperaturas de operação superiores a $45,0^{\circ} \mathrm{C}$ e mantendo-se acima deste até as $15 \mathrm{~h} 00 \mathrm{~min}$. Esta temperatura é um importante indicador de operação do protótipo de UFVa, pois representa o limite inferior NOCT da célula.

O período com temperaturas acima do NOCT iniciam e terminam, em média, às 09h43min00ss e às 15h14min00ss, respectivamente, ou seja, em média os módulos PV operam 05h31min15ss com temperaturas acima do NOCT. Neste mesmo período os módulos PV do string de teste operam com temperaturas inferiores a $37,0^{\circ} \mathrm{C}, \mathrm{T}_{\operatorname{mín}}=8,0^{\circ} \mathrm{C}$ abaixo do NOCT. Em relação às $\mathrm{T}_{\text {máx }}$ dos quatro dias analisados, estas iniciam e encerram, em média, às $12 \mathrm{~h} 08$ min00ss e as 12h43min37ss, respectivamente, ou seja, o período com maiores temperaturas de operação coincidem com o período de pico de potência dos strings e da radiação solar local, ver Tabela XI.

Tabela XI - Períodos e horários de ocorrência de temperaturas máximas e maiores que $45,0^{\circ} \mathrm{C}$.

\begin{tabular}{ccccccc}
\hline \multirow{2}{*}{ Dia } & \multicolumn{3}{c}{ Temp. $\mathbf{~} \mathbf{4 5}^{\circ} \mathbf{C}$} & \multicolumn{3}{c}{ Ocorrência das Temp. Máx. } \\
\cline { 2 - 7 } & Início & Fim & Período & Início & Fim & Período \\
\hline 08/06/2015 & $09: 53: 00$ & $14: 33: 00$ & $04: 40: 00$ & $12: 13: 00$ & $12: 35: 30$ & $00: 22: 30$ \\
09/06/2015 & $09: 43: 00$ & $15: 00: 30$ & $05: 17: 30$ & $12: 00: 30$ & $12: 45: 30$ & $00: 45: 00$ \\
10/06/2015 & $10: 00: 30$ & $15: 50: 30$ & $05: 50: 00$ & $11: 55: 30$ & $12: 43: 00$ & $00: 47: 30$ \\
11/06/2015 & $09: 15: 30$ & $15: 33: 00$ & $06: 17: 30$ & $12: 23: 00$ & $12: 50: 30$ & $00: 27: 30$ \\
\hline Média & $09: 43: 00$ & $15: 14: 15$ & $05: 31: 15$ & $12: 08: 00$ & $12: 43: 37$ & $00: 35: 38$ \\
Máximo & $10: 00: 30$ & $15: 50: 30$ & $06: 17: 30$ & $12: 23: 00$ & $12: 50: 30$ & $00: 47: 30$ \\
Mínimo & $09: 15: 30$ & $14: 33: 00$ & $04: 40: 00$ & $12: 55: 30$ & $12: 35: 30$ & $00: 22: 30$ \\
\hline
\end{tabular}

Em relação às maiores $T_{P V}$ registradas nos dias do período $\mathrm{P} 1$, estas ocorrem entre as $12 \mathrm{~h} 03 \mathrm{~min} 00 \mathrm{ss}$ e as $12 \mathrm{~h} 25 \mathrm{~min} 00 \mathrm{ss}$. A maior $\mathrm{TPV}_{\mathrm{PV}} 59,97^{\circ} \mathrm{C}$ ocorreu no dia 11/06/2015 registrada no sensor 4.02.M do módulo PV no string de comparação, neste instante a menor $\mathrm{TPV}, 34,11^{\circ} \mathrm{C}$, ocorreu no sensor 7.06.P do módulo PV no 
string de teste, $\Delta \mathrm{T}_{\text {(máx-mín) }}$ de $25,86^{\circ} \mathrm{C}$, no caso do módulo $\mathrm{PV}$ com UMAr sua temperatura foi $10,89^{\circ} \mathrm{C}$ inferior a NOCT, já o módulo PV sem a UMAr operou $14,97^{\circ} \mathrm{C}$ acima da NOCT, ver Figura $42(\mathrm{a})$

Para os outros três dias, a $\Delta \mathrm{T}_{\text {(máx-mín) }}$ apresentou diferença superior a $23,5^{\circ} \mathrm{C}$, com máximas na faixa de 57,9 a $58,6^{\circ} \mathrm{C}$, enquanto as mínimas no mesmo instante ficaram entre 33,4 a $34,3^{\circ} \mathrm{C}$, ou seja, nos períodos de máxima temperatura de operação dos módulos PV, os do string de teste operaram sempre abaixo do NOCT enquanto os do string de comparação operaram sempre acima do NOCT.

Apenas para exemplificar, no final do período de análise diário, às 17h30min, são encontradas as menores diferenças de temperaturas de operação dos módulos PV. Estas são referentes ao instante $17 \mathrm{~h} 28 \mathrm{~min}$, no qual as maiores temperaturas de operação dos módulos PV do string de comparação ficam na faixa dos $30,0^{\circ} \mathrm{C}$ enquanto as do string de teste operam na faixa dos $25,0^{\circ} \mathrm{C}$. Neste instante, a diferença de temperatura entre os módulos PV com e sem UMAr variam entre 2,70 a $4,72^{\circ} \mathrm{C}$, ver Figura $42(\mathrm{~b})$. Essa pequena diferença já era esperada uma vez que ao final do dia a temperatura dos módulos PV do string de comparação são inferiores aos do string de teste. 


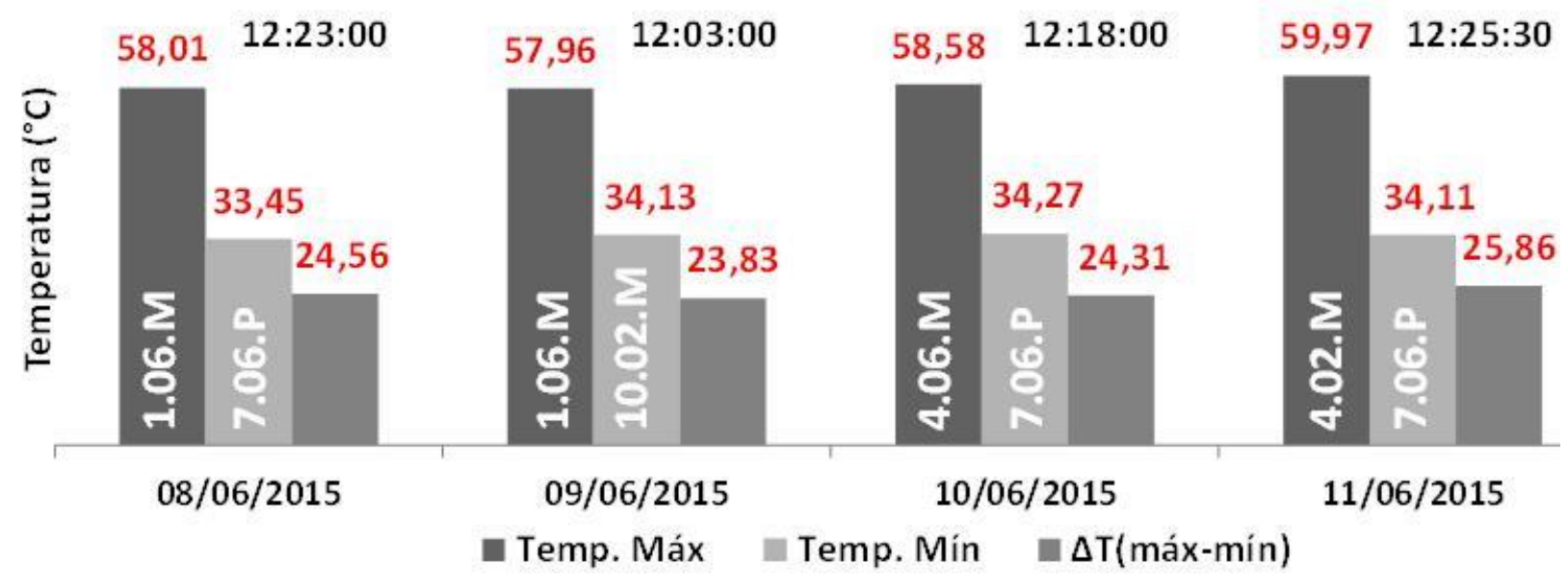

(a)

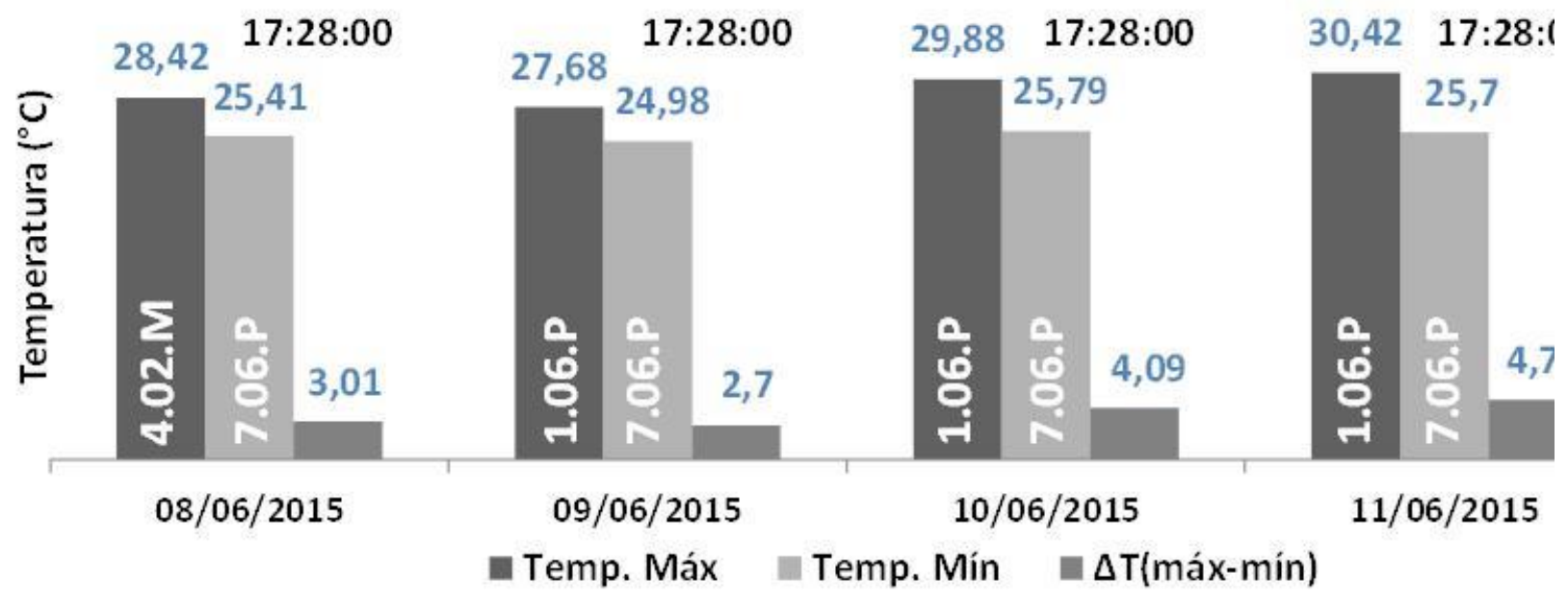

(b)

Figura 42 - Temperatura de operação dos módulos PV no Período P1. (a) Período com máxima diferença de temperatura e (b) Período com mínima diferença de temperatura.

Quanto à distribuição das $T_{\text {máx }}$ e $T_{\text {mín }}$ de operação de ambos os strings, ver Figura 43, as Tmáx ocorrem apenas nos módulos PV do string de comparação e por sua vez, as Tmín apenas nos módulos PV do string de teste.

Além disso, as Tmáx registradas ocorrem com maior frequência no módulo PV 1.06, na região do sensor $S_{M}$, e no módulo PV 4.02.M, também na região do sensor $S_{M}$. As Tmín registradas ocorrem quase que exclusivamente no módulo PV 7.06 na região do sensor de Sp. Essa recorrência, em relação às menores temperaturas, ver Figura 43, demonstram que o primeiro módulo PV da linha de série de dois das UMAr arrefece mais que a segunda, mas pela análise da Figura 44, verifica-se que a diferença de temperatura entre os módulos $\mathrm{PV}$ da primeira e segunda unidade da série é inferior $2,0^{\circ} \mathrm{C}$, diferença inferior a $\Delta T_{P V}$ que no caso dos módulos $P V$ sem 
UMAr alcançam mais de $3,5^{\circ} \mathrm{C}$ de diferença, ou seja, o sistema de arrefecimento operando em série apresenta diferenças de temperaturas inferiores às registradas pelos sensores de um mesmo módulo PV do string de comparação.

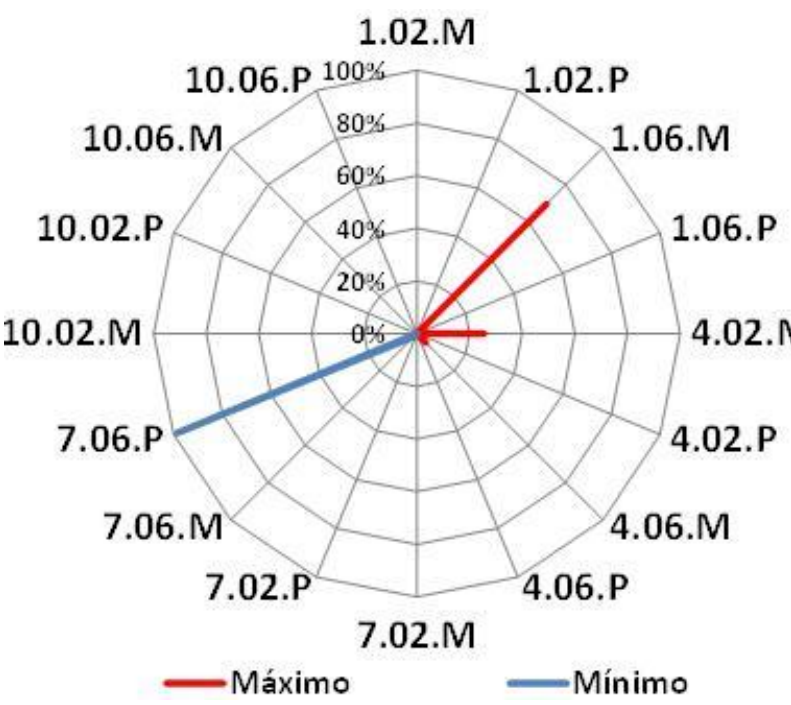

(a)

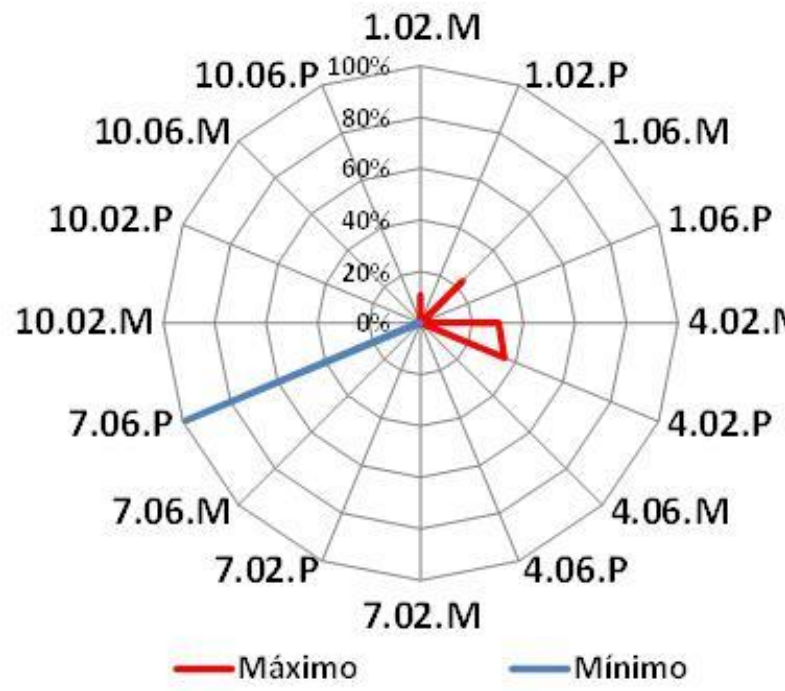

(c)

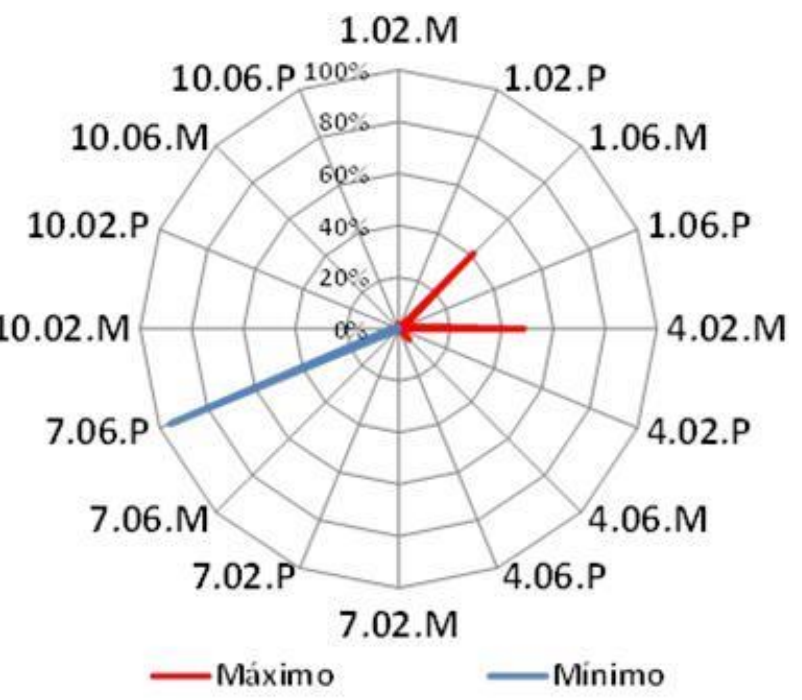

(b)

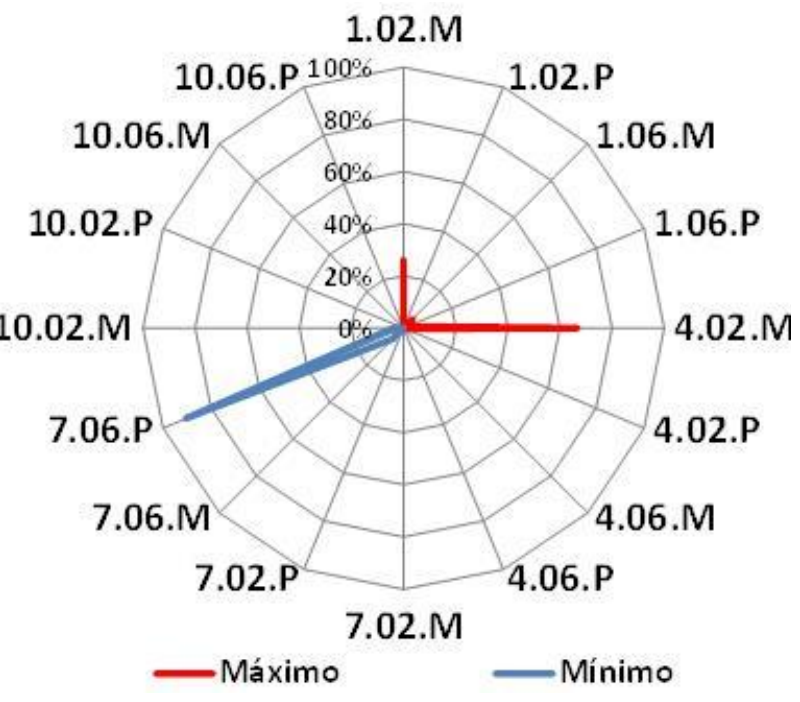

(d)

Figura 43 - Distribuição das máximas e mínimas temperaturas nos dias do período P1. (a) 08/06/2015, (b) 09/06/2015, (c) 10/06/2015 e (d) 11/06/2015. 


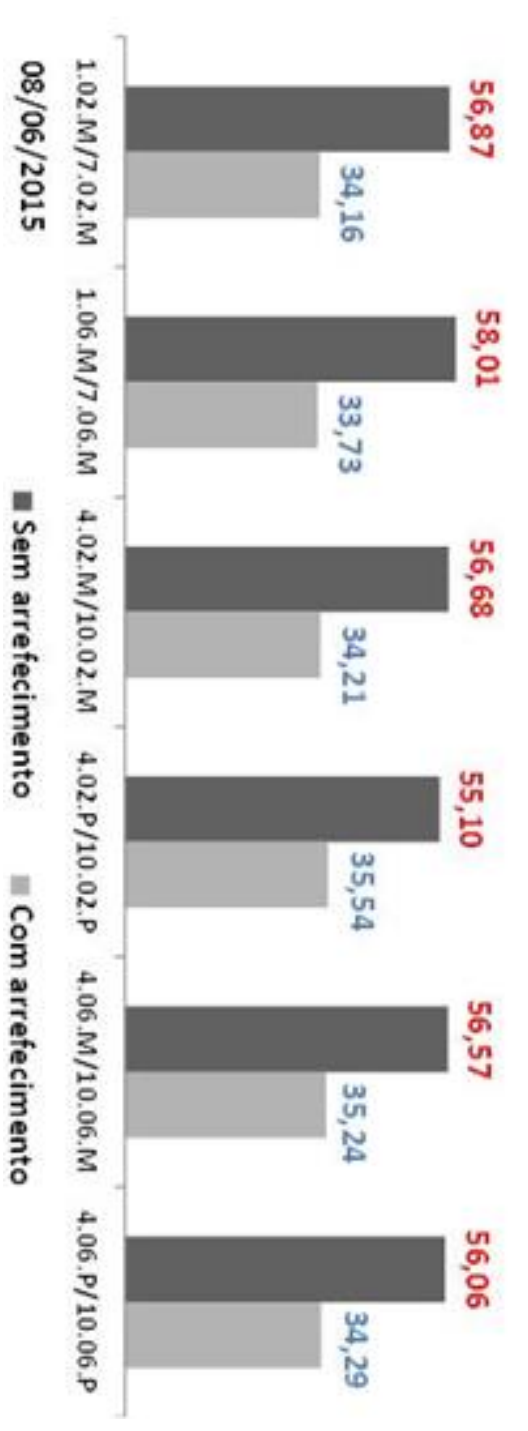

(a)

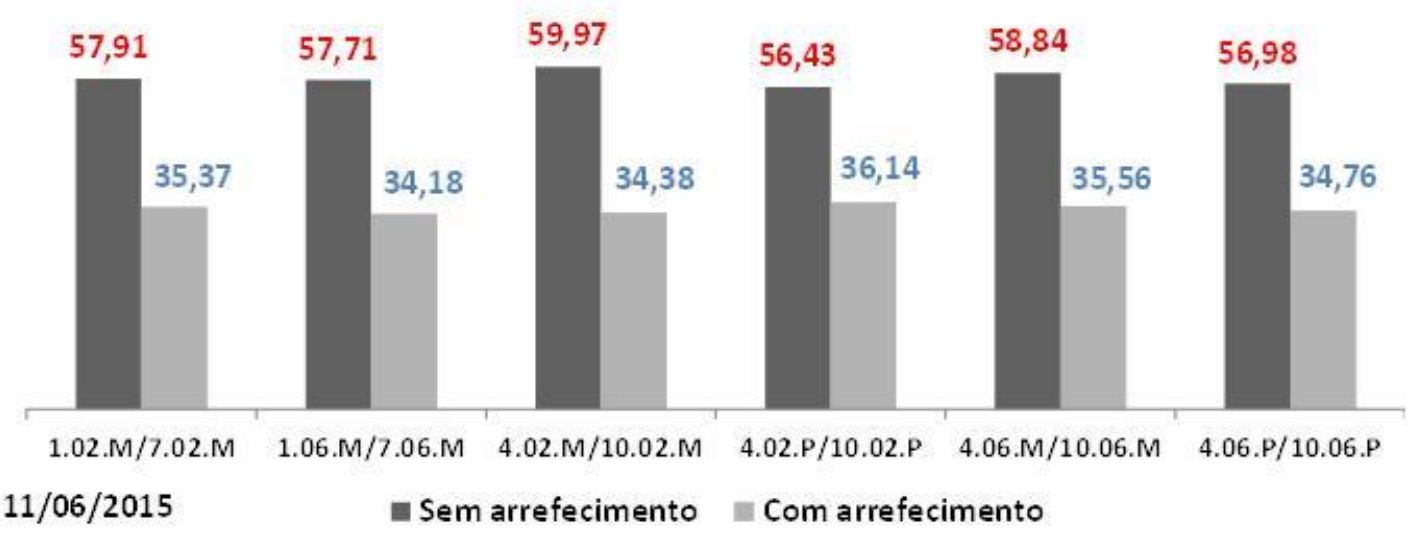

(d)

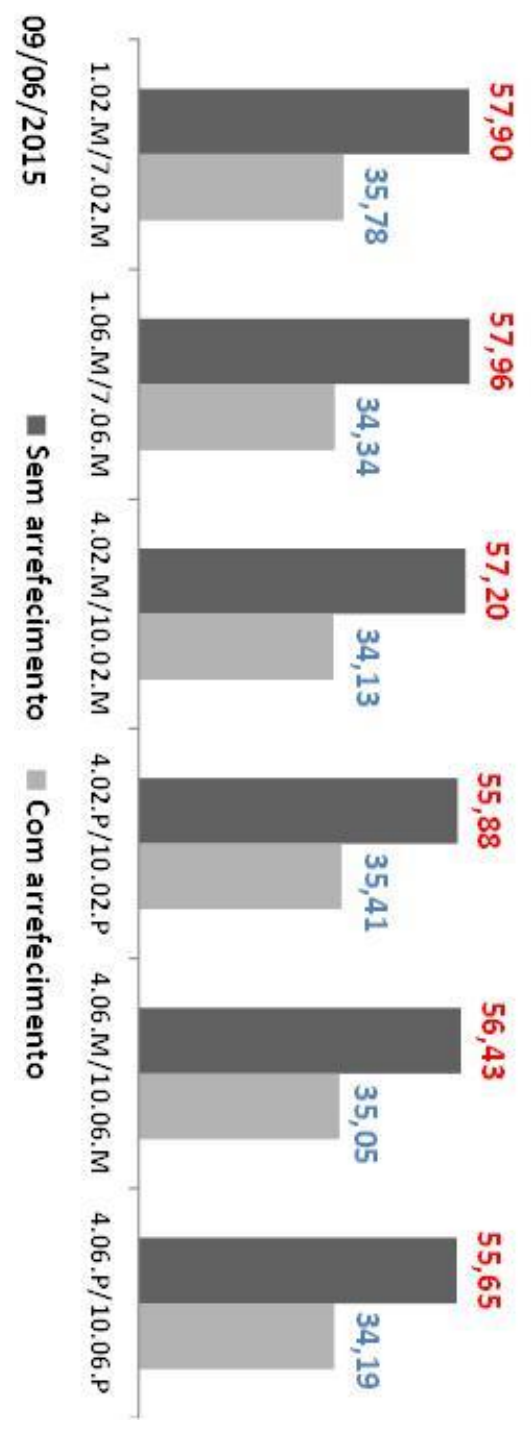

(b)

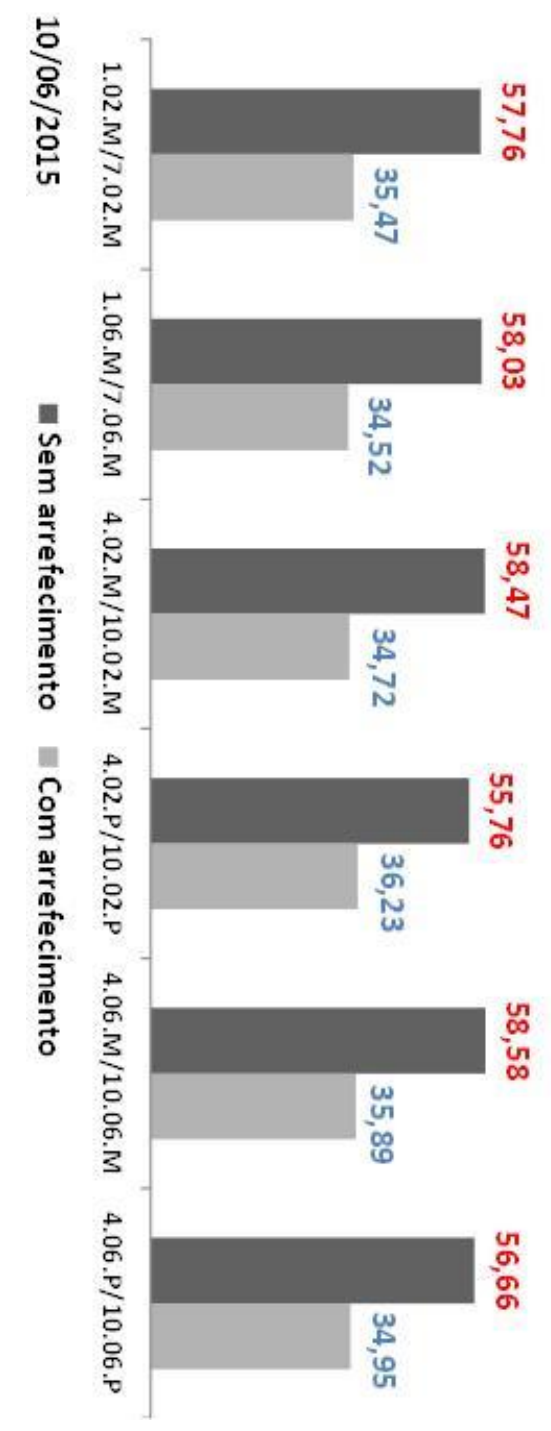

(c) 


\subsubsection{Análise da geração de energia elétrica para o Período P1}

Com a análise das curvas diárias de geração total de energia elétrica dos strings do estudo para um dia completo de operação, ver Figura 45(a), é possível verificar que a produção do string de comparação apresenta rendimento inferior ao string de teste, fato observado nos dados para os quatro dias apresentados. Esse string apresentou mínima de 55,0 kWh/dia e máxima de 56,0 kWh/dia, sendo que a produção máxima foi igual à mínima registrada no string de teste, que apresentou máxima de 59,0 kWh/dia. A média de geração nesses quatro dias para os strings de teste e comparação foram de 58,0 e 56,0 kWh/dia, respectivamente, uma produção média diária de 2,0 kWh/dia a mais para o string com sistema de arrefecimento. A diferença de geração de energia elétrica entre os strings não são equivalentes, já que o string de teste gerou 59,0 kWh/dia em ambos os dias 09/06/2015 e 10/06/2015, enquanto o string de comparação gerou 56,0 e 57,0 kWh/dia, respectivamente, uma diferença de 2,0 e 3,0 kWh/dia.

Quando analisada a geração de energia elétrica no período estabelecido para análise das temperaturas, das 09h00min00ss às 17h30min00ss, ver Figura 45(b), verificamos que o string de teste permanece, sem exceções, com a maior taxa de geração diária de energia elétrica apresentando média de 55,8kWh/dia, com máxima de 57,0 kWh/dia e mínima de 54,0 kWh/dia, enquanto o string de comparação apresenta média de 53,0kWh/dia, com máxima e mínima de 51,0 e $54 \mathrm{kWh} / \mathrm{dia}$, respectivamente. Para esse período a taxa média de ganho na geração de energia elétrica foi de $2,8 \mathrm{kWh} / \mathrm{dia}$.

Para salientar, como discutido e apresentado, o início da geração do string de comparação precede ao do string de teste, ver Figura 45(c), e mesmo assim apresenta taxas de geração inferiores.

No caso da Figura 45(b), a energia gerada antes das 09h00min, em ambos os strings, é descartada da consolidação do período, já na Figura 45(a) esta geração é incluída e como observado não é suficiente para garantir que o string de comparação apresente taxas de geração diária maiores que o string de teste, demonstrando que o sistema de arrefecimento garante um melhor rendimento da produção de energia elétrica no string. 


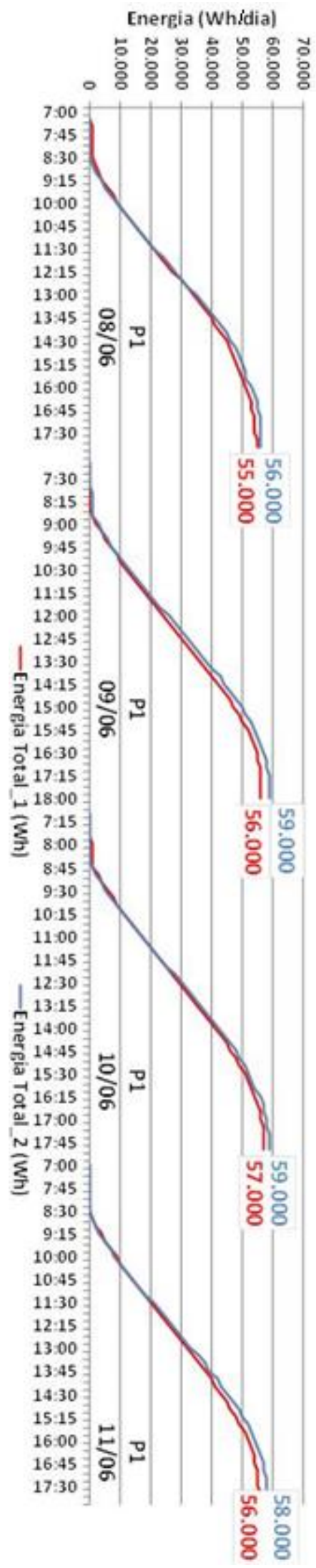

(a)

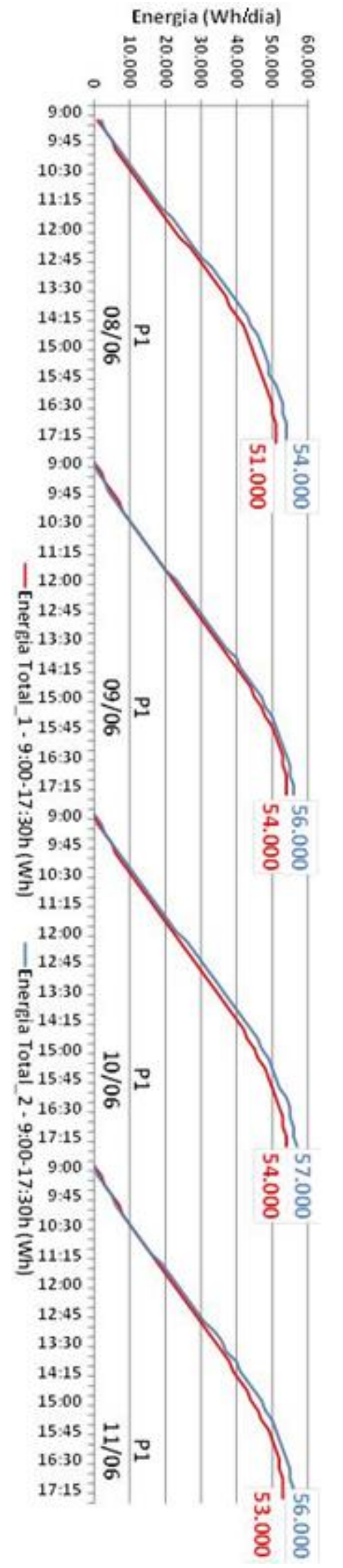

(b)

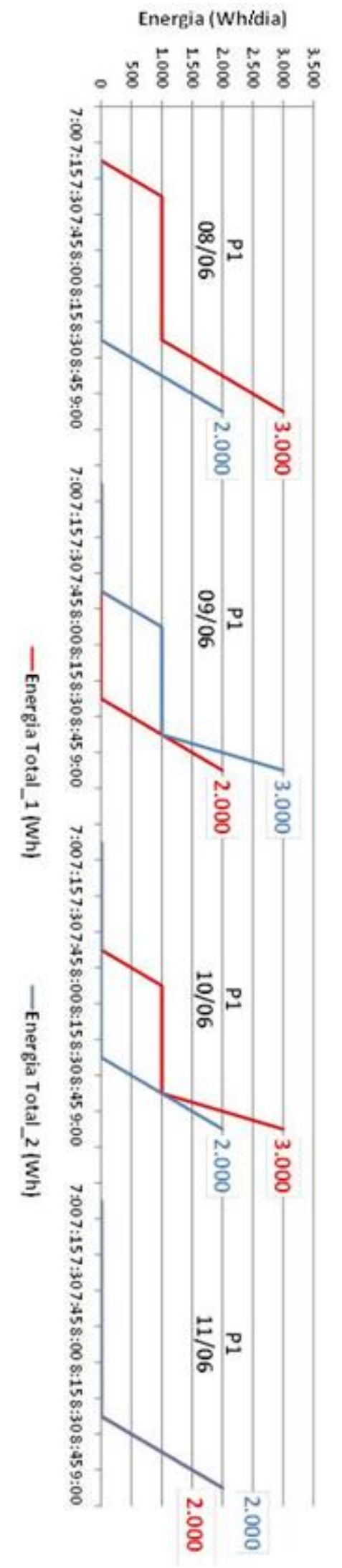

(c)

Figura 45 - Energia total $(\mathrm{Wh})$ dos strings para o período P1. (a) 07h00min às $18 \mathrm{~h} 00 \mathrm{~min}$ e (b) $09 \mathrm{~h} 00 \mathrm{~min}$ e $17 \mathrm{~h} 30 \mathrm{~min}$ e (c) $07 \mathrm{~h} 00 \mathrm{~min}$ às $9 \mathrm{~h} 00 \mathrm{~min}$. 
No caso das curvas diárias de potência (W), de ambos os strings, ver Figura 46, é possível verificar que a potência máxima instantânea do string de teste é superior ao do string de comparação em todos os dias analisados. A máxima potência registrada no período, 8,901 kWp ocorreu no dia 09/06/2015 às $12 \mathrm{~h} 15$ min00ss, 5,2\% acima da registrada no mesmo instante para o string de comparação, que apresentava 8,462 kWp diferença de $439 W_{p}$. Este instante de maior potência foi recorrente em todos os dias do período, além de ocorrer exclusivamente no string de teste, apresentando máximas superiores a $8,698 \mathrm{~kW}$ com potência superiores a 6,1\% em relação ao string de comparação, ver Figura 46(a).

No dia 08/06/2015 a potência máxima instantânea do string de teste foi de 8,873 $\mathrm{kW}_{\mathrm{p}}$ superior em 6,1\% em relação ao de comparação com 8,360 kWp. Já dos dias 10/06/2015 e 11/06/2015 esta foi superior em 6,5\%, apresentando máximas de 8,698 e $8,714 \mathrm{~kW}$, respectivamente, para o string de teste.

Assim como observado no comportamento das TPV, com e sem UMAr, e na consolidação da geração de energia, no período entre as 07h00min as 09h00min, a potência do string de comparação é superior ao string de teste, este se acentua após as 08h30min convergindo para o mesmo patamar às 09h00min, ver Figura 46(c), quando a potência do string de teste supera a do string de comparação.

Os dados apresentados demonstram e deixam evidente que o sistema de arrefecimento diminui a temperatura dos módulos PV, aumentando a potência do string de teste e por sua vez permitem uma maior taxa de geração de energia elétrica, quando comparado ao string de comparação.

Um fator importante de análise se deve à relação entre a potência instantânea e a capacidade instalada de projeto (RP), que no caso correspondem a $12,760 \mathrm{~kW}_{\mathrm{p}}$ por string. No dia 09/06/2015 durante 0 instante no qual o string de teste apresentava a maior potência, o RP correspondeu a 0,70 , já o string de comparação apresentava, no mesmo instante, 0,66 , ou seja, o sistema de arrefecimento promoveu um ganho de 0,04 no RP do protótipo de UFVa. Para os dias 08/06, 10/06 e 11/06/2015 no mesmo instante o RP foi, respectivamente de 0,70, 0,68 e 0,68 para o string de teste e 0,66, 0,64 e 0,64 para o de comparação. 


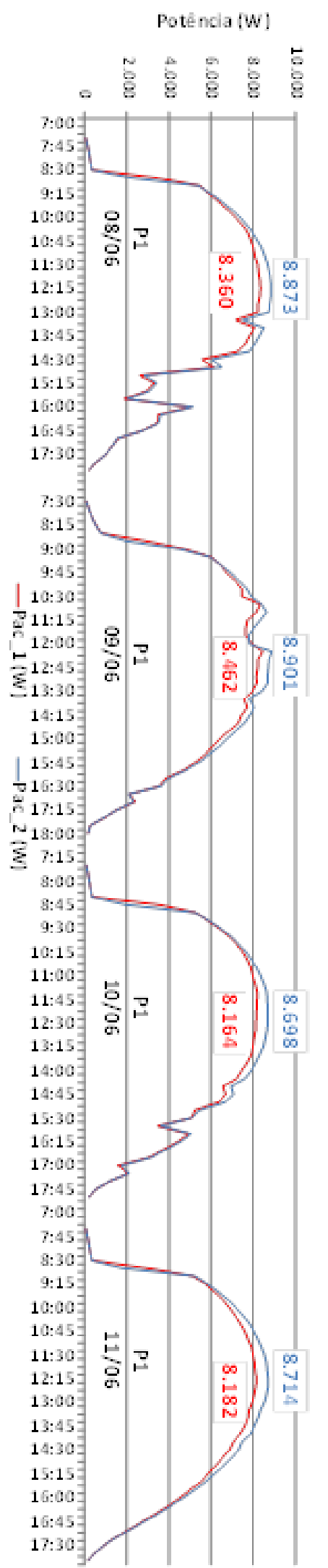

(a)

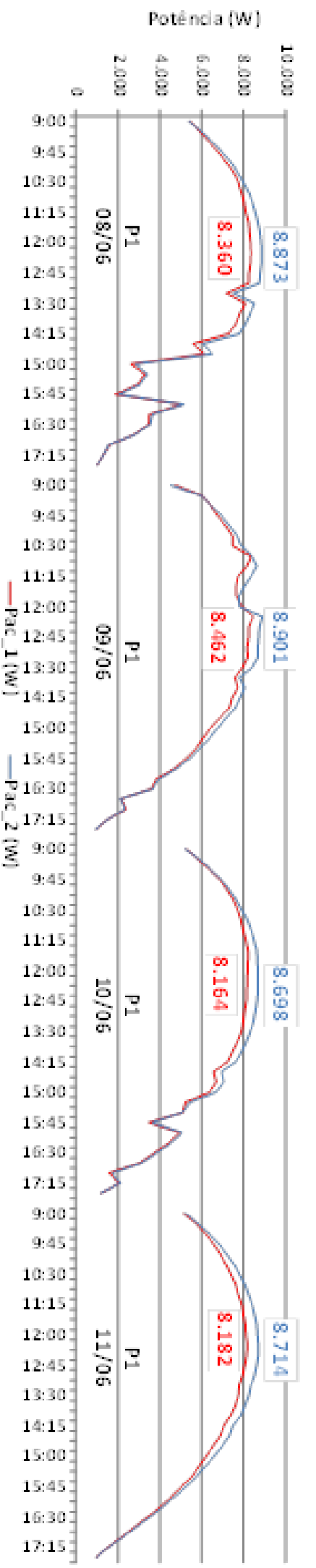

(b)

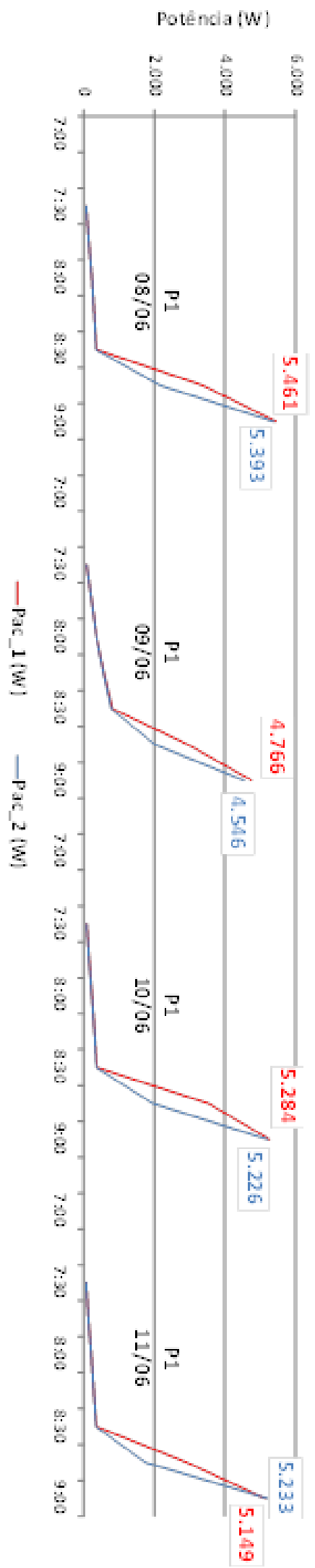

(c)

Figura 46 - Potência (W) nos strings para o período P1. (a) 07h00min às $18 \mathrm{~h} 00 \mathrm{~min}$ e (b) $09 \mathrm{~h} 00 \mathrm{~min}$ e $17 \mathrm{~h} 30 \mathrm{~min}$ e (c) $07 \mathrm{~h} 00 \mathrm{~min}$ às $9 \mathrm{~h} 00 \mathrm{~min}$. 
Além dos RP apresentados para os instantes de máxima potência, alguns períodos ao longo de um dia apresentaram valores altos e constantes de RP. Tomando como exemplo o dia 11/06/2015, no qual a curva de potência de ambos os strings apresentou comportamento isento de grandes oscilações como as ocorridas no período P1, excetuando-se o dia 08/06/2015 que apresentou sucessivas quedas e elevações da potência de ambos os strings, ver Figura 46(b).

Neste dia durante todo o período compreendido entre às $11 \mathrm{~h} 00 \mathrm{~min}$ e às 15h00min, a potência do string de teste manteve-se em média 6,6\% acima do string de comparação com máxima de 7,2\% e mínima de $6,0 \%$, neste período o RP médio dos string foi de 0,64 e 0,60, respectivamente, apresentando ganho de 0,04 no string de teste, ver Figura 47.

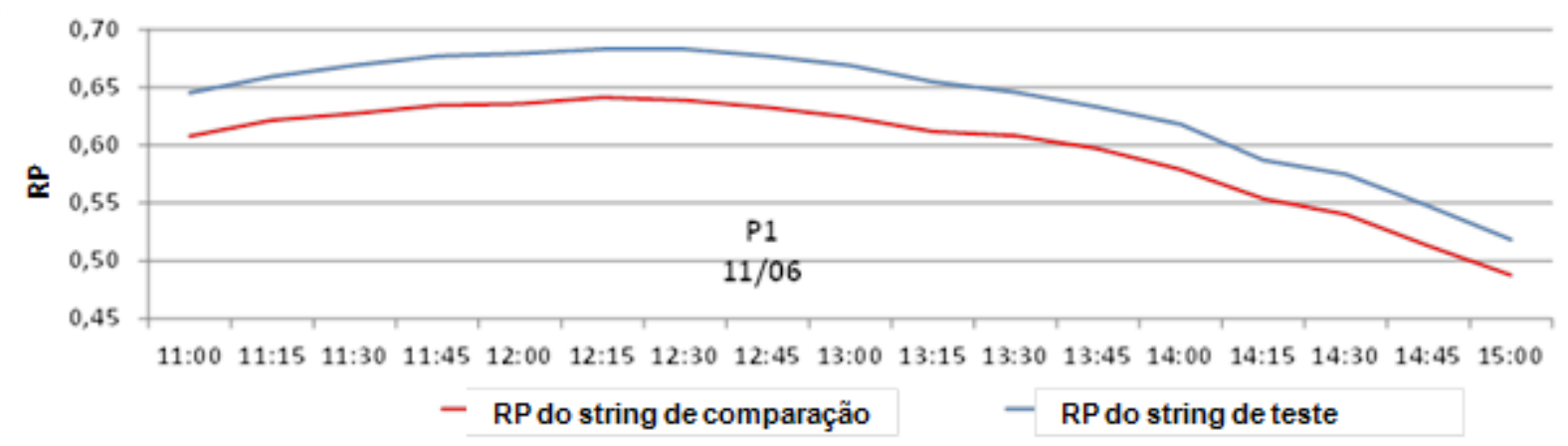

Figura 47 - Curva do RP para o período das 11h00min às 15h00min do dia 11/06/2015.

Na Tabela XII é possível verificar os dados consolidados de picos e máximos relacionados ao período $\mathrm{P} 1$ e suas totalizações, quando aplicado.

A geração de energia elétrica consolidada do string de teste para os quatro dias do período $\mathrm{P} 1$, referente à operação entre às $09 \mathrm{~h} 00 \mathrm{~min}$ e às $17 \mathrm{~h} 30 \mathrm{~min}$, foi de 223,0 kWh, um ganho de 11,0 kWh em relação à energia elétrica gerada no string de comparação para o mesmo período, dos quatro dias, três apresentaram ganho de $3,0 \mathrm{kWh} / \mathrm{dia}$ e um de 2,0 kWh/dia.

Em relação à potência, o string de teste apresentou ganho máximo de $612 \mathrm{~W}_{\mathrm{p}}$, o que corresponde à potência de máxima de 2,1 módulos $\mathrm{PV}$, mas se considerarmos 0 RP médio para o string de comparação, durante o período das 11h00min às 15h00min de máximo desempenho, o ganho é superior a potência máxima de 4,3 módulos PV. 
Com a Tabela XII, é possível verificar que o sistema de arrefecimento do protótipo de UFVa garante um ganho de desempenho razoável na geração de energia elétrica e do RP do string, essa característica viabiliza a instalação de UFV, pois aumenta a produção de energia elétrica em relação à área de implantação, isto pode, em casos em que o custo de aquisição do terreno é alto ou quando a disponibilidade de área é reduzida, garantir implantação do empreendimento.

Tabela XII - Dados consolidados de potência, Geração e RP para o período P1.

\begin{tabular}{|c|c|c|c|c|c|c|}
\hline Dado & Unidade & $08 / 06 / 2015$ & $09 / 06 / 2015$ & $10 / 06 / 2015$ & $11 / 06 / 2015$ & Total \\
\hline \multirow[b]{2}{*}{ Potência } & Pico (kWp) & 8.873 & 8.901 & 8.698 & 8.714 & NA \\
\hline & $\begin{array}{l}\text { Ganho Máx } \\
\text { (\%/Wp) }\end{array}$ & 8,7 / 547 & 7,9 / 612 & $10,3 / 536$ & 7,2 / 573 & NA \\
\hline \multirow{2}{*}{$\begin{array}{l}{ }^{1} \text { Geração } \\
\text { (kWh/dia) }\end{array}$} & Total & 54,0 & 56,0 & 57,0 & 56,0 & 223,0 \\
\hline & $\begin{array}{l}\text { Ganho } \\
\text { (\%/kWh/dia) }\end{array}$ & $5,9 / 3,0$ & $3,7 / 2,0$ & $5,6 / 3,0$ & $5,7 / 3,0$ & $\begin{array}{l}5,2 / \\
11,0\end{array}$ \\
\hline \multirow[b]{2}{*}{$\mathrm{RP}$} & Pico & 0,70 & 0,70 & 0,68 & 0,68 & NA \\
\hline & $\begin{array}{l}\text { Ganho } \\
\text { Médio }\end{array}$ & 0,04 & 0,03 & 0,03 & 0,04 & 0,04 \\
\hline
\end{tabular}

Além da análise do desempenho, baseada nos dados de irradiância diário calculados por meio das medições da estação meteorológica (EM) existente no local de instalação do protótipo de UFVa, são calculados os índices de performance dos strings de teste e comparação, que representam:

- Yield $(\mathrm{Y})$ ou produtividade relação energia gerada $(\mathrm{kWh})$ por potência instalada (Wp);

- Performance Ratio (PR) ou taxa de desempenho expressa em porcentagem (\%) que representa a produção de energia em relação à energia esperada com base na quantidade de horas e radiação solar incidente no local; e

- Fator de Capacidade (FC) ou relação energia gerada pela energia gerada caso a UFV operasse em potência nominal durante 24 horas por dia, também expresso em porcentual. 
Como demonstrado em relação à potência, geração e RP, o string de teste apresentou ganho de desempenho em relação ao string de comparação nos quatro dias do período, com destaque para o dia 09/06/2015, no qual o string de teste apresentou $Y=4,62(k W h / k W p), P R=73,9 \%$ e $F C=19,3 \%$, com ganho de $5,36 \%$, em todos os índices, ver Tabela XIII.

Tabela XIII - Dados consolidados de Yield, PR e FC para o período P1

\begin{tabular}{|l|l|l|l|l|l|l|}
\hline \multicolumn{1}{|c|}{ String } & Dado & Unidade & $\mathbf{0 8 / 0 6 / 2 0 1 5}$ & $\mathbf{0 9 / 0 6 / 2 0 1 5}$ & $\mathbf{1 0 / 0 6 / 2 0 1 5}$ & $\mathbf{1 1 / 0 6 / 2 0 1 5}$ \\
\hline \multirow{4}{*}{ Comparação } & $\mathrm{Y}$ & $(\mathrm{kWh} / \mathrm{kWp})$ & 4,31 & 4,39 & 4,47 & 4,39 \\
\cline { 2 - 7 } & $\mathrm{PR}$ & $\%$ & 71,0 & 70,2 & 71,3 & $(1)$ \\
\cline { 2 - 7 } & $\mathrm{FC}$ & $\%$ & 18,0 & 18,3 & 18,6 & 18,3 \\
\hline \multirow{4}{*}{ Teste } & $\mathrm{Y}$ & $(\mathrm{kWh} / \mathrm{kWp})$ & 4,39 & 4,62 & 4,62 & 4,55 \\
\cline { 2 - 7 } & $\mathrm{PR}$ & $\%$ & 72,3 & 73,9 & 73,8 & $(1)$ \\
\cline { 2 - 7 } & $\mathrm{FC}$ & $\%$ & 18,3 & 19,3 & 19,3 & 18,3 \\
\hline \multirow{2}{*}{ Ganho } & & $\%$ & 1,82 & 5,36 & 3,51 & 3,57 \\
\hline
\end{tabular}

${ }^{1}$ Dados de irradiância incompletos

\subsubsection{Estudo do impacto do clima local no comportamento de operação do protótipo de UFVa para o Período P1}

O período de análise das condições climáticas refere-se aos dias do período $\mathrm{P} 1$, dos quais o dia 11/06/2015 foi descartado, pois apresentou problemas de armazenamento entre às $11 \mathrm{~h} 00 \mathrm{~min}$ e às $14 \mathrm{~h} 30 \mathrm{~min}$ dos dados medidos pela EM.

Assim são discutidos apenas os dados dos dias 08/06/2015, 09/06/2015 e 10/06/2015, ou seja, três dias de medições do período P1.

Em relação às grandezas climáticas são discutidas a temperatura ambiente $\left({ }^{\circ} \mathrm{C}\right)$, velocidade $(\mathrm{m} / \mathrm{s})$ e direção do vento, e a radiação solar direta $\left(\mathrm{W} / \mathrm{m}^{2}\right)$.

No caso do vento, observa-se, ver Figura 48, que a direção predominante referese aos ventos vindos a jusante da UHE-ILS, que neste caso é o sul geográfico, talvez essa condição ocorra devido ao posicionamento da EM, pois esta se encontra a jusante da barragem que pode obstruir os ventos do norte ou a montante, ver Figura 48(a).

Em relação às velocidades dos ventos, observa-se que as velocidades médias estão na faixa entre 0,70 a $1,40 \mathrm{~m} / \mathrm{s}$, ver Figura $48(\mathrm{~b})$, com máxima de $3,5 \mathrm{~m} / \mathrm{s}$ e 
maior concentração em torno de $2,0 \mathrm{~m} / \mathrm{s}$, ou seja, para esses dias analisados as velocidades foram baixas. Além disso, como constatado na direção dos ventos, as velocidades máximas bem como as maiores velocidades médias referem-se aos ventos originados da região sul.

Quando analisada a curva horária da velocidade dos ventos, ver Figura 49(a), observa-se que o primeiro dia do período, dia 08/06/2015, apresenta as menores velocidades de vento, ficando abaixo do $2,0 \mathrm{~m} / \mathrm{s}$, salvo uma única medição referente a sua máxima diária de $2,4 \mathrm{~m} / \mathrm{s}$, além disso, este dia apresenta uma pequena faixa de amplitude de oscilação, sendo quase constante ao longo do dia.

No segundo dia, 09/06/2015 a velocidade dos ventos fica sutilmente superior ao do dia anterior oscilando numa faixa constante entre às $09 \mathrm{~h} 00 \mathrm{~min}$ e às $15 \mathrm{~h} 00 \mathrm{~min}$, após esse período a amplitude de oscilação reduz levemente, ver Figura 49(a).

Diferentemente dos dois dias anteriores, o dia 10/06/2015 apresenta velocidades de ventos no início da manhã próximos a $3,5 \mathrm{~m} / \mathrm{s}$, faixa de maior velocidade registrada, mas após às $11 \mathrm{~h} 00 \mathrm{~min}$, a amplitude de oscilação da velocidade dos ventos é reduzida, até alcançar patamares inferiores a $1,0 \mathrm{~m} / \mathrm{s}$ ao fim do período de medição estudado, ver Figura 49(a).

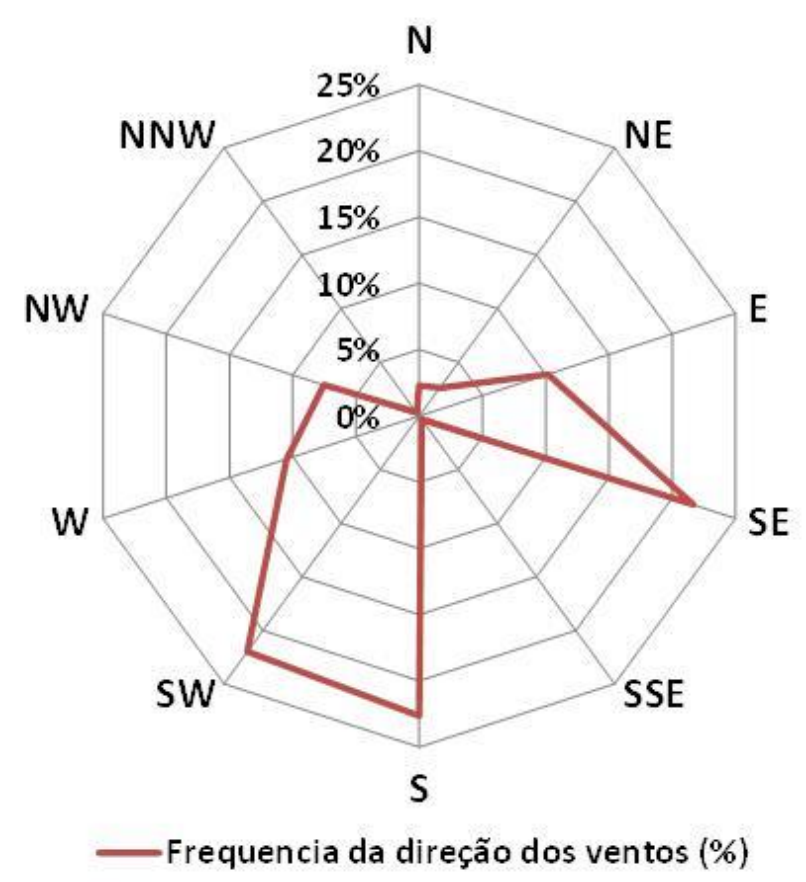

(a)

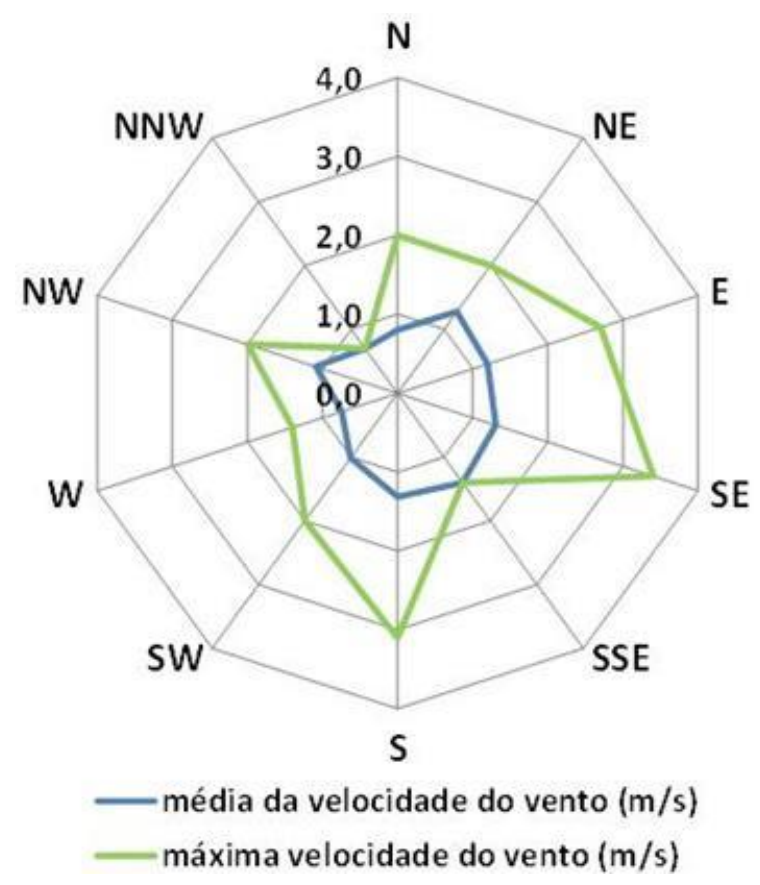

(b)

Figura 48 - Vento local entre às $09 \mathrm{~h} 00 \mathrm{~min}$ e às $17 \mathrm{~h} 30 \mathrm{~min}$ do período $\mathrm{P} 1$. (a) frequência da direção dos ventos e (b) velocidade média e máxima dos ventos. 
Quando verificada a temperatura ambiente, ver Figura 49(b), observa-se para os três dias que estas variam ao longo do dia entre 25,0 e $35,0^{\circ} \mathrm{C}$, com mínimas no início da manhã, com leve aumento até às $13 \mathrm{~h} 30 \mathrm{~min}$, momento com as maiores temperaturas do dia, após este horário a temperatura ambiente varia ligeiramente mantendo quase constante, até iniciar seu declínio após às 16h30min.

No caso da curva diária de radiação solar, Figura 49(b), observa-se uma correlação com o comportamento das curvas de temperatura dos módulos PV, ver Figura 41 , e de potência, Figura 46, dos strings de teste e comparação, pois há coerência na oscilação das curvas com picos de máximo e mínimo em horários próximos. Em ambos os dias, a geração, a temperatura de operação dos módulos PV e a radiação solar incidente aumentam acentuadamente no inicio da manhã, alcançando o período de máximas, compreendido entre às $11 \mathrm{~h} 30 \mathrm{~min}$ e às 14h00min, e logo após declinam rapidamente, no caso da geração e radiação solar esse declínio termina após às $18 \mathrm{~h} 00 \mathrm{~min}$ quando o sol se põe, já as temperaturas dos módulos se estabilizam após às $17 \mathrm{~h} 30 \mathrm{~min}$. Sobre as oscilações abruptas com sucessivas quedas e aumento da radiação solar, como não ouve registro de chuvas nesses dias, conclui-se que houve aparecimento de nuvens, que por sua vez bloquearam a radiação solar direta incidente reduzindo levemente a temperatura ambiente e dos módulos PV de ambos os strings.

Assim, com a análise desses dados é possível compreender que a temperatura dos módulos PV e a geração de energia elétrica estão fortemente ligadas à radiação solar incidente, no caso dos ventos, por apresentarem baixas velocidades, sua influência não foi identificada, mas vale ressaltar que é preciso analisar uma quantidade maior de dias e dados para concluir acerca do seu impacto na geração e operação do protótipo de UFVa.

No caso da temperatura ambiente, por permanecerem na mesma faixa de temperatura sem grandes variações ao longo do dia, não foi possível detectar a sua influência direta na geração como ocorreu com os dados analisados da radiação solar.

Portanto, para enaltecer as análises e obter conclusões mais específicas do impacto da temperatura ambiente e velocidade de vento na temperatura dos 
módulos PV do protótipo de UFVa é necessário um período mínimo de um ano de medições para posterior análise. 


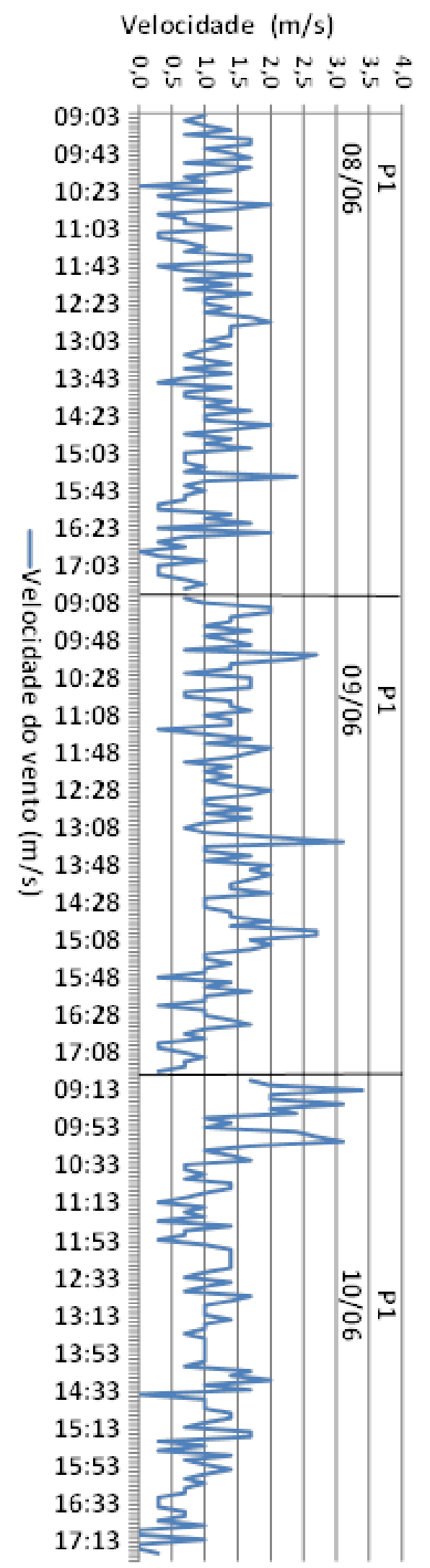

(a)

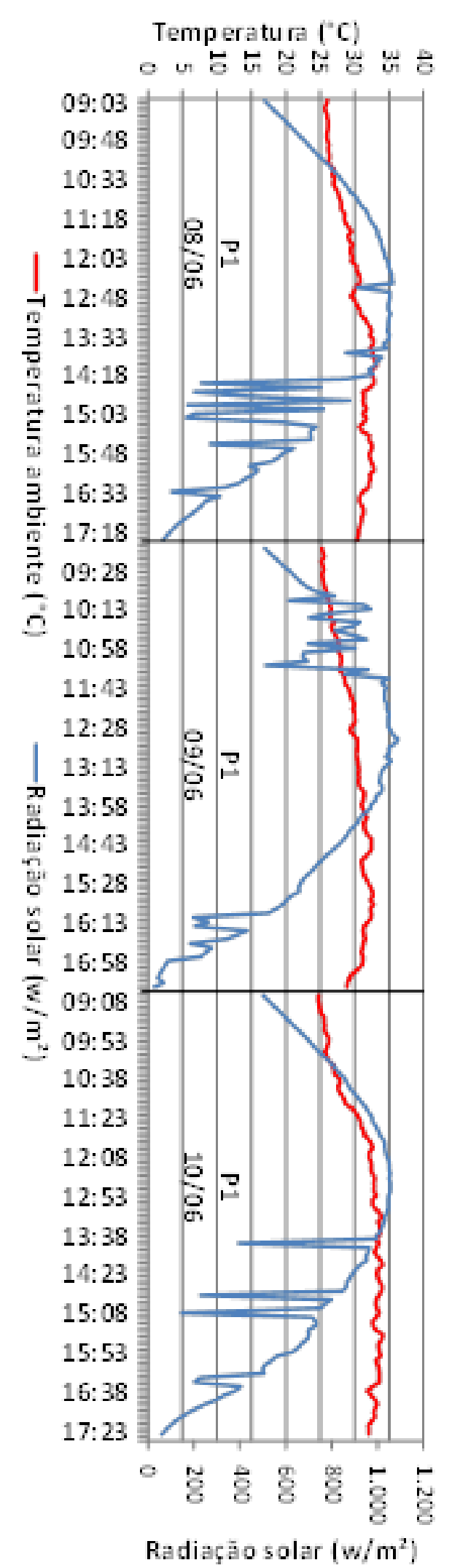

(b)

Figura 49 - Curvas diárias das grandezas climáticas analisadas. (a) Velocidade do vento e (b) Temperatura ambiente e radiação solar. 


\subsubsection{Supervisão e monitoramento com auxílio da câmera termovisora}

As temperaturas nas superfícies superior e inferior dos módulos $\mathrm{PV}$ ao longo do dia variaram entre 43,1 e $57,7^{\circ} \mathrm{C}$, ver Figura 50 .
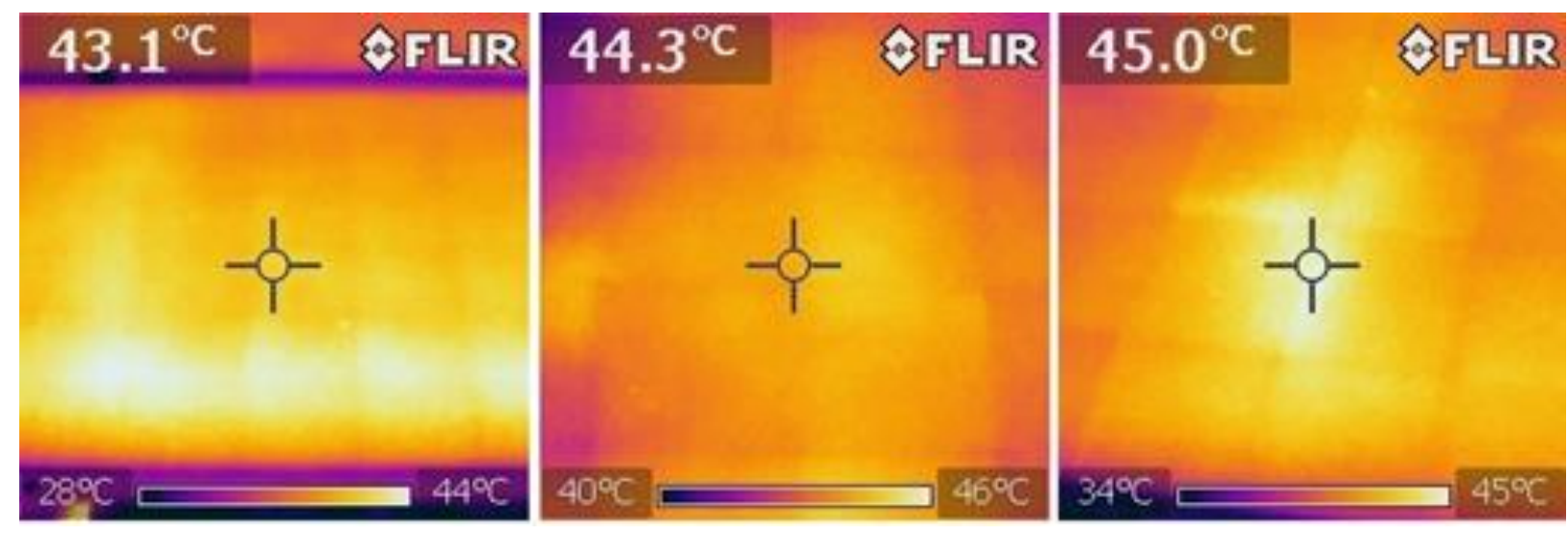

(a)
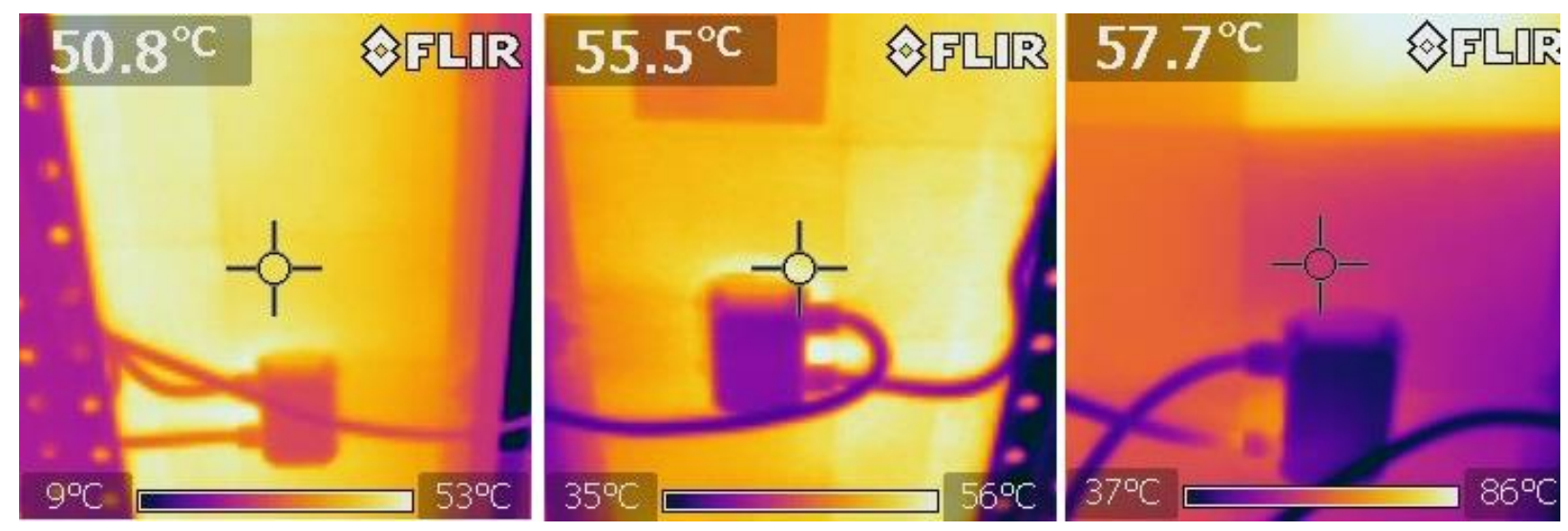

(b)

Figura 50 - Imagens da temperatura dos módulos PV com câmera termovisora. (a) superfície superior e (b) superfície inferior.

Constatou-se que a superfície inferior dos módulos PV apresenta temperaturas $10,0^{\circ} \mathrm{C}$ acima da temperatura da superfície superior, isso inferido em um mesmo módulo PV. Este fato ocorre devido à maior condutividade térmica do silício (material das células $\mathrm{PV}$ ) em relação ao material polimérico da superfície inferior, ou seja, o silício dissipa calor a uma taxa maior que o polímero. Além disso, durante o verão de 2013 verificou-se que as temperaturas da superfície superior e inferior do módulo PV eram de 54,1 e $73,6^{\circ} \mathrm{C}$, respectivamente. 


\subsubsection{Análise técnica-econômica de UMAr}

Os custos envolvidos no desenvolvimento, fabricação e instalação das unidades modulares de arrefecimento, ver Tabela XIV, foram de $\mathrm{R} \$ 291.459,55$.

Em termos de implantação do protótipo de UFVa, deve-se considerar apenas os custos envolvidos na fabricação e instalação das UMAr, sendo assim, o custo total envolvido foi de $R \$ 141.611,55$, perfazendo um custo de $R \$ 3.073,56$ por unidade instalada no protótipo UFVa, ver Tabela XIV. Valor foi alto devido a sua produção não ser em escala, mesmo com a produção de $47 \mathrm{UMAr}$ das quais 44 foram instaladas, e uma vez que a fabricação do sistema e instalação necessitou de testes preliminares, elaboração e aprendizagem de processos por parte das equipes envolvidas.

Outro grande impacto no custo se deve a grande especialização e capacitação da equipe, fato inerente e necessário para projetos de P\&D, pois as adversidades encontradas são grandes, uma vez que não há domínio das condições de operação, construção e instalação de tal sistema, e as tomadas de decisões precisam ter embasamento metodológico teórico-técnico para facilitar futuras replicações e correções quando necessário.

Tabela XIV - Custos de implantação do protótipo de UFVa

\begin{tabular}{|c|c|c|c|}
\hline Etapa & $\begin{array}{c}\text { Custo } \\
\text { (R\$) }\end{array}$ & $\begin{array}{c}\text { Unidades } \\
\text { (u) }\end{array}$ & $\begin{array}{l}\text { Custo unitário } \\
(\mathrm{R} \$ / \mathrm{u})\end{array}$ \\
\hline Fabricação & $99.871,55$ & 47 & $2.124,93$ \\
\hline Instalação & $41.740,00$ & 44 & 948,64 \\
\hline Total & $141.611,55$ & & $3.073,56$ \\
\hline
\end{tabular}

Por outro lado, este tipo de tecnologia, caso alcance escala de mercado, teria custo de fabricação e instalação reduzido, pois o know-how de implantação, métodos e processos de produção mais eficientes seriam implantados, e a empresa construtora teria demanda constante e equipe habilitada permanente para produzir este bem. Neste caso, o custo unitário poderia ser reduzido no curto prazo para menos $\mathrm{R} \$ 800,00$ a UMAr, no caso da instalação, esta também teria um decréscimo do custo, pois o tempo de implantação e número de operadores seria reduzido com o aparecimento de empresas especializadas e com processos melhorados de implantação simultânea da UFV e do sistema de arrefecimento, o número de 
equipamentos de medição e seu grau de precisão seria reduzido e em alguns casos até extintos.

Além disso, se considerarmos que a implantação de uma futura UFVa seria planejada levando-se em conta o melhor local de instalação, proximidade da captação de água, existência de controle elétrico da vazão, melhoramento da disposição dos strings e interligação da UMAr, a instalação e operação de uma UFVa seria mais prática e o tempo de implantação drasticamente reduzido.

Nas condições apresentadas, de pleno desenvolvimento dos players e tecnologia, o custo unitário de instalação do sistema de arrefecimento seria $20 \%$ do valor realizado no atual projeto de P\&D do protótipo de UFVa.

Replicando esses custos para o protótipo de UFVa, a implantação seria de apenas $32,4 \%$ do valor total praticado na atual pesquisa, ver Tabela XV.

Tabela XV - Estimativa do custo de implantação de UMAr com produção em escala.

\begin{tabular}{lccc}
\hline \multicolumn{1}{c}{ Etapa } & $\begin{array}{c}\text { Custo unitário } \\
(\mathbf{R} \mathbf{\$} / \mathbf{u})\end{array}$ & $\begin{array}{c}\text { Unidades } \\
(\mathbf{u})\end{array}$ & $\begin{array}{c}\text { Custo } \\
\mathbf{( R \mathbf { }} \boldsymbol{\mathbf { n }}\end{array}$ \\
\hline Fabricação & 800,00 & 47 & $37.600,00$ \\
Instalação & 189,73 & 44 & $8.348,00$ \\
Total & 989,73 & & $45.948,00$ \\
\hline
\end{tabular}




\section{RESULTADOS}

O desenvolvimento dos três modelos de UMAr não foi trivial, uma vez que a tecnologia é nova, não podendo ser encontrada no mercado, além dos diversos imprevistos, como disponibilidade e custo dos materiais, mão de obra, equipamentos e redimensionamentos. Essas características são recorrentes em pesquisa e desenvolvimento e devem ser consideradas em todos os processos e estágios do projeto. Dos três sistemas, apenas os dois modelos do tipo chapa-tubo mostraramse tecnicamente e financeiramente viáveis dentro das condições estabelecidas na metodologia de desenvolvimento e puderam ser testados na U.P. O modelo do tipo múltiplos canais foi descartado devido ao tempo adicional no seu desenvolvimento, tornando o seu processo de fabricação mais custoso, inviabilizando a sua produção, e necessidade de estruturas adicionais de fixação, além dos desenvolvidos, para evitar danos à estrutura física do módulo PV. Portanto, os dois modelos de UMAr selecionados para a fase de testes na U.P são do tipo chapa-tubo.

O sistema de alimentação de água do sistema de arrefecimento do protótipo de UFVa operou sem vazamentos nas tubulações e junções durante o período de comissionamento do sistema. Após cinco dias de operação o fornecimento de água foi interrompido para instalação de um filtro, este devido ao seu tamanho e capacidade de filtragem reduziu a vazão de água em $53 \%$ em um único dia e após dois dias de operação o fornecimento operava abaixo dos 0,36 l/s, prejudicando o estudo e análise dos resultados. Neste contexto, foi possível observar, pela análise sistêmica dos dados de temperatura, que a redução de vazão no sistema de arrefecimento provoca rápida redução da capacidade do sistema de arrefecimento de retirar calor dos módulos $\mathrm{PV}$, fato comprovado na análise dos resultados que mostram que as temperaturas do período $P 2(Q=0,0 \mathrm{l} / \mathrm{s})$, a diferença de temperatura entre os módulos $\mathrm{PV}$, com e sem UMAr, é inferior a $8,0^{\circ} \mathrm{C}$, neste caso mesmo os módulos com arrefecimento operam em temperatura superior a NOCT, o mesmo efeito ocorre quando o fornecimento de água é interrompido por um período médio ao longo do dia, período $\mathrm{P} 4$, neste caso a temperatura de operação do módulo PV aumenta rapidamente alcançando diferença de temperatura de apenas $5,2^{\circ} \mathrm{C}$. Desta forma, para análises futuras, é importante a substituição ou eliminação do filtro de água na linha $A$, para permitir a plena vazão mínima estabelecida no 
projeto. Quanto à interligação das UMAr, série de dois, constatou-se que a diferença de temperatura dos módulos PV da primeira e segunda unidade da série é inferior a $2,0^{\circ} \mathrm{C}$, diferença inferior a temperaturas registradas num mesmo módulo PV sem unidade modular que alcançam mais de $3,5^{\circ} \mathrm{C}$.

Quanto às condições climáticas locais é comprovado que o efeito da radiação solar impacta diretamente na temperatura do módulo PV, pois o período de maior radiação solar diária coincide com o período de maior temperatura de operação dos módulos PV, a temperatura ambiente tem um papel coadjuvante, pois mesmo com temperatura constante ocorre queda de temperatura do módulo PV com a redução da radiação solar incidente.

Quanto ao comportamento da temperatura de operação dos módulos PV, foi comprovado que a temperatura dos módulos PV dos strings de teste operam com temperaturas inferiores em relação aos do string de comparação, pois sempre operaram em temperaturas inferiores a $37,0^{\circ} \mathrm{C}$, ou seja, no mínimo $8,0^{\circ} \mathrm{C}$ abaixo do limite mínimo de NOCT, enquanto que os módulos do string de comparação operavam em temperaturas de até $59,97^{\circ} \mathrm{C}$, valor $14,97^{\circ} \mathrm{C}$ acima do limite mínimo de NOCT, neste mesmo instante, a diferença entre a máxima e mínima temperatura de operação dos módulos $\mathrm{PV}$ foi $25,86^{\circ} \mathrm{C}$. Para não deixar dúvidas, no período que compreende das $11 \mathrm{~h} 00 \mathrm{~min}$ às $15 \mathrm{~h} 00 \mathrm{~min}$, no qual ocorre a maior geração de energia elétrica e por sua vez são registradas as maiores temperaturas de operação dos módulos PV de ambos os strings, a temperatura dos módulos PV do string de comparação são sempre superiores a $45,0^{\circ} \mathrm{C}$ enquanto as do string de teste não ultrapassaram os $36,23^{\circ} \mathrm{C}$.

Quanto à geração de energia elétrica, foi comprovado que a utilização de UMAr em módulos PV aumenta o rendimento da produção de energia elétrica de uma UFV, pois o string de teste gerou até $3,0 \mathrm{kWh} /$ dia de energia a mais que o string de comparação, totalizando $11 \mathrm{kWh}$ para o período $\mathrm{P} 1$ analisado, com o aumento do RP da UFV em 4,0\% e da potência em até 10,3\%, um ganho de $612 W_{p}$, equivalente 4,3 módulos PV a mais operando nessas mesmas condições. Fato evidente com os dados de índice de desempenho, Y, PR e FC, no qual o string arrefecido apresentou ganho de 5,6\% acima do string de comparação. 


\section{CONCLUSÕES}

O estudo permitiu a construção de três modelos diferente de UMAr e posterior seleção, construção e instalação do modelo com melhor desempenho na redução de temperatura, o qual foi o de tipo chapa-tubo com raio de curvatura de $85 \mathrm{~mm}$, em uma UFV.

Os resultados obtidos foram conclusivos e indicam que o string de teste nos períodos de pico de geração e temperatura operou com temperatura sempre inferior ao NOCT enquanto que o string de comparação operou sempre acima, diferença superior a $25^{\circ} \mathrm{C}$.

Nestes momentos, a geração de energia e a potência do string de teste foi sempre superior ao do string de comparação, comprovando que o sistema de arrefecimento reduz a temperatura de operação dos módulos PV aumentando a energia gerada na UFV. Alcançando desempenho 5,6\% maior para o período analisado.

Os dados mostraram que é possível melhorar o desempenho do sistema de arrefecimento com a utilização de sistema de controle por válvulas para abertura às 08h30min e fechamento às $17 \mathrm{~h} 30$ min do fornecimento de água ou em casos de grande queda de temperatura dos módulos PV e da radiação solar incidente por longo período. Estes podem ser indicadores para regular, diminuir ou aumentar a vazão de água, mantendo os módulos PV sempre abaixo do NOCT.

A partir das análises e resultados demonstrados, a arquitetura modular de uma UFV com sistema de arrefecimento consiste da:

A instalação de uma UMAr para cada módulo PV, ou seja, as unidades devem ser individuais. Estas não devem interferir na estrutura do módulo $\mathrm{PV}$, de modo a viabilizar a continuidade da garantia do fabricante, devem apresentar fácil manuseio de montagem,

- A fixação da UMAr deve utilizar a própria estrutura do módulo PV para reduzir custos e insumos de materiais, facilitar a instalação;

- O sistema de alimentação de fluido refrigerante deve conter uma linha principal de alimentação dotada de um medidor de vazão e uma válvula de 
bloqueio para permitir a supervisão, monitoramento e controle do fornecimento de fluido ao sistema. Esta linha não pode conter equipamentos, além dos citados, que prejudique ou altere o fornecimento contínuo e perene de fluido ao longo do tempo;

Uma linha de descarga para captação do fluido após a circulação pelas UMAr e, finalmente realizar a destinação final. Nesta linha deve conter uma válvula de controle e bloqueio para facilitar manutenções e controlar o sistema de alimentação;

A interligação das UMAr deve ser, no mínimo em série de dois, para reduzir a vazão do sistema, pois resultados demonstraram que é passível de operar desta forma;

- Linhas secundárias ou ramais de distribuição e captação de fluido refrigerante. Essas linhas devem ser robustas e conter uma válvula de bloqueio e controle na entrada e uma na saída de cada série de UMAr para isolar a(s) unidade(s) em caso de manutenção isolada e, assim, permitir que o sistema continue operando;

- Sistema de supervisão e monitoramento de temperatura dos módulos PV, para auxiliar a operação e controle da alimentação de fluido ao sistema. Esse deve conter dois módulos PV monitorados, um no início e um no final da linha principal de alimentação, de modo a garantir que o sistema de arrefecimento opere de forma homogênia. 


\section{CONSIDERAÇÕES E RECOMENDAÇÕES}

As medições sistêmicas permitem a análise comparativa entre os sistemas de teste e de comparação, de modo a obter o rendimento dos dois sistemas e correlacionar às grandezas energéticas e climáticas medidas, além de auxiliar na determinação e extrapolação do desempenho do sistema em diferentes condições climáticas presentes ao longo do ano. Assim, é de extrema importância para o estudo a continuidade das medições e análise da operação de um ano de operação, para supervisão e monitoramento do comportamento do protótipo de UFVa e da alimentação de água. Essa medição visa entender o comportamento das temperaturas dos módulos PV e da água ao longo de todas as estações do ano (primavera, verão, outono e inverno). Além de ser uma grande oportunidade de pesquisa, uma vez que não existem, segundo a bibliografia, outras pesquisas deste tipo sendo realizadas no mundo.

Uma constatação importante se deu pela criação de know-how, no caso da concessionária, que adquiriu conhecimento e familiaridade com operação e manuseio de sistema PV convencional e de uma UFVa, única no mundo, e os pesquisadores envolvidos adquiriram conhecimento do estado da arte, elaboração, produção e implantação de sistema de arrefecimento para módulos $P V$, sendo passíveis de ser replicados e melhorados caso novas pesquisas e desenvolvimento sejam perpetuadas.

Considerando o estado atual de desenvolvimento, é possível implantar esse sistema em área jusante de UHE, em chegada ou saída de reservatório de água, caso haja bombeamento, em estação de tratamento de água (ETA), ou seja, em locais onde há disponibilidade de água e capacidade de utilizar desnível geométrico (energia potencial) ou água bombeada já existente para alimentação do sistema de arrefecimento.

No da UFV-ILS, este sistema é passível de ser expandido na UFV existente na UHE-ILS, caso haja a expansão da linha de alimentação de água e substituição do sistema de filtragem ou remoção completa, pois a mesma mostrou-se incapaz de permitir um fluxo contínuo e sem alteração de vazão ao longo de um dia. Além disso, com a constatação de que as UMAr apresentam bom desempenho mesmo quando 
conectadas em série de dois, promove a possibilidade de novos estudos com séries maiores, de três a oito unidades ligadas em série.

Finalizando, a análise de viabilidade prévia indica que com o conhecimento da operação anual e o desenvolvimento de um modelo cabeça de série, é possível produzir um sistema em escala com bom desempenho fabril, facilidade de produção/instalação, de tal forma que só possa obter um produto técnica e economicamente viável. 


\section{REFERÊNCIA BIBLIOGRÁFICA}

ANDERSON T.; DUKE M. Analysis of a Photovoltaic/Thermal Solar Collector for Building Integration. Department of Engineering, University of Waikato, Hamilton, New Zealand, 2010.

BAKKER M, ZONDAG HA, VAN HELDEN WGJ. Design of a dual flow photovoltaic/thermal kombi panel. Proceedings of PV in Europe-From PV Technology to Energy Solutions Conference and Exhibition, Rome, 7-11 October 2002; 617-620.

BATTISTI R, CORRADO A. Evaluation of technical improvements of photovoltaic systems through life cycle assessment methodology. Energy 2005;30:952-67.

BAZILIAN M., LEEDERS F., VAN DER REE B. G. C., PRASAD D. Photovoltaic cogeneration in the built environment. Solar Energy 2001;71:57-69.

BERNARDI, L. A., Política e formação de preços: uma abordagem competitiva sistêmica e integrada. $2^{\circ}$ ed. - São Paulo: Atlas, 1998.

BROGREN M, ROOS A, KARLSSON B. Design and evaluation of low-concentrating, stationary, parabolic reflectors for wall-integration of water-cooled photovoltaicthermal hybrid modules. Proceedings of PV in Europe-From PV Technology to Energy Solutions Conference and Exhibition, Rome, 7-11 October 2002; 551-555.

CASTRO R. M. G.; Energias renováveis e produção descentralizada: introdução à energia fotovoltaica; Universidade Técnica de Lisboa / Instituto Superior Técnico DEEC, 2008.

CEEETA, Centro de Estudos em Economia da Energia, dos Transportes e do Ambiente: www.ceeeta.pt.

CEPAGRI (2015a). Centro de Pesquisas Meteorológicas e Climáticas Aplicadas a Agricultura. UNICAMP, Campinas, Brasil, 2015a. Acessado em maio/2015 $<$ http://www.cpa.unicamp.br/outras-informacoes/clima-dos-municipios-

paulistas.html>

CEPAGRI (2015b) Centro de Pesquisas Meteorológicas e Climáticas Aplicadas a Agricultura. UNICAMP, Campinas, Brasil, 2015b. Acessado em maio/2015 <http://www.cpa.unicamp.br/outras-informacoes/clima_muni_236.html>

CHARALAMBOUS PG, MAIDMENT GG, KALOGIROU SA, YIAKOUMETTI K. Photovoltaic thermal (PV/T) collectors: a review. Applied Thermal Engineering 2007;27: 275-8.

COVENTRY J.S, Performance of a concentrating photovoltaic/termal solar collector, Solar Energy 78 (2) (2005) 211-222.

CHOW TT, HE W, JI J. Hybrid photovoltaic-thermosyphon water heating system for residential application. Sol Energy 2006;80(3):298-306.

CHOW TT, CHAN ALS, FONG KF, LIN Z, HE W, JI J. Energy and exergy analysis of photovoltaic-thermal collector with and without glass cover. Applied Energy 2009;86(3):310-6. 
CESP (2014). Companhia Hidrelétrica do Estado de São Paulo . Acesso 10/01/2014. Site: http://www.cesp.com.br/.

COVENTRY J.S. Performance of a concentrating photovoltaic/termal solar collector. Solar Energy 78 (2) (2005) 211-222.

CRESESB. Centro de Referência para Energia Solar e Eólica Sérgio de Salvo Brito. Energia Solar: Princípios e Aplicações. Disponível em: <http://www.cresesb.cepel.br>.

DE VRIES D. Design of a photovoltaic/thermal kombi panel. PhD Thesis, Eindhoven University of Technology, Eindhoven, Netherlands, ISBN 90-386-0840-3, 1998.

EICKER U, FUX V, INFIELD D, LI M. Heating and cooling of combined PV-solar air collectors facades. In: Proceedings of international conference of 16th European PV solar energy; 2000. p. 1836-9.

EMIN M., DINÇER F.; A review of the factors affecting operation and efficiency of photovoltaic based electricity generation systems Yuzuncu Yil University, Department of Electrical and Electronics Engineering, Van, Turkey, 2011.

ENDECON ENGINEERING. A guide to photovoltaic (PV) system design and installation. Energy technology development division, consultant report. California Energy Commission; 2001. p. 1-40.

ERDIL E, ILKAN M, EGELIOGLU F. An experimental study on energy generation with a photovoltaic (PV)-solar thermal hybrid system. Energy 2008;33: 1241-5.

GARCIA M.C.A., BALENZATEGUI J.L., Estimation of photovoltaic module yearly temperature and performance based on nominal operation cell temperature calculations. Renewable Energy 2004; 29 (October-12):1997-2010.

HANSEN AD, SORENSEN P, HANSEN LH, BINDNER H. Models for a stand-alone PV system. Roskilde: Riso National Laboratory; 2000. p. 1-78.

HASAN M. A., SUMATHY K.; Photovoltaic thermal module concepts and their performance analysis: A review; Renewable and Sustainable Energy Reviews 14 (2010) 1845-1859.

HENDRIE S. Photovoltaic/thermal collector development program-final report. Massachusetts Institute of Technology, Lincoln Laboratory, Lexington, Massachusetts, 1982.

IBGE (Brasil). Instituto Brasileiro de Geografia e Estatística. DOU no 16 de 23/01/2013.Brasília: IBGE, 2013.

IEC 61215: Crystalline silicon terrestrial photovoltaic (PV) modules-design qualification and type approval; 2005.

IEC 61646: Thin-film terrestrial photovoltaic (PV) modules_design qualification and type approval; 2008.

INPE (Brasil). PEREIRA E.B., MARTINS F.R., ABREU S.L., RÜTHER R.; Atlas brasileiro de energia solar (ABES). São José dos Campos: INPE, 2006.

IQBAL, M. Introduction to Solar Radiation, Academic Press, 1983. 
JANUZZI, G. M.; Sistemas fotovoltaicos conectados à rede elétrica no Brasil: panorama da atual legislação. Internacional Energy Initiative, Campinas, Brasil, 2009.

KALOGIROU S. Solar energy engineering: processes and systems: chapter 9. Academic Press; 2009. p. 469-517.

KRAUTER S. Increased electrical yield via water flow over the front of photovoltaic panels. Solar Energy Materials and Solar Cells 2004;82:13-37.

LEENDERS F., VAN DER REE B. C.G., PRASAD D., Photovoltaic cogeneration in the built environment. Solar Energy 2001; 71(1): 57-69).

MAKRIDES G., ZINSSER B., GEORGHIOU G. E., SCHUBERT M., WERNER J. H., Temperature behavior of different photovoltaic systems installed in Cyprus and Germany. Solar Energy Materials \& Solar Cells 93 (2009) 1095-1099.

MARKVART, T. Solar electricity. New York, USA: John Waley and Sons Ltd, 1994.

MERAL, M. E., DINÇER, F.; A review of the factors affecting operation and efficiency of photovoltaic based electricity generation systems. Yuzuncu Yil University, Department of Electrical and Electronics Engineering, Van, Turkey, 2011.

ODEH S., BEHNIA M., Improving Photovoltaic Module Efficiency Using Water Cooling, Heat Transfer Engineering, (2009), 30:6, 499-505, DOI: 0.1080/01457630802529214.

OH, J., SAMY, G., MANI, T.; Temperature Testing and Analysis of PV Modules Per ANSI/UL 1703 and IEC 61730 Standards, Conference Record of the IEEE Photovoltaic Specialists Conference, Program - 35th IEEE Photovoltaic Specialists Conference, PVSC 2010, p 984-988, (2010).

OTHMAN M.Y.H., YATIM B., SOPIAN K., BAKAR M.N.A. Performance analysis of a double-pass photovoltaic/thermal (PV/T) solar collector with CPC and fins. Renewable Energy 2005;30:2005-17.

PLATZ R, FISCHER D, ZUFFEREY M.A, ANNA SELVAN J.A., HALLER A., SHAH A. Hybrid collectors using thin-film technology. Proceedings of 26th IEEE Photovoltaic Specialists Conference, Anaheim, 1997; 1293-1296).

PRAKASH J. Transient analysis of a photovoltaic thermal solar collector for cogeneration of electricity and hot air water. Energy Conversion and Management, 1994;35:967-72.

PRIEB, C. W. M.; Desenvolvimento de um Sistema de Ensaio de Módulos Fotovoltaicos; Dissertação para Obtenção do Título de Mestre em Engenharia, UFERGS, 2002.

SANDNES B, REKSTAD J. A photovoltaic/thermal (PV/T) collector with a polymer absorber plate-experimental study and analytical model, Solar Energy 2002; 72(1): 63-73).

SEE (BRASIL). Secretaria de Energia do Estado de São Paulo. Energia Solar Paulista: Levantamento do Potêncial, Secretaria de Energia, Subsecretaria de Energias Renováveis, São Paulo, 2006. 
SHENCK N. S., Alternative energy systems. U.S. Naval Academy Lecture Readings, 2010.

SUNEDISON. MEMC SilvantisTM P290 Modulo: Data Sheet_Q2 2012, United States, 2012.

TEE, Tools for Electrical engineering, e-learning: http://e-lee.ist.utl.pt.

TEO, H. G., LEE, P. S., HAWLADER M. N. A.; An active cooling system for photovoltaic modules, Applied Energy, 90, 309-315, (2012).

TRIPANAGNOSTOPOULOS Y, NOUSIA TH, YIANOULIS P. Hybrid photovoltaic/thermal solar systems. Solar Energy 2002; 72(3): 217-234.

UNESP, 2013. Site: http://clima.feis.unesp.br/recebe_formulario.php.

VAN HELDEN WGJ, ZONDAG HA. Photovoltaic Thermal panels: on the brink of demonstration. Proceedings of PV in Europe-From PV Technology to Energy Solutions Conference and Exhibition, Rome, 7-11 October 2002; 825-828.

VAN HELDEN W. G. J., VAN ZOLINGEN R. J. CH, ZONDAG H. A.; PV thermal systems: PV panels supplying renewable electricity and heat. PROGRESS IN PHOTOVOLTAICS: RESEARCH AND APPLICATIONS, Progress in Photovoltaic: Res. Appl. 2004; 12:415-426 (DOI: 10.1002/pip.559).

YAMAGUCHI T, KAWAKAMI M, KITANO K, NAKAGAWA S, TOKORO T, NAKANO $\mathrm{T}$, et al. Data analysis on performance of PV system installed in south and north directions. In: 3rd world conference on photovoltaic energy conversion. 2003. p. 2239-42.

ZONDAG HA, DE VRIES DW, VAN HELDEN WGJ, VAN ZOLINGEN RJC, VAN STEENHOVEN AA. The thermal and electrical yield of a PV-Thermal collector. Solar Energy 2002; 72(2): 113-128.

ZONDAG HA, DE VRIES DW, VAN HELDEN WGJ, VAN ZOLINGEN RJC, VAN STEENHOVEN AA. The yield of different combined PV-Thermal collector designs. Solar Energy 2003; 74(3): 253-269.

ZONDAG $\mathrm{H}$, BAKKER M, VAN HELDEN WGJ, AFFOLTER P, EISENMANN W, FECHNER $\mathrm{H}$, et al. PVT roadmap: a European guide for the development and market introduction of PVT technology. In: Proceedings of (CD) 20th European photovoltaic solar energy conference; 2005. 


\section{ANEXO A}

O módulo fotovoltaico utilizado na UFV-ILS é o modelo MEMC SILVANTIS ${ }^{T M}$ P290 MODULE da fabricante SunEdison®, ver Figura 51.

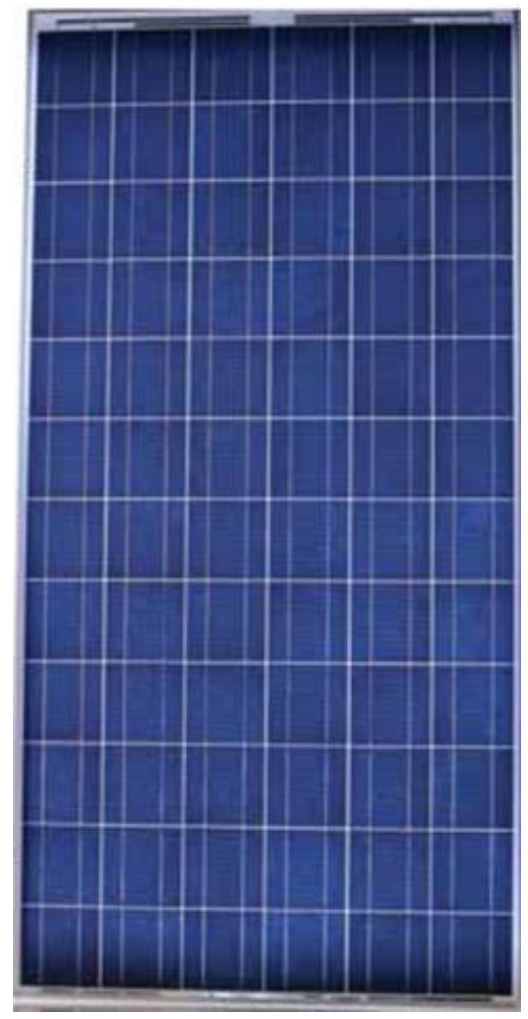

Figura 51 - Módulo solar fotovoltaico MEMC SILVANTIS ${ }^{\text {TM }}$ P290 MODULE.

Fonte: SunEdison, 2012.

Do tipo p-Si com superfície de vidro antirreflexo e estrutura (armação) de alumínio anodizado resistente a corrosão e a carregamentos de até 5,4 kPa. Contém 72 células PV com temperatura nominal de operação (NOCT) de $47 \pm 2{ }^{\circ} \mathrm{C}$ e potência total máxima $290 \mathrm{~W}$, podendo operar em temperatura ambiente variando entre $-40 \mathrm{a}$ +85 ${ }^{\circ} \mathrm{C}$. Além disso, o módulo possui dimensões básicas de 1.976×990x50 mm e peso total de $23 \mathrm{~kg}$, com área superficial de 1,81 $\mathrm{m}^{2}(\mathrm{ExF}=940 \mathrm{~mm} \times 1.926 \mathrm{~mm})$.

As características elétricas, segundo o fabricante do módulo, foram medidas em condição de teste padrão (STC) com radiação incidente de $1.000 \mathrm{~W} / \mathrm{m}^{2}$ a temperatura ambiente de $25^{\circ} \mathrm{C}$, podendo variar entre $\pm 5 \%$, a potência de $-0 /+5 \mathrm{~W}$ e os coeficientes de temperatura entre $\pm 10 \%$. 
As dimensões, características físicas, parâmetros físicos, elétricos e de temperatura, e curvas características de operação e funcionamento dos módulos PV podem ser verificados na Figura 52 e Tabela XVI.

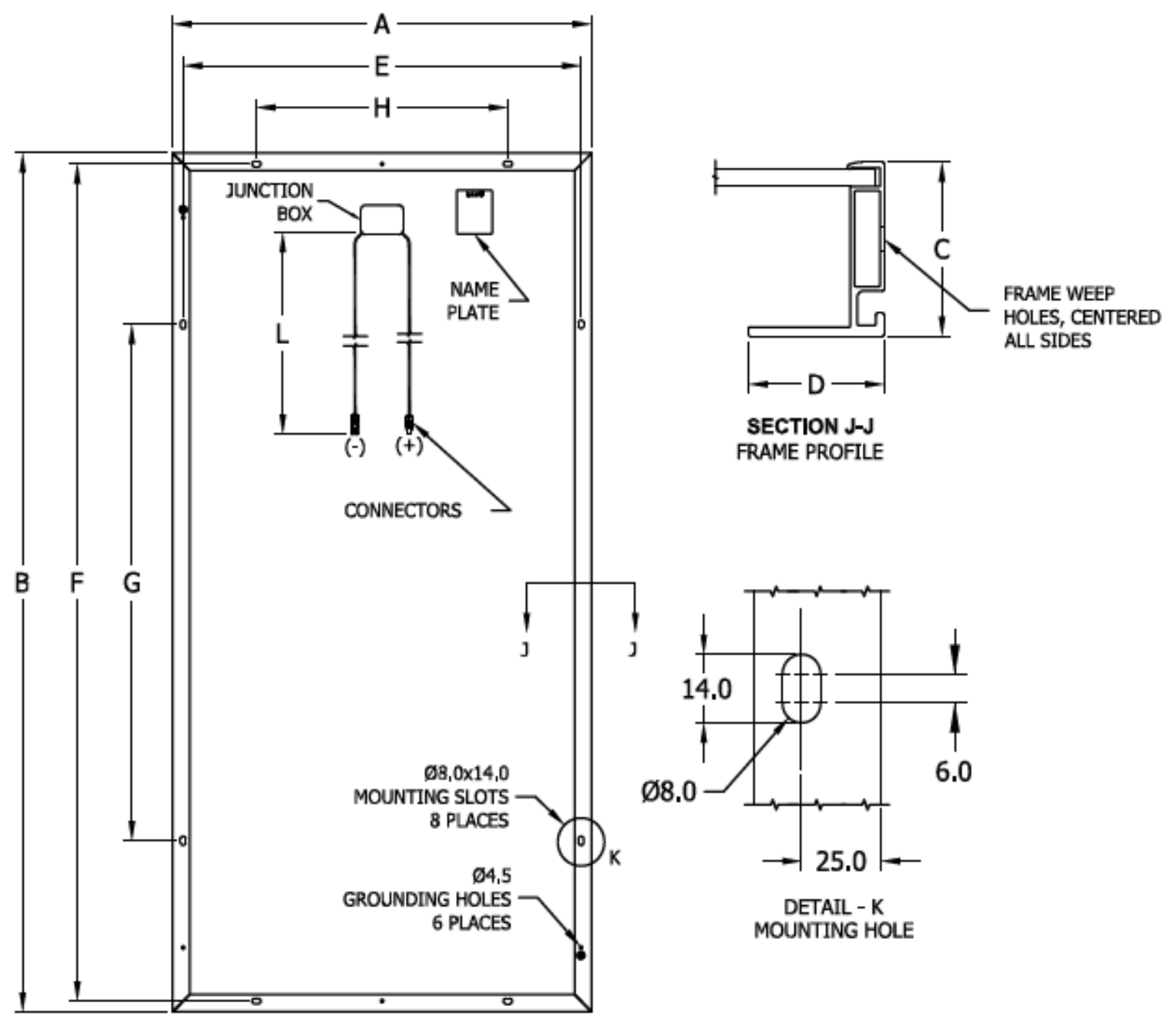

Figura 52 - Desenho representativo das dimensões do módulo PV utilizado no projeto.

Fonte: SunEdison, 2012. 
Tabela XVI - Dados técnicos do Módulo PV.

\begin{tabular}{|c|c|}
\hline DIMENSÕES & UNID. \\
\hline $\mathrm{A}(\mathrm{mm})$ & 990 \\
\hline $\mathrm{B}(\mathrm{mm})$ & 1.976 \\
\hline $\mathrm{C}(\mathrm{mm})$ & 50 \\
\hline $\mathrm{D}(\mathrm{mm})$ & 40 \\
\hline $\mathrm{E}(\mathrm{mm})$ & 940 \\
\hline $\mathrm{F}(\mathrm{mm})$ & 1.926 \\
\hline $\mathrm{G}(\mathrm{mm})$ & 1.188 \\
\hline $\mathrm{H}(\mathrm{mm})$ & 594 \\
\hline $\mathrm{L}(\mathrm{mm})$ & 1.000 \\
\hline PARÂMETROS FÍSICOS & UNID. \\
\hline Peso (kg) & 23 \\
\hline Tipo de célula & $\mathrm{p}-\mathrm{Si}$ \\
\hline Número de células & 72 \\
\hline Material da armação & Alumínio anonizado \\
\hline Vidro & Vidro temperado ARC 3,2 \\
\hline PARÂMETROS DE TEMPERATURA & UNID. \\
\hline $\mathrm{NOCT}\left({ }^{\circ} \mathrm{C}\right)$ & $47 \pm 2$ \\
\hline Coeficiente de temperatura para $\mathrm{P}_{\operatorname{máx}}\left(\% /{ }^{\circ} \mathrm{C}\right)$ & $-0,45$ \\
\hline Coeficiente de temperatura para $\mathrm{V}_{\mathrm{oc}}\left(\% /{ }^{\circ} \mathrm{C}\right)$ & $-0,33$ \\
\hline Coeficiente de temperatura para Isc $\left(\% /{ }^{\circ} \mathrm{C}\right)$ & $+0,066$ \\
\hline Temperatura de operação $\left({ }^{\circ} \mathrm{C}\right)$ & -40 até +85 \\
\hline CARACTERISTICAS ELÉTRICAS & UNID. \\
\hline Máxima taxa de potência $P_{\operatorname{máx}}(\mathrm{W})$ & 290 \\
\hline Corrente de circuito aberto $\mathrm{V}_{\mathrm{oc}}(\mathrm{V})$ & 44,7 \\
\hline Corrente curto-circuito Isc (A) & 8,71 \\
\hline Eficiência do módulo (\%) & 14,8 \\
\hline Tensão no ponto de máxima potência $V_{\mathrm{mpp}}(\mathrm{V})$ & 35,4 \\
\hline Corrente no ponto de máxima potência Impp $(A)$ & 8,20 \\
\hline Máxima voltagem do sistema (V) & 1.000 (UL \& IEC) \\
\hline Corrente reversa limite $(A)$ & 8,40 \\
\hline Máxima taxa de corrente em série $(A)$ & 15 \\
\hline Intervalo de potência (W) & $-0 /+5$ \\
\hline
\end{tabular}

Fonte: SunEdison, 2012. 


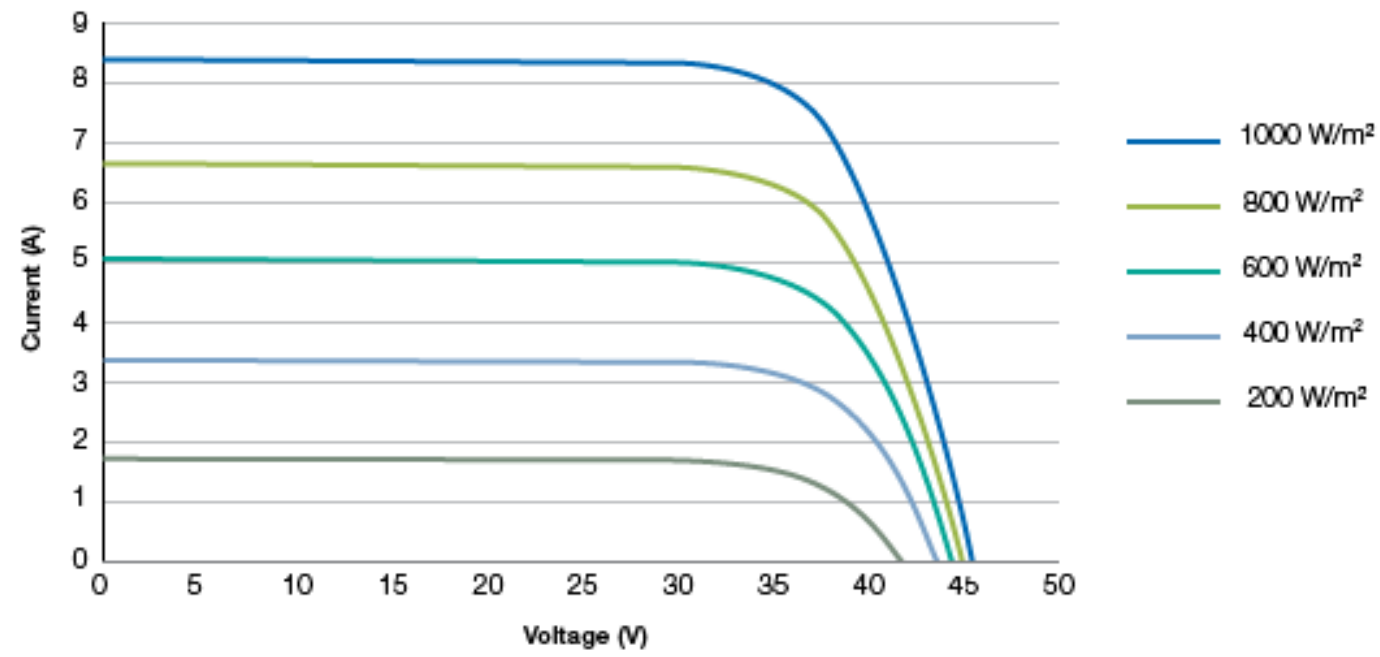

(a)

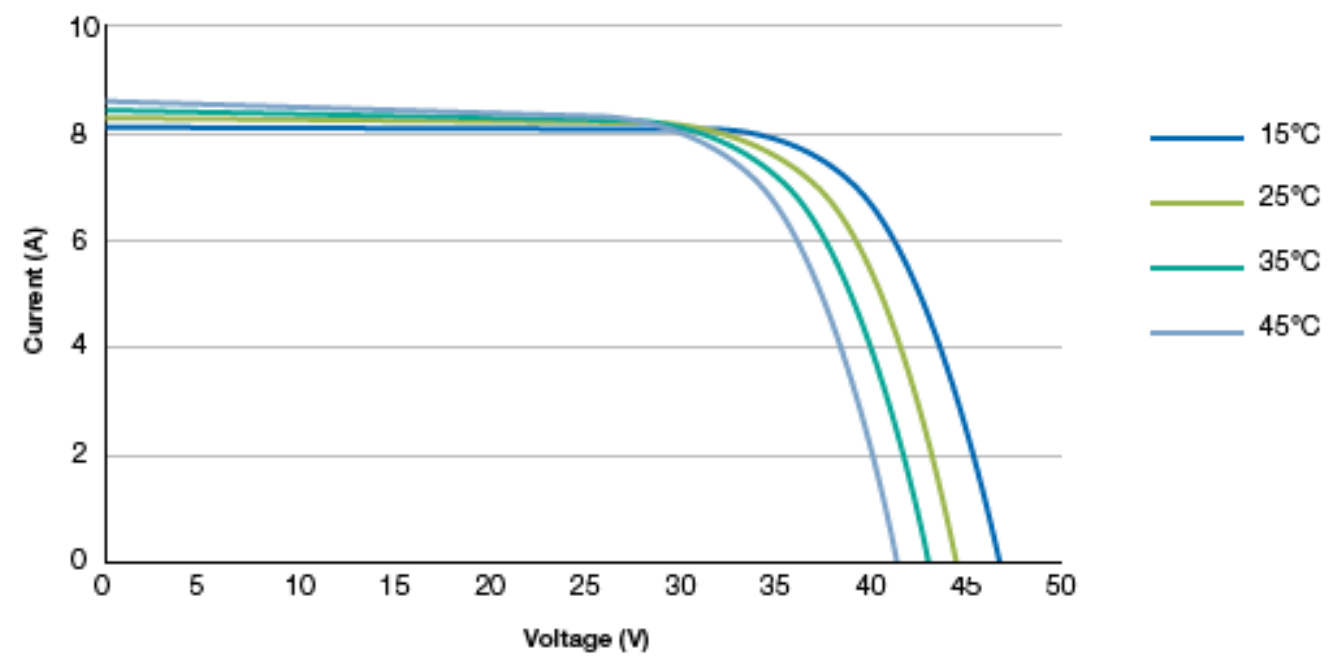

(b)

Figura 53 - Curvas características de operação do módulo PV (a) por faixa de radiação incidente operando a $25^{\circ} \mathrm{C}$ e (b) em relação à temperatura de operação considerando radiação incidente de $1.000 \mathrm{~W} / \mathrm{m}^{2}$.

Fonte: SunEdison, 2012. 


\section{ANEXO B}

Equipamentos de medições das grandezas térmicas.

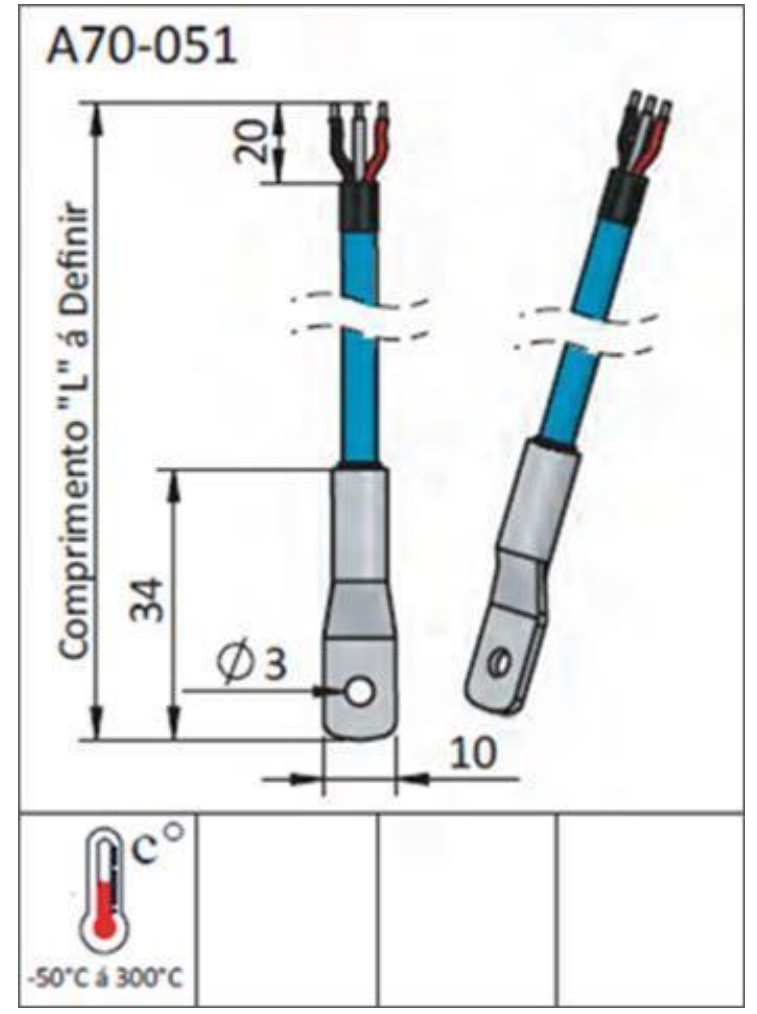

Figura 54 - Representação do sensor de temperatura do tipo termoresistência PT-100.

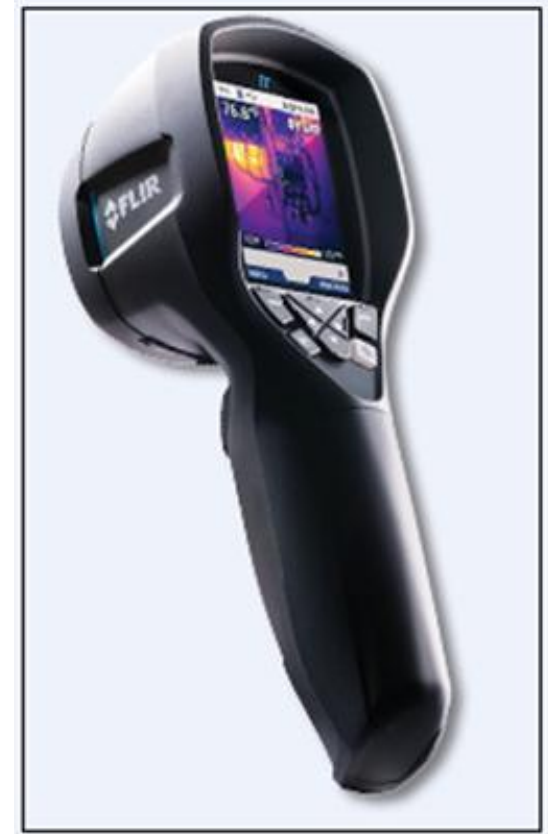

Figura 55 - Câmera termovisora FLIR i5. 


\begin{abstract}
ANEXO C
Considerando as características pré-definidas, as quais foram estudadas os sistemas de arrefecimento e as características de funcionamento e aquecimento dos módulos PV, sendo definidos os três tipos de modelos de equipamento de arrefecimento para, posteriormente serem construídos, e a metodologia estabelecida no presente trabalho, o desenvolvimento dos modelos de UMAr devem considerar as seguintes características:
\end{abstract}

Sistema deve ser adequado para regiões com clima tropical, quente e seco, uma vez que a cidade de llha Solteira, local de instalação da UFVILS que futuramente será arrefecida, encontra-se neste tipo de clima. Além disso, a região apresenta grandes gradientes de temperatura e irradiação solar levando os módulos PVs a operarem em altas temperaturas, reduzindo a sua eficiência na produção de energia elétrica;

Como os módulos PVs disponíveis comercialmente não são adequados para esta aplicação e nem seguem mesmo padrão construtivo, o modelo de arrefecimento deve ser o mais adaptável possível, considerando que o equipamento desenvolvido possa ser utilizado em diferentes tipos de módulos PVs com pouca ou nenhuma adaptação;

- Sistema do tipo coletor PVT-líquido, como definido é o que apresenta as melhores condições de arrefecimento para os módulos PVs;

- Fluido de arrefecimento, que neste caso é água, por se tratar de uma UFV instalada na área de serviço de uma UHE, com disponibilidade de fornecimento de água sem que afete a produção de energia elétrica, condição primordial para sua utilização. Além disso, a água como fluido refrigerante apresenta características significativas como não toxidade, condição extremamente importante para que não afete o meio ambiente $\mathrm{e}$ os operadores da UHE e UFV, baixo custo de fornecimento, boa condutividade térmica;

Arrefecedores consistem em um absorvedor de calor que pode ser uma serpentina ou uma série de dutos paralelos acoplados à superfície inferior 
do módulo PV e/ou fixados com material adesivo epóxi. Essas condições, também exemplificadas neste trabalho, definem o desenvolvimento dos modelos de UMAr; e

Sistema de arrefecimento Ativo ou Passivo, sendo escolhido o tipo passivo, para evitar o uso de bombas hidráulicas na alimentação dos arrefecedores, garantindo que toda a energia produzida na UFVa seja disponibilizada à rede. Esta condição requereu grande atenção na identificação e valoração de todas as opções disponíveis na UHE e que garantissem que toda a água disponibilizada para os arrefecedores não comprometesse a geração e operação da usina, ou seja, deveria assegurar que a água utilizada a montante deveria retornar para a montante ou direcionada para algum processo existente na UHE ou no caso da água de fim de processo, esta poderia ser direcionada para jusante da usina.

Quanto à construção de tais modelos, suas premissas iniciais devem:

Abranger a maior área possível do módulo PV, de modo que todos os conjuntos em linha de células PV sejam atendidos igualmente;

- Distância entre o absorvedor e módulo PV mínima, de preferência em contato direto;

- Fornecimento de fluido refrigerante deve ter fluxo ascendente, ou seja, o fluido deve subir enquanto flui pelo absorvedor; e

- Absorvedores sem isolação térmica.

O fluxograma da cadeia de construção dos modelos de arrefecedores até a seleção do modelo final pode ser visualizada na Figura 56. 


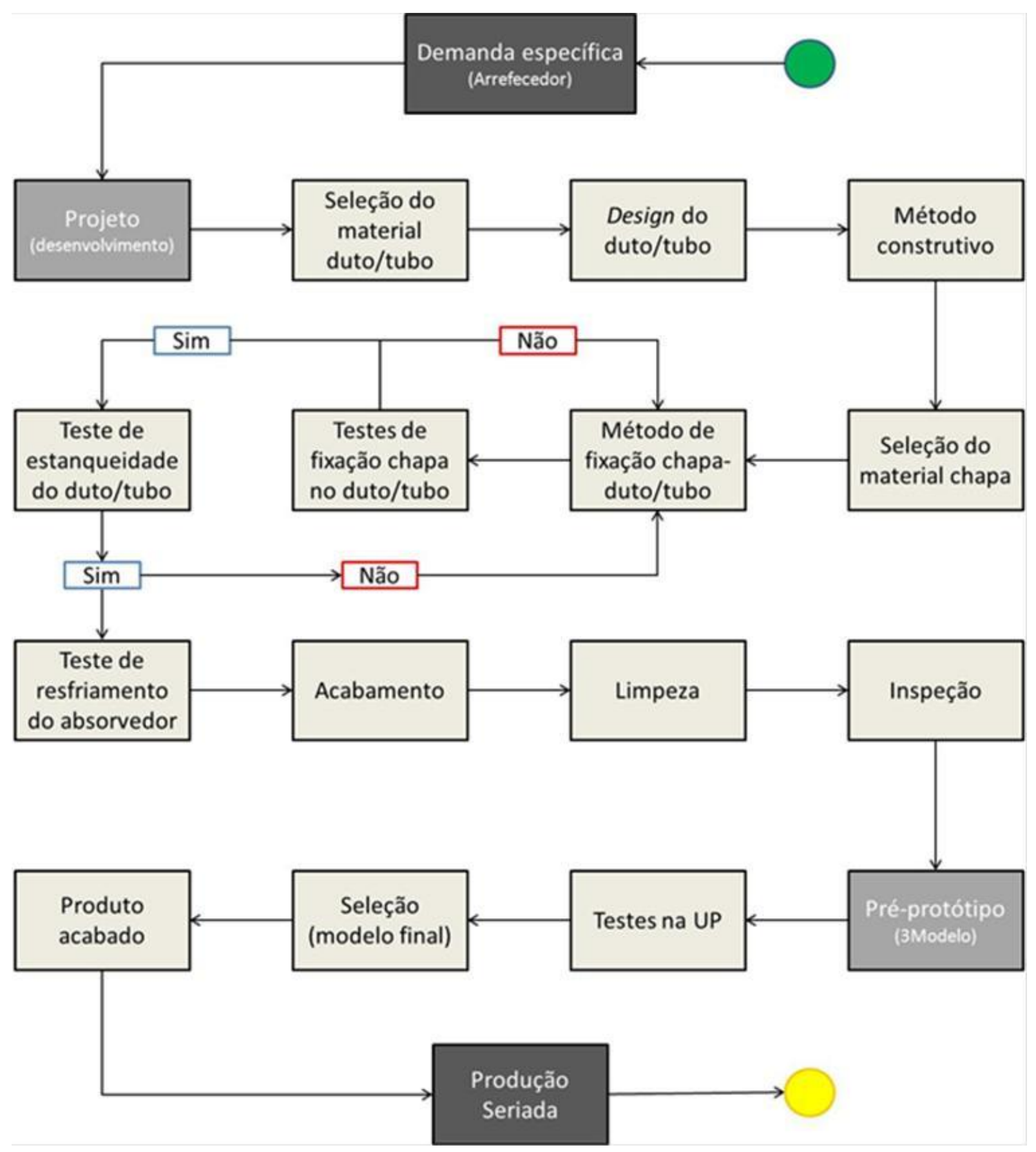

Figura 56 - Fluxograma de construção do modelo final de arrefecimento.

\section{C.1 DESENVOLVIMENTO DOS MODELOS DE UMAR DO TIPO CHAPA-TUBO}

Os dois primeiros modelos de arrefecedores desenvolvidos foram do tipo chapatubo. Cada parte que constitui o arrefecedor foi desenvolvida separadamente, primeiro houve o desenvolvimento do absorvedor, seguido pela junção chapa-tubo e pasta térmica. 


\section{C.1.1 Chapa-tubo}

O desenvolvimento iniciou-se com a seleção do tipo de material da chapa e do tubo, por meio de levantamentos bibliográficos, identificou-se a utilização de materiais metálicos de diversos tipos, sendo o alumínio, o cobre, o aço e o aço inoxidável os comumente mais empregados na construção de trocadores de calor do tipo serpentina.

No caso específico de arrefecedores para módulos fotovoltaicos, um estudo abrangente de Anderson et. al. (2010), no qual testou diferentes tipos de materiais para a construção do coletor térmico, arrefecedor. Neste estudo foi utilizado aço carbono, alumínio, cobre e aço inoxidável, concluindo que não há aumento da eficiência térmica, independentemente do tipo do material do coletor. Observou-se que o alumínio e o cobre, mesmo possuindo coeficiente de condutividade térmica maior que o aço, não apresentam ganhos significativos de eficiência. Essa conclusão é um bom indicativo, pois o aço, dentre os quatro materiais deste estudo, apresenta o menor custo de aquisição, além disso, não exige processo de fabricação altamente especializado, como é o caso dos outros três materiais.

Assim, analisando a Figura 57, fica evidente que as curvas de eficiência térmica, dos diferentes materiais, sobrepõem-se umas as outras e que o aço é o material que melhor se adequa ao desenvolvimento dos modelos de UMAr. O fenômeno apresentado é fácil de explicar se observarmos que a superfície inferior do módulo PV é de material polímero, com baixa condutividade térmica, por isso, mesmo que se utilizem materiais com grande condutividade térmica, o ganho de eficiência seria baixo, não justificando os altos custos na sua aquisição. 


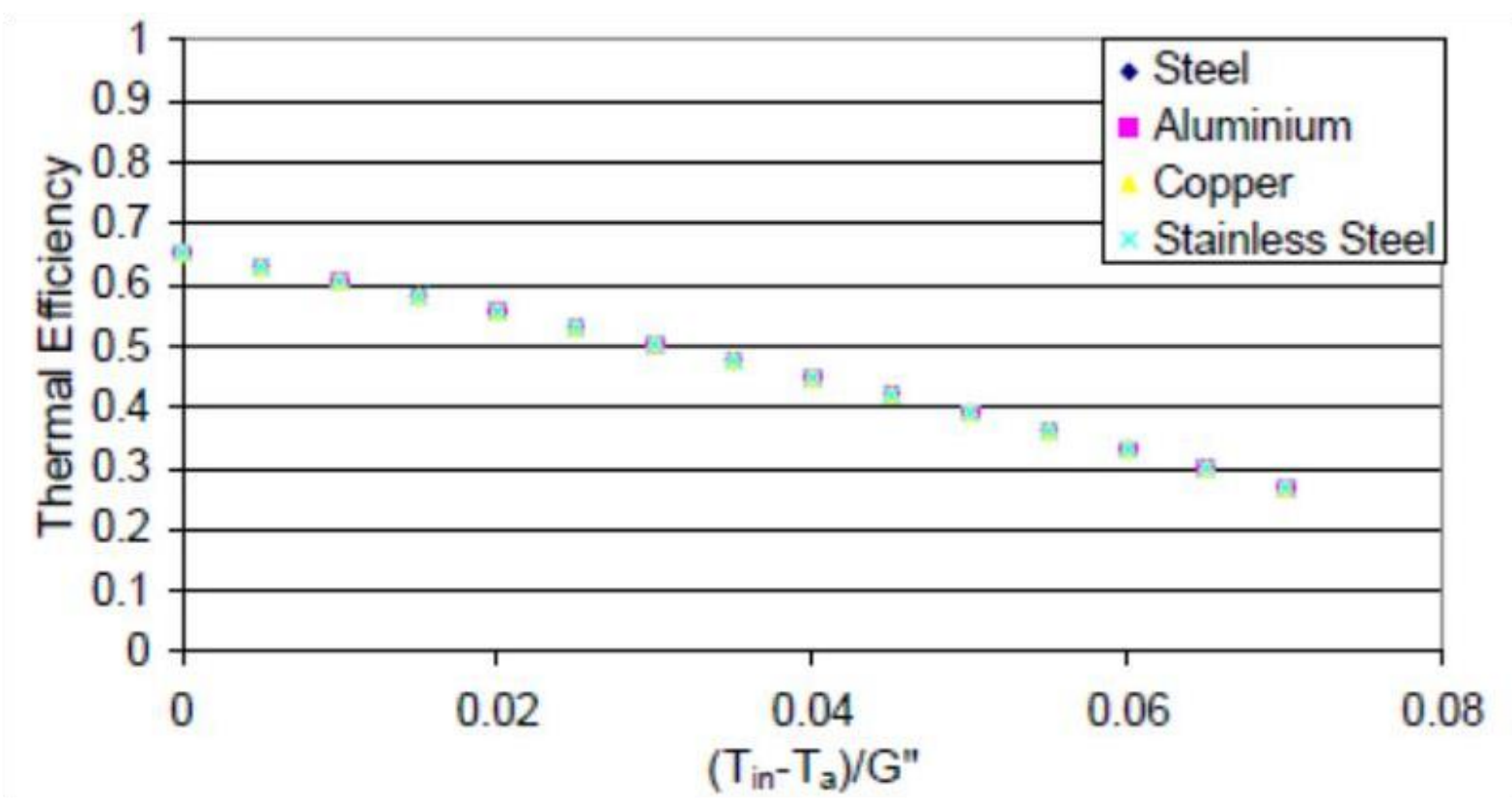

Figura 57 - Eficiência térmica em relação ao tipo de material utilizado no coletor de calor.

Fonte: Anderson et. al. 2010.

Portanto, o material selecionado para a chapa e tubo é o aço.

A seleção da chapa levou em consideração aspectos técnicos construtivos, operação, características física e química do material como:

- As dimensões, comprimento e largura do módulo PV, que devem ser iguais ou próximas à chapa para evitar processos de corte, e por sua vez, descarte de material;

- Peso, considerando a espessura já que a chapa serve, principalmente, para aumentar a região de contato entre o coletor e o módulo PV;

- Não há necessidade de material com alta resistência mecânica a flexão, assim o material pode apresentar pequena espessura e garantir que o modelo não apresente elevado peso seco facilitando a sua montagem, fixação e operação;

- Capacidade de resistir às intempéries do tempo, já que o arrefecedor fica exposto ao tempo vinte quatro horas por dia, ou seja, o material deve ser resistente à corrosão, pois estará sujeito a chuvas, sol e inversões térmicas ao longo do dia; e

- Permitir processos de soldagem. 
Portanto, o tipo de chapa escolhido foi de aço fina com revestimento de zinco em bob. (bobina), de norma NBR 7008 grau ZC, ver Figura 58, detalhes de peso, dimensões e composição ver Anexo .

A seleção do tubo, assim como da chapa, levou em consideração os aspectos técnicos de construção e operação, características física e química do material como:

- O diâmetro do tubo, que deve ser pequeno, para garantir que a velocidade de escoamento do fluido seja de aproximadamente $2,0 \mathrm{~m} / \mathrm{s}$, sem demandar volume de água extremamente grande, inviabilizando o modelo;

- Espessura do tubo, ponderando o peso, pois o seu comprimento é padronizado $(6.000 \mathrm{~mm})$, e resistência mecânica a flexão para garantir a rigidez e integridade estrutural do arrefecedor;

- Capacidade de resistir às intempéries do tempo, já que o arrefecedor fica exposto ao tempo vinte quatro horas por dia, ou seja, o material deve ser resistente à corrosão, pois estará sujeito a chuvas, sol e inversões térmicas ao longo do dia; e

- Permitir processos de soldagem.

Portanto, o tipo de tubo escolhido foi de aço carbono DIN 2394 (atualmente DIN EM 10.305-3), no estado de fornecimento NBK (normalizado em atmosfera controlada), ver Figura 58, detalhes técnicos de dimensões, composição química e propriedades mecânicas ver Anexo E. 


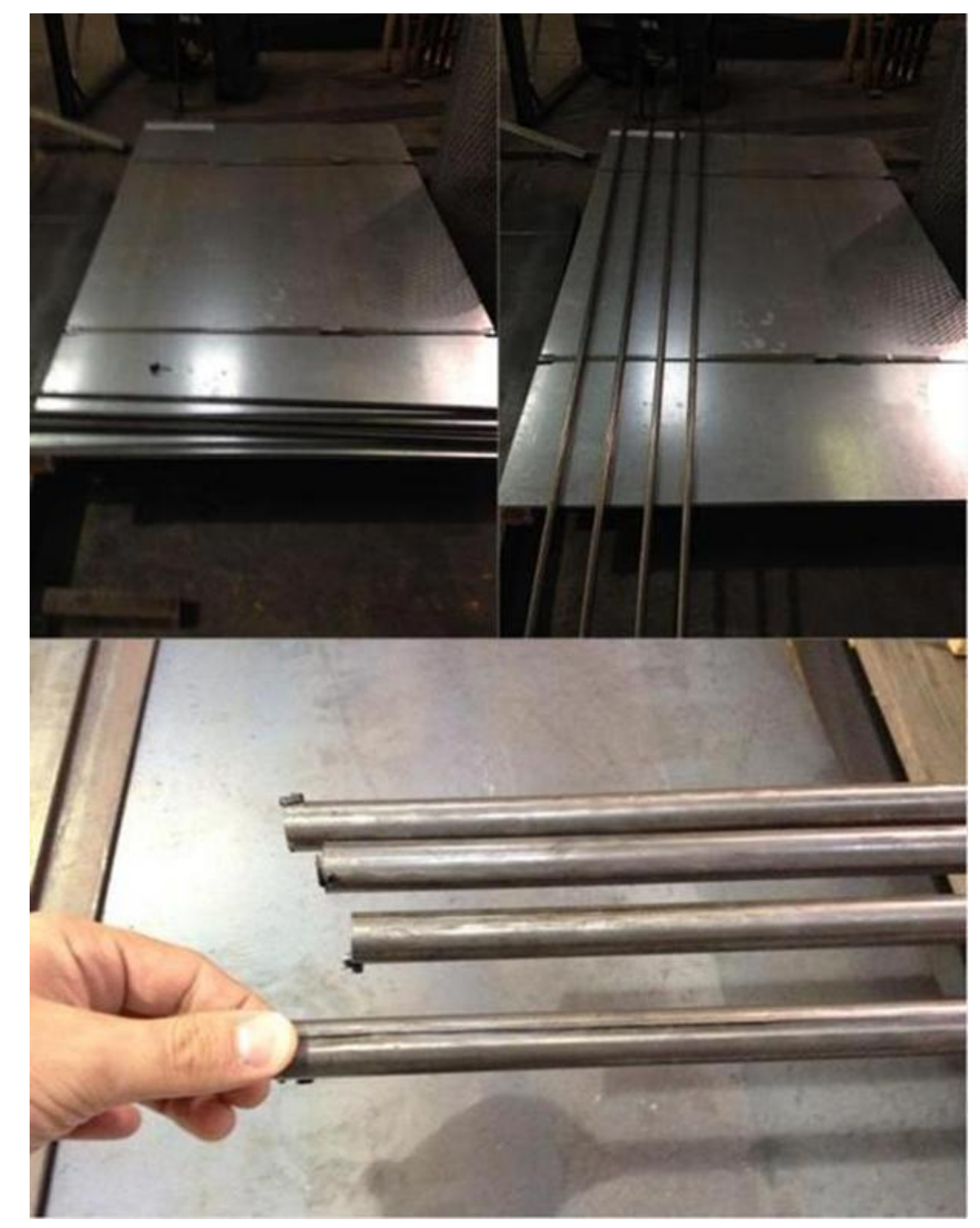

Figura 58 - Materiais selecionados e comprados para a produção dos modelos de UMAr

Após a seleção e obtenção dos materiais, começou a produção das serpentinas a partir do dobramento e soldagem dos tubos. Inicialmente, testou-se a capacidade do material de se deformar por meio do dobramento com uma dobradeira manual a frio, ver Figura 59. 


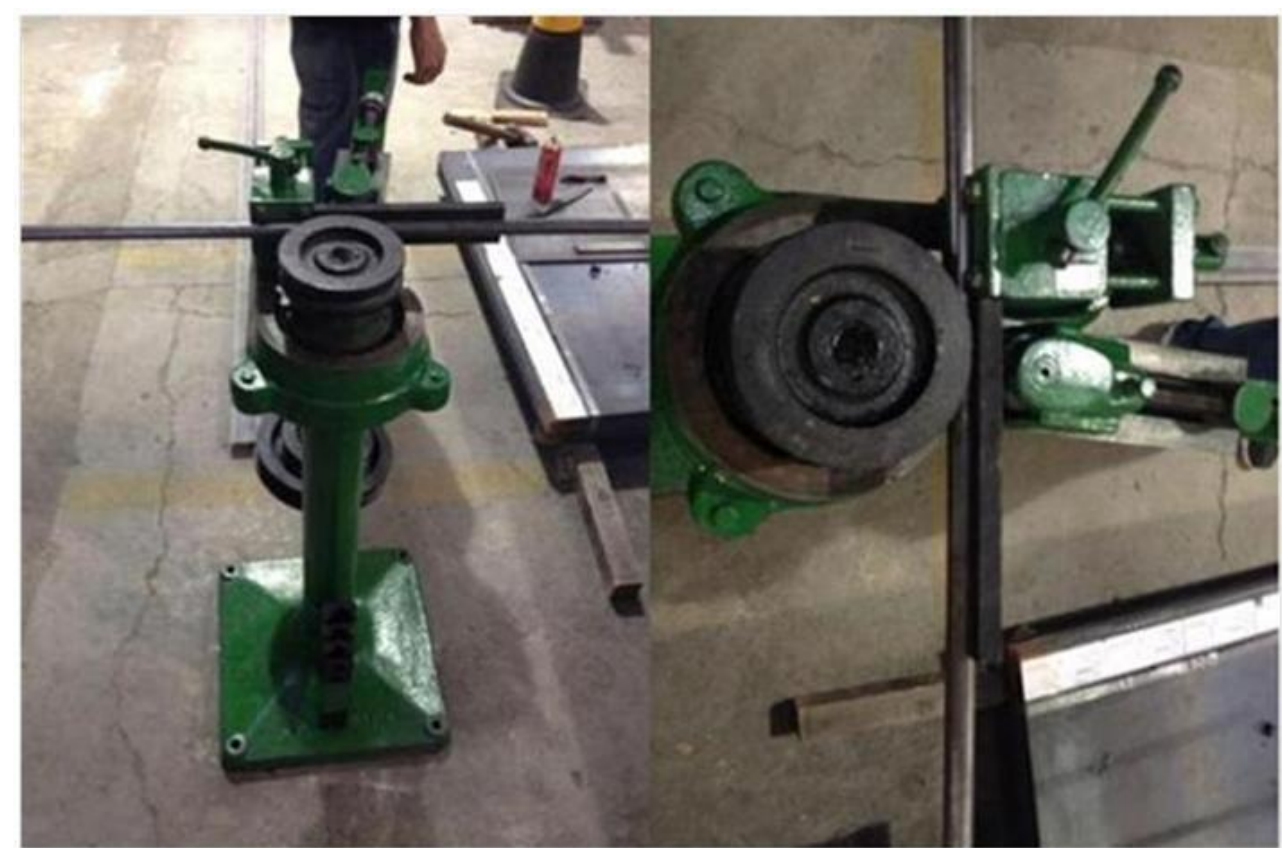

Figura 59 - Dobradeira manual a frio para teste

Com esse teste, analisou-se que o material selecionado apresenta boa capacidade de deformação plástica sem sofrer ruptura, ver Figura 60

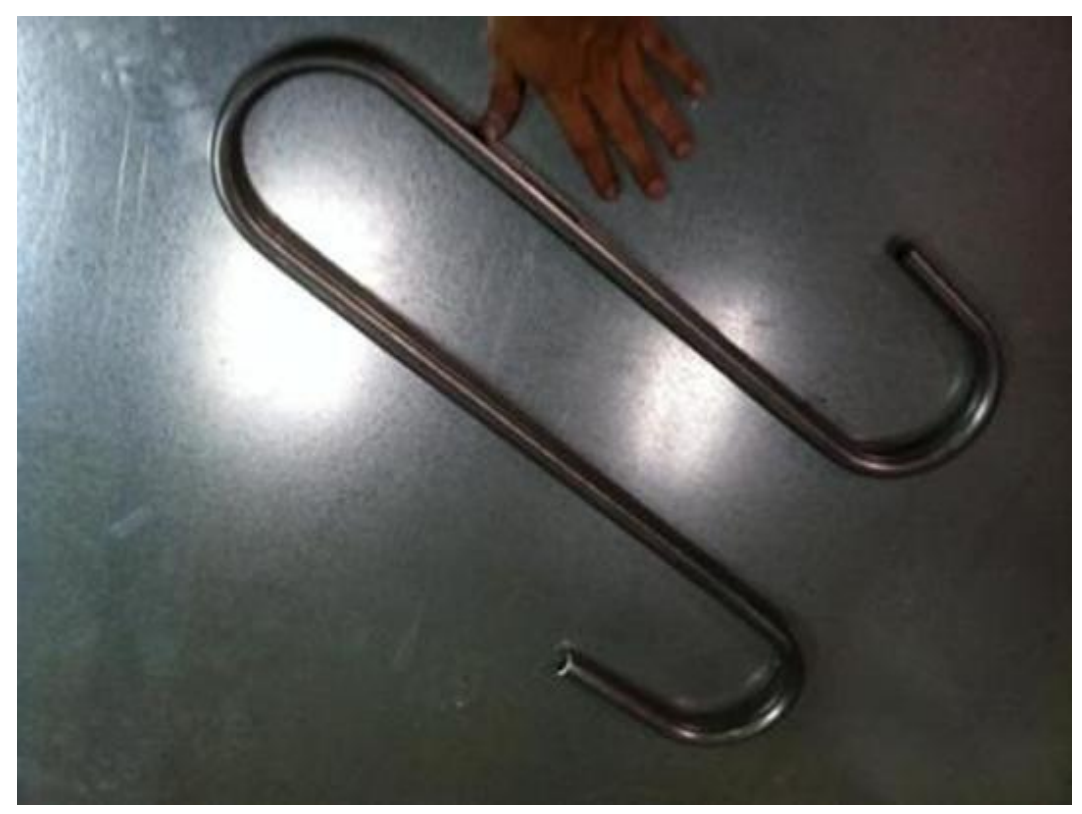

Figura 60 - Tubo de aço carbono DIN 2394 após teste de dobragem

Com a constatação de que o material selecionado para produção da serpentina supria as condições de dobragem, as serpentinas, do modelo 1 e do modelo 2 , foram construídas utilizando uma dobradeira automática a frio, ver Figura 61, 
garantindo que as dimensões de projeto fossem obedecidas, assim, evitando desperdício de material, além de reduzir o tempo de mão de obra.

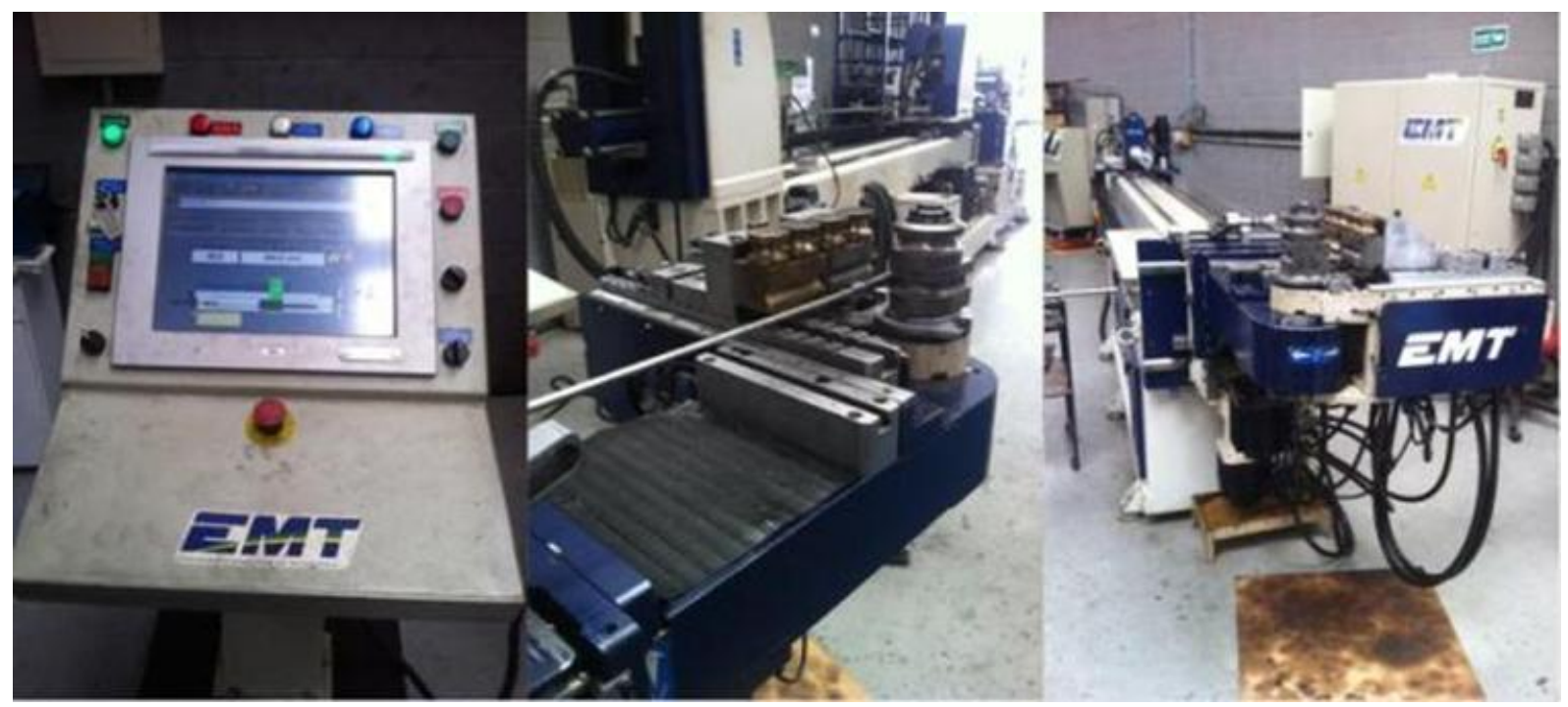

Figura 61 - Dobradeira automática a frio utilizada na produção das serpentinas dos dois modelos do tipo chapa-tubo.

Os tubos, após serem conformados pela dobradeira automática, ver Figura 62, foram unidos por meio do processo de soldagem do tipo MIG, ver Figura 63(a), e posteriormente passaram pelo teste de estanqueidade, no qual receberam fornecimento contínuo de água para verificar vazamentos e a integridade da solda, não sendo constatado nenhum tipo de vazamento na junção soldada e ao longo da sua superfície.

Ratificando, o tipo de processo de soldagem final foi concluído após teste com solda tipo MAG, ver Figura 63(b), que apresentou péssimo acabamento, além de pequeno vazamento na junção soldada durante o teste de estanqueidade, sendo descartado como solução. 


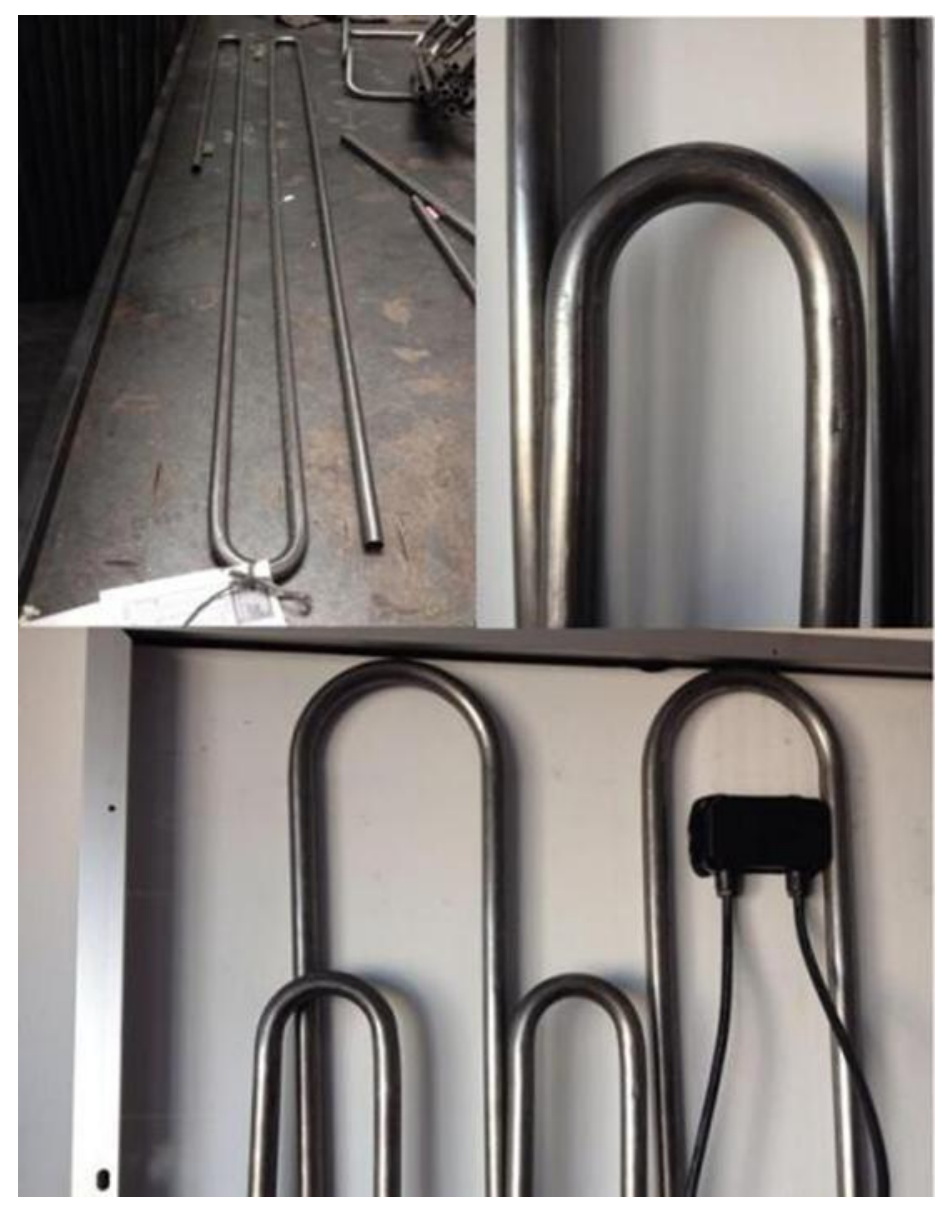

Figura 62 - Serpentinas dos modelos 1 e 2.

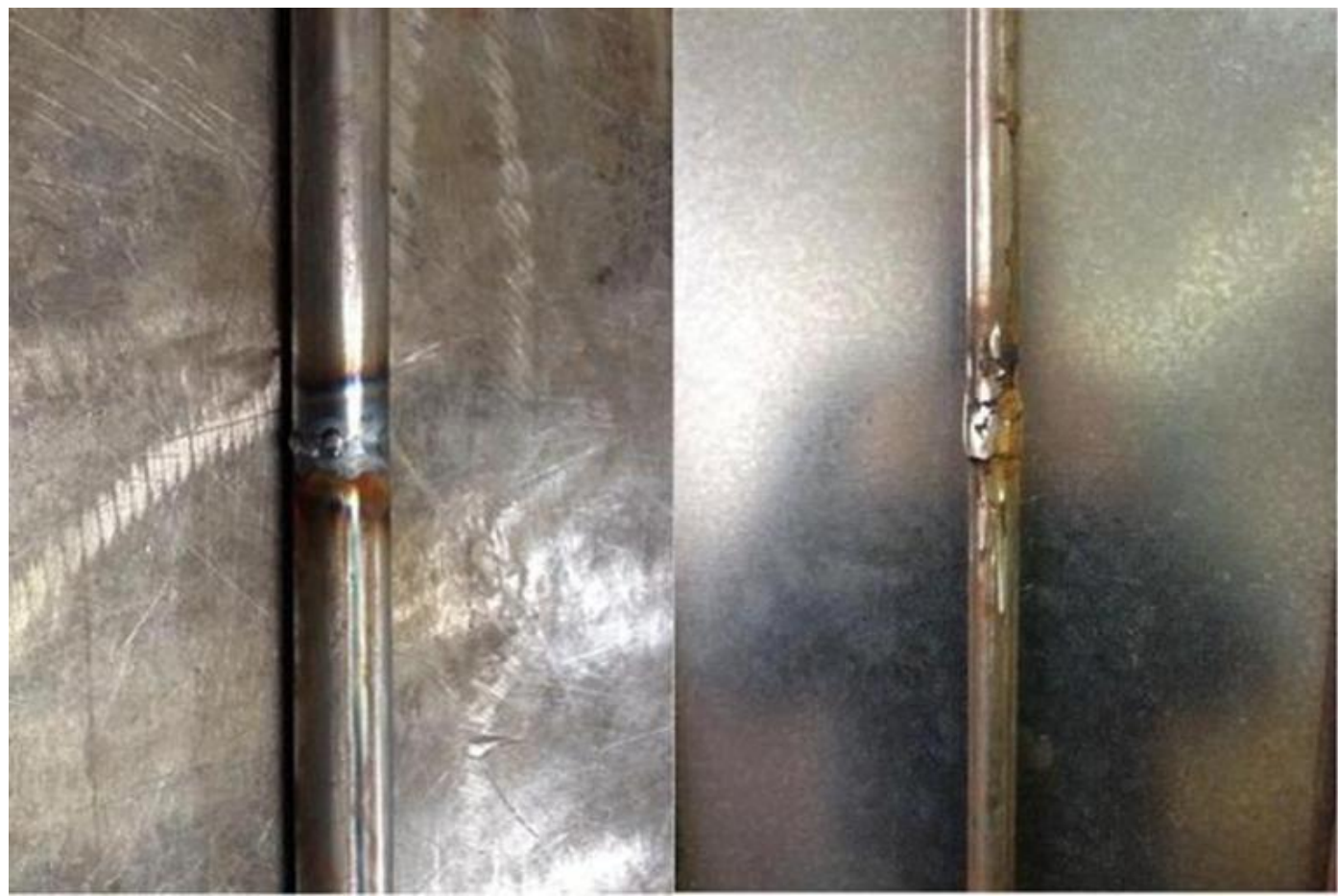

(a)

(b)

Figura 63 - Junção dos tubos por processo de soldagem do tipo (a) MIG e (b) MAG. 
A soldagem MIG (sigla em inglês para Metal Inert Gas) utiliza um arco elétrico entre a peça (tubos) e o eletrodo consumível (arame metálico), fornecido por um alimentador automático de forma contínua, realizando uma união de materiais metálicos pelo aquecimento e fusão. O arco elétrico funde de forma contínua o arame à medida que alimenta a poça de fusão. O metal de solda é protegido da atmosfera por um fluxo de gás inerte (argônio ou hélio que não possui nenhuma interatividade física com a poça de fusão). Neste processo de soldagem, é utilizada corrente contínua (CC). A diferença entre a solda MIG em relação à MAG (siglas em inglês para Metal Active Gas) é a utilização de gás ativo, ou seja, um gás que interage com a poça de fusão, geralmente CO2.

\section{C.1.2 Junção chapa-tubo}

A junção chapa-tubo apresentou maiores dispêndios de tempo e de desenvolvimento relacionados à seleção de materiais, processo de fabricação e prétestes fabris. No que tange à junção chapa-tubo, foram realizados diversos testes de soldagem para fixar o tubo na chapa. O processo de ponteamento de solda foi definido como procedimento padrão para a junção chapa-tubo para os dois modelos. Este processo é utilizado para fixar componentes antes de executar uma soldagem posterior, além de evitar movimento relativo entre as diferentes partes constituintes de um equipamento, quando este é colocado em serviço.

Testes iniciais foram realizados para determinar o tipo de solda empregado no processo de ponteamento de solda devido à dificuldade de unir a chapa, pequena espessura, com o tubo, pequena superfície de contato e espessura, de modo que nenhum dos componentes sofresse fratura, deformação e empenamento.

Primeiramente testou-se a solda tipo TIG (sigla em inglês para Tungsten Inert Gas) com deposição de material metálico na poça de fusão, resultando na deformação dos componentes e de ponto de solda irregular, isso ocorreu devido a grande temperatura do arco elétrico e da pequena espessura dos componentes. $O$ resultado da soldagem dos componentes com a solda TIG pode ser visto na Figura 64. 


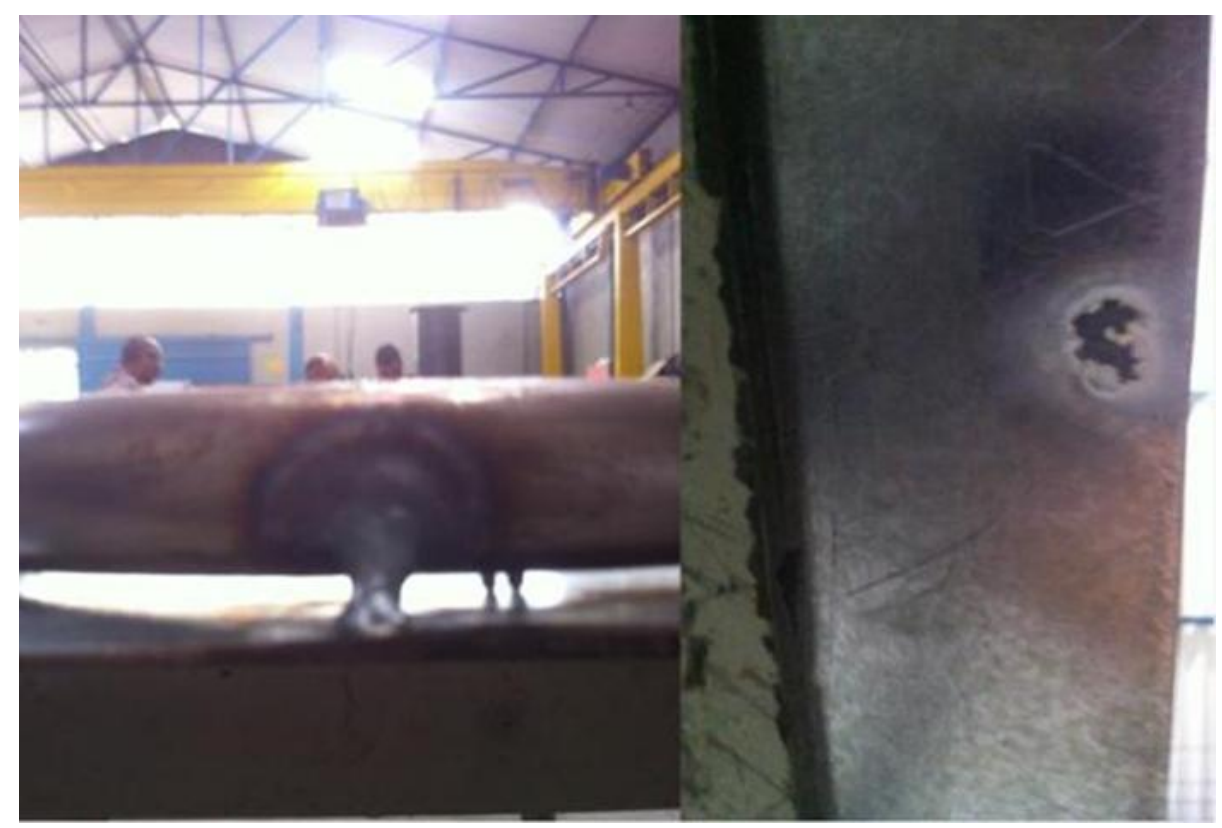

Figura 64 - Junção Chapa-Tubo por soldagem tipo TIG de teste.

A solda tipo TIG é um processo de soldagem a arco elétrico entre um eletrodo não consumível de tungstênio com proteção gasosa feita por um gás inerte (hélio) e a poça de fusão, sobre a qual se utiliza ou não a deposição de um metal de adição, normalmente na forma de um arame.

Após constatar que a solda tipo TIG não apresentou o acabamento esperado ao processo de ponteamento de solda, testou-se a solda tipo MIG, a mesma utilizada na junção dos tubos da serpentina. Essa solda apresentou bom desempenho, como pode ser observado na Figura 65, garantindo a integridade física do material, provendo bom acabamento e, além disso, o processo de ponteamento de solda com solda tipo MIG demonstrou ser mais rápido quando comparado à solda tipo TIG.

Assim, como no caso do teste de estanqueidade da junção tubo-tubo foi realizado outro teste para verificar se houve algum tipo de perfuração nos tubos durante processo de ponteamento de solda, no qual se verificou que a integridade física dos tubos estava mantida, não apresentando nenhum tipo de vazamento. 


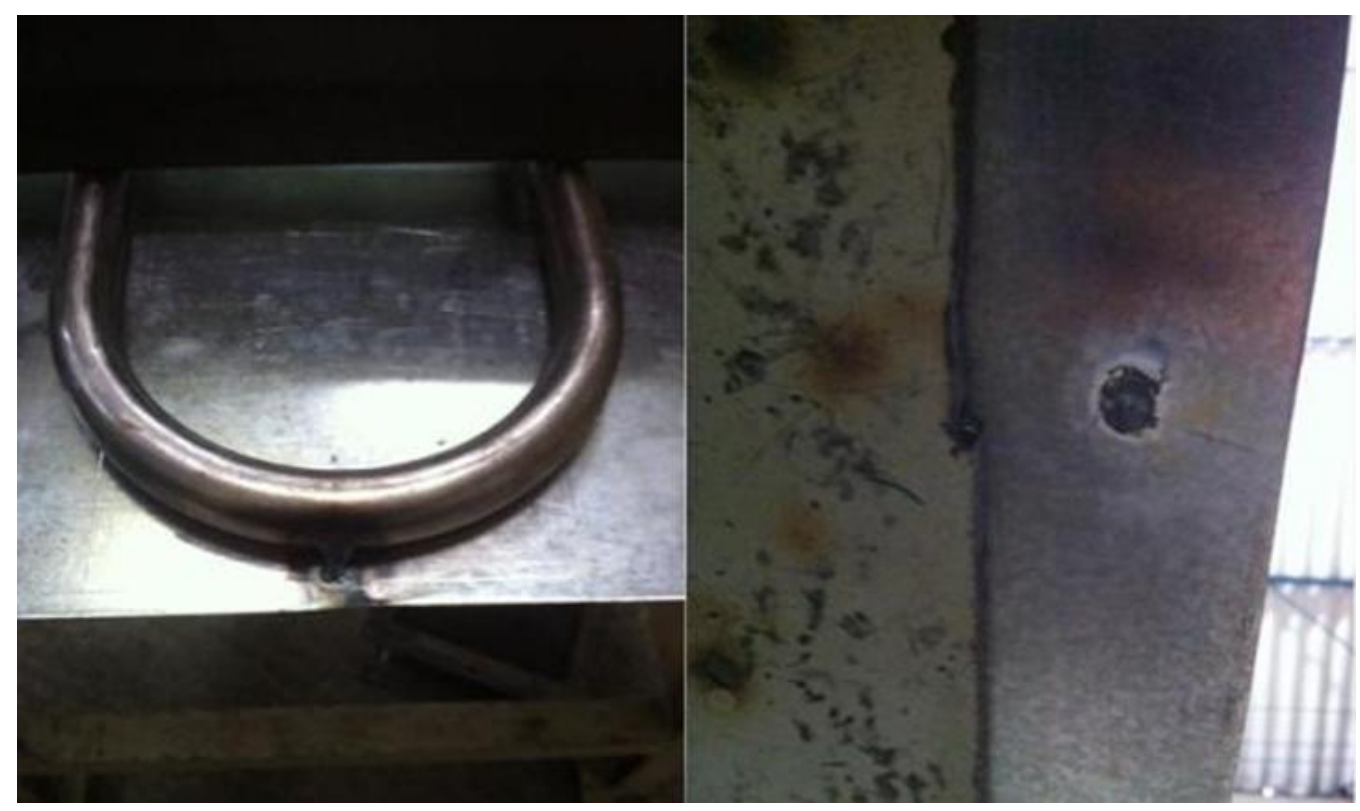

Figura 65 - Junção Chapa-Tubo por soldagem tipo MIG de teste.

Assim, com a constatação de que o processo de ponteamento de solda seria feito por meio da solda tipo MIG, a junção das serpentinas em suas respectivas chapas foi realizada. O resultado deste processo pode ser observado na Figura 66.

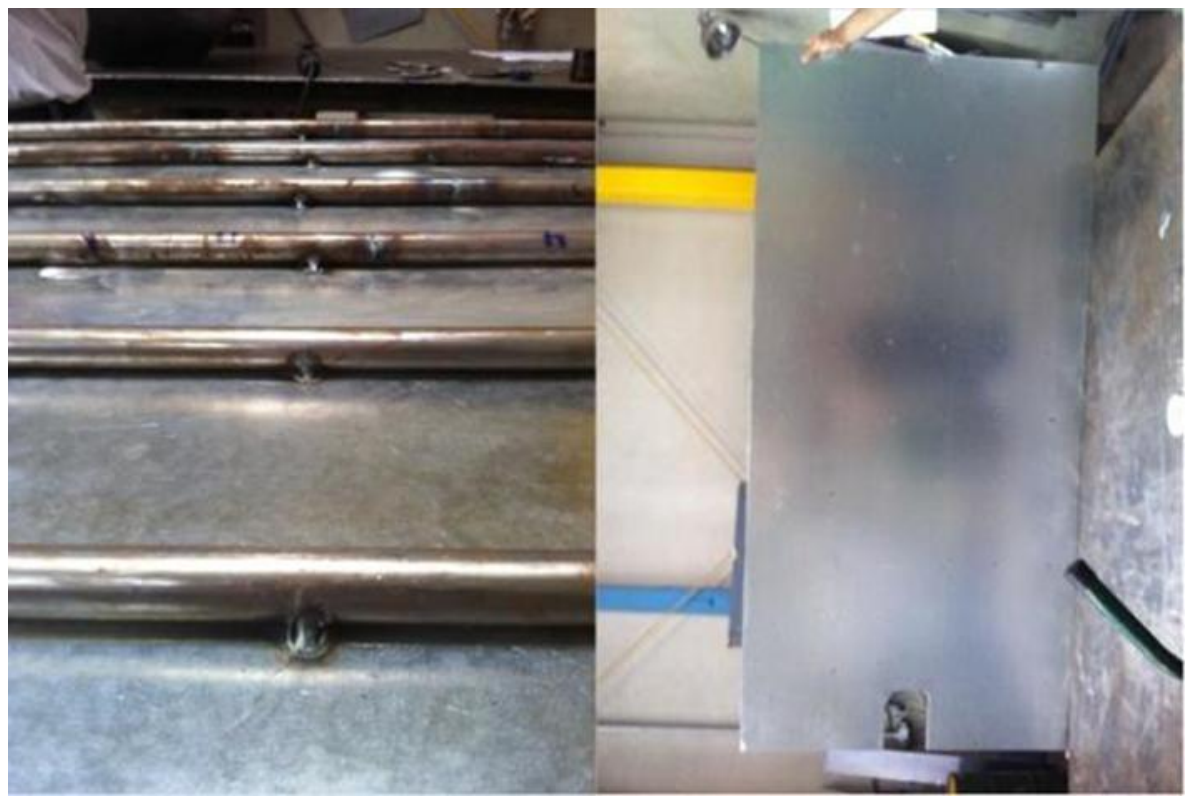

Figura 66 - Junção chapa-tubo final do tipo MIG.

Após a determinação dos processos de fixação do tubo na chapa, estudou-se o aumento do contato entre tubo e chapa, essa característica é primordial para aumento da superfície de contato e das trocas térmicas entre o fluido refrigerante e o equipamento de arrefecimento, sendo extremamente importante para garantir que 0 módulo PV arrefeça. 
O primeiro teste, de aumento da superfície de contato, foi realizado por meio do processo de deposição de material metálico, no caso barra de estanho, por fusão, utilizando-se um maçarico alimentado por combustível GLP (gás liquefeito de petróleo). Este procedimento apresentou diversas dificuldades relacionadas à qualidade da deposição do material com formação de bolhas, espaços vazios e não linearidade da solidificação do material fundido, além de ser um processo demorado devido ao excessivo gasto de tempo com a manipulação do filamento de estanho e o controle da temperatura de chama, ver Figura 67.

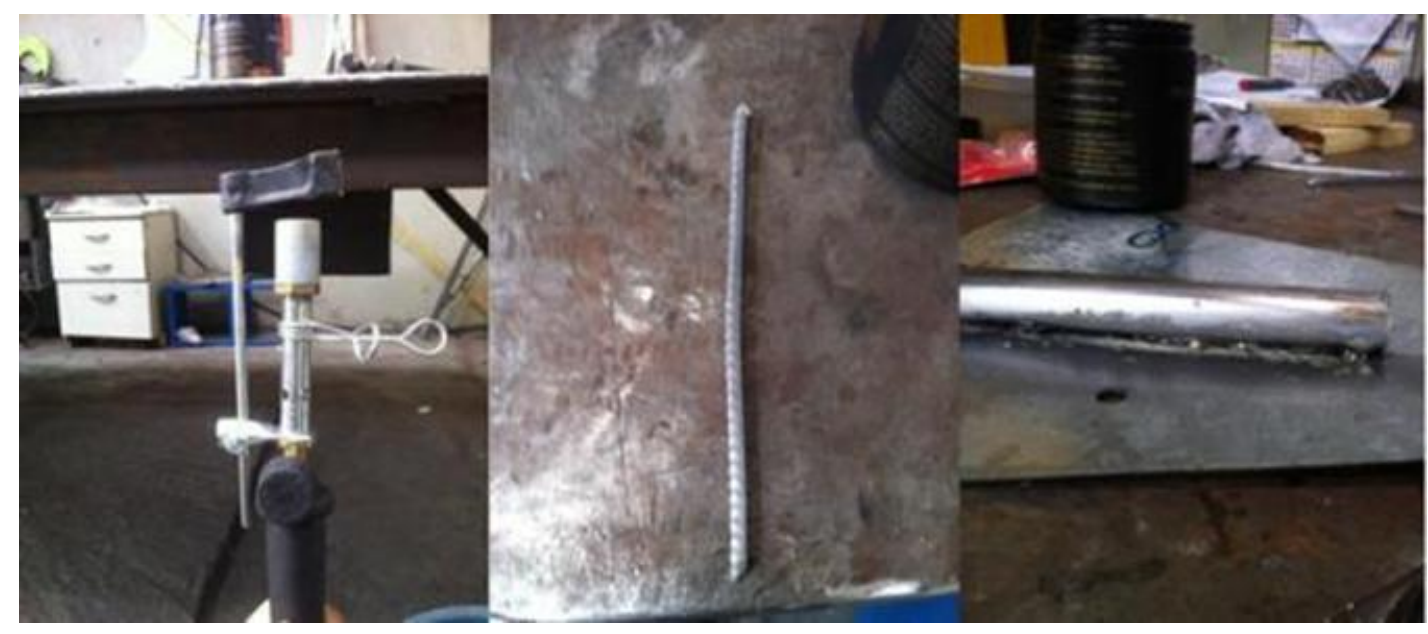

Figura 67 - Maçarico, filamento de estanho e acabamento da deposição de material.

Assim o método de deposição de material por fusão foi descartado, partindo para a utilização de material epóxi com razoável condutividade térmica, fácil manipulação, atóxica, e que confira boa rigidez à junção. Essa solução pode parecer trivial, mas a disponibilidade de pasta epóxi condutora de calor disponível no mercado é escassa necessitando de importação, o que confere grandes dificuldades ao projeto devido ao alto custo do material e pelo grande tempo de espera do recebimento, um mês após a efetivação da compra, e pela impossibilidade de adquirir pouco volume do produto. Essas condições implicaram em pesquisas paralelas como solução deste problema, que se tornou um gargalo para o andamento do desenvolvimento dos modelos de UMAr.

Assim, três tipos diferentes de pasta epóxi condutoras foram desenvolvidas e posteriormente testadas para verificar a capacidade de junção chapa-tubo, ver 
Figura 68, na qual a pasta representada pela Figura 68(b) apresentou melhor acabamento, facilidade de manipulação e menor tempo de espera de secagem.

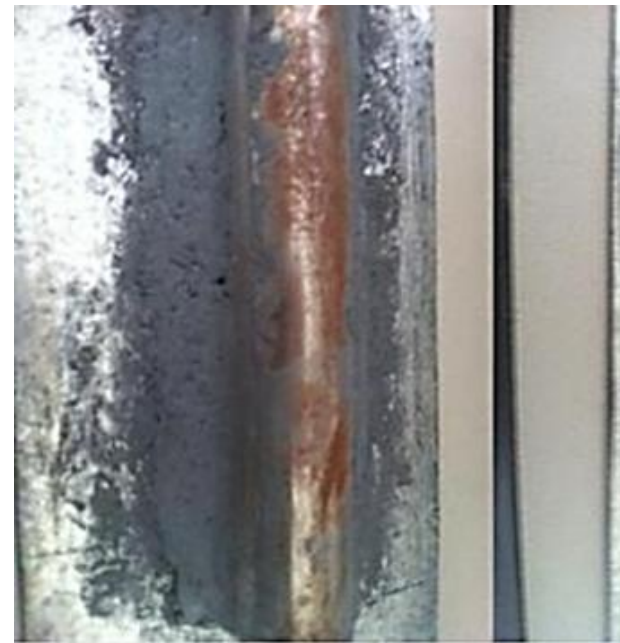

(a)

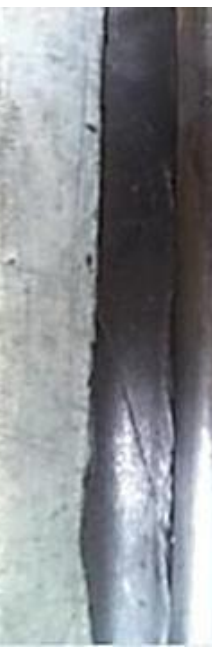

(b)

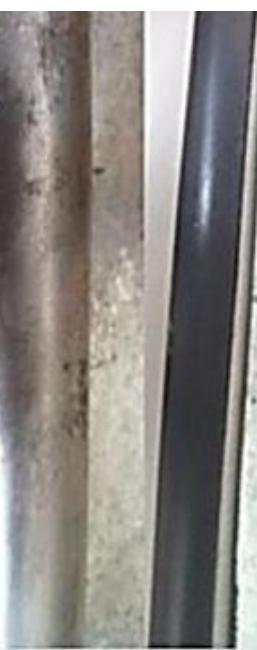

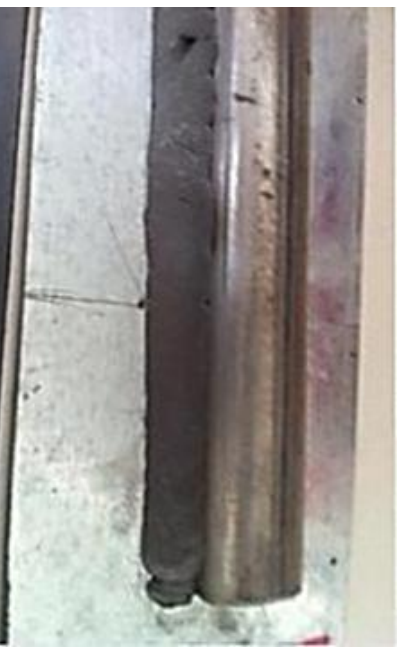

(c)

Figura 68- tipos de acabamento da junção chapa-tubo utilizando três diferentes pastas epóxi condutora.

Portanto, com a determinação do tipo de pasta epóxi condutora, os dois modelos do tipo chapa-tudo puderam ser finalizados, e a pasta foi adicionada a eles, ver Figura 69.

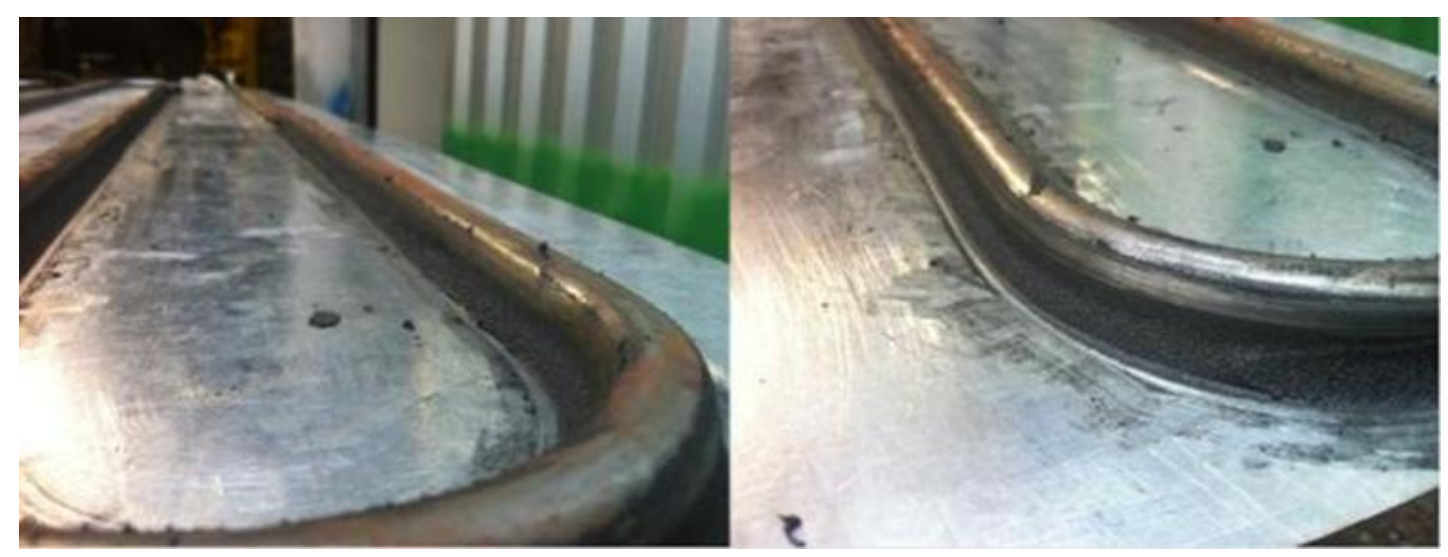

Figura 69 - Modelos de UMAr após receberem aplicação de pasta epóxi condutoras.

É importante frisar que esta pasta epóxi não possui nenhum estudo sobre a sua durabilidade ao longo do tempo, um, dois e até dez ou vinte como é o caso da garantia de funcionamento do módulo PV.

Após a aplicação da pasta e, posteriormente secagem da junção chapa-tubo, os modelos passaram pelos processos finais de construção. 


\section{C.1.3 Acabamento, limpeza e inspeção}

Para finalizar os modelos de UMAr do tipo chapa-tubo e disponibilizá-los para instalação na U.P., eles passaram por processos de acabamento, limpeza e inspeção visual.

Processo de Acabamento, ver Figura 70:

- Polimento das superfícies da chapa para evitar a formação de veios e espaços entre o arrefecedor e a superfície inferior do modulo PV;

- Corte dos cantos e rebarbas para evitar acidentes durante a manipulação do equipamento;

- Aplicação de uma cobertura de tinta para evitar a oxidação dos pontos que passaram por polimento; e

- Aplicação de tinta sobre toda a superfície inferior do arrefecedor.

Processo de Limpeza:

- Facilitar a inspeção do equipamento e garantir a sua integridade durante a armazenagem.

Inspeção visual:

- Garantir que o equipamento não possui nenhum defeito visível adquirido durante os processos finais de acabamento e limpeza.

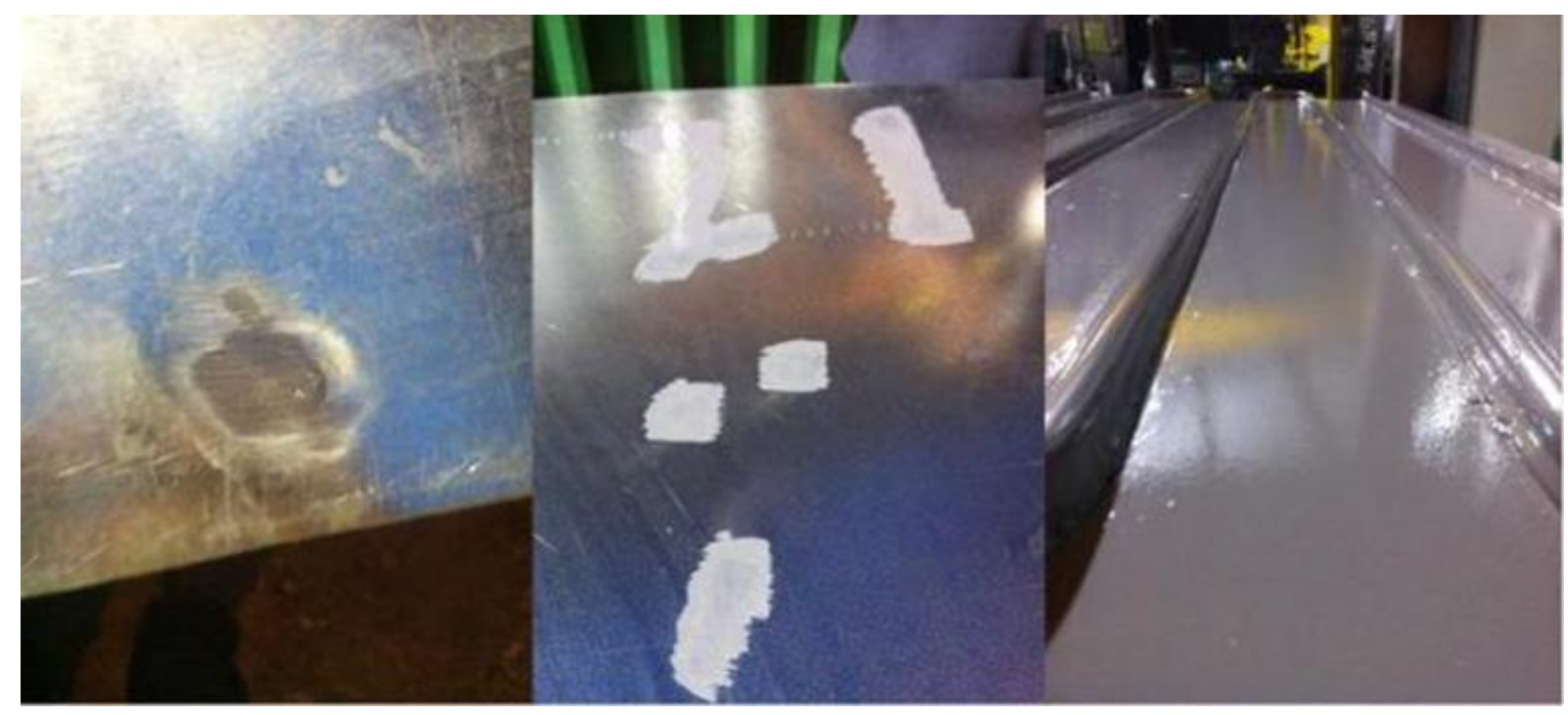

Figura 70 - Figuras representativas do polimento e aplicação de tinta anticorrosão. 


\section{C.2 DESENVOLVIMENTO DO MODELO DE UMAR DO TIPO MÚLTIPLOS CANAIS}

O desenvolvimento do modelo do tipo múltiplos canais se assemelha ao apresentado anteriormente.

A seleção da chapa utilizou as conclusões e testes realizados no desenvolvimento dos modelos chapa-tubo. Assim o tipo de chapa escolhido é o mesmo utilizado na construção dos modelos anteriores

A fabricação dos canais, dutos de direcionamento da passagem de água, consistiu na utilização de equipamentos de corte, tipo guilhotina para garantir uniformidade das dimensões e do corte, e dobradeira mecânica para deformar as chapas cortadas e permitir a existência de dobras, perfil "U", facilitando o processo de ponteamento de solda, assim como na seleção da chapa metálica, a seleção do processo de fixação dos dutos na chapa metálica utilizou a conclusão do modelo anterior que definiu que a solda empregada na manipulação de chapas finas é tipo MIG.

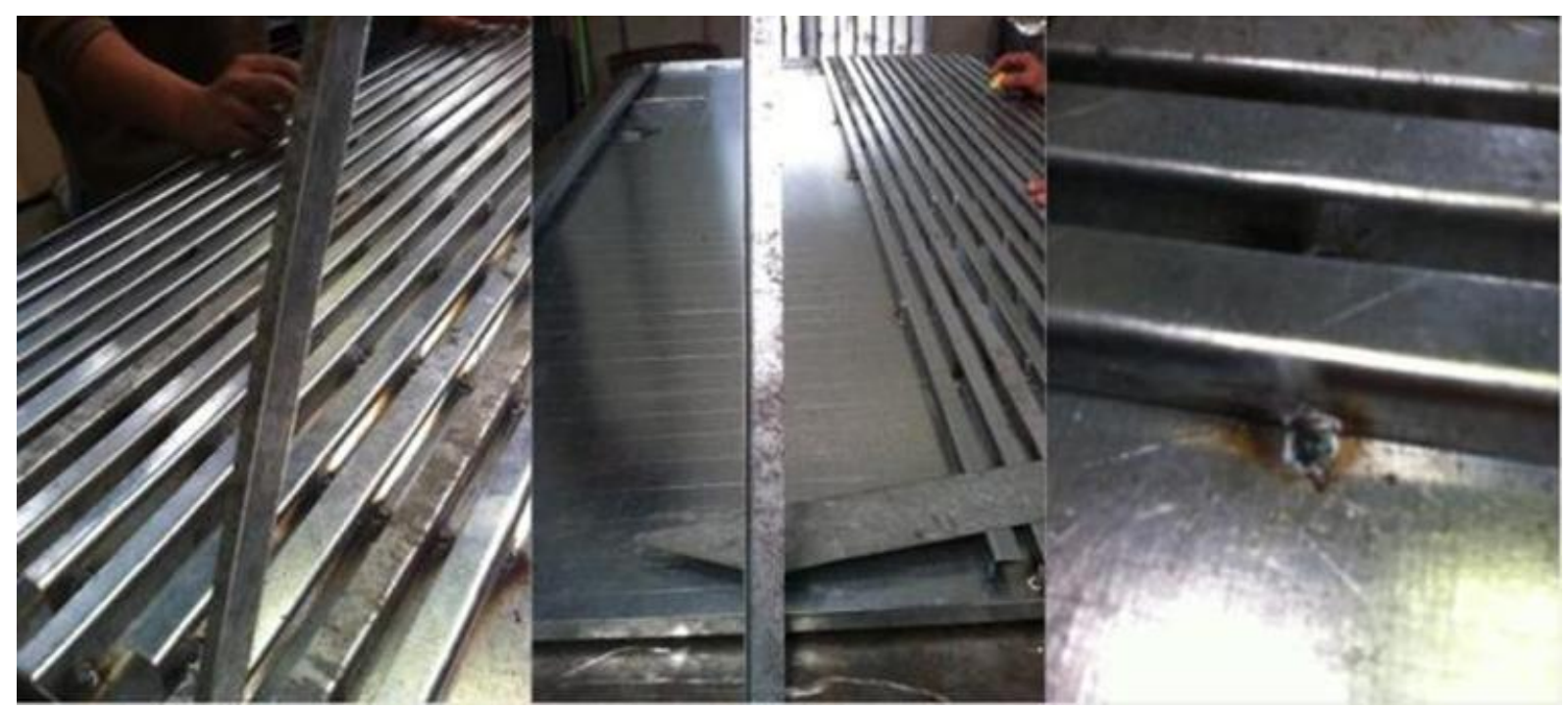

Figura 71 - Chapas finas cortadas, dobras e fixadas por ponteamento de solda de solda.

Após a fixação de todos os dutos na chapa fina dobrada utilizada como base de fixação, ver Figura 72, o equipamento passou por uma limpeza, para retirar objetos, rebarbas e escorias de dentro a fim de evitar futuros entupimentos, e inspeção visual para garantir que todos os dutos estivessem devidamente fixados e que nenhum objeto estivesse dentro do equipamento podendo causar entupimento e, 
posteriormente, receber uma cobertura metálica, chapa fina devidamente cortada, para selar o equipamento.

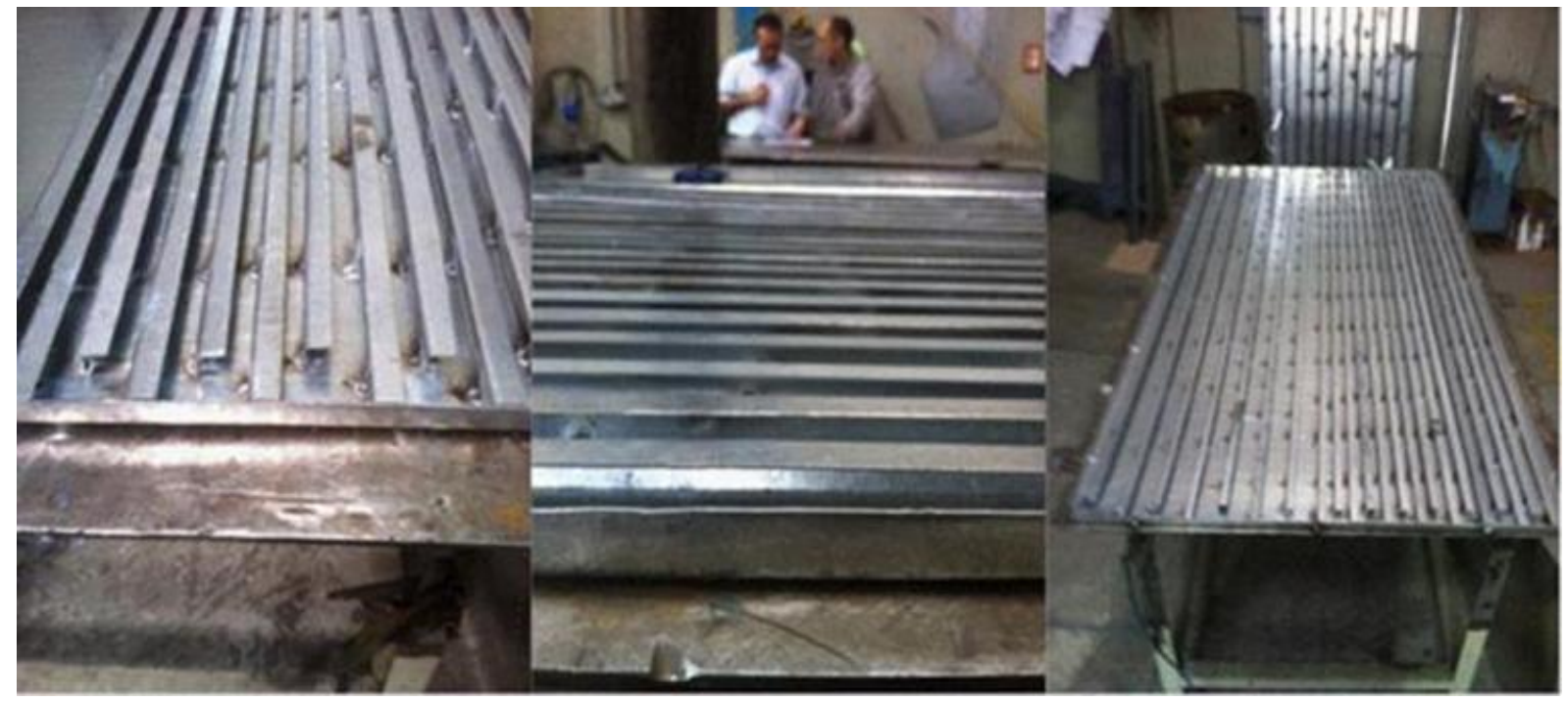

Figura 72 - Dutos fixados na chapa.

Assim como nos modelos do tipo chapa-tubo, o arrefecedor depois de finalizada sua construção, foi pesado, apresentando peso seco muito elevado, o que dificultou a sua manipulação e se somado o peso da água, quando o modelo estiver operando, seu peso total seria excessivamente grande comprometendo a integridade física do módulo PV, uma vez que os arrefecedores serão fixados por meio do quadro metálico do módulo. Além disso, o modelo finalizado passou por teste de estanqueidade, o qual não foi aprovado devido à ruptura das soldas. O modelo voltou para a mesa de soldagem diversas vezes para ser reparado e mesmo assim não passou no teste de estanqueidade.

Portanto, o modelo do tipo múltiplos canais foi descartado como alternativa de UMAr por não apresentar condições construtivas economicamente viáveis para sua finalização, uma vez que chapas mais grossas e outros tipos de solda poderiam ser empregados, mas isto necessitaria que outros modelos de fixação fossem elaborados, aumentando os custos de desenvolvimento com mobilização de pesquisadores, para selecionar novos materiais e processos de fabricação, compra de mais material e necessidade de mais testes. 


\section{C.3 DESENVOLVIMENTO DA ESTRUTURA DE FIXAÇÃO MODELO DE UMAR/MÓDULO PV}

O desenvolvimento da estrutura de fixação dos modelos de UMAr nos módulos PV ocorreu a partir da premissa de que este deve utilizar apenas a estrutura do quadro metálico do módulo PV, ver Figura 73b, e de que, ao mesmo tempo, não prejudique o seu funcionamento e integridade física, essa característica é importante, pois as estruturas, nas quais os módulos PV são instalados para formarem uma usina, não possuem padronização. Além disso, a instalação deste suporte deve ser simples, rápida e sem a necessidade de ferramentas especiais.

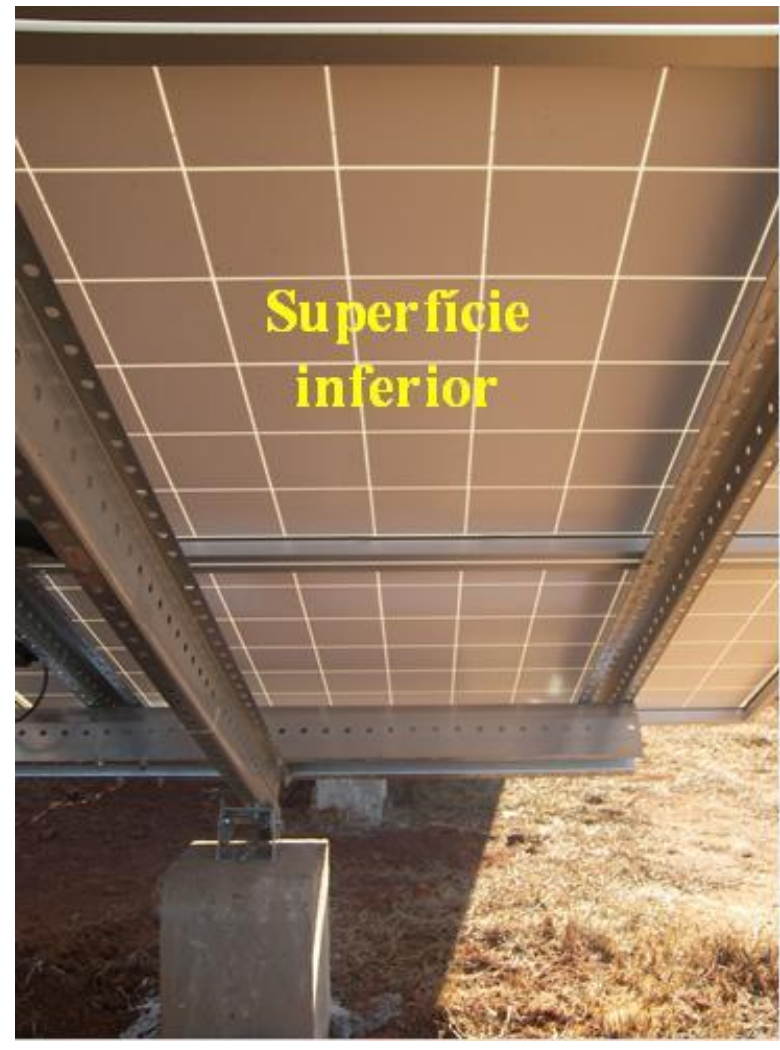

(a)

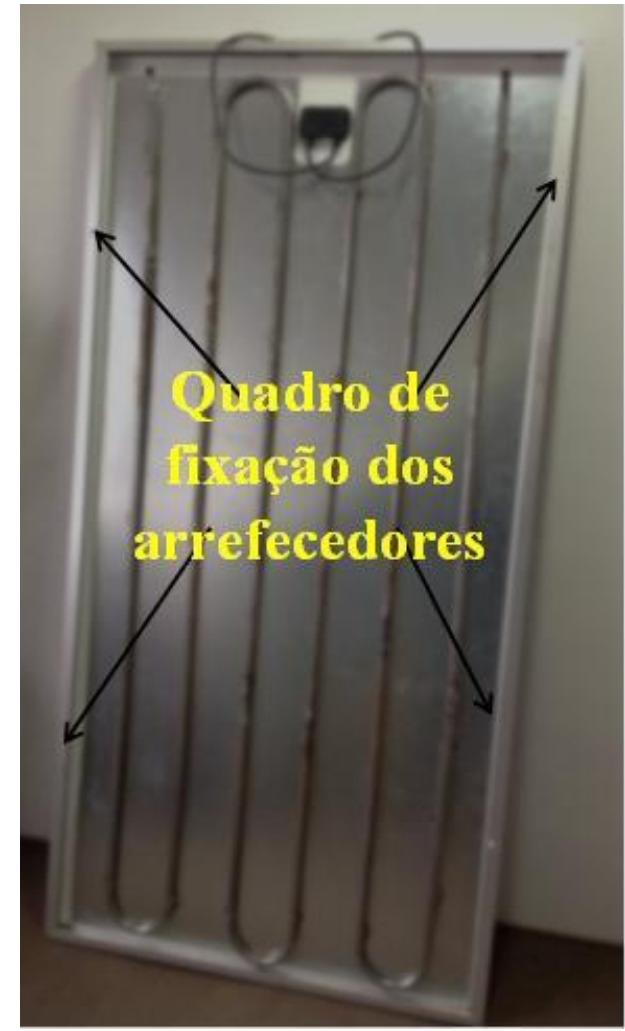

(b)

Figura 73 - Representação dos locais de instalação do arrefecedor. (a) superfície inferior do módulo PV e (b) quadro metálico do módulo PV.

A fabricação do suporte consistiu na utilização de equipamentos de corte tipo guilhotina para garantir uniformidade das dimensões, seguido pelo ponteamento de solda do tipo MIG, conferindo à estrutura um perfil do tipo "T". As chapas, após a soldagem, foram suavemente conformadas em uma dobradeira mecânica de modo a permitir a fixação por pressão no quadro metálico do módulo PV. Esta configuração 
permite que 0 arrefecedor, independentemente do modelo final escolhido, seja instalado manualmente sem nenhum tipo de ferramenta. Além disso, as estruturas passaram pelos processos de acabamento, limpeza e inspeção visual. 


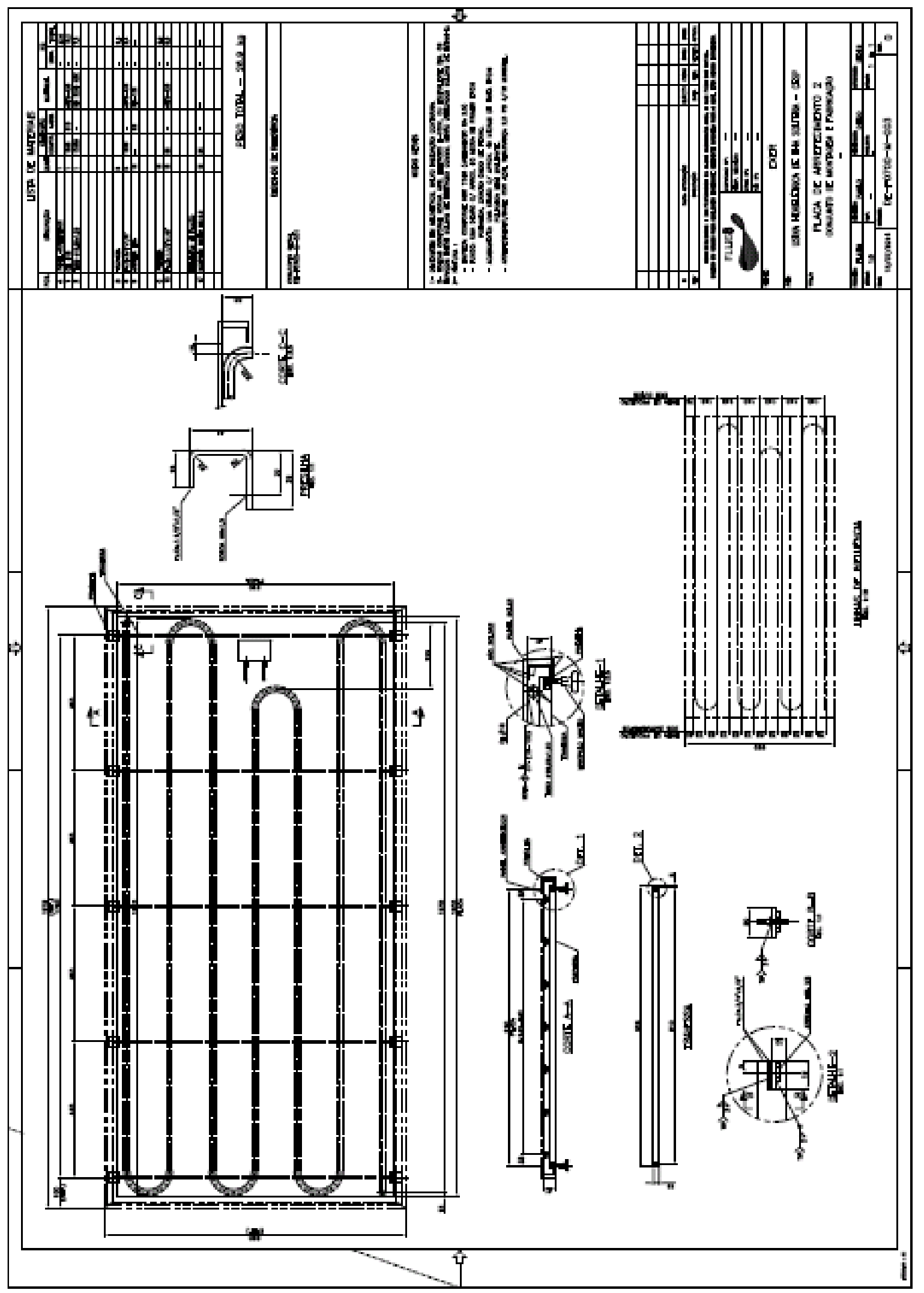

Figura 74 - UMAr do tipo chapa-tubo com raio de curvatura de 140,00 mm. 


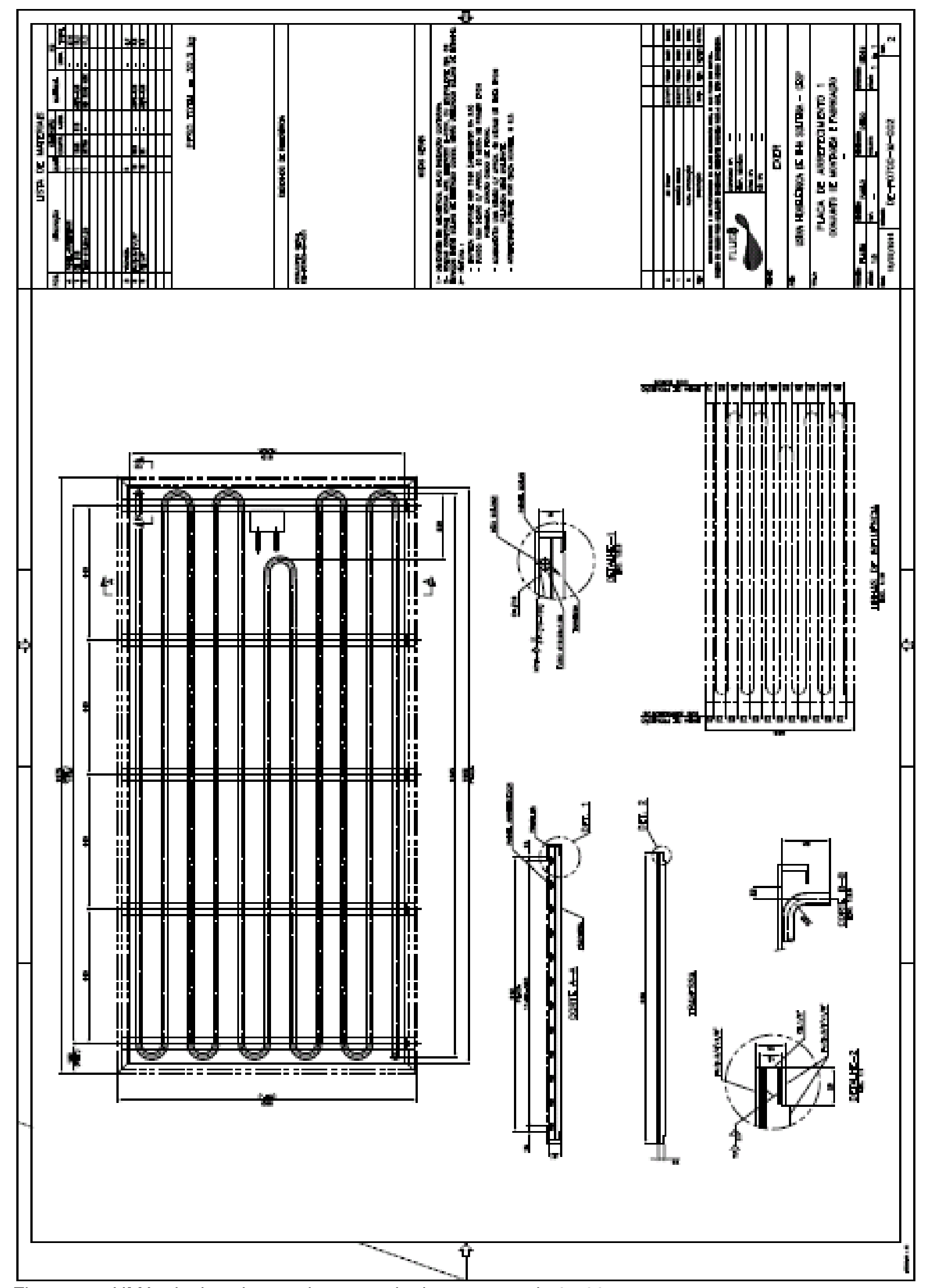

Figura 75 - UMAr do tipo chapa-tubo com raio de curvatura de $85,00 \mathrm{~mm}$. 


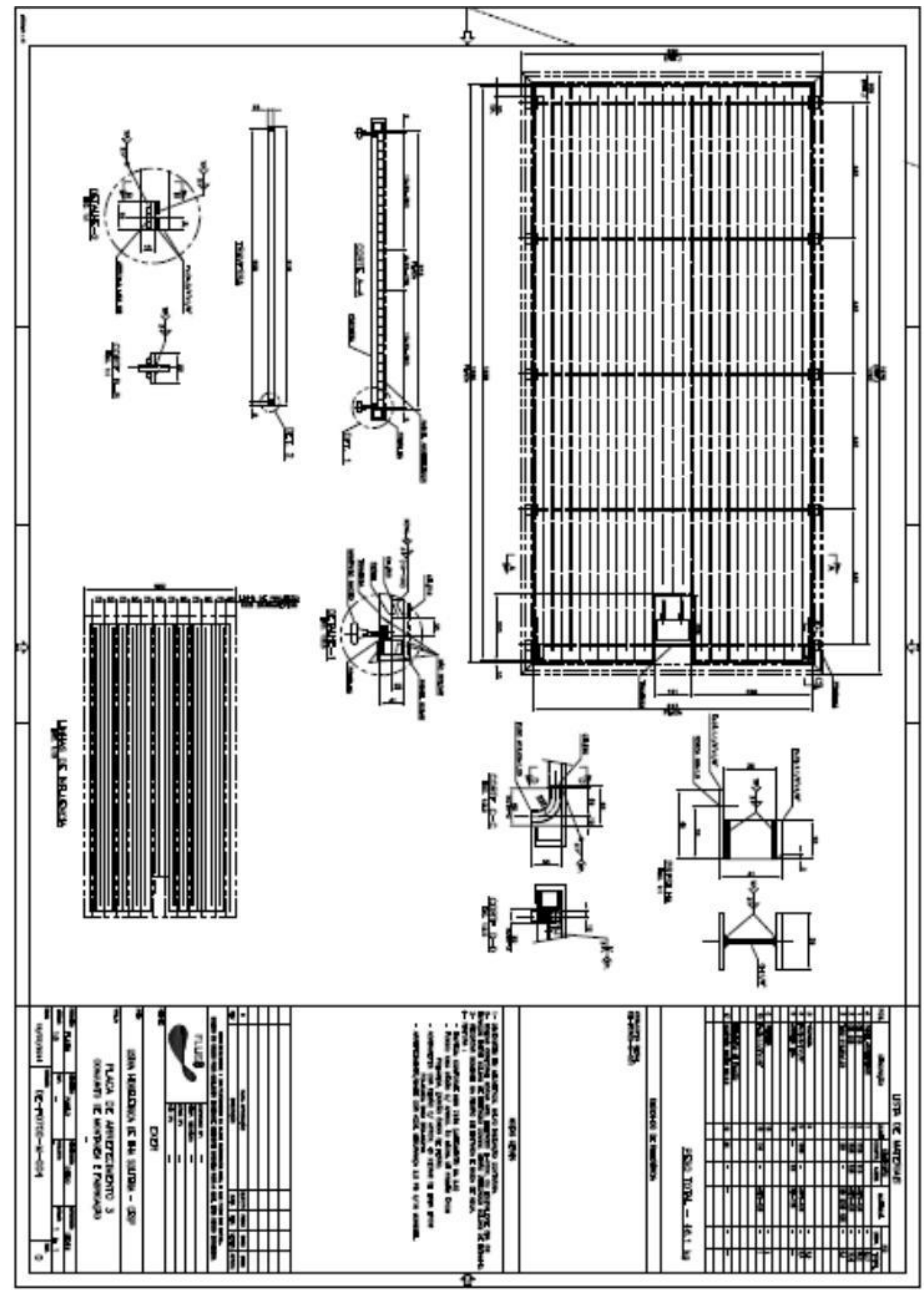

Figura 76 - UMAr de múltiplos canais. 


\section{ANEXO D}

Certificado das chapas utilizadas na produção dos modelos de UMAr.

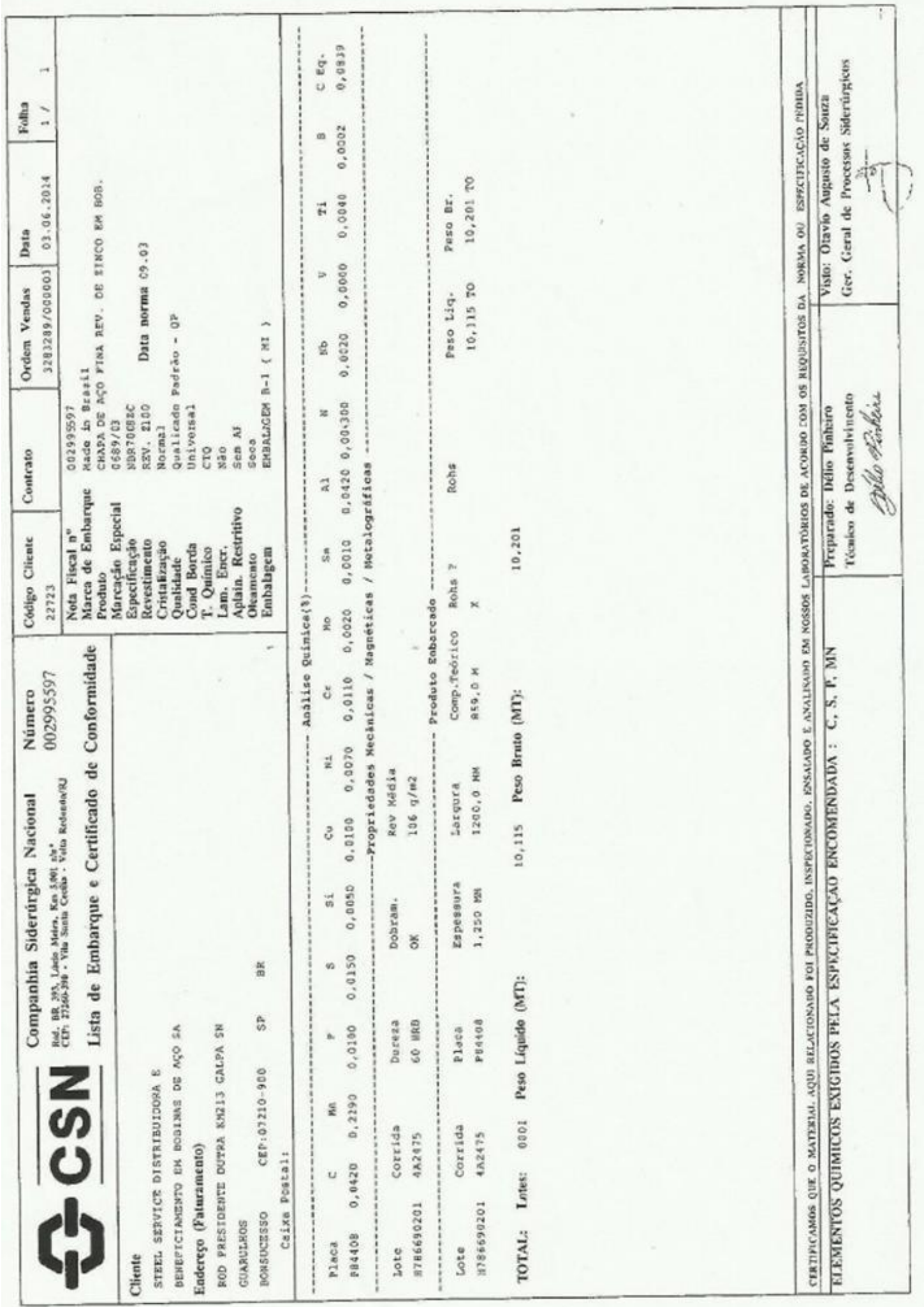




\section{ANEXO E}

Certificado dos tubos utilizados na produção dos modelos de UMAr.

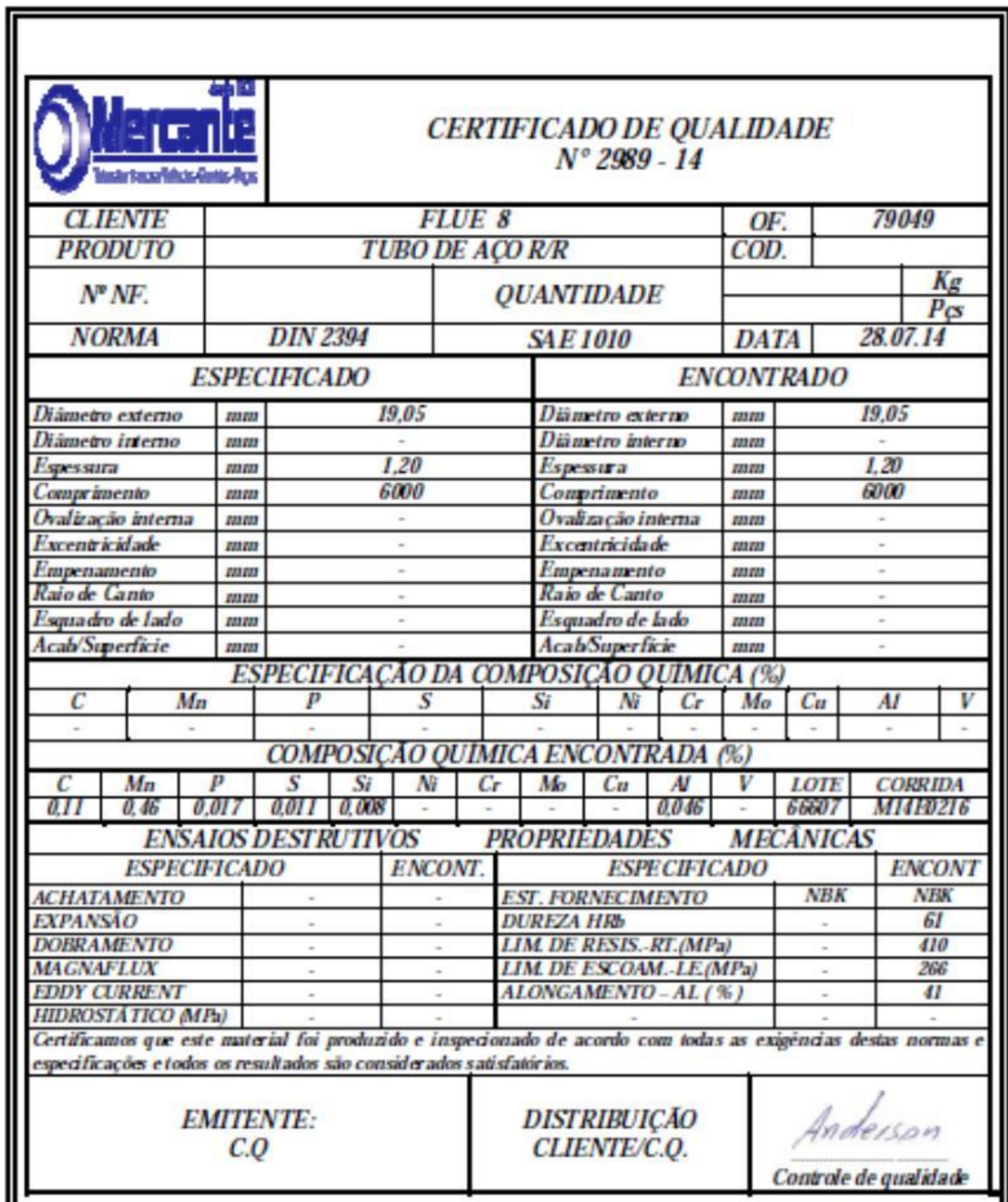

Rua Enaila Golim, 436 - CEP 07250-140 - Guand hos - SP, Fone: (0112147 - 7000 - Fax: 011) 2147-7001

FMastRev03-2406/0 


\section{ANEXO F}

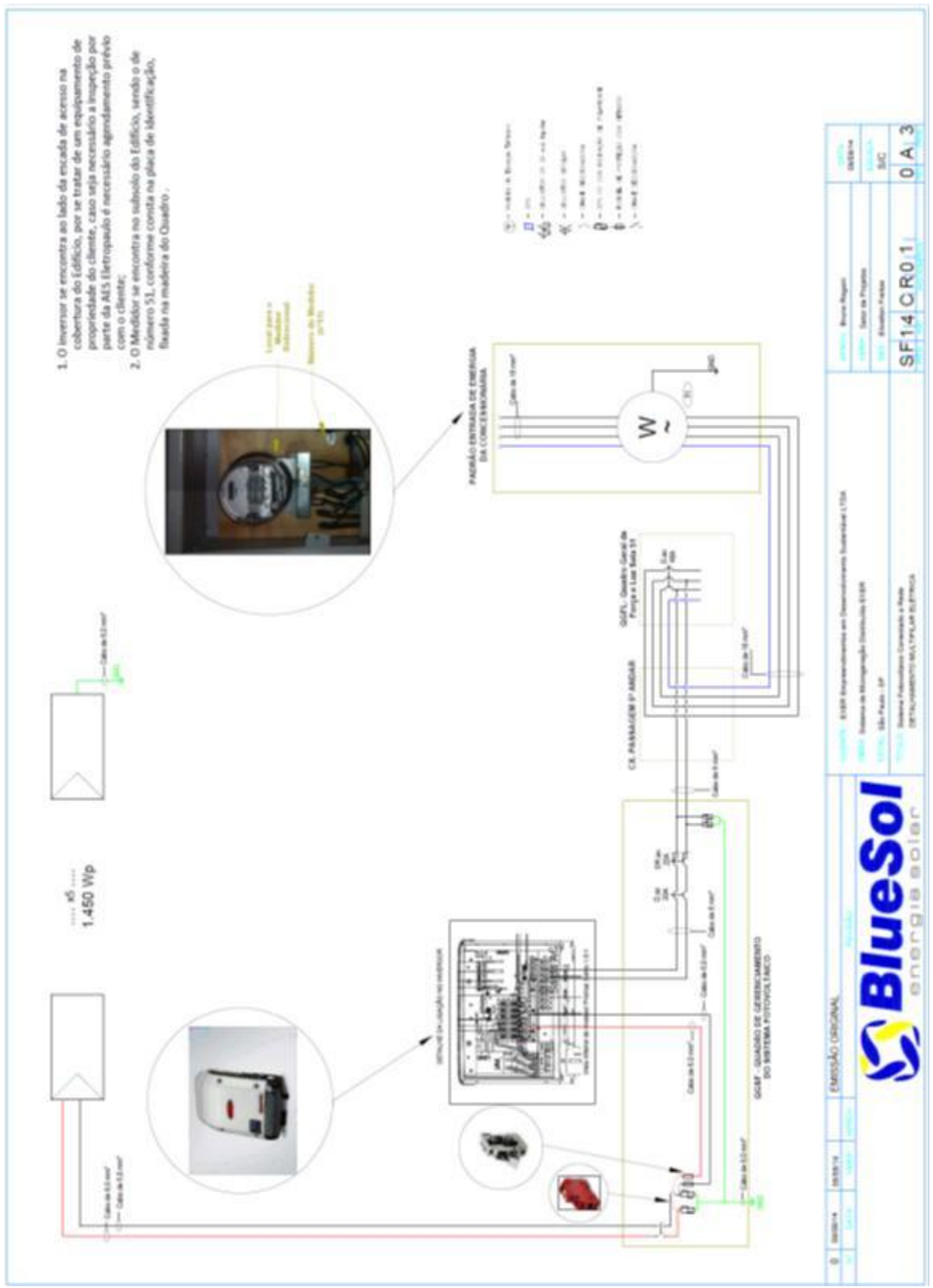

Figura 77 - Representação do diagrama multifilar elétrico da U.P. 
ANEXO G

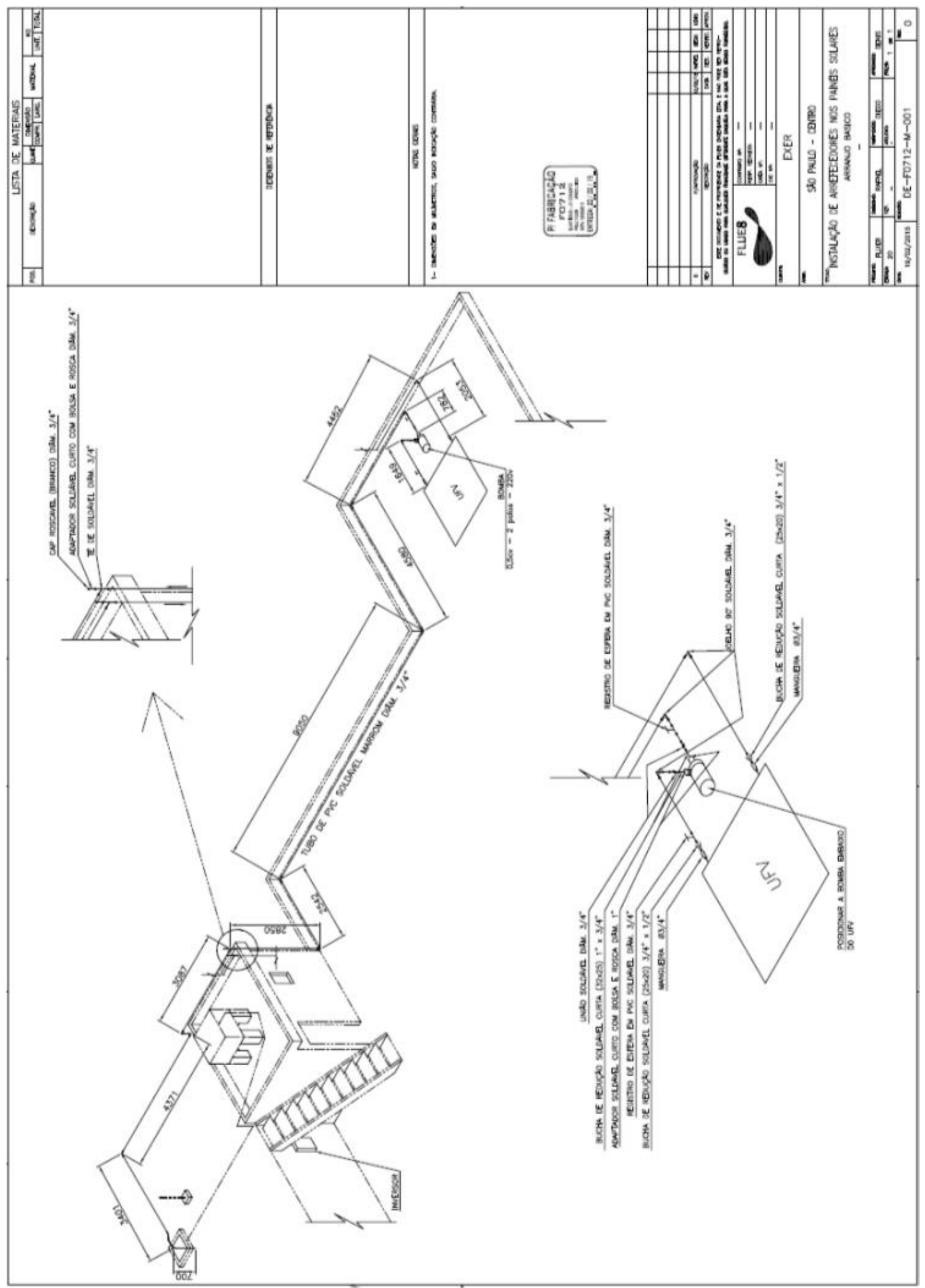

Figura 78 - Layout da linha de alimentação de água do sistema de arrefecimento da U.P. 
ANEXO H

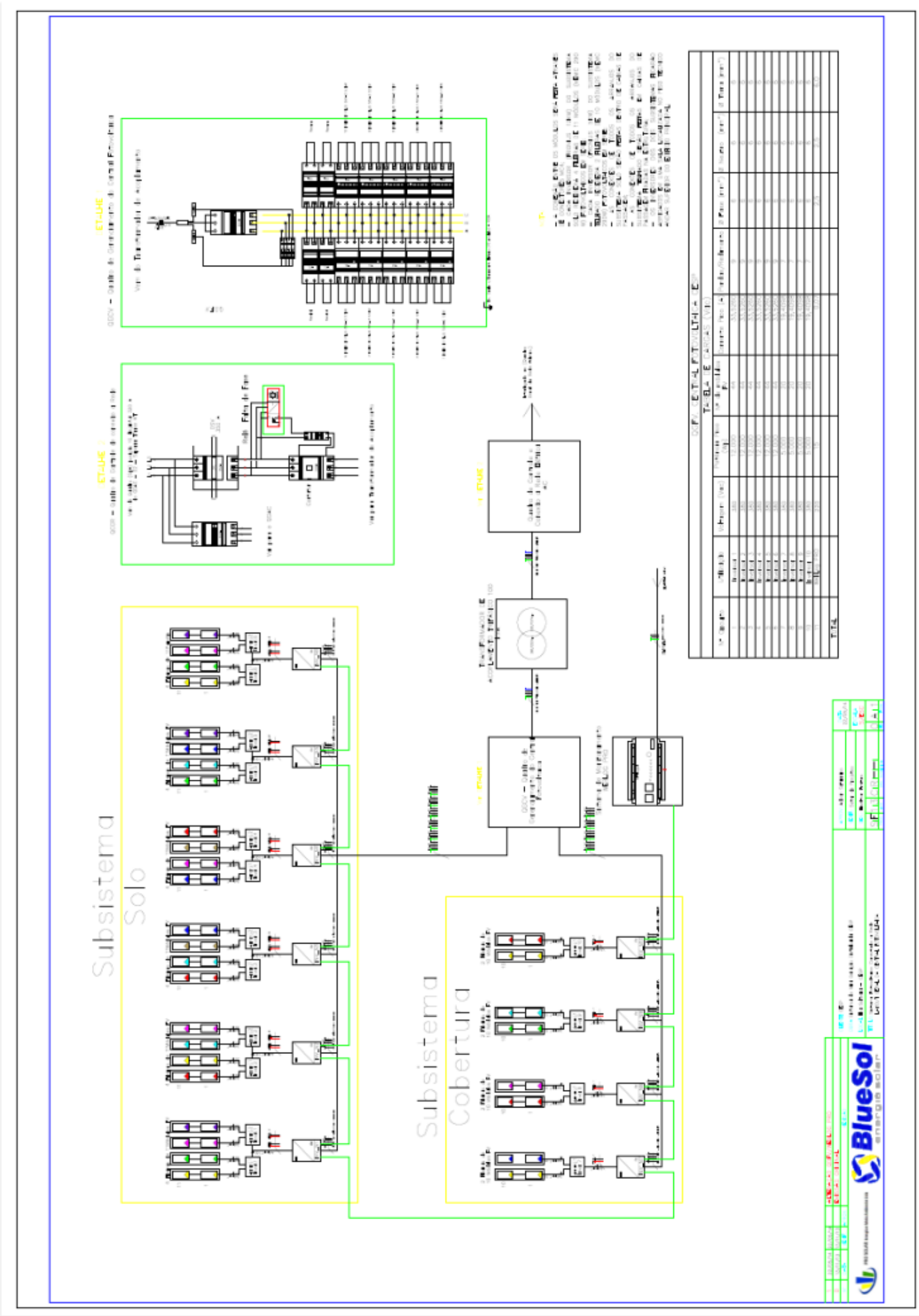

Figura 79 - Representação do diagrama multifilar elétrico da UFVa-ILS. 


\section{ANEXO I}

A alimentação de água do sistema de arrefecimento da usina fotovoltaica será fornecida pela tubulação existente de água bruta $(75 \mathrm{~mm})$ do enrocamento da UHE, ver Figura 80.

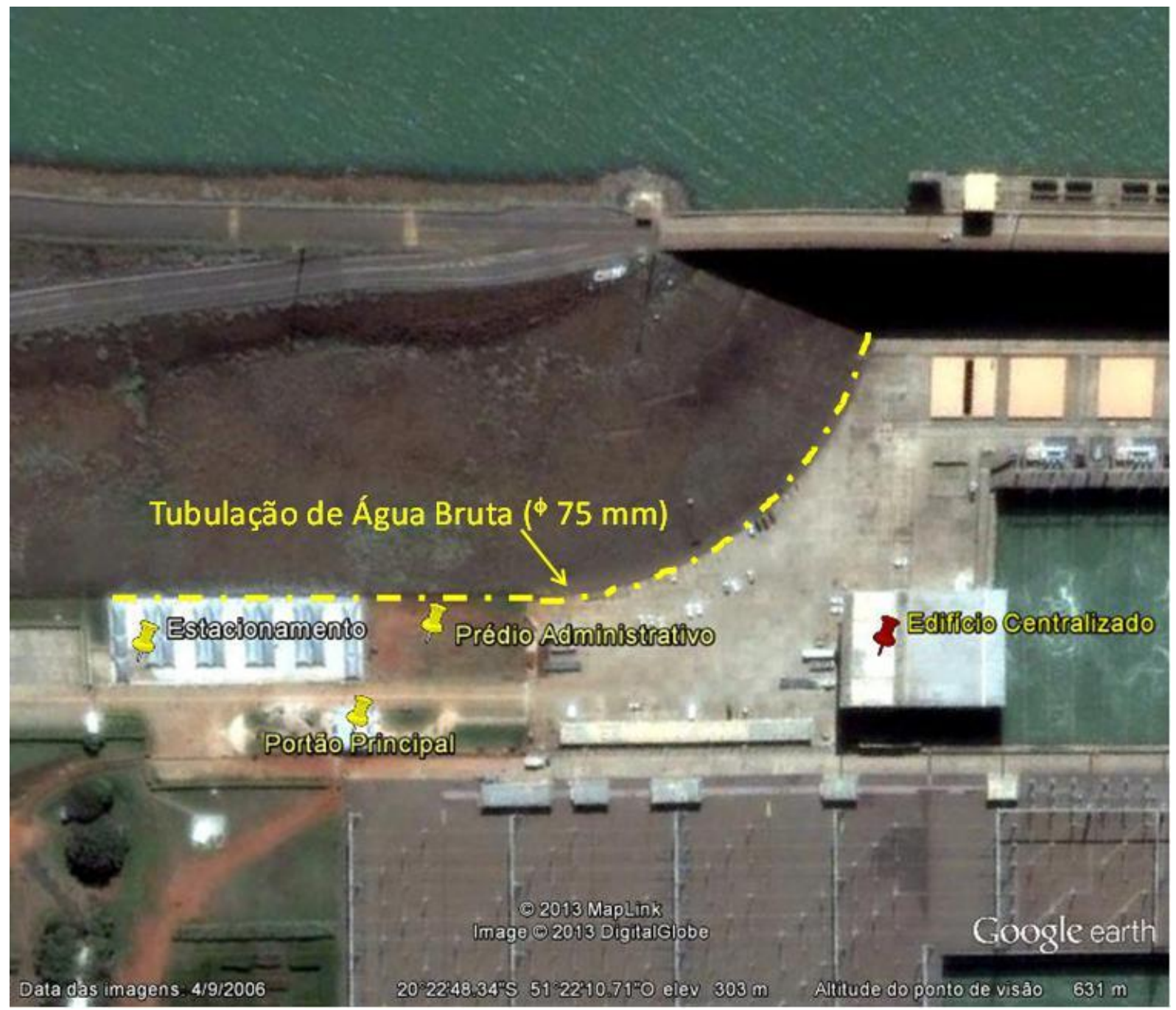

Figura 80- Figura representativa da tubulação de água bruta do enrocamento ME-UHE ILS.

Para que a água chegue até a área de instalação da usina, ver Figura 81, será minimamente necessário realizar algumas intervenções físicas no terreno como:

- Instalação de suportes na canaleta dos pontos 1 ao 2 para prolongar a tubulação de enrocamento até a área de instalação da usina PV;

- Escavação do terreno do ponto 2 até a chegada dos módulos PV no ponto 3; 
- Construção de caixa de passagem para fácil acesso a válvula de controle da tubulação de alimentação, entre os pontos 2 e 3; e

- Instalação de uma derivação no final da linha de enrocamento, ponto 1, por meio de um conector "T" $(75 \times 60 \mathrm{~mm})$ para ampliar a tubulação até a área de instalação da UFVa-ILS.

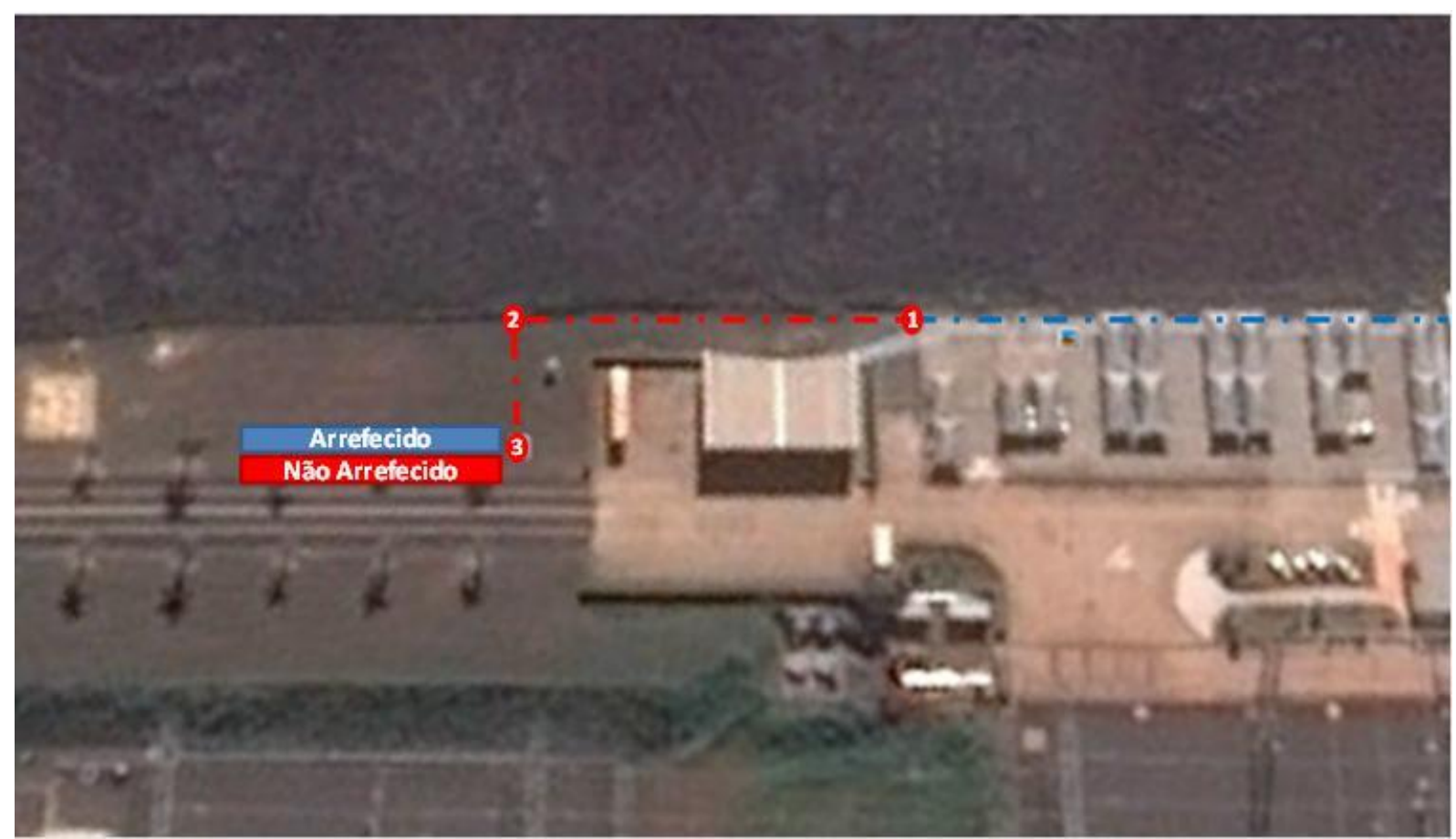

Figura 81 - Figura representativa da tubulação de água bruta do enrocamento ME-UHE ILS e da sua expansão até a usina fotovoltaica. 


\section{ANEXO J}

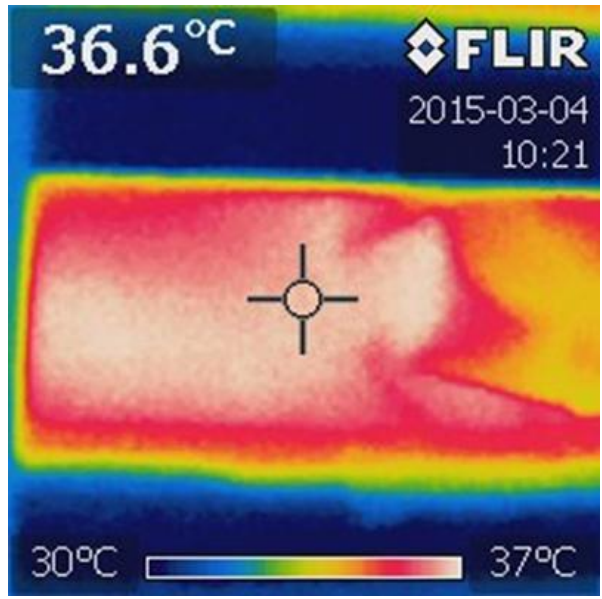

(a)

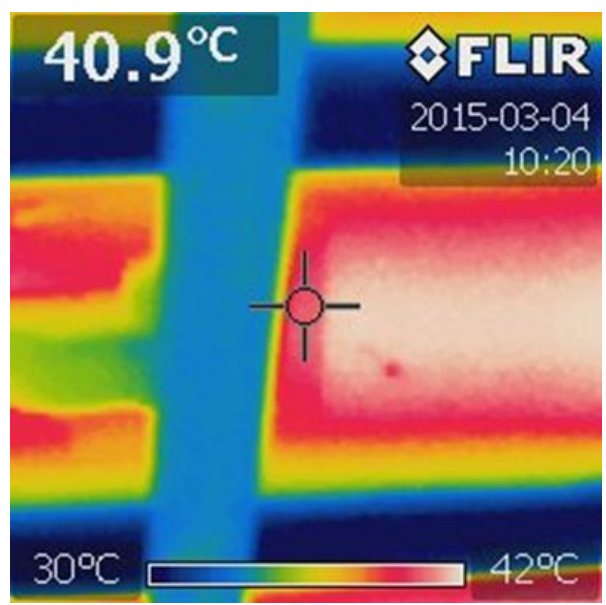

(c)

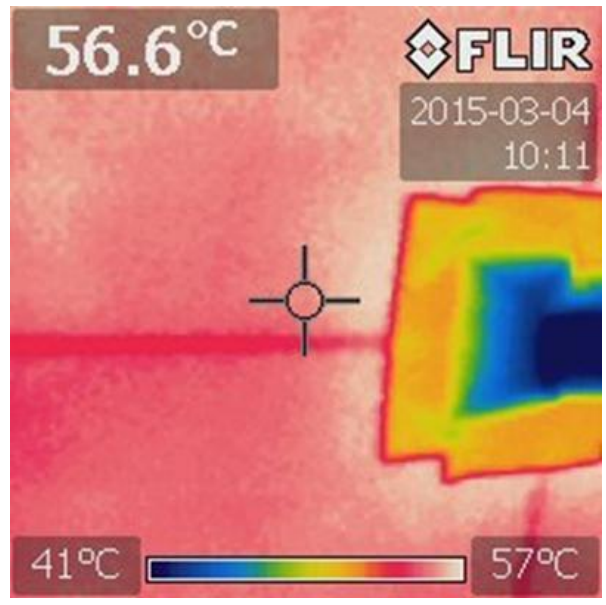

(e)

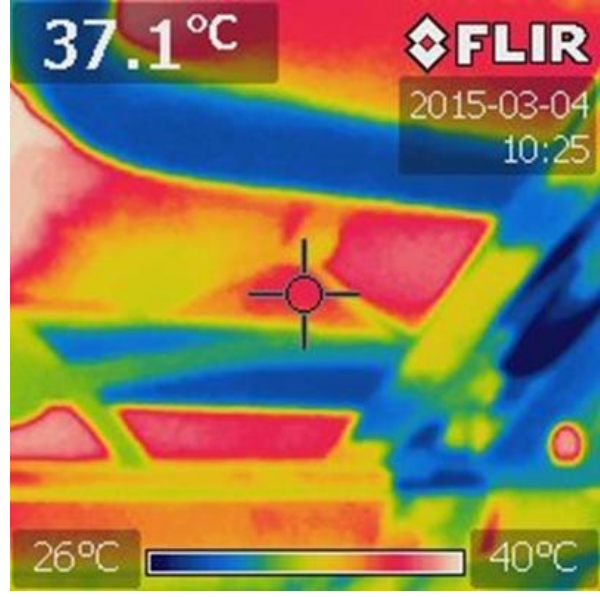

(b)

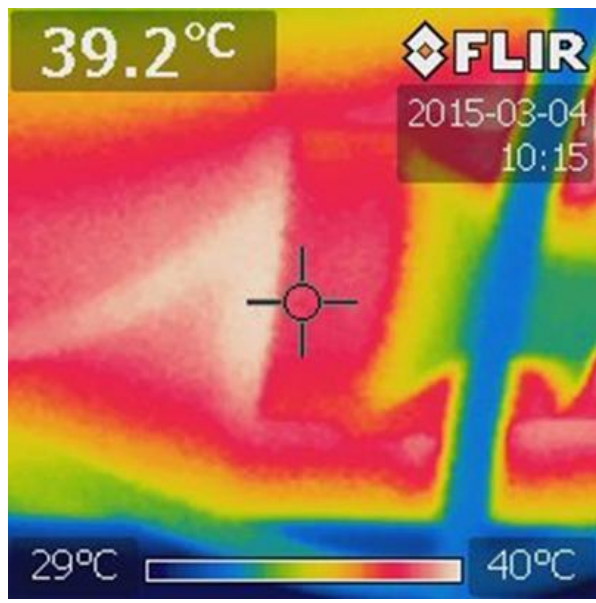

(d)

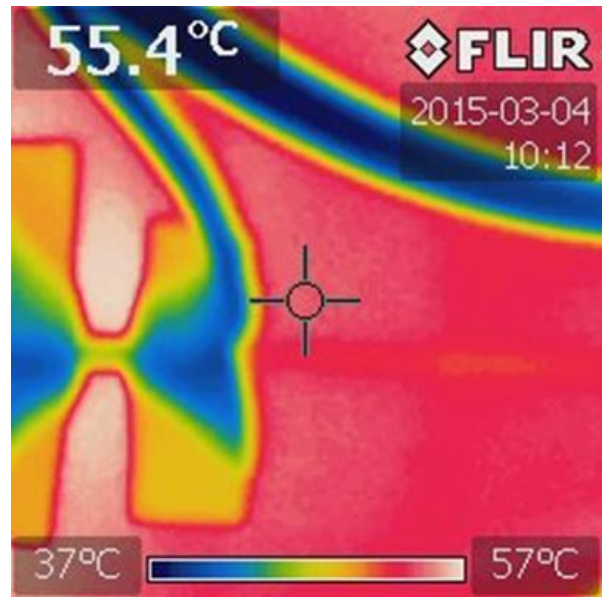

(f)

Figura 82 - Fotos registradas com a câmera térmica em 04/03/2015 para o período das 10h00min00ss (a) Meio_A, (b) Ponta_A, (c) Meio_B, (d) Ponta_B, (e) Meio_Sem e (f) Ponta_Sem. 


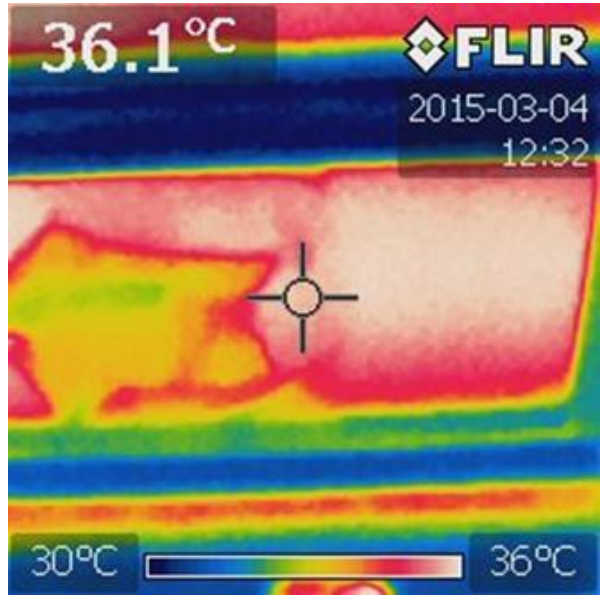

(a)

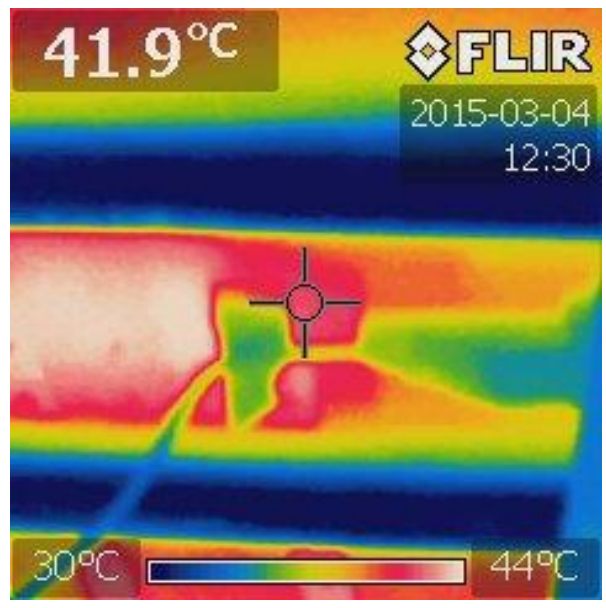

(c)

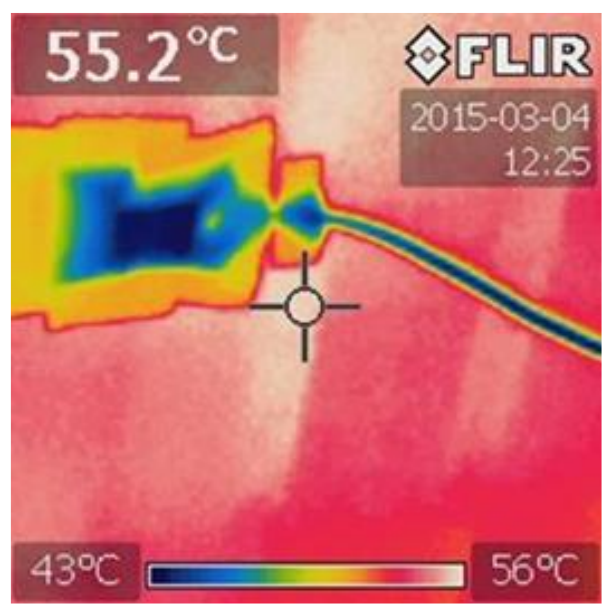

(e)

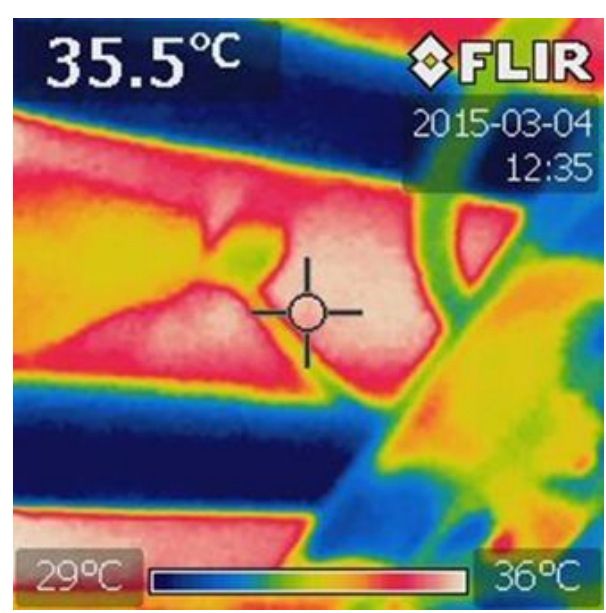

(b)

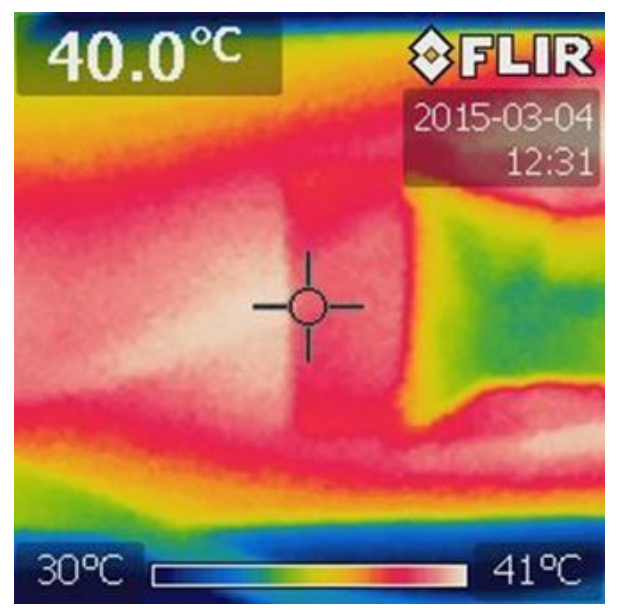

(d)

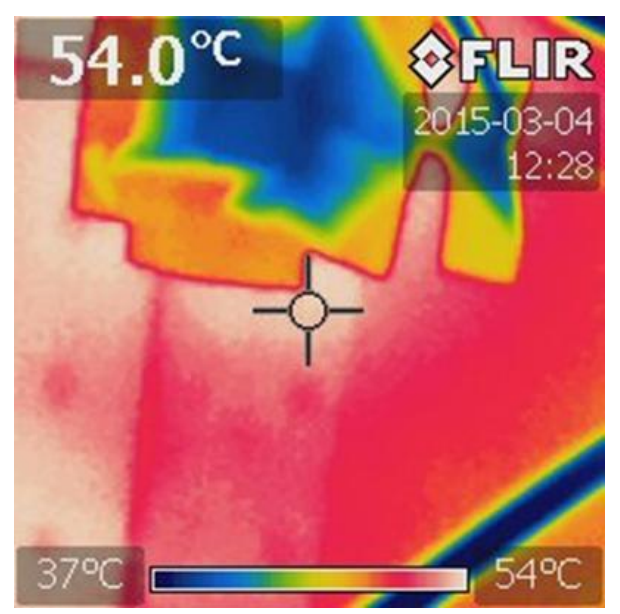

(f)

Figura 83 - Fotos registradas com a câmera térmica em 04/03/2015 para o período das 12h00min00ss (a) Meio_A, (b) Ponta_A, (c) Meio_B, (d) Ponta_B, (e) Meio_Sem e (f) Ponta_Sem. 


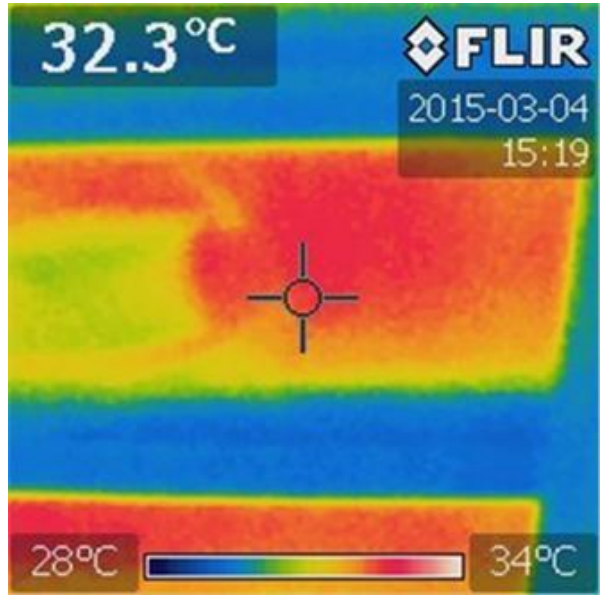

(a)

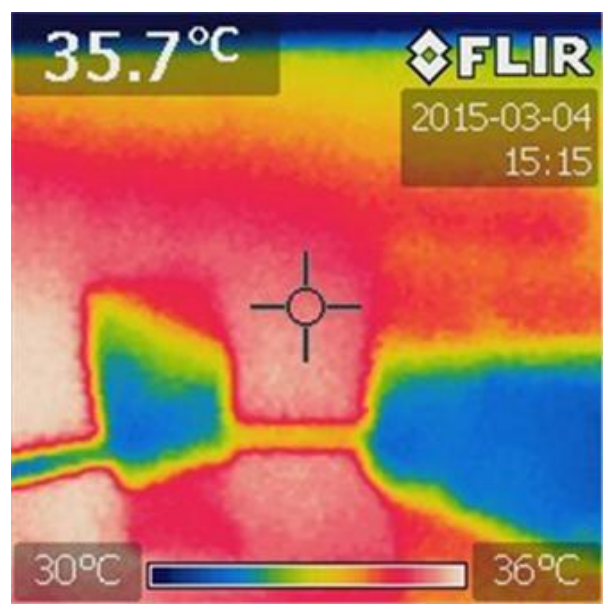

(c)

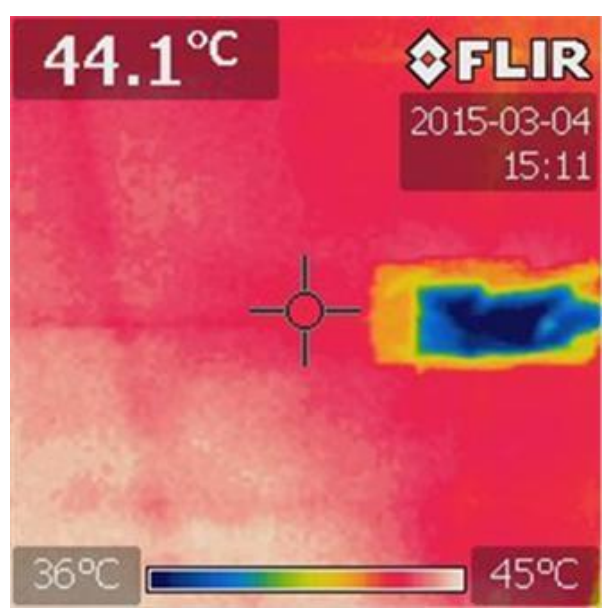

(e)

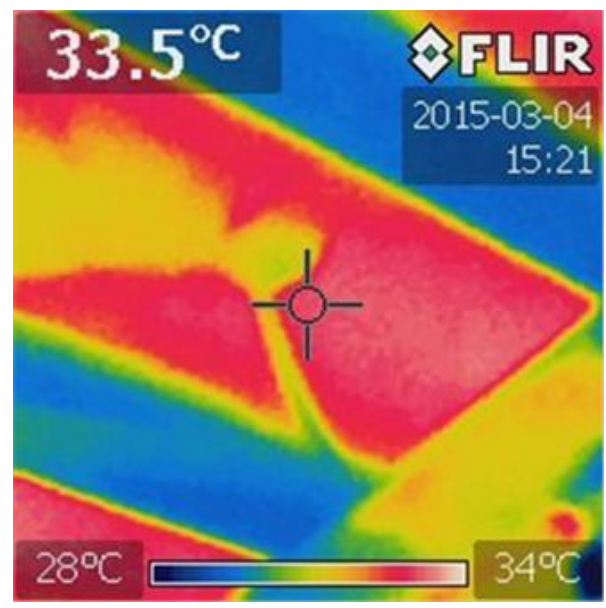

(b)

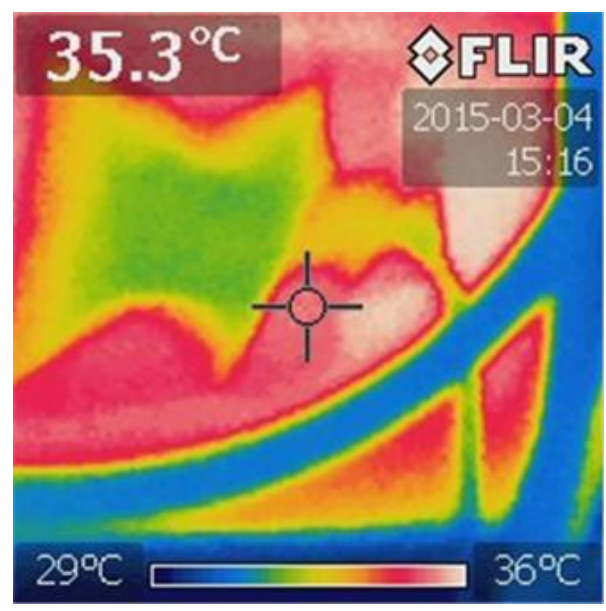

(d)

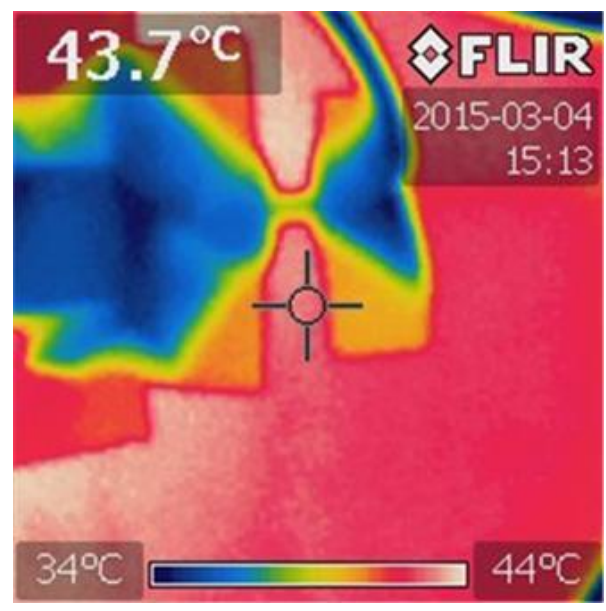

(f)

Figura 84 - Fotos registradas com a câmera térmica em 04/03/2015 para o período das 15h00min00ss (a) Meio_A, (b) Ponta_A, (c) Meio_B, (d) Ponta_B, (e) Meio_Sem e (f) Ponta_Sem 


\section{ANEXO K}

\section{K.1 SUPERVISÃO E MONITORAMENTO DA INSTALAÇÃO DE UMAR EM STRING DE TESTES}

Os trabalhos de instalação de UMAr no módulo PV do string de teste, realizados em 09 de dezembro de 2014, iniciaram-se com a verificação física e operativa da UFVa, na qual se constatou que o inversor do string de teste estava desligado. Assim a equipe da CESP, formada por dois técnicos, iniciou a desmontagem e retirada do módulo PV. Esta tarefa não apresentou dificuldades que consistiu na retirada de quatro parafusos com a utilização de uma chave Allen e uma de boca, a duração da operação foi de 4 min32ss. $O$ módulo $P V$ retirado foi levado à oficina para receber o arrefecedor.

Na oficina, o módulo PV foi colocado sobre a manta com a superfície superior para baixo, para receber o arrefecedor e evitar avarias. O arrefecedor foi instalado por uma pessoa sem a necessidade de ferramentas, já que o sistema fixação, do arrefecedor no módulo PV, foi projetado para funcionar sobre pressão, sem a necessidade de ferramentas, e ser montado por apenas uma pessoa treinada. Esta operação durou 46 segundos.

Após a instalação do arrefecedor no módulo PV, a equipe da CESP recolocou o módulo PV no string, ver Figura 85, essa operação foi dispendiosa, pois durante a fixação dos parafusos um deles caiu no solo, elevando o tempo da operação para 7min13ss. Tendo constatado que a fixação não apresentou nenhuma dificuldade de instalação e/ou ajustes, o sistema foi, mais uma vez, desmontado e encaminhado para a oficina, no qual o arrefecedor foi desmontado e o módulo PV pôde ser recolocado em seu string. O tempo de operação de recolocação do módulo PV em sua estrutura foi de $4 \min 22 \mathrm{ss}$.

O procedimento de instalação de UMAr não apresentou problemas vinculados à instalação, comprovando a sua praticidade devido a pequenos tempos despendidos na sua operação e necessidade de apenas dois operadores. Isto comprova que os testes realizados no período de construção dos pré-protótipos foram satisfatórios. 


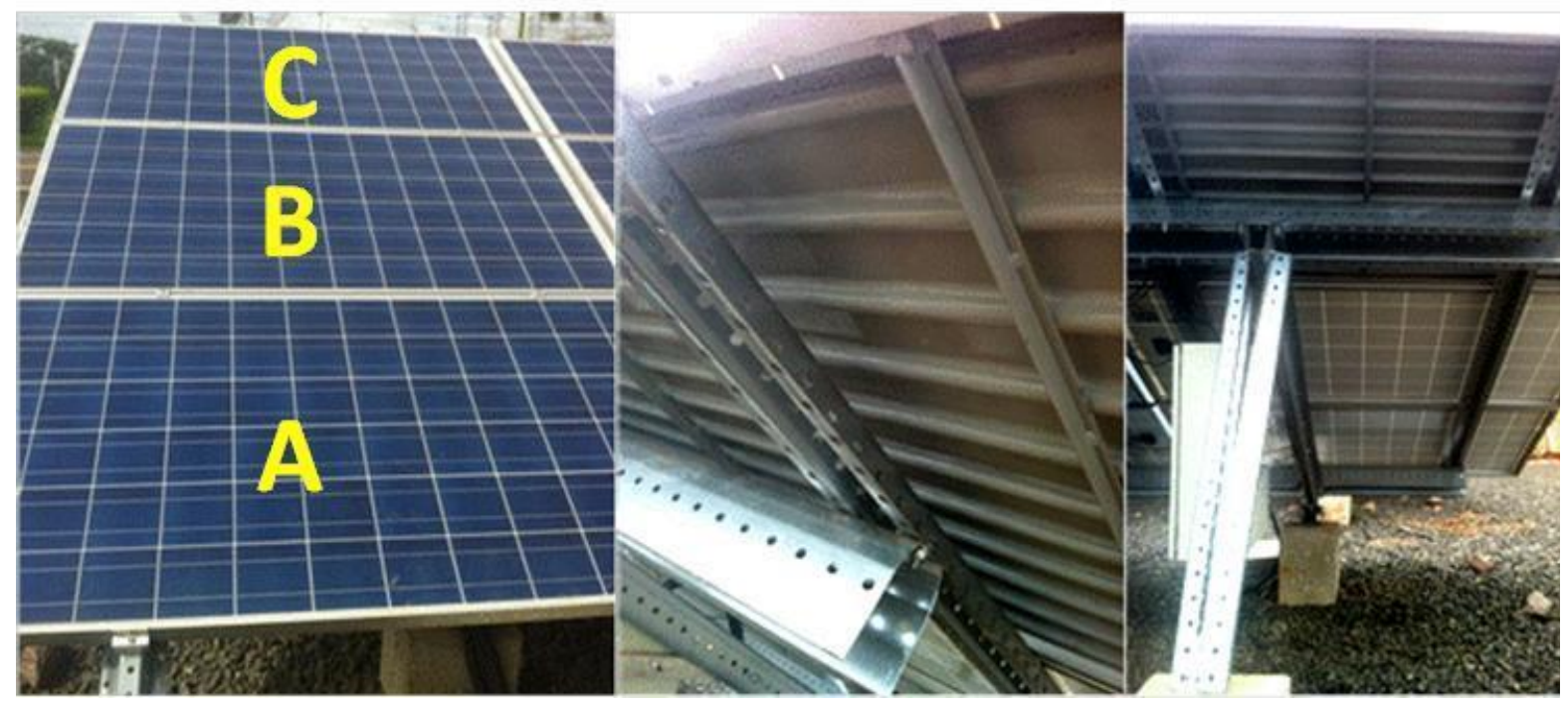

Figura 85 - Módulo PV com UMAr instalada na UFVa.

K.2 DESCRIÇÃO DOS PROBLEMAS DO SISTEMA DE FORNECIMENTO DE ÁGUA

Durante o período de teste de operação do protótipo de UFVa., o fornecimento de água apresentou diversas interrupções como:

- Parada entre o período de constatação da presença de grandes fragmentos circulando no sistema de arrefecimento até a instalação do filtro d'água;

- Paradas aleatórias para limpeza do filtro d' água;

- Parada para substituição de uma conexão plástica das mangueiras flexíveis; e

- Parada para instalação e conexão do sistema de medição residual de cloro na linha D.

As diversas interrupções comprometeram o período das medições para análise do desempenho do sistema de arrefecimento do protótipo de UFVa. Sendo a principal compreendendo o período entre a constatação de fragmentos circulantes pelo sistema de arrefecimento até a instalação do filtro na linha A. Este filtro tem a função de retirar fragmentos da água como pedras, mexilhão dourado e outros detritos presentes, já que esta vem do enrocamento da UHE. O sistema de filtragem possui um filtro de água e duas válvulas tipo esfera, uma a montante e outra a 
jusante, com função de isolar o filtro para procedimentos de limpeza e manutenção, ver Figura 86.

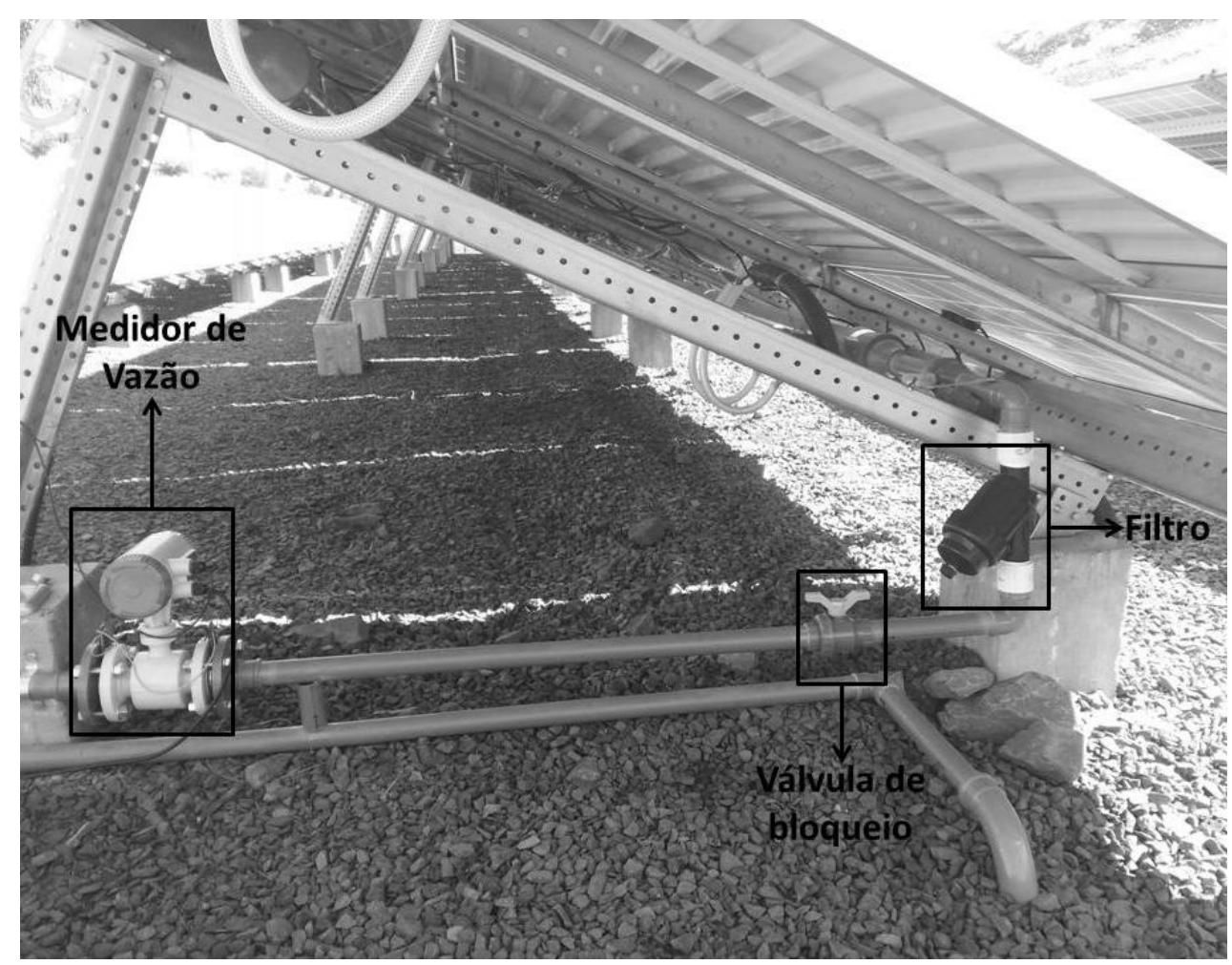

Figura 86 - Filtro da linha A do sistema de alimentação de água do protótipo de UFVa.

Após um breve período de operação do sistema verificou-se que o filtro entupia a linha devido à grande absorção de sujeira e fragmentos, Figura 87 (b), reduzindo a vazão de água no sistema de arrefecimento em $53 \%$ durante um dia de operação, o que ocasiona redução da capacidade de trocas térmicas entre os arrefecedores e os módulos PV do protótipo de UFVa, além de provocar, quando a vazão é muito baixa, deposição de material sólido e formação de lodo nas tubulações e mangueiras do sistema de arrefecimento, fato constatado quando o filtro permaneceu sem limpeza duas semanas com vazão mínima de $1,3 \mathrm{~m} 3 / \mathrm{h}$. Desta forma foi sugerida a limpeza do filtro em dias alternados no primeiro horário da manhã. Limpeza esta que não foi seguida, inviabilizando parte do período de análise dos dados. 


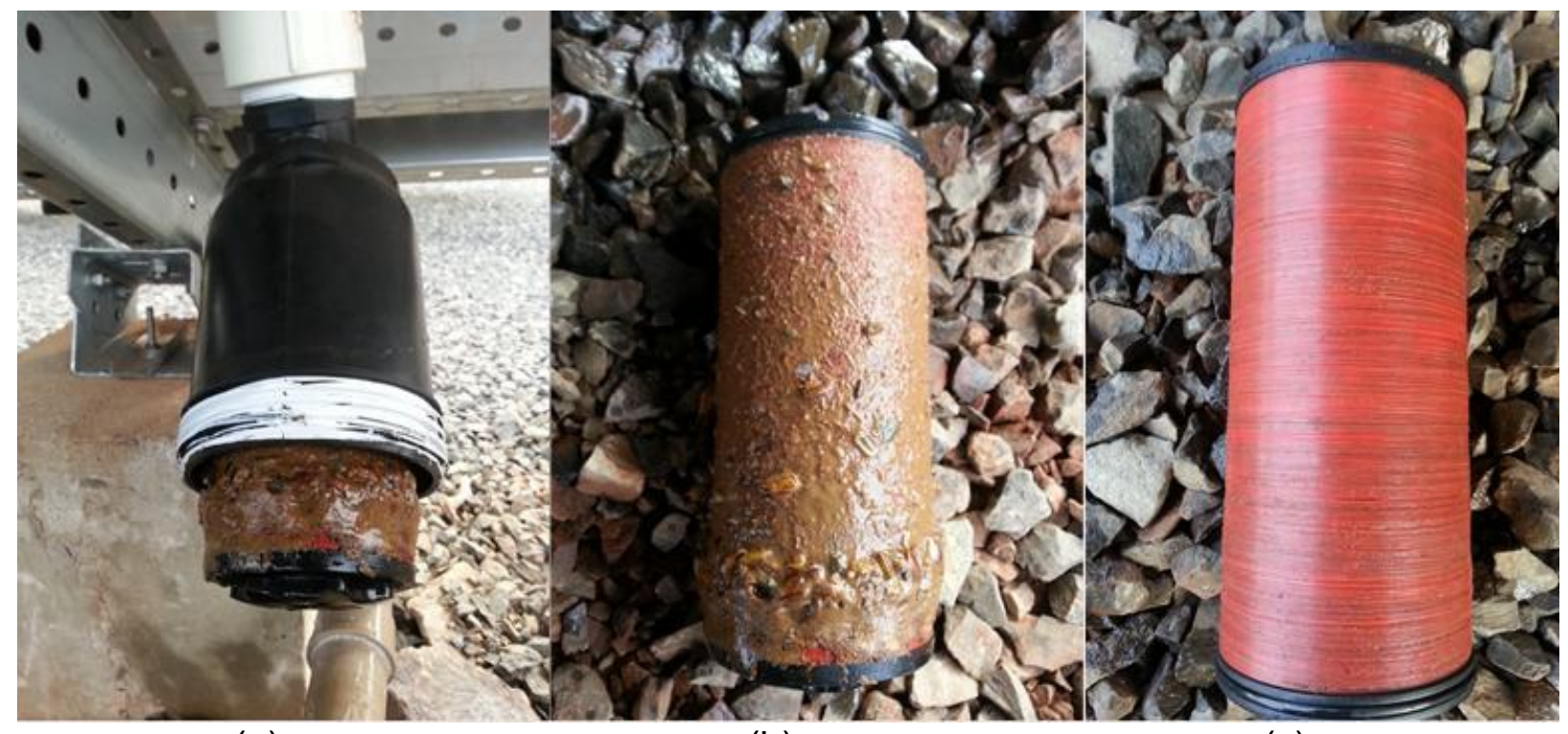

(a)

(b)

(c)

Figura 87 - Filtro da linha A. (a) Filtro conectado a linha A, (b) filtro sujo e (c) filtro limpo. 